
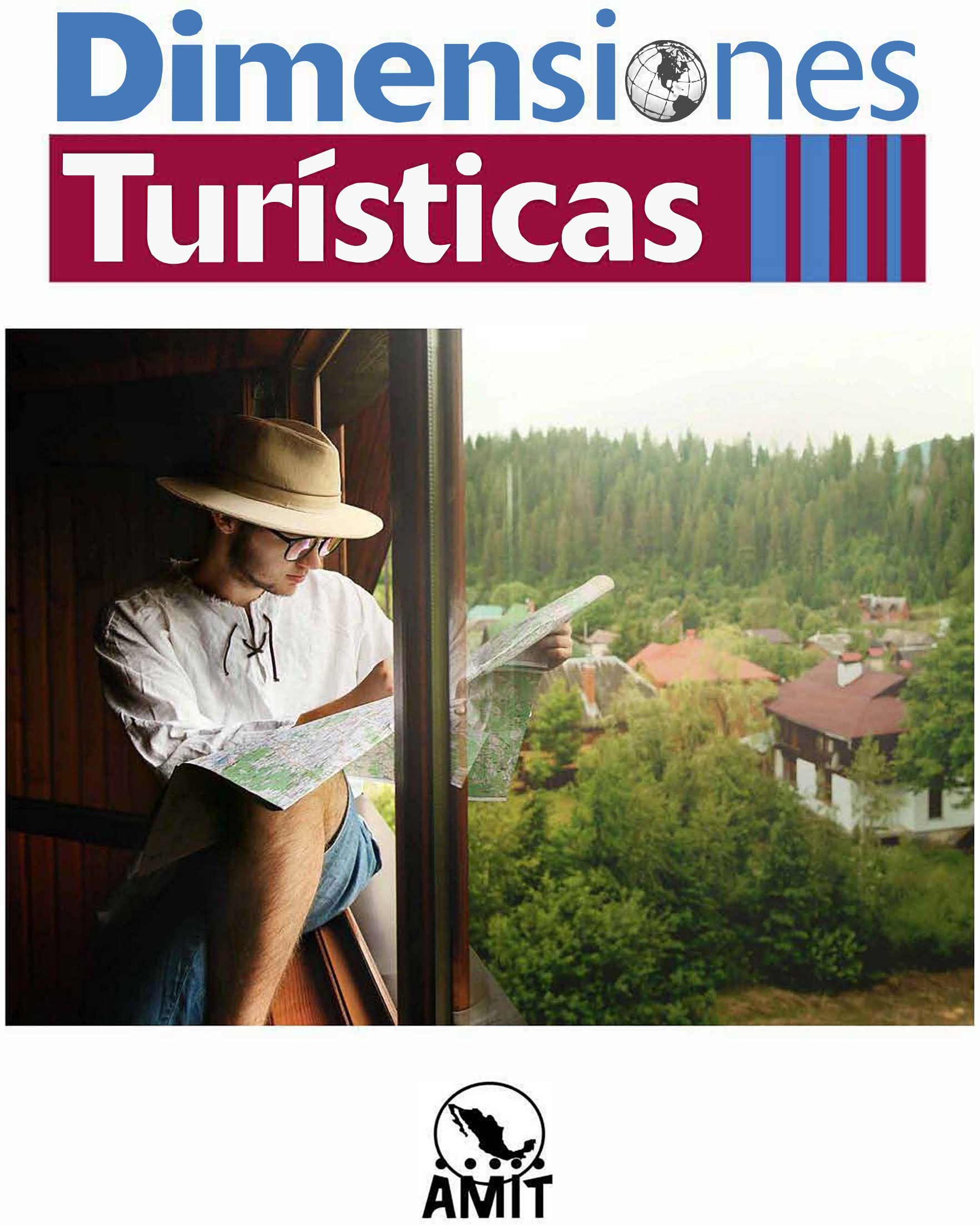

Publicación semestral • Vol. 3 • Núm. 4 • Enero-junio 2019 e-ISSN:2694-2069 Academia Mexicana de Investigación Turística, A. C. https://doi.org/10.47557/CSGE7990 

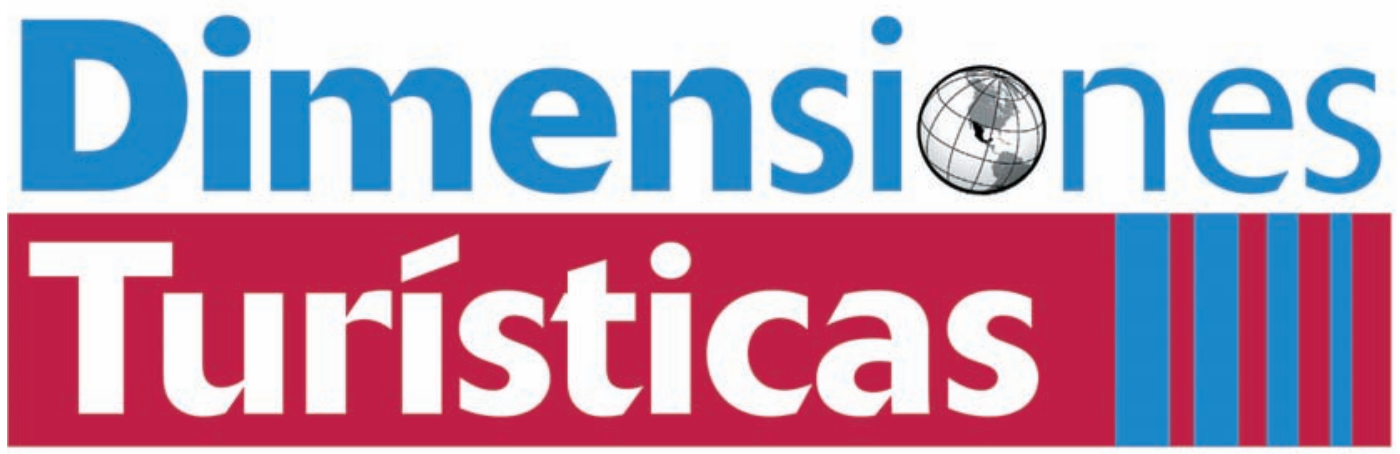

Publicación semestral • Vol. $3 \bullet$ Núm. 4 • Enero-junio $2019 \bullet$ e-ISSN: 2594-2069 https://doi.org/10.47557/CSGE7990

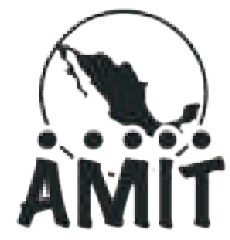

Academia Mexicana de Investigación Turística, A. C. 


\section{Academia Mexicana de Investigación Turística, A. C.}

La Academia Mexicana de Investigación Turística, A.C. (АMIт), de acuerdo con sus estatutos es una sociedad sin fines de lucro cuyos miembros, adscritos a universidades, centros de investigación u otro tipo de entidades públicas y privadas, proceden del campo de estudio del turismo así como de disciplinas como la geografía, economía, sociología, comunicación, antropología, psicología, administración, ciencia política, demografía, ecología, entre otras. La Aміт pretende generar un espacio de trabajo colegiado entre los investigadores(as) dedicados a los estudios del turismo.

Directora de Dimensiones Turísticas

Nora Leticia Bringas Rábago

Teléfono: +52 (664) 6316300 ext. 1306

Correo electrónico: amit.dimentur@gmail.com

Contacto de asistencia

Teresa López Avedoy

Teléfono: +52 (664) 6316300 ext. 1315

Correo electrónico: amit.dimentur@gmail.com

Diseño, formación y cuidado de la edición: Alfa/Zeta

Ma. Eugenia Varela Carlos

zet.alfa@gmail.com

Dimensiones Turísticas, Vol. 3, Núm. 4, Año 3, Enero-junio 2019, es una publicación semestral, editada por la Academia Mexicana de Investigación Turística, Villa Costa Azul núm. 55, Mediterráneo Club Residencial, Mazatlán, Sinaloa, C. P. 82113, tel.: +52 (664) 6316300 ext. 1306, https://dimensionesturisticas.amiturismo.org, amit.dimentur@gmail.com. Editora responsable: Nora Leticia Bringas Rábago. Reserva de Derechos al Uso Exclusivo: 04-2018-082217054200-203, e-ISSN: 2594-2069, ambos otorgados por el Instituto Nacional de Derechos de Autor. Responsable de la última actualización de este número, administrador web de la Academia Mexicana de Investigación Turística: Carlos Vladimir Ruelas González, Carretera Escénica Tijuana-Ensenada Km 18.5, San Antonio del Mar, Tijuana, Baja California, C. P. 22560, fecha de última modificación, 7 de junio de 2019.

Las opiniones expresadas por los autores no necesariamente reflejan la postura del editor de la publicación. 


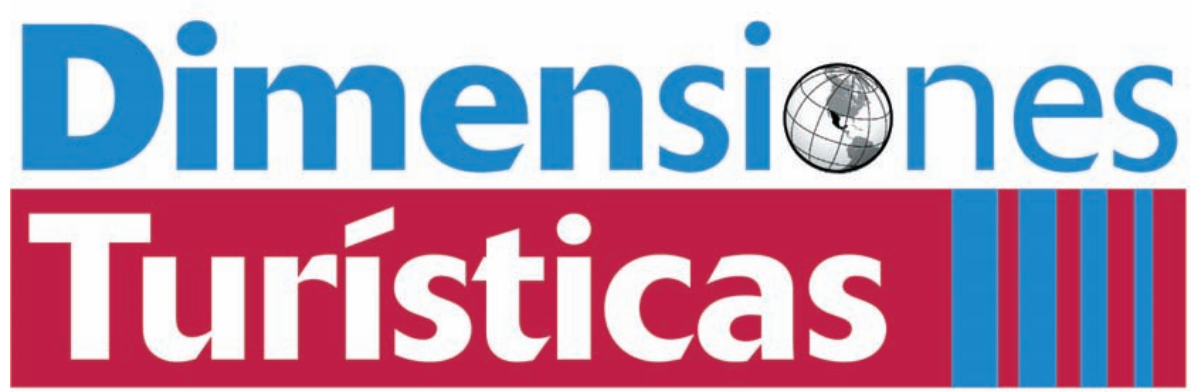

Publicación semestral • Vol. 3 • Núm. 4 • Enero-junio 2019 • e-ISSN: 2594-2069

Nora Leticia Bringas Rábago

DiRECTORA

\section{Consejo científico}

Salvador Gómez Nieves • Universidad de Guadalajara, México

Daniel Hiernaux-Nicolas • Universidad Autónoma de Querétaro, México

Raquel Huete Nieves • Universidad de Alicante, España

Antonina Ivanova Boncheva - Universidad Autónoma de Baja California Sur, México

Alfonso de Jesús Jiménez Martínez • Universidad Autónoma de Guerrero, México

Tomás López Guzmán • Universidad de Córdoba, España

Alejandro Palafox Muñoz • Universidad de Quintana Roo, México

Agustín Santana Talavera • Universidad de La Laguna, Canarias, España

Regina G. Schlüter • Centro de Investigación y Estudios Turísticos, Argentina

Rocío del Carmen Serrano Barquín - Universidad Autónoma del Estado de México

Pablo Szmulewicz, Universidad Austral de Chile, Chile

Miguel Ángel Troitiño Vinuesa, Universidad Complutense de Madrid, España

José Fernando Vera Rebollo • Universidad de Alicante, España

\section{COMITÉ EDITORIAL}

Andrea Muñoz Barriga • Pontificia Universidad Católica del Ecuador, Ecuador Alfonso González Damián • Universidad de Quintana Roo, México Maximiliano Korstanje • Universidad de Palermo, Argentina Álvaro López López • Universidad Nacional Autónoma de México Ana Pricila Sosa Ferreira - Universidad del Caribe, Quintana Roo, México Basilio Verduzco Chávez • Universidad de Guadalajara, México Lilia Zizumbo Villarreal • Universidad Autónoma del Estado de México, México 


\section{Dimensiones Turísticas ||||}

Publicación semestral

Vol. 3, Núm. 4

Enero-junio 2019

e-ISSN: 2594-2069
Nora Leticia Bringas Rábago

Articles

Ana Karen Reyes-Aguilar Rocío del Carmen Serrano-Barouín

Carlos Alberto Pérez-Ramírez Ruth Moreno-Barajas

Martha Marivel Mendoza Ontiveros Rafael Hernández Espinosa

Ana María Larrañaga Núñez Anel Yadira Pérez Melo

Carlos Amaya Molinar Irma Magaña Carrillo ILEANa Ochoa Llamas Yadira Guerra Montes

María Teresa Martínez-Almanza Santos Alonso Morales-Muñoz Carlos Jesús González-Macías

EsSAY

TzintLI Chávez Luna

Congress Review

José F. Domínguez Estrada

BOOK REVIEW

Alfonso González Damián

About Dimensiones

TURÍSTICAS
9-25 Peasant Women and Rural Tourism: An

Environmental Conservation Strategy in Los

Tuxtlas, Veracruz

26-42 Pro-Poor Community Tourism and its Definition of Poverty

43-62 Knowledge for Innovation in the Family Hotel Business. The Case of Mazatlán Tourist Destination

63-86 Perception of Tourism as a Source of Well-Being in Rural Communities of Colima

87-109 Medical Tourism Governance and Management in the Border Region of Ciudad Juárez-El Paso

110-116 Tourism as an Instrument of Neoliberal Colonization: a Foucaultian perspective

117-125 XII International Congress of Tourism Research Mexican Academy of Tourism Research (АMIT)

126-129 Monterrubio Cordero (2018)

Sociocultural impacts of tourism. Conceptual, theoretical and empirical dimensions

$130-142$ 


\section{Dimensiones Turísticas ||||}

Publicación semestral

Vol. 3, Núm. 4

Enero-junio 2018

e-ISSN: 2594-2069

\section{ÍNDICE}

Nora Leticia Bringas Rábago

Artículos

Ana Karen Reyes-Aguilar

Rocío del Carmen Serrano-Barquín

Carlos Alberto Pérez-Ramírez

Ruth Moreno-Barajas

Martha Marivel Mendoza Ontiveros

Rafael Hernández Espinosa

Ana María Larrañaga Núñez

Anel Yadira Pérez Melo

Carlos Amaya Molinar Irma Magaña Carrillo ILEANa Ochoa Llamas

YadiRa GuerRa Montes

María Teresa Martínez-Almanza

Santos Alonso Morales-Muñoz

Carlos Jesús González-Macías

\section{NotA CRÍTICA}

Tzintli Chávez Luna

Reseña de CONGREso

José F. Domínguez Estrada

\section{ReseñA}

Alfonso González Damián

Acerca de Dimensiones

TURÍSTICAS
7-8 Presentación

9-25 Mujeres campesinas y turismo rural: estrategia de conservación ambiental en Los Tuxtlas, Veracruz

26-42 Turismo comunitario pro pobre y su definición de pobreza

43-62 Conocimiento para la innovación en la empresa familiar hotelera. Caso destino turístico Mazatlán

63-86 Percepción del turismo como fuente de bienestar en comunidades rurales de Colima

87-109 Gobernanza y gestión del turismo médico en la región fronteriza de Ciudad Juárez-El Paso

110-116 El turismo como instrumento de colonización neoliberal: una perspectiva foucaultiana

117-125 XII Congreso Internacional de Investigación Turística Academia Mexicana de Investigación Turística (AMIT)

126-129 Monterrubio Cordero (2018) Impactos socioculturales del turismo.

Dimensiones conceptuales, teóricas y empíricas

$130-142$ 


\section{Presentación}

L

a presente edición contiene textos que problematizan teórica y prácticamente un turismo bien ponderado social y académicamente: el ecoturismo, turismo pro pobre, turismo rural o comunitario. Este tipo de turismo, de distintas variaciones, se engloba en el paradigma sustentable, y en esencia se afirma que potencialmente contribuye a la mejora y empoderamiento de comunidades vulnerables, sobre todo rurales. Los diferentes textos que componen este volumen muestran la importancia de complejizar críticamente en las implicaciones políticas, filosóficas, histórica, culturales o socioambientales de los conceptos y modelos que utilizamos para pensar la relación multidimensional entre turismo y desarrollo.

En el primer artículo Mujeres campesinas y turismo rural: estrategia de conservación ambiental en Los Tuxtlas, Veracruz, Ana Karen Reyes-Aguilar, Rocío del Carmen Serrano-Barquín, Carlos Alberto Pérez-Ramírez y Ruth Moreno-Barajas analizan el caso de autoorganización de las campesinas de la reserva de la biosfera Selva del Marinero en Catemaco, Veracruz, México. Los autores distinguen diferentes tipos de empoderamiento (con, dentro, para, sobre) y explican cómo estas mujeres reconvirtieron un proyecto de turismo gubernamental inicialmente fallido en un proyecto de turismo rural autogestivo, en el que el aprovechamiento con responsabilidad dio lugar a la incorporación de las participantes en actividades productivas, de conservación y de gestión turística.

En el segundo artículo, Turismo comunitario pro pobre y su definición de pobreza, de Martha Marivel Mendoza Ontiveros y Rafael Hernández Espinosa, se discuten las definiciones tradicionales de pobreza, destacando que se suelen obviar y reducir a lo económico las implicaciones multidimensionales de este fenómeno. Según los autores, en los discursos del llamado "ProPoor Tourism", se suele argumentar que el turismo contribuye al desarrollo de las comunidades principalmente por la derrama económica que genera. No obstante, afirman que aunque exista una buena intención en el discurso, este turismo no puede ser tomado como herramienta de combate a la pobreza, principalmente porque organismos y tomadores de decisión suelen confundirlo como un turismo que requiere poca infraestructura y ello es contraproducente para los posibles beneficiarios y sus regiones. Concluyen que aunque este tipo de turismo se centra en el beneficio a las personas menos favorecidas, estos grupos no necesariamente se benefician, pues las condiciones estructurales reproducen una falta de autonomía que no modifica ni los modos de vida ni de producción de los más vulnerables.

El tercer artículo, Conocimiento para la innovación en la empresa familiar hotelera. Caso destino turístico Mazatlán, de Ana María Larrañaga Núñez y Anel Yadira Pérez Melo, retoman los tradicionales análisis de clúster y de economías de escala aplicándolos al análisis turístico y para abonar en la discusión del conocimiento para la innovación en procesos organizacionales. Las autoras analizan 15 hoteles gestionados como empresas familiares bajo la hipótesis de que en este tipo de empresa existe transferencia de conocimiento. Quizá dicha hipótesis pudiera parecer obvia, pero las autoras concluyen que, a diferencia de muchas empresas de manufactura, en el caso de estas empresas turísticas se prefiere no innovar, porque ello se percibe como gasto y riesgo, la compra de conocimiento.

El cuarto artículo Percepción del turismo como fuente bienestar en comunidades rurales de Colima, de Carlos Amaya Molinar, Irma Magaña Carrillo, Ileana Ochoa Llamas y Yadira Guerra Montes parten del principio de que el turismo planificado y operado desde las comunidades 
contribuye al bienestar de un área rural mediante la utilización sostenible de sus recursos ambientales, sociales y culturales, lo que dará frutos no solo económicos, sino de empoderamiento de las comunidades. Los autores contrastan en campo lo propuesto por la teoría sobre turismo basado en la comunidad (ТBC), destacando el carácter único y original de cada una de las seis unidades de negocios estudiadas, las cuales se enfrentan a problemas comunes internos y externos. Según los autores, de los seis modelos analizados mediante técnicas mixtas, solo un par de proyectos tuvieron resultados económicos positivos. De esta forma, aunque el turismo pro pobre pudiera ser percibido positivamente debido a un incremento económico, no necesariamente contribuye a la construcción de comunidad, la sustentabilidad, la participación o la gestión y operación turística, y menos aún a la conservación de la identidad sociocultural o el cuidado del ambiente.

El último artículo, Gobernanza y gestión del turismo médico en la región fronteriza de Ciudad Juárez-El Paso está dedicado a un turismo considerado complejo como lo es el turismo médico. María Teresa Martínez-Almanza, Santos Alonso Morales-Muñoz y Carlos Jesús González-Macías explican por qué vale la pena pensar la gestión del turismo médico según los principios de la buena gobernanza. Estos principios básicos son la participación, el predominio de un imperio de las leyes, la transparencia y la rendición de cuentas, la capacidad de respuesta, la orientación al consenso, la equidad, la eficiencia y la eficacia, así como una verdadera visión estratégica. Después de entrevistar a actores clave, los autores concluyen que para revertir las condiciones del turismo médico en la región fronteriza de Ciudad Juárez-El Paso no bastan las acciones aisladas, sino que se necesitan líderes que no solo gestionen, sino que planifiquen e integren las distintas acciones y a los diferentes actores, que exista un mayor apoyo y se coordinen las acciones entre los diferentes niveles de gobierno.

En la nota crítica intitulada El turismo como instrumento de colonización neoliberal: una perspectiva foucaultiana, Tzintli Chávez Luna se centra clara y brevemente en el análisis de los discursos de desarrollo y su imposibilidad de abarcar las múltiples dimensiones de la realidad y sus complejidades históricas y presentes. La autora señala que los enfoques sociopolíticos y filosóficos no han podido superar el discurso en torno al "encuentro con el otro", visto como sujeto rezagado, vulnerable, en el que se ejerce poder o es colonizado. Su reflexión nos recuerda que el turismo no está al margen de los paradigmas de nuestros tiempos políticos, filosóficos y productivos, y la aparente imposibilidad de imaginar(nos) escenarios distintos a lo ya conocido. La nota cierra la preocupación enfatizando que la realidad muestra que los modelos que prevalecen están ligados a concepciones neoliberales globales, por lo que, aunque nos pese, el turismo continúa acentuando los desequilibrios y la continuidad de la dominación en un contexto llamado poscolonial en el que "el otro" (las comunidades, los vulnerables) continúa y continuará diluido.

Finalmente, se incluyen dos reseñas: una preparada por Alfonso González Damián sobre el libro Impactos socioculturales del turismo. Dimensiones conceptuales, teóricas y empíricas de Juan Carlos Monterrubio Cordero, y otra, realizada por José Francisco Domínguez Estrada sobre el XII Congreso Internacional de la AMIT, XVI Seminario de Turismo y Sustentabilidad de la UniCaribe y VIII Congreso CLAIT que tuvo como tema central "El turismo frente a los objetivos de desarrollo sustentable", realizado del 28 al 31 de octubre de 2018 en la ciudad de Cancún, Quintana Roo, México. 


\title{
MuJeRES CAMPESINAS Y TURISMO RURAL: ESTRATEGIA DE CONSERVACIÓN AMBiental EN LOS TuXTLAS, VERACRUZ
}

\author{
Ana Karen Reyes-Aguilar \\ karenreyesaguilar@hotmail.com \\ Rocío del Carmen Serrano-Barouín \\ rocioserba14@gmail.com \\ Carlos Alberto Pérez-Ramírez \\ caperezr@uaemex.mx \\ Ruth Moreno-Barajas \\ alin_ruth@hotmail.com \\ Universidad Autónoma del Estado de México
}

\begin{abstract}
Las mujeres han incursionado en diversas actividades productivas que a su vez les permiten ejercer su papel dentro de la unidad doméstica y mejorar sus condiciones de vida. Ante ello, se analiza la participación de la mujer campesina en el aprovechamiento de recursos naturales a partir de prácticas de turismo rural en Los Tuxtlas, Veracruz, y se identifica su aportación al desarrollo local sustentable. Esta es una investigación cualitativa, basada en entrevistas dirigidas a mujeres que laboran en la actividad turística. Se concluye que la mujer campesina contribuye a la conservación ambiental a través de prácticas de turismo rural y actividades productivas, mediante una relación armónica hombre-naturaleza que implica el largo plazo.
\end{abstract}

Palabras clave: Mujer campesina, turismo rural, conservación ambiental, empoderamiento.

\section{Peasant Women and RURal tourism: an enVIRONMENTAL CONSERVATION STRATEgy IN LOS TuXtLAS, VERACRUZ}

\begin{abstract}
Women have ventured into various productive activities that allow them to exercise their role within the domestic unit and in turn improve their living conditions. In view of this, the present work identifies the contribution of rural women to sustainable local development by analyzing the roles they play in the use of natural resources through rural tourism practices in Los Tuxtlas, Veracruz. This is a qualitative research, based on interviews to women who work in the tourist activity. The study concludes that peasant women contribute to environmental conservation through rural tourism practices and productive activities through a harmonious long-term relationship between man and nature.
\end{abstract}

Keywords: Peasant women, rural tourism, environmental conservation, empowerment.

Fecha de recepción: 30 de enero de 2019. Fecha de aceptación: 17 de mayo de 2019

CÓMO CITAR: Reyes-Aguilar, A., Serrano-Barquín, R., Pérez-Ramírez, C. A. y Moreno-Barajas, R. (2019). Mujeres campesinas y turismo rural: estrategia de conservación ambiental en Los Tuxtlas, Veracruz. Dimensiones Turísticas, 3(4), 9-25. https://doi.org/10.47557/DZJD3473 


\section{Mujeres campesinas y turismo rural: estrategia de conservación ambiental}

en Los Tuxtlas, Veracruz

$\mathrm{E}$ n México persisten diferencias entre hombres y mujeres respecto a los derechos económicos, sociales, políticos y ambientales, especialmente para las mujeres en el medio rural. Ante la participación de las mujeres en actividades productivas y el turismo, se considera una estrategia utilizada por el feminismo contemporáneo para promover los derechos de estas en sociedades con un marcado dualismo entre lo socialmente aceptable para las mujeres y los hombres, como espacios productivos que por tradición han sido considerados del dominio masculino y soportan la idea de una sola persona como proveedora de los medios necesarios para cubrir las necesidades del grupo doméstico, mientras que a las mujeres, como consecuencia de su función reproductora, se les asigna el rol de cuidadoras del hogar. Frente a este panorama, se origina un pensamiento crítico que contribuye al reconocimiento del derecho de las mujeres a realizar un trabajo productivo que desde la Revolución Industrial pasaba fuertemente desapercibido (Díaz-Carrión, 2012).

En este sentido, la incursión de las mujeres campesinas en actividades productivas y proyectos como el turismo les permite lograr un cambio positivo en su calidad de vida y bienestar emocional, además de llevar a cabo un mejor manejo y aprovechamiento de los recursos naturales con los que disponen en su lugar de origen. Se estima que la gestión para promover tales actividades puede ser llevada a cabo por diversos actores sociales: desde los organismos multinacionales, el sector público en los ámbitos federal, estatal y municipal, hasta las organizaciones de la sociedad civil, y sobre todo los propios actores locales, entre ellos las mujeres.

De acuerdo con García (2004) y Hernández Flores y Martínez Corona (2006), en la actualidad se observa que la participación productiva de las mujeres ha hecho posible un cambio en la organización social que logra ser parte del desarrollo de las comunidades, debido a que generan ingresos económicos y les permite el acceso a la toma de decisiones, variaciones en su autopercepción y en las relaciones entre los géneros, con la finalidad de potenciar el cambio en su lugar de origen y favorecer transformaciones que propicien una mejor posición social y el bienestar de las mujeres y sus familias. De esta manera, las mujeres se perciben como un agente de desarrollo local y de modernización, en especial las campesinas, ya que cuentan con un alto grado de identidad que les permite mantener fuertes relaciones con el entorno y con elementos de la ruralidad tradicional, además de desempeñar un papel estratégico para la supervivencia de los pueblos a partir de su incorporación en actividades productivas.

Por otra parte, Martínez Corona (2003) menciona que la participación social es una condición necesaria para la ciudadanía puesto que por medio de esta se ejerce la potestad de influir en los procesos que afectan el propio destino, y en la toma de decisiones como un elemento central que conlleva al empoderamiento, término definido por Hernández Flores y Martínez Corona (2006) como el proceso por el cual los individuos adquieren control sobre sí mismos; esto les permite desarrollar nuevas capacidades y ser reconocidos como protagonistas y sujetos sociales capaces de superar la vulnerabilidad, la exclusión, contribuir al progreso y gozar de sus beneficios a partir de su ideología y los recursos que determinan el poder. En este sentido, la noción de empoderamiento ha cobrado relevancia en 
los últimos años en los estudios vinculados con la conformación de sujetos sociales, particularmente en los surgidos de organizaciones o movimientos de grupos desfavorecidos.

Lo anterior refleja que la participación de las mujeres en diversas actividades productivas y fuera del grupo doméstico genera un proceso de empoderamiento con el que se vislumbra como protagonista principal en distintos sectores a partir de la inducción de nuevas alternativas emprendedoras que resultan una fuente de autoempleo. Asimismo, cambia la distribución del poder, tanto en las relaciones interpersonales como en las instituciones de la sociedad. En el caso del turismo rural, visto como aquella actividad que aporta beneficios económicos a la población local a través de la generación de empleos y autoempleos, y en cuanto estrategia para la conservación del medio ambiente debido a actividades específicas que oferta, se considera también una práctica por medio de la cual las mujeres pueden contribuir al aprovechamiento de los recursos naturales a través de su incorporación y participación en diversas labores.

Por esta razón, se propone el análisis de la participación de la mujer campesina en el aprovechamiento y conservación de recursos naturales a partir de prácticas de turismo rural y actividades productivas como estrategia para la conservación ambiental con base en el proyecto turístico Selva del Marinero, en el ejido Adolfo López Mateos (ALM) perteneciente al municipio de Catemaco, Veracruz, México. Cabe destacar que el ejido forma parte del área natural protegida (ANP) Reserva de la Biósfera Los Tuxtlas debido a la riqueza biológica con la que cuenta la región, por lo que ha sido reconocida por la Comisión Nacional para el Conocimiento y Uso de la Biodiversidad (Conabio) como zona prioritaria para la conservación, gracias a su diversidad de ecosistemas y especies biológicas (Piñar, Nava y Viñas, 2011); ante ello, solo se permite la realización de actividades sustentables para fomentar su protección y conservación.

Para efectuar este análisis, el documento se divide en seis apartados. Los primeros tres presentan las nociones conceptuales que dieron soporte a la investigación; el cuarto da cuenta del procedimiento metodológico utilizado; el quinto muestra los resultados encontrados a partir de la descripción del proyecto Selva del Marinero como estrategia de conservación ambiental, la participación de la mujer en el turismo rural y actividades productivas, y su proceso de empoderamiento; y el sexto expone las conclusiones de la investigación, que destacan la necesidad de reconocer el papel que desempeña la mujer campesina, tanto para la dinamización productiva del medio rural, como para impulsar el bienestar de la unidad doméstica y la continuidad de las dinámicas comunitarias.

\section{Mujer campesina y empoderamiento}

En México, el desarrollo de la sociedad ha estado representado, en algunos sectores, por el rol que han ejercido las mujeres, sin embargo, en la actualidad este sigue pasando desapercibido en diversas esferas e, incluso, en el núcleo familiar, por lo que se intenta reconocer o hacer énfasis en tal papel, pues ser mujer ya no solo significa desempeñar 


\section{Mujeres campesinas y turismo rural: estrategia de conservación ambiental en Los Tuxtlas, Veracruz}

actividades como ama de casa o madre. Hoy en día esta busca ser más independiente, productiva y generadora de ingresos económicos, los cuales obtendrá a través de su inclusión en diversas actividades. En este aspecto, la mujer campesina no es ajena al cambio y a la búsqueda de nuevas y mejores oportunidades ya que, más allá de dedicar su tiempo al hogar y a la familia, requiere alternativas de desarrollo para mejorar su bienestar económico y social.

Toda mujer se define, de manera general, como operadora de una serie de tareas, tanto reproductivas como productivas, donde las primeras se entienden en dos sentidos: biológico, porque tiene que ver con la reproducción de la vida misma; y social, en el cual las tareas involucradas tienden a mantener y reproducir las condiciones del sistema social, las que generalmente se circunscriben al ámbito doméstico por cuanto las tareas productivas son aquellas de las que se obtiene un ingreso monetario, ya sea mediante la fuerza de trabajo o por la venta de un bien producido (Torres, 2004). Pérez-Ramírez, Zizumbo Villarreal y Miranda Contreras (2012) y Campaña (1982) conciben a la mujer campesina y a la urbana como aquella que se caracteriza por enfocarse al trabajo doméstico no remunerado, rutinario, desvalorizado, sujetándose a trabajos como el cuidado de los hijos, de animales, o las diversas tareas del hogar, consideradas propias de su género, que aseguren la permanencia y continuidad del grupo familiar, en el desarrollo de la sociedad.

En contraparte, las tareas productivas revierten el concepto tradicional de mujer campesina a partir de su incorporación en actividades fuera del núcleo familiar o doméstico, puesto que se espera que las mujeres adquieran una concepción estratégica de su propio desarrollo y logren visualizarse como una fuerza social importante y, por lo tanto, evitar sentimientos de desvalorización e improductividad (Villarreal, 2000). Lo anterior se entiende como una oportunidad para que las mujeres, mediante un proceso de empoderamiento, adquieran habilidades como seres multidimensionales, es decir, con aspectos físicos, mentales, emocionales, con inteligencias múltiples y con una dimensión de cambios sociales, políticos y económicos necesarios para tornar sus visiones alternativas en realidades, y que además permita que el desarrollo sea implementado con éxito respecto al alcance de su desarrollo humano autosustentable y que sean totalmente responsables de su realidad (Rowlands, 1997; Casique, 2010; Sierra Pacheco, 2015).

De esta manera, se ha dado un nuevo sentido al concepto de mujer campesina, logrando con ello la valorización de esta, destacando la importancia de los roles que desempeña desde varios ámbitos como el social, económico, político, académico, ambiental, entre otros. Ligado a esto, Buendía-Martínez y Carrasco (2013) definen a la mujer campesina como el eje del mundo rural, no solo por su aportación al empleo y al producto interno bruto, sino por el potencial de la producción agrícola, que le permite ser uno de los principales contribuyentes a la seguridad alimentaria global; asimismo, cumple un papel fundamental tanto en la sociedad rural como en su economía, aunque con un acceso más limitado a los insumos, los servicios, las organizaciones rurales, la infraestructura productiva y la tecnología. 


\section{Turismo rural: proyecto Selva del Marinero}

En la actualidad, el turismo constituye una de las actividades económicas de mayor relevancia, en particular para aquellos países que poseen destacados recursos naturales y culturales susceptibles de aprovechamiento turístico; tal es el caso de México, que cuenta con diversos sitios identificados como destinos turísticos. Si bien el desarrollo del turismo tradicionalmente se ha enfocado al aprovechamiento recreativo de los recursos presentes en los litorales, como un turismo de sol y playa, hoy se hace referencia a la diversificación de esta actividad con el posicionamiento de destinos como ciudades industriales, de negocios, coloniales, zonas arqueológicas, áreas naturales protegidas u otros en función de las corrientes de turistas y visitantes.

El turismo alternativo se presenta como una corriente que tiene por objetivo la realización de viajes donde el turista participa en actividades recreativas de contacto con la naturaleza y las expresiones culturales de comunidades rurales, indígenas y urbanas, respetando los patrimonios natural, cultural e histórico del lugar visitado. Presupone que los organizadores están conscientes de los valores naturales, sociales y comunitarios, y que los turistas desean interactuar con la población local (Ibáñez y Rodríguez, s. f.).

En este sentido y bajo el concepto que maneja el turismo rural, surge el proyecto turístico Selva del Marinero, ubicado en el ejido ALM, Catemaco. Sus antecedentes parten de la presencia de diversas organizaciones de la sociedad civil, con base en el proyecto Sierra de Santa Marta dentro del Anp Reserva de la Biósfera Los Tuxtlas, Veracruz, quienes impulsaron la creación del "destino turístico ecológico" en el sitio.

A pesar de este impulso externo, esta estrategia de actividad productiva y conservación tiene el objetivo de frenar y dar fin al deterioro ambiental que años atrás habían propiciado los mismos habitantes del lugar ante la falta de oportunidades de trabajo, lo cual los condujo tanto a deforestar la selva con la finalidad de vender madera y obtener un ingreso económico, como a cazar distintas especies para alimentarse y, en ocasiones, para venderlas a externos. Sus acciones tuvieron como consecuencia el agotamiento de especies forestales y animales, además de la desaparición de algunos ríos, principalmente de los que se abastecían de agua para consumo, fue entonces cuando se percataron del problema que habían ocasionado, no solo al ambiente sino a ellos mismos, y que no tenían más que vender y tenían que trasladarse largas distancias para conseguir el vital líquido.

De tal modo, los habitantes decidieron tomar medidas para recuperar su hábitat, y años más tarde, con ayuda de algunos investigadores de la Universidad Nacional Autónoma de México (UNAM), iniciaron la experiencia de turismo responsable con un taller participativo. La asamblea ejidal acordó una restricción voluntaria del uso de sus recursos naturales para la conservación de 100 hectáreas de terrenos de selva. Al inicio, el proyecto fue impulsado por las autoridades ejidales e integró a la mayoría de los habitantes, no obstante, a medida que avanzaron los trabajos voluntarios de capacitación y construcción de la infraestructura, algunos integrantes fueron desertando, instados por las necesidades materiales del momento, hasta que el proyecto quedó en manos de un grupo de 26 ejidatarios de un total de 101 habitantes. 


\section{Mujeres campesinas y turismo rural: estrategia de conservación ambiental en Los Tuxtlas, Veracruz}

Un rasgo interesante de este proyecto es la participación de las mujeres, no solo en lo que respecta a las actividades tradicionales de elaboración de alimentos, sino también como guías y administradoras de la empresa. En general, para los integrantes del proyecto, hombres y mujeres, este representa, además de una alternativa económica y de conservación ambiental, la posibilidad de mejorar sus condiciones de vida, la revaloración de su condición campesina, de su saber y de su ser.

Ante ello, en 1997 se establecieron los primeros senderos interpretativos e interactivos en la zona, con la participación de estudiantes de la unAm, de la Universidad Autónoma Metropolitana, y habitantes de la comunidad; eran los primeros pasos que marcaban la distancia de una idea y la realidad sobre el manejo de los recursos naturales, una realidad que no se entendía del todo en la visión comunitaria. Estos senderos consistían en una visita a la diversidad paisajista y de vegetación, como ríos, cascadas y pozas y el sendero para la caminata al Cerro del Marinero donde comienza el bosque de niebla. Así, en diciembre del mismo año se inició el proyecto con los primeros visitantes logrando consolidar las expectativas para la implementación de un proyecto piloto que la comunidad llamó "La Selva del Marinero".

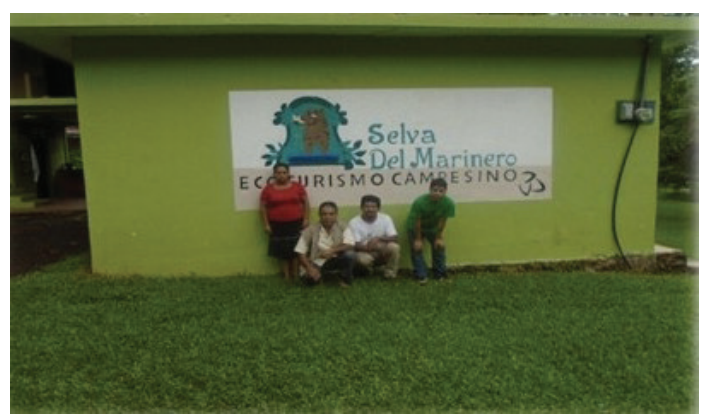

Fotos: Ana Karen Reyes-Aguilar (2016)
Figura 1. Proyecto Selva del Marinero, Los Tuxtlas, Veracruz

\section{Metodología}

La investigación se llevó a cabo en dos etapas, una de investigación documental y otra de trabajo de campo. En la primera se realizó una revisión de literatura respecto a la mujer campesina, el turismo rural y la conservación ambiental. En la segunda se aplicaron instrumentos con enfoque etnográfico en la zona de estudio mediante estancias en el ejido ALM, durante los meses de junio a julio de 2016 y abril de 2017, periodo donde se aplicaron 24 entrevistas semiestructuradas e individuales a las mujeres que participan en la actividad turística, y a quienes cuentan con un huerto de agricultura. Del mismo modo, se elaboró una bitácora de campo que incluía información a partir de observaciones y entrevistas informales a los hombres del ejido, particularmente a los esposos de las mujeres a quienes se entrevistó para conocer su posición respecto a la participación de estas en la actividad turística. 
Para la interpretación de la información recopilada, se empleó el método de análisis del discurso como una herramienta que permitió comprender tanto el sentido que tienen los cambios de conducta, visiones, objetivos y empoderamiento de las mujeres en el ejido, como las prácticas sociales que se han reflejado en las generaciones actuales respecto a la mejora de la calidad de vida, el bienestar, y la conservación de recursos naturales a través de su relación armónica con ellos.

Este análisis se dividió en cuatro ejes. El primero se enfoca en el turismo rural, con base en las contribuciones de Cañada y Gascón (2007), quienes plantean un enfoque crítico del fenómeno turístico, el cual posibilita el estudio del impacto socioeconómico, ambiental y cultural en el nivel de la comunidad y el grupo doméstico, destacando que no es posible comprender las consecuencias que tiene o puede tener la actividad, sin razonar la estructura de los beneficios o detrimentos que esta aporta a las condiciones sociales, culturales, económicas y biofísicas de la comunidad anfitriona. Ello se explica a partir del turismo como economía local, las actividades y servicios, oferta y demanda y la participación de la mujer en el proyecto Selva del Marinero.

El segundo eje, aprovechamiento de recursos naturales y conservación ambiental, considera al paisaje como uno de los elementos que favorecen el surgimiento del turismo en una región, debido a que este suele mostrarse frágil con su desarrollo ante la llegada de turistas porque se genera un cambio de uso de suelo respecto a la propiedad y tenencia de la tierra, además de la gestión y destino de los recursos naturales, los cuales muchas veces tienden a ser sobreexplotados. De esta manera, se propusieron los siguientes criterios de análisis: sentido social de los recursos naturales, agentes sociales locales, gestión de recursos y alternativas de uso y preservación.

El tercer eje de análisis pretende conocer la participación de la mujer y su incorporación en actividades productivas para propiciar la conservación ambiental y el uso y aprovechamiento de recursos naturales. Finalmente, el cuarto eje considera la metodología que propician Knight y Cottrell (2015) sobre los procesos de empoderamiento, definidos por cuatro tipos: poder sobre, poder para, poder con y poder dentro.

En la figura 2 se muestra a la mujer campesina como eje rector para llevar a cabo la actividad turística y la conservación ambiental ya que, a partir de su participación en tales actividades y las diferentes variables consideradas, pasa por distintas etapas que le permiten concretar su empoderamiento, lo cual ayuda a forjar la conservación de recursos naturales y, por ende, un desarrollo local sustentable. Lo anterior se aborda mediante la perspectiva de los sistemas complejos, debido a que abarca esferas como la económica, sociocultural y ecológica, realizando así un análisis del turismo rural desempañado por la mujer campesina desde las variables de actividades y servicios, valoración de los recursos naturales y culturales, además de los efectos colaterales que genera la actividad turística respecto a las condiciones de la mujer campesina.

Este análisis holístico de variables, tanto en el aprovechamiento sustentable de recursos naturales, a partir del sentido de pertenencia hacia estos, como en el empoderamiento de la mujer, el cual se va a identificar a partir de su participación en la actividad turística, ayuda a ver de qué manera se influye en la conservación ambiental. 


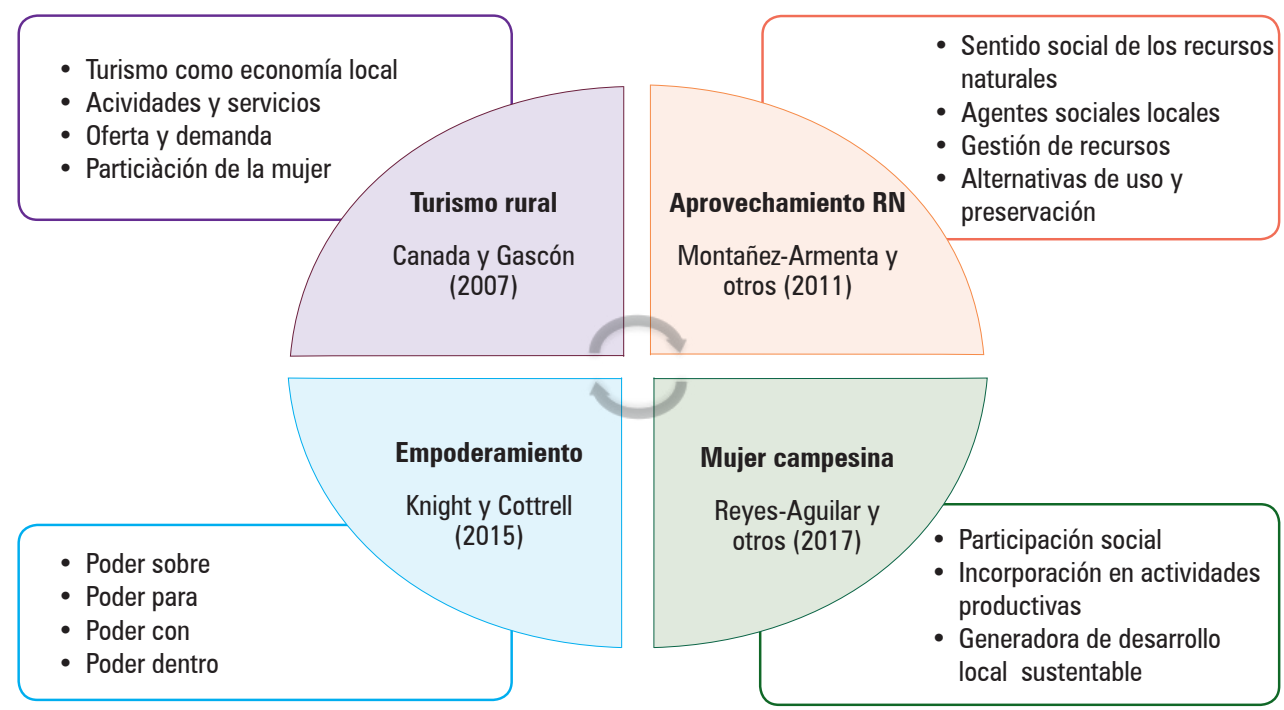

Fuente: Reyes-Aguilar (2017), con base en Cañada y Gascón (2007), Montañez-Armenta, Yanes y Silva (2011), Reyes-Aguilar, Serrano-Barquín, Pérez-Ramírez y Moreno-Barajas (2017) y Knight y Cottrell (2015).

FIGURA 2. Análisis de la participación de la mujer en el aprovechamiento y conservación de recursos naturales y sus procesos de empoderamiento

\section{Resultados}

Los resultados del análisis se dividen en tres temas: la descripción del proyecto Selva del Marinero como una estrategia de conservación ambiental, la mujer campesina en el proyecto y, por último, su proceso de empoderamiento a través de la actividad turística.

\subsection{Proyecto Selva del Marinero: una estrategia de conservación ambiental}

El ejido ALm fue fundado en 1971, después de décadas de disputas con los propietarios de las tierras circundantes y actores jurídicos. En 1984, la Secretaría de la Reforma Agraria entregó la concesión con un total de 535 hectáreas a los actuales pobladores. Tuvieron patrocinio del gobierno federal para fomentar la cría de ganado y cultivos agrícolas, lo que aceleró el cambio del ambiente natural de la selva y el uso de suelo, creando sitios de potreros y milpas principalmente. Sin embargo, debido a la pendiente por encima de 40 grados, la mayoría de la selva ejidal permaneció intacta, lo cual propiciaba una dependencia de la caza y la extracción de madera con un eventual agotamiento de recursos naturales, que a su vez incidió en las limitadas actividades económicas y fuentes de empleo que ofrecían los ranchos vecinos donde se sembraban maíz y productos agrícolas básicos. 
De esta manera surge el proyecto Selva del Marinero como promesa de turismo rural comunitario y estrategia de conservación de un grupo de habitantes del ejido ALM en las laderas del Cerro del Marinero. Así, se inició una experiencia de turismo responsable con un taller participativo, cuando la asamblea ejidal decidió una restricción voluntaria del uso de sus recursos naturales y destinarlos para su conservación.

Hoy en día existen más de tres cabañas tipo hostal, de estilo rústico y confortables, dos de ellas clasificadas como búngalos familiares y las demás como grupales; tienen servicio eléctrico y algunas baño individual y completo; llegan a hospedar a grupos mayores de 30 personas, siendo la capacidad de las cabañas para 40 y 20 en la zona de acampar. Cuentan con una comisión de "hospedaje", la cual, en las diferentes administraciones, ha estado a cargo de mujeres y son quienes realizan la limpieza de las cabañas y las dotan de productos básicos, además de informar al administrador si hace falta algo o si se requiere mantenimiento.
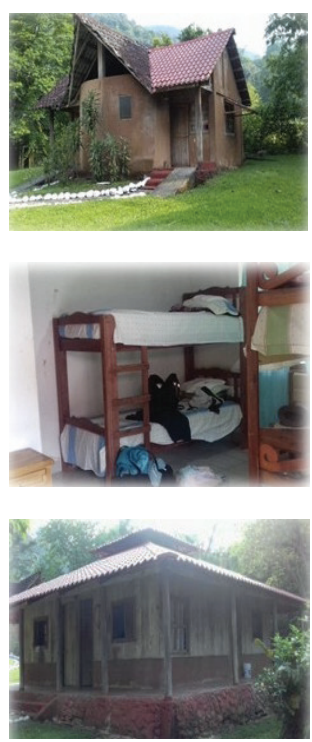

Fotos: Ana Karen Reyes-Aguilar (2017)

Figuras 3,4 y 5 . Cabañas,

Los Tuxtlas, Veracuz

Para los ejidatarios, el hospedaje y campamento son parte fundamental de los servicios ofertados. Desde que se creó el proyecto, ha ido mejorando gracias a las sugerencias de los visitantes y a la iniciativa propia, por ejemplo, el empleo de material firme como machimbloque o bloque de tierra comprimida estabilizada y techo de tejas para la construcción de las cabañas. Otro servicio que brindan es la alimentación, la cual está a cargo de las "anfitrionas", un grupo de nueve a 12 integrantes, actualmente conformado por mujeres que tomaron cursos de gastronomía, higiene, autoestima, entre otros, para poder formar parte de la comisión de alimentación.

Como parte de las actividades recreativas y en contacto con la naturaleza, ofrecen caminatas por los distintos senderos interpretativos en el bosque de niebla y la selva tropical, a fin de conocer algunos tipos de plantas, árboles, aves y ecosistemas representativos tanto para los habitantes como para la región en general, así como la importancia y función ecológica de cada especie. A través de los senderos, se llega a los diferentes atractivos naturales, por ejemplo la cueva de murciélagos, la cual alberga más de 30 tipos de esa especie; en esta zona se le pide al turista guardar silencio y no tomar fotografías con flash debido a la sensibilidad de los murciélagos. Cerca de esta zona hay un lecho rocoso que presenta características adecuadas para practicar rapel, sin embargo, en temporada de lluvias se invita al turista a tomar precaución, ya que la misma estructura da lugar a la formación de una cascada.

También se arriba a la cascada y a las pozas del río Coxcoapan, donde se permite al visitante practicar natación; asimismo, se llega a la caseta para la observación de aves entre 

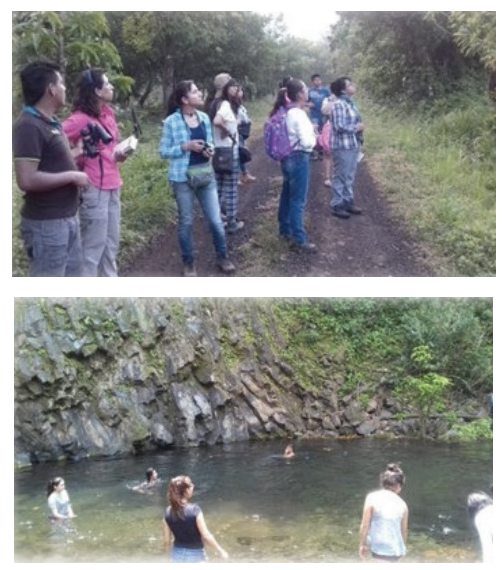

Fotos: Ana Karen Reyes-Aguilar (2017).

FiguRAs 6 y 7 . Actividades recreativas, Los Tuxtlas, Veracruz

las cuales destacan tucanes (Ramphastos sulfuratus), águilas (Spizaetus ornatus) y loros cariamarillos (Amazona autumnalis). Se recomienda realizar esta actividad entre las 6 y 7 de la mañana, cuando las aves comienzan a buscar alimento; los demás recorridos se sugiere llevarlos a cabo antes de las 6 de la tarde, con la finalidad de que el visitante pueda disfrutar del paseo. Los encargados de fungir como guías de turismo son los hombres que, al igual que las mujeres, tienen su comisión y tomaron cursos de capacitación para poder tener el cargo.

Respecto al transporte, la distancia de Catemaco al ejido y el proyecto Selva del Marinero son más de ocho kilómetros, y en el centro del municipio salen camionetas que ofrecen el servicio a diferentes comunidades y en horarios indistintos, incluyendo el ejido. En caso de tener reservación, los mismos ejidatarios realizan un convenio con los operadores de transporte público de Catemaco, el cual consiste en trasladar a los visitantes del centro de este al ejido y viceversa; cabe mencionar que el costo del servicio se incluye en la reservación. Ello da lugar a que personas ajenas al proyecto Selva del Marinero se beneficien de la actividad turística que se oferta en el ejido ALM.

Por último, se dan talleres de educación ambiental con la finalidad de concientizar a los visitantes acerca de la importancia del cuidado, aprovechamiento sustentable y conservación de los recursos naturales, a través de pláticas sobre experiencias vividas por los habitantes del ejido, de modo que puedan comprender que el ser humano es capaz de adaptarse al medio natural sin necesidad de dañarlo para poder ofrecerlo a generaciones futuras.

\subsection{Participación de la mujer campesina en el turismo y actividades productivas}

El turismo rural y la implementación de huertos agrícolas familiares representan las actividades productivas que han dado lugar a la inserción de las mujeres campesinas en una dinámica diferente al hogar. Asimismo, les ha permitido ser más independientes, productivas y generadoras de ingresos económicos, con lo que han logrado mejorar su calidad de vida y su bienestar social. Por esta razón, vale la pena describir la participación de la mujer en la actividad turística y proyectos productivos, además de los beneficios y efectos colaterales que derivan de tal actividad: su empoderamiento. En particular, para aquellos lugares que, como el ejido ALm, poseen destacados recursos naturales susceptibles de aprovechamiento, pero sobre todo para su conservación.

La experiencia de la mujer campesina a partir del turismo rural en el proyecto Selva del Marinero ha hecho posible el reconocimiento del papel de las mujeres tanto en el sector social como en el político, económico y ambiental, ya que actualmente se les considera 
para participar y colaborar en diversos escenarios de la mano con el género opuesto para obtener mejores resultados. La lucha a favor de intereses personales y para la transformación de las estructuras ha propiciado que las mujeres del ejido ALM ejerzan principios de autonomía, igualdad, realización propia, respeto, libertad, entre otros, ante los miembros de su comunidad.

No obstante, las mujeres del ejido pasaron por diversos procesos de transformación para llegar a ser lo que ahora representan tanto en el sitio como en el proyecto y personalmente. Haber sido integradas al trabajo turístico les ha generado grandes satisfacciones debido a que se consideran aptas para llevar a cabo cualquier actividad diferente del ámbito doméstico. Su incorporación a actividades no domésticas dio lugar a la valorización de su existencia como sujetos capaces de identificar distintas problemáticas y dejar de lado la sujeción de su género, además de contribuir a la conservación ambiental y aprovechamiento sustentable de recursos naturales, actividades que les permitieron mejorar sus condiciones de vida y su desarrollo personal y familiar.

Hoy las mujeres participan en el proyecto como "anfitrionas", cuyo trabajo se basa en el servicio de alimentación para los visitantes. Como ya se indicó, el grupo lo componen entre nueve y 12 mujeres, quienes tomaron cursos de gastronomía, higiene, autoestima, entre otros, para formar parte de la comisión de alimentación, pero sobre todo para aprender a autovalorarse y así ofrecer mejores servicios al visitante. Así, adoptaron una organización tal que entre ellas se ponen de acuerdo para decidir el menú cuando saben que llegará un grupo de visitantes; realizan una junta en donde elaboran una lista de las comidas que van a preparar así como de los ingredientes que van a ocupar, esta última se la hacen llegar al administrador para que sepa lo que se tiene que comprar; después, una o dos de ellas salen a comprar los insumos que no obtienen directo de la selva, como la carne de res o pollo.

De acuerdo con su organización, cada mujer sirve 36 comidas, las cuales les son remuneradas equitativamente; el servicio consta de tres comidas típicas al día: desayuno, que se sirve a las 8:00 a.m.; comida, a las 2:00 p.m.; y cena, a las 8:00 p.m. Este servicio se considera especial, debido a que las comidas se sirven en la casa de la "anfitriona", lo cual hace la diferencia con otros sitios, además de que la mayoría de los insumos utilizados

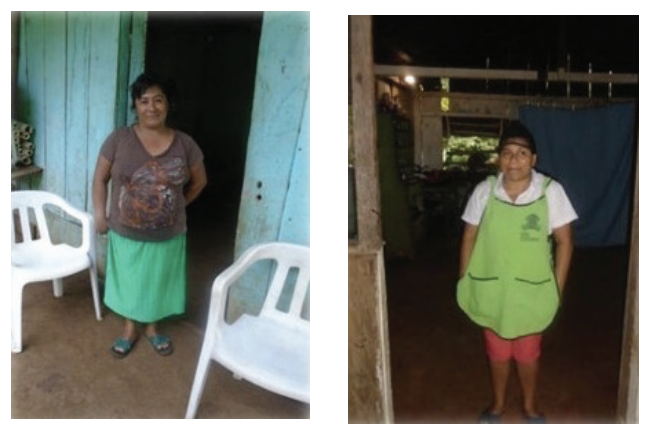

Fotos: Ana Karen Reyes-Aguilar (2016).
FiguRAS 8 y 9. Mujer campesina y actividad turística, Los Tuxtlas, Veracruz 

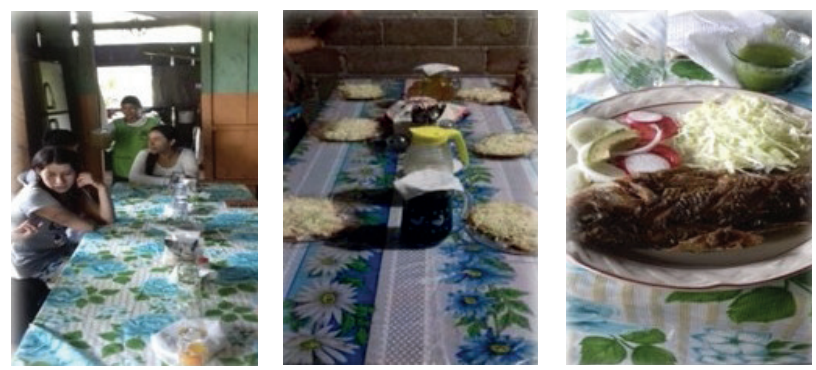

Fotos: Ana Karen Reyes-Aguilar (2017).

FigurAs 10, 11 y 12. Casa de la "anfitriona" y alimentación, Los Tuxtlas, Veracruz
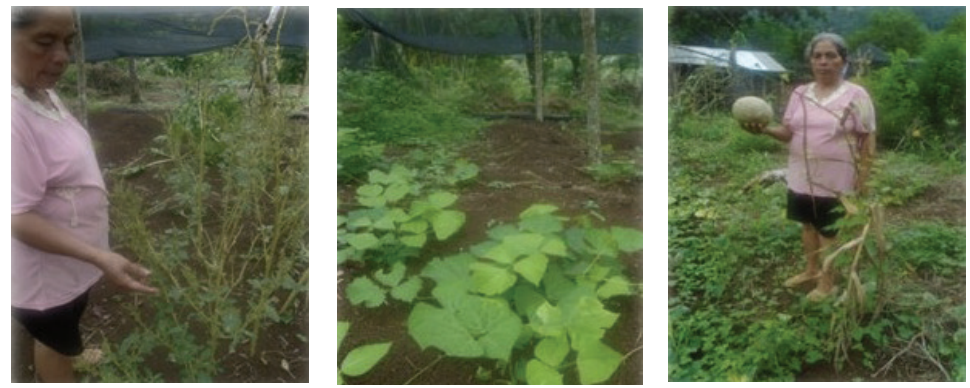

Fotos: Ana Karen Reyes-Aguilar (2016).

FiguRAs 13,14 y 15. Mujer campesina y huertos de traspatio, Los Tuxtlas, Veracruz

para la elaboración de alimentos se extraen de la misma selva, aprovechando al máximo los recursos que se obtienen de las hortalizas.

Las mujeres se han empleado en otra actividad diferente del hogar y la actividad turística: en talleres de producción orgánica de especies comestibles, en la modalidad de hortalizas de traspatio, mediante los cuales generan sus propios alimentos, pero también les funcionan como fuente de ingresos económicos extra, pues en ocasiones llegan a vender sus productos dentro del ejido.

En este caso, el rol de las mujeres del ejido ALM, y en particular las que participan en el proyecto Selva del Marinero, ha permitido conservar los recursos naturales y otorgarles mayor valor, no monetario; es decir, se han incorporado en el sector ambiental de tal manera que no se sienten dueñas de los recursos sino parte de ellos, de ahí el sentido de responsabilidad para que estos perduren en el tiempo. Por otro lado, solo dos de las mujeres que conforman el grupo llegaron a ser guías de turistas durante una de las administraciones del proyecto, pero no continuaron en el cargo porque prefieren formar parte de las "anfitrionas", además de los procesos de empoderamiento. 


\subsection{Empoderamiento de la mujer campesina}

Como se ha mencionado, el proyecto turístico Selva del Marinero dio lugar a la integración de la mujer campesina en actividades fuera del núcleo familiar, lo cual contribuyó a que fuesen escuchadas y tomadas en cuenta, además de conseguir las mismas oportunidades que los hombres. Con ello se afirma que la mujer campesina pasó de ser una simple ama de casa a socia del proyecto y emprendedora de proyectos productivos (anfitrionas y huertos).

El proyecto turístico no solo generó un cambio en la organización social del ejido, sino también en las condiciones de vida y creencias respecto a la igualdad de género, ya que las mujeres como socias del proyecto se incorporaron al trabajo remunerado, lo que les permitió formar parte en la toma de las decisiones respecto a lo que se iba a llevar a cabo en el ejido, pero sobre todo a su empoderamiento. Se cree que el cambio principal se dio dentro del hogar, puesto que las mujeres tomaban talleres y cursos de capacitación sin desatender sus actividades cotidianas, lo cual en algunos casos originó conflictos familiares, aunque en el largo plazo su entrada al proyecto también traería beneficios a los integrantes de sus familias. Pese a esas circunstancias, hoy en día los hombres, orgullosamente, avalan que las mujeres participen en actividades externas al hogar. Mediante el trabajo de campo, se identificaron los criterios planteados en cuanto al tipo de empoderamiento que adquirió la mujer en el ejido ALM, lo cual se muestra en el cuadro 1.

En este sentido, a partir de las características que adquirieron las mujeres durante el proceso de incorporación al proyecto turístico, es posible mencionar que, actualmente, son capaces de desenvolverse en diversos medios y enfrentar situaciones futuras, como aprovechar y cuidar los recursos naturales, con la finalidad de obtener algún beneficio económico y al mismo tiempo contribuir a la conservación ambiental y al desarrollo local sustentable en el ejido, a través de la generación de una relación armónica y respetuosa con la naturaleza.

Respecto al desarrollo local sustentable, se considera una realidad en el ejido, puesto que, con la actividad turística, los habitantes han conseguido mejorar sus condiciones de vida, si bien no cuentan con grandes lujos, tienen la oportunidad de atender necesidades básicas. Por otra parte, las generaciones jóvenes buscan emprender estudios superiores que les posibilite saber más sobre recursos naturales y formas de conservación, actuando de manera individual y con mayor libertad, lo que no solo ayudará a su superación personal sino también a la del ejido con sus respectivas aportaciones a futuro.

\section{Conclusiones}

En México, las mujeres cuentan con los medios necesarios para incursionar en diversos ámbitos diferentes del doméstico, no obstante, siguen existiendo zonas, especialmente las rurales, con gran índice de subordinación femenina, donde se busca incluir a la mujer 


\section{Mujeres campesinas y turismo rural: estrategia de conservación ambiental}

en Los Tuxtlas, Veracruz

CuAdro 1. Tipo de empoderamiento de la mujer campesina en el ejido ALM

\begin{tabular}{|c|c|c|}
\hline Tipo de poder & Características & Análisis respecto a las mujeres en el ejido \\
\hline Poder con & $\begin{array}{l}\quad \text { Colectividad } \\
\text { Capacidad para abordar } \\
\text { necesidades e intereses } \\
\text { individuales o grupales }\end{array}$ & $\begin{array}{l}\text { Fue el poder más representativo entre las mujeres del ejido, ya } \\
\text { que a partir de su incorporación en el proyecto Selva del Marinero } \\
\text { pudieron reforzar el trabajo colectivo entre ellas y los hombres. } \\
\text { Se mejoraron sus condiciones de vida de manera general a } \\
\text { partir de los cursos y talleres que recibieron durante el proceso } \\
\text { de consolidación del proyecto. }\end{array}$ \\
\hline Poder dentro & $\begin{array}{l}\text { Conocimiento de sí misma } \\
\text { Concientización, } \\
\text { autodeterminación y } \\
\text { respeto }\end{array}$ & $\begin{array}{l}\text { Este poder se observó entre las mujeres que participan en } \\
\text { el proyecto, logrado a partir de los talleres de capacitación, } \\
\text { especialmente gracias a los talleres de autoestima que } \\
\text { recibieron. }\end{array}$ \\
\hline Poder para & $\begin{array}{l}\qquad \text { Agencia } \\
\qquad \text { Capacidad de existir } 0 \\
\text { actuar con libertad y valor } \\
\text { individual }\end{array}$ & $\begin{array}{l}\text { Las mujeres adquirieron mayor libertad, autoridad y autonomía } \\
\text { dentro del proyecto turístico y de sus hogares. Sus decisiones } \\
\text { empezaron a ser consideradas y respetadas, lo que dio lugar a } \\
\text { la mejora de la calidad de vida de todos en el ejido. }\end{array}$ \\
\hline Poder sobre & $\begin{array}{l}\text { Dominación } \\
\text { Control hacia otras } \\
\text { personas }\end{array}$ & $\begin{array}{l}\text { Se refleja en menor medida en las mujeres del ejido, ya que } \\
\text { ellas trabajan en equipo con una función de liderazgo, más que } \\
\text { de dominio, lo que les otorga grandes beneficios tanto en el } \\
\text { nivel personal como colectivo. }\end{array}$ \\
\hline
\end{tabular}

Fuente: Reyes-Aguilar (2017), con base en Knight y Cottrell (2015).

campesina en actividades productivas que le permitan mejorar tanto su percepción como sus condiciones de vida.

La participación de las mujeres campesinas en el proyecto Selva del Marinero les ha permitido vivir un proceso de empoderamiento cuyos resultados, de acuerdo con las aportaciones de Knight y Cottrell (2015), muestran cuatro tipos de poderes: el poder con, que tiene que ver con su capacidad para abordar colectivamente necesidades e intereses individuales o grupales; es el más representativo entre las mujeres del ejido, ya que a partir de su integración al proyecto pudieron reforzar el trabajo colectivo entre ellas. El segundo es el poder dentro, representativo del conocimiento de sí mismas, se obtuvo mediante su asistencia y participación en los talleres de capacitación, pero sobre todo por los talleres de superación y aceptación personal que recibieron. En tercer lugar se consideró el poder para, el cual se representa con la participación de las mujeres en el proyecto, puesto que dio lugar a que tuviesen oportunidades de crecimiento individual y colectivo, además de la adquisición de un nuevo compromiso basado en la autonomía y libertad dentro y fuera de la unidad doméstica. Finalmente, el poder sobre, que se basa en la dominación y/o control hacia otras personas; este tipo de poder se vio reflejado en menor porcentaje en las mujeres, ya que, más que dominar al grupo, ellas están de acuerdo con el trabajo en equipo que desempeñan, pues les ha dejado grandes beneficios tanto en el nivel personal como colectivo. 
Así, se evidencia que la participación de las mujeres en el ejido ha sido una estrategia utilizada para promover los derechos de estas en su grupo social, fungiendo como ejemplo para las comunidades aledañas, lo cual ha dado pie a un marcado dualismo entre lo socialmente aceptable para las mujeres y los hombres, dado que ya no solo los hombres son los proveedores de los medios necesarios para cubrir las necesidades del grupo doméstico.

Tales transformaciones han tenido lugar a partir de las prácticas turísticas. El turismo constituye una actividad económica relevante para los habitantes del ejido, que han logrado ofertar servicios y actividades recreativas de contacto directo con la naturaleza y con las expresiones culturales de la población local, en una modalidad diferente del turismo convencional de sol y playa, y que da prioridad a temas de educación ambiental y conservación de los recursos naturales para fomentar su continuidad a largo plazo. Por tanto, el ejido ha considerado su proyecto como una estrategia generadora de oportunidades tanto de trabajo como de conservación a través del involucramiento de hombres y mujeres con la inclusión de sus experiencias, conocimientos e intereses.

De esta forma, se demuestra que el turismo rural opera como una estrategia que propicia oportunidades de desarrollo en los ámbitos personal, social y, de cierta manera, económico, pues se patentiza que las actividades llevadas a cabo en el ejido no son incompatibles con la conservación ambiental, por ello, el proyecto Selva del Marinero constituye un ejemplo de una relación armónica entre el hombre y la naturaleza con beneficios positivos para la conservación ambiental. Alguna de las ventajas ambientales que tal actividad genera es permitir la conservación de los recursos naturales, no solo por el potencial turístico que se tiene, sino porque además les brinda a los participantes materia prima para subsistir, les aporta beneficios económicos como el pago por servicios ambientales y los concientiza de que contribuyen a mitigar el cambio climático.

Por último, se considera que el turismo rural tiene la función de promover y fortalecer la participación social en el ejido, donde las mujeres han sido pieza clave del desarrollo gracias a su empoderamiento, lo cual ha ayudado a mantener una armonía entre los recursos naturales y las actividades económicas en el sitio. Así, se hace notoria la aportación de los habitantes del ejido al desarrollo local sustentable, y se ve a las mujeres campesinas como factor importante en la preservación de los recursos sociales y naturales, ya que queda demostrado que tanto ellas como los hombres tienen la capacidad de promoverla.

No obstante, es necesario seguir abordando y profundizar en la participación de la mujer y su contribución en la conservación ambiental a partir de proyectos productivos que le posibiliten tanto asumir su papel en la unidad doméstica como obtener beneficios económicos alternos, para mejorar su bienestar personal, el del grupo social y el entorno natural. Asimismo, es necesario reconocer la importancia de continuar con estudios sobre el empoderamiento de las mujeres campesinas, destacando sus aportes en las esferas económica, política, y el desarrollo local sustentable. 
Mujeres campesinas y turismo rural: estrategia de conservación ambiental en Los Tuxtlas, Veracruz

\section{Fuentes consultadas}

Buendía-Martínez, I. y Carrasco, I. (2013). Mujer, actividad emprendedora y desarrollo rural en América Latina y el Caribe. Cuadernos de Desarrollo Rural, 10(72), 21-45. Recuperado de http://www.scielo.org.co/scielo.php?pid=S0122-14502013000300003\&script=sci_abstract\&tlng=es

Campaña, P. (1982). La organización de la mujer campesina: realidad y esperanza. Santiago de Chile: Grupo de Investigaciones Agrarias.

Cañada, E. y Gascón, J. (2007). Turismo y desarrollo: herramientas para una mirada crítica. Managua: Enlace.

Casique, I. (2010). Factores de empoderamiento y protección de las mujeres contra la violencia. Revista Mexicana de Sociología, 72(1), 37-71. Recuperado de http://www. ejournal.unam.mx/rms/2010-1/RMS010000102.pdf

Díaz-Carrión, I. (2012). Género y turismo alternativo: aproximaciones al "empoderamiento" (Tesis doctoral). Universidad Complutense de Madrid, Madrid, España.

García, B. (2004). La mujer rural en los procesos de desarrollo de los pueblos. Revista del Ministerio de Trabajo y Asuntos Sociales, 55, 107-120. Recuperado de https://dialnet.unirioja.es/servlet/articulo?codigo $=1243724$

Hernández Flores, J. y Martínez Corona, B. (2006). Género, empoderamiento y movimientos sociales: Ia Unión Campesina Emiliano Zapata Vive, en la región Tepeaca-Tecamachalco, Puebla. Región y Sociedad, 18, 107-146.

Ibáñez, R. y Rodríguez, I. (s. f.). Tipologías y antecedentes de la actividad turística: turismo tradicional y turismo alternativo. Medio ambiente y política turística (pp. 17-33). Recuperado de https://micrositios.inecc.gob.mx/publicaciones/libros/669/tipologias.pdf

Knight, D. y Cottrell, S. (2015). Evaluating tourism-linked empowerment in Cuzco, Peru. Colorado State University, United States. Elsevier: Annals of Tourism Research.

Martínez Corona, B. (2003). Género, sustentabilidad y empoderamiento en proyectos ecoturísticos de mujeres indígenas. Revista de Estudios de Género. La Ventana, 17, 188217. Recuperado de http://148.202.18.157/sitios/publicacionesite/pperiod/ laventan/Ventana 17/17-6.pdf

Montañez-Armenta, M., Yanes, G. y Silva, H. (2011). Manejo de recursos naturales en la Sierra de Sonora bajo el esquema de UMAFOR. Casos de estudio: Sierra Alta y Sierra la Madera. Ra Ximhai, 7(2), 187-194.

Pérez-Ramírez, C., Zizumbo Villarreal, L. y Miranda Contreras, S. (2012). Incorporación al turismo rural y transformación del habitus en la mujer campesina de San Pedro Atlapulco, México. Rosa dos Ventos, 4(II), 158-177. Recuperado de https://www. redalyc.org/articulo.oa?id $=473547089004$

Piñar, A., Nava, M. y Viñas, D. (2011). Migración y ecoturismo en la Reserva de la Biosfera de Los Tuxtlas (México). PASOS. Revista de Turismo y Patrimonio Cultural, 9(2), 383396. Recuperado de http://pasosonline.org/Publicados/9211/PS0211_13.pdf

Reyes-Aguilar, A. K., Serrano-Barquín, R. C., Pérez-Ramírez, C. A. y Moreno-Barajas, R. (2017). Turismo rural, mujeres campesinas y conservación ambiental: modelo para el análisis de su empoderamiento en Iberoamérica. Revista Brasileira de Gestão 
e Desenvolvimento Regional. G\&DR, 13(3), 26-54. Recuperado de www.rbgdr.net/ revista/index.php/rbgdr/article/download/3235/621

Rowlands, J. (1997). Empoderamiento y mujeres rurales en Honduras: un modelo para el desarrollo. En M. León (comp.), Poder y empoderamiento de las mujeres (pp. 213245). Santafé de Bogotá: Tercer Mundo. Recuperado de http://www.bdigital.unal. edu.co/53100/1/9586017354.pdf

Sierra Pacheco, M. (2015). Realidad y práctica del empoderamiento de la mujer: Proyecto Tulix. México: Instituto Nacional de Ciencias Penales.

Torres, G. (2004). Mujer campesina y trabajo. Su rol en la actividad productiva y reproductiva de los Valles Calchaquíes. Andes, 15. Recuperado de https:/ /www.redalyc.org/ articulo.oa?id=12701508

Villarreal, M. (2000). La reinvención de las mujeres y el poder en los procesos de desarrollo rural planeado. Revista de Estudios de Género. La Ventana, 11, 7-35. Recuperado de https://www.redalyc.org/toc.oa?id=884\&numero $=12392$ 


\title{
TURISMO COMUNITARIO PRO POBRE Y SU DEFINICIÓN DE POBREZA
}

\author{
Martha Marivel Mendoza Ontiveros \\ marivelmo@hotmail.com \\ Rafael Hernández Espinosa \\ ra_fa@hotmail.com \\ Universidad Autónoma del Estado de México
}

El escrito parte de revisar el enfoque del turismo comunitario como mecanismo para combatir la pobreza de familias indígenas y campesinas. Se discute la definición del concepto de pobreza que sustenta al turismo pro pobre, el cual, entre otras cosas, supone una visión del mundo cuantitativa y universalmente válida, una perspectiva etic, sin contemplar que la pobreza es una construcción social que implica también aspectos cualitativos, como los elementos ideológicos inherentes a su definición o las significaciones que subyacen en el punto de vista de los sujetos considerados pobres -perspectiva emic-. La noción predominante sobre la pobreza ha dejado de lado la multidimensionalidad del fenómeno y la necesidad de estudiar las dinámicas que reproducen la desigualdad y conducen a la exclusión social, lo cual no permite comprender por qué el turismo comunitario pro pobre, incumple con el propósito de mitigar la pobreza.
\end{abstract}

Palabras clave: Turismo rural comunitario, pobreza, exclusión social, construcción social.

\section{PRO-POOR COMMUNITY TOURISM AND ITS POVERTY DEFINITION}

The paper begins by revising the point of view of community-based tourism as a mechanism to combat poverty among indigenous and peasant families. It continues by discussing the definition of poverty sustained by pro-poor tourism, which, among other things, presupposes a quantitatively and universally valid vision of the world, an etic perspective. Furthermore, said definition does not consider that poverty is a social construction that also involves qualitative aspects, such as the ideological elements inherent in its definition or the meanings underlying the point of view of people considered poor -an emic perspective. The predominant notion of poverty has left aside the multidimensional nature of this phenomena, as well as the need to study the dynamics that reproduce inequality and contribute to social exclusion, which does not allow us to understand why pro-poor community tourism fails to alleviate poverty.

Key words: Community-based rural tourism, poverty, social exclusion, social construction. 
$\mathrm{D}$ esde sus inicios, los estudios antropológicos del turismo han estado vinculados con el desarrollo. En varios contextos se ha preguntado: el turismo, ¿es un pasaporte para el desarrollo? (De Kadt, 1979); si es así, ¿bajo qué circunstancias? y ¿en qué condiciones? (Cañada y Gascón, 2007). Actualmente, el turismo como vía de desarrollo representa un tópico clásico en los estudios de los antropólogos. Por ello, el fenómeno turístico y su promoción no pueden comprenderse fuera del paradigma desarrollista en el que se inscriben, sobre todo desde la segunda mitad del siglo pasado, por haber logrado una posición central en las políticas de alcance global (Milano, 2016).

Gascón (2011) señala que, tras la crisis de la década de 1980 y con la generalización de las políticas económicas neoliberales en los noventa, la aportación de Latinoamérica a la economía mundial fue constreñida a centrarse en la producción de alimentos y materias primas para la exportación, recuperando la tesis principal del modelo librecambista y primario-exportador decimonónico (Gascón, 2010). Pero también se estimularon otras opciones complementarias, como la maquila o el turismo.

Dentro de las diversas prácticas turísticas, el turismo comunitario, por sus especiales características, ha sido planteado como una estrategia para el desarrollo local y, a partir de la puesta en marcha de las metodologías Pro-Poor Tourism (PPT) y Turismo Sostenible-Eliminación de la Pobreza (Sustainable Tourism for Eliminating Poverty, ST-EP), ha entrado con fuerza en la agenda política de la cooperación internacional. De esta manera, el turismo rural comunitario surge por la necesidad de generar alternativas económicas que diversifiquen los ingresos de las familias del campo, enfrentadas a un modelo de desarrollo rural depredador de los recursos naturales, que ha profundizado la inequidad y concentrado la propiedad de la tierra, generando desempleo, emigración y deteriorando el vínculo de la comunidad rural.

No obstante, los propios impulsores del PPT no han podido dar ejemplos que demuestren los beneficios reales para los pobres cuando estos se dedican al turismo (Ashley y Goodwin, 2007). Las voces críticas del PPT afirman que solo se ha enfocado en el nivel micro, como un producto nicho en los casos de ecoturismo y turismo rural. Asimismo, se ha puesto poca atención en los vínculos con el mercado. Los recursos económicos de organismos nacionales e internacionales se destinan a proporcionar capacitación, en el mejor de los casos, o a la construcción de infraestructura, en su mayoría, pero los productos fracasan por no tener una demanda doméstica o internacional, y esto redunda en que no se mejoren los medios de vida. La mayoría de las veces, se anima a las comunidades a iniciar proyectos turísticos y, luego de invertir dinero, trabajo y propiedades, los turistas no llegan (Ashley y Goodwin, 2007).

Aquí se discute la definición de pobreza que subyace en la propuesta del turismo en el combate de esta, y se pretende complementar su abordaje para comprender las causas de su fracaso o su éxito incorporando al análisis a los teóricos de la exclusión. La investigación convencional de la pobreza ha dejado fuera la importancia de las relaciones sociales, la multidimensionalidad del fenómeno y la urgencia de estudiar las dinámicas que conducen a la exclusión social. 
El escrito inicia examinando el turismo rural comunitario como mecanismo para combatir la pobreza de familias indígenas y campesinas. Después se analiza el concepto de pobreza, que sustenta al PPT, y que es una definición tecnocrática fundamentada en la teoría económica; se debate el concepto caracterizándolo desde la imposición de una visión del mundo que se erige como el modo universalmente válido, una perspectiva etic, sin tener en cuenta que la pobreza es una construcción social que implica aspectos ideológicos, además de no considerar el punto de vista de las personas identificadas como pobres, es decir, la perspectiva emic. Por último, una forma de avanzar en el análisis es plantear el fenómeno de la pobreza vinculado a la exclusión social, para comprender por qué el turismo comunitario pro pobre incumple con el propósito de mitigarla.

\section{Turismo comunitario pro pobre}

En las décadas recientes, incluso antes del neoliberalismo, el turismo se impulsó y se propuso como una estrategia fácil y rápida de desarrollo y de lucha contra la pobreza, capaz de generar elevados beneficios con muy poca inversión, pues sus principales elementos de atracción (el paisaje y la cultura autóctona) ya estaban gratuitamente establecidas (Gascón, 2011).

El binomio turismo-desarrollo llevó a promover un turismo gestionado por unidades familiares campesinas o indígenas, por comunidades, por empresas comunitarias o por cooperativas, con la finalidad de contraponerse a los modelos de turismo dominantes, como el de enclave, que han mostrado muy pocos beneficios para el mundo rural. El turismo así gestionado, que en las últimas décadas se ha denominado turismo rural comunitario, debía ayudar a la mejora de las pauperizadas economías campesinas, ofreciendo un aporte de recursos económicos y diversificando sus fuentes de ingresos.

Sin embargo, el turismo rural comunitario, a pesar de ser novedoso y reciente, se comenzó a gestar en 1967, fecha en que la Organización de las Naciones Unidas declaró el Año Internacional del Turismo, y algunas de sus agencias empezaron a financiar estudios de mercado, planes maestros, capacitación y restauración de áreas culturales (cuadro 1).

En la primera década del siglo XXI, las bases conceptuales de estas estrategias comenzaron a plasmarse en los proyectos turísticos de las agencias de desarrollo internacionales, bajo diferentes formas: turismo comunitario, turismo rural comunitario, turismo de base local, turismo solidario, turismo voluntario, etc. La cooperación internacional para el desarrollo ha sido aceptada como principio básico y se ha liberalizado el sector turístico, concibiéndolo como panacea para todos los males.

Durante la Cumbre Mundial sobre el Desarrollo Sostenible, celebrada en septiembre de 2002 en Johannesburgo (Sudáfrica), se presentó el Programa Turismo Sostenible-Eliminación de la Pobreza (ST-EP) para contribuir a dos objetivos del milenio: el combate a la pobreza extrema y la promoción de la igualdad de género: 
Cuadro 1. Cronología del turismo comunitario pro pobre

\begin{tabular}{|c|c|}
\hline Décadas & Caracterísitca \\
\hline 1970 & $\begin{array}{l}\text { Entre } 1969 \text { y } 1977 \text { se financiaron alrededor de } 24 \text { proyectos en } 18 \text { países (Pleumaron, } \\
\text { 1994; Unesco, 1976). }\end{array}$ \\
\hline 1980 & $\begin{array}{l}\text { Los impactos del turismo no pasaron desapercibidos, e incluso dieron lugar a un } \\
\text { movimiento apoyado por el Consejo Mundial de Iglesias, que introdujo la crítica al } \\
\text { desarrollo turístico en la agenda social: la Ecumenical Coalition on Third World Tourism } \\
\text { (ECTWT). }\end{array}$ \\
\hline \multirow[t]{4}{*}{1990} & $\begin{array}{l}\text { Hubo esporádicas referencias a la relación entre turismo y desarrollo sostenible desde } \\
\text { instancias políticas y del sector de organizaciones no gubernamentales (oNG). }\end{array}$ \\
\hline & $\begin{array}{l}\text { Empero, en Europa, la plataforma Tourism European Network (TEN), en colaboración con } \\
\text { la Coalición Ecuménica de Turismo (ECOT, anteriormente ECTWT), y con financiamiento de } \\
\text { ONG alemanas, siguieron alimentando esta visión crítica. }\end{array}$ \\
\hline & $\begin{array}{l}\text { Fue a partir de mediados de la década de los noventa que algunas oNG empezaron a } \\
\text { considerar el turismo como una estrategia adecuada para recaudar fondos, tanto para } \\
\text { su propia financiación (turistas que visitan los proyectos de cooperación) como para } \\
\text { beneficiar a las comunidades anfitrionas con las que trabajaban. }\end{array}$ \\
\hline & $\begin{array}{l}\text { En esta década, oNG de países de acogida o beneficiarios comenzaron a poner en marcha } \\
\text { proyectos turísticos financiados por entidades y organizaciones occidentales. }\end{array}$ \\
\hline \multirow[t]{6}{*}{2000} & $\begin{array}{l}\text { En 1999, tras las primeras iniciativas de la Unesco y del BM, surgió la metodología Pro } \\
\text { Poor Tourism con su visión: Putting poverty at the heart of the tourism agenda, la cual } \\
\text { enfocó el interés de las agencias internacionales de desarrollo hacia el sector turístico. }\end{array}$ \\
\hline & $\begin{array}{l}\text { Los tres creadores y principales teóricos involucrados con la implementación del PPT son } \\
\text { Caroline Ashley, Harold Goodwin y Dilys Roe. }\end{array}$ \\
\hline & $\begin{array}{l}\text { Desde el inicio del PPT, la Organización Mundial del Turismo (омT) ha publicado gran } \\
\text { cantidad de manuales teóricos y prácticos que adoptan las bases teóricas del PPT y, en } \\
\text { 2002, lanzó la iniciativa Sustainable Tourism for Eliminating Poverty. }\end{array}$ \\
\hline & $\begin{array}{l}\text { El primer manual Turismo y atenuación de la pobreza, publicado en } 2002 \text {, brindaba } \\
\text { un análisis de la interrelación entre el turismo y el desarrollo económico, incluyendo } \\
\text { factores tales como la mejora de los beneficios económicos, la mejora del acceso } \\
\text { para las pequeñas y medianas empresas y la intensificación de los efectos locales del } \\
\text { turismo para los pobres. }\end{array}$ \\
\hline & $\begin{array}{l}\text { Una segunda publicación de la omT, de } 2004 \text {, Turismo y atenuación de la pobreza: } \\
\text { recomendaciones para la acción, proponía un marco de siete medidas prácticas para la } \\
\text { aportación eficaz de beneficios económicos y sociales para los pobres. }\end{array}$ \\
\hline & En 2005, se creó la Fundación ST-EP con sede en Seúl, en la República de Corea. \\
\hline
\end{tabular}

Fuente: Milano (2016). 
En este documento se argumentaba, si bien el turismo se comercializa internacionalmente, se consume en el punto de producción. En otras palabras: los turistas visitan la fábrica. Es a nivel del destino que deben maximizarse las oportunidades para que los residentes obtengan beneficios de esta industria de exportación si el turismo se quiere utilizar para reducir la pobreza. Central en el debate sobre turismo y desarrollo son los temas de la forma de empleo y otros beneficios económicos que pueden ser maximizados a nivel local en los destinos, y cómo se pueden minimizar los impactos sociales y ambientales negativos. Los principios y los enfoques que maximizan los impactos económicos del turismo a escala local son los que están asociados con el enfoque del Pro-Poor Tourism, el cual se define por tener un enfoque basado en los beneficiarios [Goodwin, 2013, p. 388].

El PPT considera que, al incrementar los ingresos de la población más depauperada, el turismo es una eficiente herramienta para reducir la pobreza en los países menos desarrollados (Gascón, 2011). Para tal propósito se plantean tres ámbitos de actuación:

1. Aumento de oportunidades de trabajo asalariado.

2. La creación de microempresas locales.

3. La generación de ingresos comunitarios.

Para lograr esos objetivos se propone una intervención financiando proyectos de turismo rural comunitario y el apoyo de políticas empresariales turísticas de gran capital que generen empleo directo e indirecto para la población local. Tal mecanismo de cooperación internacional busca incidir en la realidad para transformarla, y se basa en el paradigma de que la pobreza puede combatirse incrementando los ingresos de los pobres hasta alcanzar un mínimo de bienestar (Gascón, 2011).

Al referirnos a casos específicos de resultados empíricos positivos la evidencia es limitada, porque no se ha realizado un monitoreo sistemático y documentado sobre los cambios en los medios de vida de la gente pobre debido al turismo. No se sabe de ningún destino donde la gama completa de impactos del desarrollo del turismo en todos los niveles de pobreza (no solo de un grupo) haya sido rigurosamente evaluada. Hacen falta estudios longitudinales que comparen con precisión y minuciosidad antes del turismo y después del turismo, existe poca literatura que cuantifique resultados tangibles, y lo que se presenta como casos de éxito genera más preguntas que respuestas. Sin embargo, algunos autores piensan que se puede hablar de casos que ponen de relieve los beneficios de este tipo de proyectos.

En Experiencias de turismo comunitario en Nicaragua. Aportes a la economía campesina, Cañada y Fandiño (2009) exponen cuatro casos, a decir de ellos, de procesos exitosos de introducción del turismo, que se han dado en cooperativas cafetaleras en Centroamérica, las cuales, gracias a la introducción del turismo, han logrado ampliar sus fuentes de ingresos e incidido en los procesos de desarrollo rural. En términos generales argumentan que los principales aportes del turismo comunitario en estos ejemplos son una mayor demanda de alimentos, por lo que algunas familias han reducido la extensión de tierra dedicada a un solo cultivo destinado al mercado, en este caso café, y han preferido diversificar y aumentar la producción de verduras y hortalizas para consumo directo. Señalan que 
los nuevos empleos vinculados al turismo no solo han generado ingresos monetarios, permitiendo que las familias involucradas en estas actividades mejoren su bienestar y condiciones de vida, sino que también han contribuido a una mejora de la alimentación familiar y a la educación de hijas e hijos. Además, con la ampliación de las actividades productivas que las familias campesinas pueden llevar a cabo en sus territorios, en particular por parte de mujeres y jóvenes, se ha ampliado la base social que se beneficia directamente de las actividades vinculadas al campo.

Por otro lado, a partir de sistematizar nueve experiencias de turismo rural comunitario en Nicaragua y Guatemala, Pérez, Barrera Pérez, Peláez y Lorío (2010) sostienen haber identificado procesos positivos como el incremento en el ingreso de los hogares, mejora en el consumo, principalmente en ropa y en inversiones sociales relacionadas con infraestructura básica: escuelas, caminos y puestos de salud. Precisan además que los ingresos complementarios del turismo rural comunitario aumentan el gasto familiar, la compra de insumos agrícolas y de ropa, con lo cual han expandido las áreas de siembra y, en consecuencia, los niveles de seguridad alimentaria; de igual manera, hay mejoras en las viviendas de quienes participan en el servicio.

Pérez et al. (2010) afirman que, en cuanto a la generación de empleo, por lo general, el turismo representa para la población local un empleo estacional, poco calificado y suele ser inestable. Asimismo, prestar servicios a los visitantes ha sido todo un reto para ellos, iniciando con el cambio cultural de cobrar por "el servicio", pasando por aprender español y, con limitados recursos, levantar la infraestructura de alojamiento y de comedores. Esta inversión ha sido bastante intensiva en mano de obra, por lo que el aporte de los comunitarios ha sido relevante, al sustituir actividades propias para garantizar su existencia por una actividad de futuro.

No obstante, a la luz de los argumentos a favor, existe una cantidad de opiniones críticas acerca del papel del turismo como una vía para aliviar la pobreza.

\section{Las críticas al turismo pro pobre}

Las acciones del turismo pro pobre están dirigidas a favorecer al sector empresarial, confiando en que una parte de los beneficios escurrirán hacia abajo, es decir, hacia la población menos favorecida, al activarse el denominado efecto trickle down, "goteo" o "derrame". Sin embargo, estas estrategias no han estado exentas de críticas. Por ejemplo, el PPT no solo no pone en duda el modelo económico dominante, sino que busca como socio al capital turístico transnacional, de forma que quienes más se han beneficiado han sido los inversionistas de capital foráneo y las agencias internacionales de desarrollo. Así, es altamente cuestionable el resultado de la redistribución de los ingresos.

Según sus críticos, el problema fundamental de esta estrategia es que no tiene en cuenta la desigualdad existente entre los distintos actores relacionados con la actividad turística y cómo el mayor desarrollo de las grandes estructuras empresariales genera subordinación, 
dependencia y vulnerabilidad de los otros actores, acentuando las diferencias sociales preexistentes (Cañada, 2011).

De hecho, lo observado es que las grandes empresas turísticas están tratando de captar parte de los fondos de la cooperación internacional, en un modelo en el que gana terreno el sector empresarial desplazando en el interés a algunos grandes donantes, a las ONG O a los mismos Estados. Esta perspectiva estima que la cooperación debe facilitar e impulsar las dinámicas de internacionalización de la empresa turística y buscar formas de vinculación e inclusión de los "pobres" en estas estructuras empresariales exitosas en el mercado global (Cañada, 2015). Empero, consolidar este tipo de estrategia productiva no es tarea fácil. Más allá de los muchos proyectos de cooperación que orientan a las comunidades hacia una "nueva ruralidad", mantener en el tiempo este tipo de apuesta requiere mucho esfuerzo, voluntad y preparación por parte de las familias campesinas, comunidades rurales o pueblos indígenas implicados.

Bajo este esquema de turismo, las comunidades sufren un proceso de intervención para "ser convertidas" en espacios con "calidad turística", bajo el entendido de responder a la demanda conforme a estándares de calidad sugeridos por los grupos promotores y operadores del turismo internacional. Los espacios rurales con alta pobreza participan del turismo con claras desventajas, dada la dificultad de invertir recursos financieros en el desarrollo de una oferta de servicios competitiva desde el punto de vista del mercado turístico, además de las limitaciones sociales, infraestructura pública disponible y adecuada, tal como se encuentran en los espacios rurales de rezago social en países pobres (Picón Cruz y Hernández Ulate, s. f.).

Asimismo, el turismo comunitario ha sido fuertemente cuestionado como modelo de desarrollo debido a su bajo impacto en materia de empleo e ingresos, a la excesiva dependencia de financiamiento y asesoría externa, a la monopolización de beneficios por parte de las élites locales, desigualdades dentro de las comunidades o falta de capacidad para hacer funcionar los negocios de forma operativa (Gascón, 2013).

Se ha planteado también que, a causa de la desigual situación en la que se hallan las poblaciones más empobrecidas con respecto a los grandes capitales turísticos, este tipo de intervención amplía la brecha en cuanto a la capacidad política de las comunidades rurales para tomar decisiones sobre los aspectos que afectan a esos territorios y sus recursos, lo cual contribuye a incrementar su pobreza relativa. Por más que algunas políticas de cooperación puedan apoyar iniciativas comunitarias, su lógica pasa por una relación de los sectores sociales más desfavorecidos en términos de supeditación y subordinación hacia la gran empresa (Pinto Faria e Hidalgo Moratal, 2012; Gascón, 2012; Gascón, 2013).

Por su parte, Jiménez López y Cavazos Arroyo (2012, p. 453) afirman que el turismo orientado a los pobres (TOP) no se sustenta en un modelo o teoría determinada ni busca instaurar un cambio estructural, sino que se trata de una orientación o aproximación pragmática que pretende disminuir la pobreza en zonas que pueden ofrecer algún tipo de turismo, en donde los beneficios retornen a los más desfavorecidos. 
Forstner (2004) postula que las iniciativas de turismo rural comunitario pueden maximizar las ganancias del sector servicio para las comunidades rurales. Pese a ello, precisa que su principal cuello de botella está asociado al proceso de intermediación del servicio, pues tienen limitado acceso a mercados, por tanto, las ganancias de las comunidades estarán asociadas al poder de negociación que tengan con un operador turístico. Cañada y Fandiño (2009) advierten la obligación de ser conscientes de las posibilidades reales del mercado turístico y evitar falsas expectativas. Lo anterior hace necesario reconocer que no todas las comunidades en el ámbito rural pueden esperar el mismo éxito con el turismo, sencillamente porque no es posible que la demanda pueda ampliarse de forma indefinida. Poner en marcha iniciativas turísticas comunitarias es complicado y requiere voluntad, esfuerzo, organización, pero también algunas condiciones (atractivos turísticos, accesibilidad, diferenciación, etcétera).

Mitchell y Muckosy (2008) señalan que el turismo rural comunitario presenta dos problemas: débil (pobre) gobernanza y débil (pobre) acceso a mercados. Forstner (2004) identifica solo la segunda, y propone como solución el aprovechamiento del capital social para superarla, es decir, que no son pobres en cuanto a gobernanza de redes, aunque se considera que el comité comunal y la gerencia del servicio deben ser estructuras ligadas, pero con límites bien definidos.

Más de un autor advierte que el turismo rural comunitario debe ser parte de una estrategia de desarrollo turístico alternativo al modelo dominante. Pero únicamente puede ser una parte, Por sí solo no puede ser la alternativa. Necesita construir una alianza con la pequeña y mediana empresa turística local y nacional. El turismo, en definitiva, puede ser una forma de diversificar las actividades económicas de una comunidad, pero no la única ni necesariamente la primordial, y mucho menos una opción para todo el mundo. El fortalecimiento de la economía de base comunitaria, sea a través de la agricultura, la ganadería, la pesca, la agroindustria, la apicultura o el turismo, de forma diversificada y complementaria, en la que el protagonismo y control de los recursos esenciales queda en manos de la gente organizada del lugar, es la clave que puede permitir a las comunidades seguir viviendo en sus territorios tradicionales (Cañada y Fandiño, 2009).

Por último, un elemento que ha desatado críticas trascendentales al turismo comunitario pro pobre es la definición de pobreza que subyace en él, donde la pobreza se concibe como la privación de las necesidades vinculadas al mínimo vital y los indicadores son el ingreso per cápita o el valor de una canasta de consumo (Pinto Faria e Hidalgo Moratal, 2012). Según Gascón (2011, p. 4), a partir de esta definición de pobreza, la finalidad del PPT es "el incremento de los ingresos de los sectores más desfavorecidos de la población, aunque estas ganancias sean marginales y otros acaparen la mayor parte de los beneficios que genera la actividad". Tal concepción se sustenta en que, a pesar de que los beneficios para la población local no sean de gran relevancia a nivel macro, pueden significar un aporte esencial para las grandes masas sumergidas en la pobreza. No importa si afecta a la pobreza absoluta o la pobreza relativa. 
Ello fortalece la interpretación de que la pobreza, al igual que el bienestar y el progreso, son construcciones sociales. De otro modo no podría calificarse como exitoso el caso en el que la empresa comunitaria reciba cuatro veces al año a un grupo de estudiantes y que con ello mejoren sus ingresos de acuerdo con los entrevistados. Asimismo, en los análisis se ponen en evidencia las ventajas que tienen los directamente relacionados con el turismo y no la situación de los que, siendo parte de la comunidad, quedan excluidos de las ganancias. Este esquema es semejante a los destinos de turismo tradicional en donde se valoran como exitosos a partir de las ganancias que obtienen los grandes empresarios y no de la situación económica de la población trabajadora.

De cualquier modo, es necesario hacer una reflexión más puntual sobre las definiciones de pobreza que subyacen en los programas de desarrollo donde se ubica el PPT, así como definiciones alternativas y las repercusiones que podrían tener no solo en la gestión del turismo, sino en ámbitos más generales de la sociedad.

\section{La pobreza como construcción social}

La pobreza, en su carácter de fenómeno social, ha sido abordada desde varias disciplinas, principalmente la economía y la sociología. Sin embargo, la antropología también ha hecho presencia en la discusión del concepto aportando reflexiones interesantes. En este sentido, resulta pertinente analizar el concepto distinguiendo dos aspectos en las distintas perspectivas académicas de su estudio y su medición, uno objetivista, que podríamos adscribir a una perspectiva etic, de carácter más cuantitativo, y otro más cualitativo y subjetivista, que podríamos adscribir a una perspectiva emic.

El enfoque etic involucra el estudio de las dimensiones que inciden en las condiciones materiales que permiten definir los umbrales de la pobreza. En esta discusión destacan diferentes definiciones y modelos para su medición, desde el de necesidades básicas insatisfechas (NBI), pasando por el de la línea de pobreza (LP), hasta el método de medición integrada de la pobreza (MmiP) (Cuéllar, 1995; Hernández, 2001). Tales modelos están dirigidos sobre todo a identificar los umbrales cuantitativos para decidir a quién puede considerarse pobre y a quién no (Boltvinik, 2001). Para ello se tienen en cuenta la insatisfacción de necesidades básicas o los niveles de ingresos. La pobreza se interpreta, desde un punto de vista monetario, como la insuficiencia de recursos para adquirir la canasta de consumo mínima aceptable socialmente (Herrera, 2002). Esta perspectiva, paradigma dominante en los estudios empíricos, estima el costo de una canasta mínima de alimentos y servicios y, por lo tanto, califica como pobres a todos aquellos cuyo consumo está por debajo de este valor. El segundo enfoque es el de la pobreza relativa, que reconoce como pobres al grupo de personas cuyos ingresos están por debajo de un determinado nivel, e insiste en la capacidad de comprar los bienes y servicios considerados básicos y no su consumo efectivo. Estos aspectos han predominado en las polémicas, es decir, si lo uno o lo otro puede determinar el umbral, o si se tienen que hacer modelos más complejos que incluyan 
también características contextuales y relativas como el periodo histórico o la riqueza de la nación en cuestión, entre otras cosas. Todo, con la finalidad de generar un consenso numérico en cuanto a la magnitud "real” de la pobreza, y así producir mejores programas para combatirla.

Es precisamente la intención de generar un conocimiento "real” u objetivo de la pobreza lo que permite entender esta perspectiva como etic, ya que se trata de identificar sus elementos objetivos independientemente de las significaciones o las experiencias subjetivas de quienes quedarían clasificados en esa condición.

La perspectiva emic, por su parte, se caracteriza por el interés de recuperar una noción de la pobreza desde el punto de vista del grupo, comunidad o actor. El término cultura de la pobreza que acuñó Oscar Lewis (1961) figura como una aproximación pionera de esta perspectiva; mas esta se ha complejizado, pues se incluyen los aspectos significativos de la experiencia de las personas, sus modos particulares de entender el mundo y sus formas de autoadscribirse en las categorías que las versiones oficiales (etic) señalan como pobreza; es decir, el cómo se producen desde ahí determinadas significaciones de la pobreza. Ello implica necesariamente privilegiar el punto de vista interno de una comunidad o grupo, frente a la posición externa, lo etic. Se parte de la visión de los sujetos, sus categorizaciones, valoraciones y percepciones en torno a la pobreza, y el papel del investigador es el de intérprete de lo interpretado por los sujetos (Ceirano, 2000).

Desde esta perspectiva puede señalarse un amplio abanico de significaciones de la pobreza, más allá de lo económico, que van desde las cualidades personales y espirituales, como la humildad y la sencillez, entre otras virtudes, hasta las que se refieren a aspectos negativos relativos a las carencias materiales y los sufrimientos derivados. No obstante, estos aspectos simbólicos y culturales de la pobreza en general son poco tratados, quizá porque a veces son los menos visibles y los que alejan más la definición de la idea más material de la pobreza (Estivill, 2003).

De tal suerte, no siempre, ni de manera irremediable, las definiciones emic y etic de la pobreza se corresponden; de hecho, por lo general se hallan en una dinámica de negociación en la que se confrontan diversos discursos sobre lo que es la pobreza y lo que no. Empero, a través de los procesos legitimadores, mediados por las instituciones, se genera un efecto decisivo en la construcción social de la realidad (Berger y Luckman, 1972). Como señala Gergen (2007), la socialización del conocimiento científico social tiene repercusiones de gran trascendencia en el comportamiento de la población al prescribir de forma indirecta la deseabilidad de las condiciones y las conductas sociales. Los organismos oficiales basados en conocimientos científicos e intelectuales tienen un efecto importante en la población a la hora de difundir sus "descubrimientos".

Con base en lo anterior, puede sostenerse que en el proceso de construcción social de la pobreza participan de manera notable los discursos científicos que determinan los criterios a partir de los cuales debe evaluarse y calificarse la incidencia "real" de la misma, así como los mecanismos considerados pertinentes y adecuados para combatir esa 
condición. Con todo, debe tenerse en cuenta que en este proceso de construcción social también existe una fuerte carga ideológica que está presente tanto en la explicación de las causas de la pobreza como en la justificación de los mecanismos de alivio.

Desde una perspectiva del conflicto social se piensa que la imposición de ideologías por parte de los sectores dominantes requiere la apropiación de los medios de producción intelectual a través de los cuales se generan nociones de la realidad acordes con sus intereses (Collins, 1994). En este sentido, puede decirse que la construcción social de la pobreza no es un campo de disputas simbólicas equitativas, pues la parte más influyente corresponde a quienes tienen la voz legitimada por las instituciones y organismos que representan los intereses de los sectores hegemónicos.

La teoría económica de la pobreza induce, por un lado, la colonización cuantitativa en su delimitación y, por el otro, impone una consideración estática de la misma, en la que se obvian las relaciones sociales y los conflictos entre los individuos (Ortiz Sandoval, 2004). Desde una postura tecnócrata neoliberal, medir es la consigna, la cuantificación deriva del credo supremo de la maximización de la ganancia y todo lo que no sea mesurable y cuantificable no tiene dignidad conceptual ni legitimidad. El punto central de ello, como apunta Ortiz Sandoval (2004), es la separación entre dos clases de sujetos, los pobres y los no pobres, que alude a la distinción de estamentos diferenciados por su posición en la estructura de consumo. Al hacer esto, se desviaría la atención de un conflicto de relaciones de poder hacia una visión meramente mercantil, donde la mediación fundamental está a cargo del Estado y la democracia capitalista. Así, el núcleo de la desigualdad social es compensado ideológicamente como igualdad abstracta en la esfera jurídico-política. Es por ello que en las sociedades democráticas las luchas y formas de protesta social en la relación capital-trabajo se juzgan poco racionales, pues de lo que se trata es de dedicar más empeño a la participación en el mercado, como productor y como consumidor, de lo cual derivarían, a la larga, necesarias recompensas (Ortiz Sandoval, 2004). Este es un aspecto central de la dimensión ideológica en el proceso de construcción social de la pobreza. No obstante, la igualdad política en la democracia no solo coexiste con la desigualdad económica, sino que la deja intacta en esencia.

Por todo esto, es posible establecer que las limitaciones actuales de los programas y las acciones institucionales para el bienestar social se derivan de la conceptualización de la pobreza subyacente en los mismos. De ahí que sea indispensable dirigir la mirada hacia otros elementos conceptuales más holistas que permitan incluir aspectos cualitativos relevantes, los cuales podrían observarse considerando la perspectiva emic y que, además, no contribuyan a la reproducción de las condiciones de injusticia y desigualdad social. Se propone que un concepto útil para tal fin es el de exclusión social, pues con el apoyo de este recurso heurístico será posible avanzar en el diseño de mecanismos más efectivos de intervención para el bienestar social, entre los que puede incluirse el turismo. 


\section{Turismo, desigualdad y exclusión social}

Un enfoque que puede fungir como puente o bisagra entre las perspectivas emic y etic de la pobreza se encuentra en los aportes de Amartya Sen (2000), quien plantea que la falta de ingresos es una de las principales causas de la pobreza, pero que el análisis no debe limitarse a este factor. Sen explica el tema de la pobreza y la desigualdad social y económica a partir del análisis de la igualdad. Si bien en todas las teorías de orden social se busca la procuración de la igualdad en algún ámbito, estas pueden resultar ineficaces y conllevar a la desigualdad en otros. Para Sen, la idea de igualdad se enfrenta con dos aspectos fundamentales. En primer lugar, la profunda diversidad humana y, en segundo, la multiplicidad de variables a partir de las cuales puede juzgarse la igualdad.

Para Sen la pobreza debe entenderse como la privación de capacidades; este enfoque se centra en las privaciones que son intrínsecamente importantes, a diferencia de los ingresos que solo son instrumentalmente relevantes. Así, puede hablarse de dos tipos de pobreza que están íntimamente ligados, pues uno conlleva al otro: la pobreza de ingresos y la pobreza de capacidades (Sen, 2000; Nussbaum, 1997). Las capacidades determinan "las definiciones alternativas que una persona puede hacer o ser: los distintos funcionamientos que puede lograr" (Sen, 1996, p. 54). La relación entre capacidades y funcionamientos remite a "las cosas que las personas logran hacer o ser al vivir"; como el mismo autor señala, estas definiciones muestran una combinación de "quehaceres y seres", donde el concepto de calidad de vida adquiere relevancia "en términos de la capacidad para lograr funcionamientos valiosos". Este enfoque de pobreza recupera los aspectos culturales, simbólicos y la experiencia. Las reflexiones teóricas muestran la complejidad del fenómeno de la pobreza, que obliga a analizar esa condición desde la experiencia de las personas "en situación de pobreza" (Pont Suárez, 2010).

Otra perspectiva alternativa en consonancia con Sen se encuentra entre los llamados teóricos de la exclusión, quienes llaman la atención hacia "cómo vive la gente"; postulan que los pobres presentan una variedad de problemas y privaciones que van más allá de los bajos ingresos y constituyen un círculo vicioso. De este modo, la pobreza es definida como un fenómeno multidimensional que debe incluir habilidades y capacidades del pobre para manejar su propia vida, capacidad de adaptarse, tener acceso a servicios, participar en la vida social o comunitaria de su grupo, tener seguridad, entre otros (Mitchell y Ashley, 2010).

La definición de pobreza que manejan los economistas no da cuenta de la variedad de problemas que afrontan día a día los ciudadanos. Tales estudios economicistas ofrecen una visión estática y unidimensional de las personas de bajos ingresos en un momento determinado del tiempo, incapaz de comprender aspectos multidimensionales, dinámicos y vinculados a la participación social implícitos en el concepto exclusión. En este contexto puede haber personas pobres sin estar absolutamente excluidas, como ocurre en el caso de colectivos cuyo nivel de vida se sitúa bajo un umbral de pobreza, pero que mantienen vínculos laborales y sociales para participar en sociedad; así como personas excluidas por motivos que abarcan prejuicios sociales, discriminación religiosa, sexual o racial y tener un ingreso por encima de tal línea de pobreza (Fundación Encuentro, 2001). 
Si se comparan los términos de pobreza y exclusión social se identifica que, aunque ambos pueden tener aspectos coincidentes y espacios de intersección, no por fuerza son sinónimos. En ese sentido, no conviene perder de vista el papel fundamental de los procesos de exclusión social, así como el hecho de que la pobreza es, casi siempre, la forma a través de la cual se manifiesta la exclusión. Pero los prejuicios y discriminaciones solo producen exclusión social, en última instancia, en la medida en que provocan incapacidad para lograr unos ingresos y un nivel de vida aceptables, generando una carencia de opciones y alternativas que quienes no son pobres, aunque estén excluidos en algún sentido, pueden, sin embargo, disfrutar (Tezanos, 2001, p. 60).

Entendemos por exclusión un proceso de acumulación de desventajas en una serie de ámbitos que vacían de contenido el concepto de ciudadanía: exclusión de un nivel de ingresos o de consumo mínimo, de empleo seguro y permanente, de una vivienda digna, de la educación, de las políticas de protección social, de la participación democrática, de los bienes públicos, de la vida social y familiar, etcétera.

Así pues, uno de los logros importantes del concepto de exclusión social es que obliga a centrar el debate en aspectos que la investigación convencional de la pobreza ha dejado al margen, como la trascendencia de las relaciones sociales, la multidimensionalidad del fenómeno o la necesidad de estudiar las dinámicas que conducen a la exclusión (Jiménez Ramírez, 2008). Por otro lado, el concepto de exclusión social permite recuperar la dimensión ideológica en torno a las relaciones de conflicto entre los diversos sectores y estratos sociales en términos de apropiación de los recursos y de los medios de producción y distribución de la riqueza.

En el caso del turismo rural comunitario se observa que, como mecanismo, falla en el combate contra la pobreza, ya que a ciertos individuos y grupos se les impide sistemáticamente el acceso a posiciones que les permitirían una subsistencia autónoma dentro de los niveles sociales determinados por las instituciones y valores en un contexto dado, es decir, empresas, agencias de cooperación y ong. La población campesina ve muy limitada su posibilidad de acceder a un trabajo remunerado más o menos estable. De hecho, un mecanismo de exclusión social se refleja en el proceso que califica y descalifica a una persona como trabajador en el contexto del capitalismo. El turismo representa un choque entre una actividad moderna y el mundo campesino, pues significa una experiencia ajena a las comunidades rurales indígenas o mestizas, esto es, se trata de una actividad ajena a la "vocación social del territorio". El campesino y su familia, por lo general, no han experimentado el ser turistas, ni mucho menos saben qué es un prestador de servicios turísticos; tampoco tienen conocimientos ni destrezas para imaginar, crear y gestionar una empresa de corte mercantil que compita en el mercado global. Al no tener idea de sus características, la gente no puede participar con pleno conocimiento en su diseño y gestión (Cañada, 2012) y, consecuentemente, en los beneficios. 


\section{Reflexiones finales}

La consideración del origen de la pobreza en un modo de acumulación de explotación y exclusión social lleva de manera inevitable a la necesidad de abordar el concepto de la pobreza (y su solución) desde un ámbito global y multidimensional, nunca meramente sectorial y mágico, en lugar de concebir el turismo como una posibilidad cuasi mágica de desarrollo económico al aumentar las oportunidades de trabajo asalariado, crear microempresas locales y generar ingresos comunitarios dentro de un mercado globalizado. Lo que debe destacarse es el aspecto relacional que las nociones de equidad/desigualdad o exclusión/ inclusión implican, además de sus múltiples dimensiones objetivas y subjetivas -emic y etic-. En este sentido, el turismo debe pensarse en cuanto fenómeno que ha derivado de una actividad que nace como un medio de producción bien definido en el sistema capitalista y que se ha adaptado por completo al sistema neoliberal. Cuando se habla del turismo como una herramienta para combatir la pobreza se le está concibiendo como una actividad económica capitalista en la que los beneficios hacia los más pobres solo llegarán cuando los beneficios sean abundantes para los grandes empresarios inversionistas.

El turismo pro pobre, en cualquiera de las modalidades que las empresas turísticas hayan definido para este "nicho de mercado" (turismo voluntario, turismo comunitario, turismo rural, etc.), sigue representando un mayor negocio para los actores externos a las comunidades, pues surge a partir de explotar la idea dominante de pobreza, centrada en la dimensión puramente económica y monetaria. Para generar un cambio positivo en los impactos sociales del turismo "pro pobre" se requiere problematizar las dimensiones que definan no solo las condiciones económicas (pobreza), sino también las relaciones sociales y políticas, por ejemplo las de igualdad-desigualdad y exclusión-inclusión.

Emplear pobres en las empresas turísticas; suministrar bienes y servicios a las empresas turísticas que empleen pobres; vender directamente bienes y servicios a los visitantes por los pobres (economía informal); crear empresas turísticas por los pobres -microempresas, pequeñas y medianas empresas, o empresas de base comunitaria (economía formal)-; poner impuestos sobre los ingresos o beneficios del turismo, cuya recaudación se destine a beneficiar a los pobres; fomentar las donaciones y el apoyo voluntario de las empresas turísticas y de los turistas; invertir en infraestructura, estimulada por el turismo, que beneficie también a los pobres de la localidad de forma directa o mediante el apoyo a otros sectores, etc. no cambia la situación estructural, por el contrario mantiene su inscripción dentro de la trayectoria histórica de las desigualdades sociales.

El proceso por el cual a ciertos individuos y grupos se les impide de manera sistemática el acceso a posiciones que les permitirían una subsistencia autónoma dentro de los niveles sociales determinados por las instituciones y valores en un contexto dado se agudiza con la introducción del turismo en la vida rural, la mayor parte de los casos así lo evidencian: trabajos precarios con altos índices de temporalidad y rotación del empleo, explotación en el trabajo y la pérdida del mismo, entre otros. 
Por lo anterior, lo que hace falta es recuperar y proponer nociones que contribuyan a superar estas limitaciones del concepto de pobreza tradicional, que no reproduzcan las condiciones actuales de desigualdad y exclusión, y permitan una intervención efectiva en el diseño de proyectos sociales, en general, y del turismo en particular.

Por parte de la academia y de las oNG se requiere un análisis más profundo y menos simplista del supuesto de que la pobreza se combate automáticamente con proyectos turísticos y, de este modo, no caer en engaños que llevan a la frustración y al desánimo a las comunidades que creen en ellos. De hecho, uno de los riesgos actuales del turismo rural comunitario es que después de la ejecución de numerosos proyectos de cooperación se consolide la idea de que es una actividad condenada al fracaso, sin revisar con minuciosidad las razones que lo habrían provocado. Por ello, en México, habría que revisar cuántos recursos han sido asignados a comunidades rurales para iniciar proyectos turísticos y cuántos han ayudado a sacarlas de "la pobreza".

\section{Fuentes consultadas}

Ashley, C. y Goodwin, H. (junio, 2007). “Turismo pro-pobre” ¿Qué ha ido bien y qué ha ido mal? Overseas Development Institute. Opinion, 80. Recuperado de http://www.odi. org.uk/sites/odi.org.uk/files/odi-assets/publications-opinion-files/142.pdf

Berger, P. y Luckman, T. (1972). La construcción social de la realidad. Buenos Aires: Amorrortu.

Boltvinik, J. (2001). Opciones metodológicas para medir la pobreza en México. Comercio Exterior, 51(10), 869-878.

Cañada, E. (2011). ¿Debe el turismo comunitario orientarse hacia el mercado de altos ingresos? Barcelona: Alba Sud.

Cañada, E. (2012). Turismo comunitario, un espacio en disputa. En J. Buades, E. Cañada y J. Gascón, El turismo en el inicio del milenio: una lectura crítica a tres voces (pp. 130-131). Madrid: Foro de Turismo Responsable.

Cañada, E. (2015). La comercialización del turismo comunitario en América Latina. Anuario de Estudios Centroamericanos, 41(1), 159-189.

Cañada, E. y Fandiño, J. M. (2009). Experiencias de turismo comunitario en Nicaragua. Aportes a la economía campesina. Managua: Edisa.

Cañada, E. y Gascón, J. (2007). Turismo y desarrollo: Herramientas para una mirada crítica. Managua: Enlace.

Ceirano, V. (2000). Las representaciones sociales de la pobreza. Cinta de Moebio, 9, 337350.

Collins, R. (1994). Cuatro tradiciones sociológicas. México: Universidad Autónoma Metropolitana-Iztapalapa.

Cuéllar, O. (1995). Perspectivas en el estudio de la pobreza. Entrevista con Julio Boltvinik, Fernando Cortés y Rosa María Rubalcava. Sociológica, 10(29), 181-208.

Estivill, J. (2003). Panorama de la lucha contra la exclusión social, conceptos y estrategias. Ginebra: Oficina Internacional del Trabajo. 
Forstner, K. (2004). Community ventures and access to markets: The role of intermediaries in marketing rural tourism products. Development Policy Review, 22(5), 497-514.

Fundación Encuentro. (2001). Informe España 2001. Una interpretación de su realidad social. Madrid: Autor.

Gascón, J. (2010). Limitaciones del turismo rural comunitario como instrumento de cooperación internacional. El concepto de Vocación Social del Territorio. En M. Nel-lo (ed.), Turismo, cooperación y desarrollo. Actas I Congreso coodtuR (pp. 81-82). Tarragona: Universidad Rovira y Virgili.

Gascón, J. (enero, 2011). La metodología "Pro-Poor Tourism": un análisis crítico. Opiniones en Desarrollo. Programa Turismo Responsable. Artículo 9. Recuperado de www.albasud.org info@albasud.org

Gascón, J. (2012). La metodología “Pro-poor Tourism” (PPT) un análisis crítico. En J. Buades, E. Cañada y J. Gascón, El turismo en el inicio del milenio: una lectura crítica a tres voces (pp. 157-171). Madrid: Foro de Turismo Responsable.

Gascón, J. (2013). The limitations of community-based tourism as an instrument of development cooperation: The value of the Social Vocation of the Territory concept. Journal of Sustainable Tourism, 21(5), 716-731.

Gergen, K. (2007). La psicología social como historia. En Á. Estrada y S. Diazgranados (comps.), Kennet Gergen, construccionismo social. Aportes para el debate y la práctica (pp. 3-26). Bogotá: Universidad de los Andes.

Goodwin, H. (2013). Turismo y reducción de la pobreza. En J. Gascón, S. Morales y J. Tresseras (eds.), Cooperación en turismo. Nuevos desafíos, nuevos debates (pp. 387-405). Barcelona: Foro de Turismo Responsable/Xarxa de Consum Solidari/coodtur/Universitat Oberta de Catalunya/Universitat de Barcelona.

Hernández, E. (2001). Retos para la medición de la pobreza en México. Comercio Exterior, $51(10), 860-868$.

Herrera, J. (junio, 2002). La pobreza en el Perú en 2001: Una visión departamental. Lima: Instituto Nacional de Estadística e Informática/Institut de Recherche pour le Développement. Recuperado de http:/ / repositorio.minedu.gob.pe/handle/123456789/244

Jiménez López, O. y Cavazos Arroyo, J. (2012). El turismo orientado a los pobres: una alternativa estratégica para los países en desarrollo. PASOS. Revista de Turismo y Patrimonio Cultural, 10(5), 451-465.

Jiménez Ramírez, M. (2008). Aproximación teórica de la exclusión social: complejidad e imprecisión del término. Consecuencias para el ámbito educativo. Estudios $\mathrm{Pe}$ dagógicos, 34(1), 173-186. Recuperado de https://dx.doi.org/10.4067/S071807052008000100010

Kadt, E. de (1979). Turismo: ¿Pasaporte al desarrollo? Madrid: Endymion.

Lewis, O. (1961). Antropología de la pobreza. México: Fondo de Cultura Económica.

Milano, C. (2016). Antropología, turismo y desarrollo en cuestión: el turismo comunitario a debate. Quaderns de l'Institut Català d'Antropologia, 32, 145-166.

Mitchell, J. y Ashley, C. (2010). Tourism and Poverty Reduction: Pathways to Prosperity. Londres: Earthscan.

Mitchell, J. y Muckosy, P. (mayo, 2008). A misguided quest: Community-based tourism in Latin America. Overseas Development Institute. Opinion, 102. 
Nussbaum, M. (1997). Capabilities and human rights. Fordham Law Review, 66(2), 273300. Recuperado de http://ir.lawnet.fordham.edu/flr/vol66/iss2/2

Ortiz Sandoval, L. (2004). Pobreza, ideología y construcción social. Población y Desarrollo, 26, 5-17.

Pérez, F. J., Barrera Pérez, O. D., Peláez, A. V. y Lorío, G. (2010). Turismo rural comunitario como alternativa de reducción de la pobreza rural en Centroamérica. Managua: Nitlapan-Universidad Centroamericana.

Picón Cruz, J. C. y Hernández Ulate, A. (s. f.). El turismo rural comunitario en los procesos de la nueva ruralidad: la experiencia latinoamericana. Recuperado de https:/ /www. aecit.org/files/congress/18/papers/42.docx

Pinto Faria, D. M. e Hidalgo Moratal, M. (septiembre, 2012). ¿Hay evidencias del turismo como un factor para aliviar la pobreza? Trabajo presentado en el $5^{\circ}$ Congreso Latinoamericano de Investigación Turística, São Paulo.

Pleumaron, A. (1994). The political economy of tourism. The Ecologist, 24(4), 142-148.

Pont Suárez, E. S. (2010). "Yo no me siento pobre". Percepciones y representaciones de la pobreza. Revista de Estudios de Género. La Ventana, 4(31), 37-63. Recuperado de http://www.scielo.org.mx/scielo.php?script=sci_arttext\&pi$\mathrm{d}=\mathrm{S}$ 1405-94362010000100004\&lng=es\&tlng=es.

Sen, A. K. (1996). Nueva economía del bienestar. Escritos seleccionados (Honoris Causa 11). Valencia: Universitat de València.

Sen, A. K. (2000). Social Exclusion: Concept, Application, and Scrutiny (Social Development Papers 1). Manila: Asian Development Bank.

Tezanos, J. F. (2001). La sociedad dividida. Estructuras de clases y desigualdades en las sociedades tecnológicas. Madrid: Biblioteca Nueva.

Unesco. (1976). The effects of tourism on socio-cultural values. Annals of Tourism Research, (4) 2, 74-105. 


\title{
CONOCIMIENTO PARA LA INNOVACIÓN EN LA EMPRESA FAMILIAR hotelera. Caso: destino turístico Mazatlán
}

\author{
Ana María Larrañaga Núñez \\ amlarranaga2607@gmail.com \\ Anel Yadira Pérez Melo \\ aypmudomzt@hotmail.com \\ Universidad Autónoma de Occidente \\ Unidad Regional Culiacán
}

El objetivo de este trabajo es identificar la integración de conocimientos para la innovación de procesos y organizativa en la empresa familiar hotelera de Mazatlán, Sinaloa. El conocimiento es un recurso clave que procede de distintas fuentes y vínculos internos y externos y coadyuva con la innovación en un mercado globalizado. La descripción cuantitativa emana de los cuestionarios aplicados a cuatro empresas. Los hallazgos demuestran la realización de actividades de innovación, a excepción de la introducción de investigación y desarrollo externo; además, el conocimiento proviene de fuentes gratuitas e internas. Se concluye que estas empresas evitan riesgos para innovar por el costo que representa la compra de conocimiento.

Palabras clave: Gestión del conocimiento, vinculación del conocimiento, innovación, empresa familiar hotelera, destino turístico.

\section{KNOWLEDge FOR INNOVATION IN THE FAMILY HOTEL BUSINESS. Case: tourist destination Mazatlan}

The objective of this work is to identify the integration of knowledge for process and organizational innovation in the family hotel business of Mazatlan, Sinaloa. Knowledge is a key resource that comes from different sources and internal and external links and that contributes to innovation in a globalized market. The quantitative description emanates from the questionnaires applied to four companies. The findings demonstrate the realization of innovation activities except for the introduction of external research and development, in addition the knowledge comes from free and internal sources. It is concluded that these companies avoid risks to innovate because of the cost of buying knowledge.

Key words: Knowledge management, Knowledge linking, Innovation, Hotel family business, Tourist destination.

Fecha de recepción: 17 de enero de 2019. Fecha de aceptación: 15 de abril de 2019

CÓMO CITAR: Larrañaga, A. M. y Pérez, A. (2019). Conocimiento para la innovación en la empresa familiar hotelera. Caso: destino turístico Mazatlán. Dimensiones Turísticas, 3(4), 43-62. https://doi.org/10.47557/ZDIW3995 
$E^{\prime}$ conocimiento es un recurso clave en la hotelería para mantener ventajas competitivas en un mercado globalizado (Borman, 2015; Ozigbo y Taiwo, 2014), por lo que resulta indispensable identificarlo, capturarlo, transferirlo y compartirlo. Además, este activo intangible se ha convertido en un factor de producción y es prioridad de las organizaciones en la sociedad del conocimiento, de ahí la importancia para el desarrollo de tecnologías, metodologías y estrategias que permitan su medición, creación y difusión (Rodríguez, 2006).

Davenport y Prusak (1998) señalan que el conocimiento constituye una mezcla en donde fluyen experiencias enmarcadas, valores e información contextual, y que en las organizaciones se inserta frecuentemente no solo en documentos o repositorios, sino también en rutinas, procesos, prácticas y normas organizacionales. Asimismo, este recurso es la base de aprendizajes e innovaciones, por lo que resulta una estrategia de gestión que, entre otras, "disminuye la redundancia de tareas y el número de errores en su ejecución, al aprovechar la experiencia existente dentro de la organización” (Medina, Medina y Nogueira, 2017, p. 17).

Por otra parte, la Organización para la Cooperación y el Desarrollo Económicos (OCDE, 2006) menciona que la innovación es la introducción de un producto (bien o servicio) nuevo o significativamente mejorado; un proceso; un método de comercialización, o un método organizativo en las prácticas internas de la empresa, la organización del lugar de trabajo o las relaciones exteriores.

La OCDE (2006) vincula la gestión del conocimiento con la innovación y apunta que la primera implica la apropiación, el manejo y la forma de colocar en común este conocimiento por la organización. De esta manera, enfatiza que se deben gestionar los vínculos externos y los flujos de conocimiento al interior de la empresa y establecer relaciones estrechas con otras compañías, clientes o instituciones de investigación. Nagles (2007) señala que, desde la perspectiva de la gestión del conocimiento, la innovación necesita desarrollar tres acciones fundamentales: reconocer las oportunidades de innovación, identificar los conocimientos relevantes que permitan la innovación, y generar soluciones sostenibles y rentables para la organización.

En la empresa familiar (EF) el conocimiento es una ventaja competiva (Leach, 1999), por lo tanto, la actitud emprendedora de los fundadores o de las generaciones subsecuentes juega un papel relevante como parte de la flexibilidad estratégica mediante las habilidades, conocimientos, capacidades, experiencia y valores, vistos como agentes detonantes, y que se forjan al inicio y durante su desarrollo (Rodríguez, Pico y Méndez, 2013). Esta actitud emprendedora en la EF también se relaciona, según Belausteguigoitia (2012), con la generación y aceptación de ideas en las organizaciones para enfrentar los cambios tecnológicos, regulatorios y demográficos, por lo que deben renovar constantemente sus prácticas, capacidades y actividades.

En las empresas pueden presentarse obstáculos para innovar (OCDE, 2006), entre ellos se encuentra el costo que implica la actividad y los factores asociados con el conocimiento, además, pueden tener éxito o no al tratar de alcanzar los objetivos que se habían fijado 
al introducir innovaciones, las cuales, a su vez, pueden tener efectos inesperados o adicionales con relación a los que se habían sustituido con su introducción. Hjalager (2010) indica que en el turismo las barreras para innovar tienen que ver con el acercamiento al conocimiento como, por ejemplo, patentes; a la difusión de la información y a la imitación.

Por otro lado, Martínez (2010) enfatiza que las ef son la esencia de la economía de mercado y las observa como la fuente generadora de un gran número de empleos y motor de la economía en casi todos los países. Por ello, la importancia del estudio de la ef se relaciona con la afirmación de $\mathrm{KPMG}^{1}$ México (2013) al mencionar que "más de 90 \% de las empresas que cotizan en la Bolsa Mexicana de Valores (BMv) tienen una clara representación familiar en el capital y en el control” (p. 5); además, se hace hincapié, con base en datos del Instituto Nacional de Estadística y Geografía (INEGI) publicados entre 2010 y 2012 citados por KPMG México (2013), que “las Micro, Pequeñas y Medianas Empresas (Mipymes), que básicamente corresponden al modelo familiar, suman $99 \%$ del total, con un promedio de 5.4 empleados" (p. 6). Por su parte, San Martín y Durán (2017, pp. 29-31) señalan que en México 83 \% de las empresas son familiares, correspondiendo 79.4 \% a los servicios, y que, por el tamaño de las EF, existen $57 \%$ de microempresas, $29 \%$ pequeñas, $11 \%$ medianas y $3 \%$ grandes.

En este contexto, el estudio de la ef hotelera es relevante en el destino turístico de Mazatlán, ya que, de acuerdo con cifras del INEGI (2016, p. 385 y 2017, p. 383), el número de hoteles de 2015 a 2016 fue de 138, mientras que la ocupación mediante la llegada de turistas a establecimientos de hospedaje en 2016 fue de 2154570 (INEGI, 2017, p. 388), observándose un crecimiento de $8.7 \%$ respecto a 2015 . Este incremento de la actividad hotelera es ante todo en la llegada de turistas nacionales provenientes del noreste del país, lo cual se debe a la operación de la autopista a Durango desde hace tres años.

El comportamiento de la actividad turística y la importancia de la EF hotelera en Mazatlán, Sinaloa, son elementos que se relacionan en este estudio de la integracion de conocimiento para la innovación. El destino turístico se caracteriza por ser tradicional. Al respecto, Herbert (2019), ${ }^{2}$ en una entrevista con el propietario de uno de los establecimientos de hospedaje, señala: "Las Flores, como muchos otros hoteles locales, es una empresa familiar. Eso distingue a Mazatlán de otros destinos de gran turismo mexicano: aunque han llegado franquicias internacionales, una importante presencia del empresariado autóctono se mantiene..." (s. p.).

Por lo anterior, el objetivo es identificar la integración de conocimientos para la innovación de procesos (IP) y organizativa (IO) en la EF hotelera de Mazatlán, Sinaloa, en el entendido de que el conocimiento es un recurso clave que procede de distintas fuentes y vínculos internos y externos y coadyuva con la innovación en un mercado globalizado. De esta manera, un cuerpo teórico de conceptos y teorías orienta y soporta la metodología y

${ }^{1}$ KPMG es la sigla conformada a partir de las iniciales de los apellidos de los principales miembros fundadores de la firma: $K$ de Piet Klynveld, $P$ de William Barclay Peat, $M$ de James Marwick y $G$ de Reinhard Goerdeler. Esta firma fusiona compañías de servicios profesionales en el mundo.

${ }^{2}$ El texto es un reportaje sobre el destino turístico en una revista en línea. 
el instrumento diseñado (OCDE, 2006; Choo, 1998; Hjalager, 2010; Jacob y Aguiló, 2008). Los resultados que se presentan corresponden al proyecto de investigación "Determinantes de la innovación y política turística en el destino Mazatlán, Sinaloa” (DIPTDMS).

Este documento se estructura de un cuerpo teórico denominado el conocimiento para la innovación y ef hotelera, así como la integración de conocimiento y la innovación; la metodología utilizada; los resultados obtenidos y las conclusiones.

\section{Conocimiento e innovación en la empresa familiar hotelera}

El conocimiento en la organización es un bien intangible, que se caracteriza por su renovación y que adquiere valor para la economía al compartirse con otras personas internamente, pero también con suministradores o clientes (Hernández, 2016). Suppiah y Sandhu (2011) citados por Bañegil, Barroso y Sanguino (2013) mencionan que el "conocimiento es reconocido como el recurso distintivo único y exclusivo, así como el diferenciador clave y crucial para cualquier organización para mantener su ventaja competitiva" (p. 74). El conocimiento en la organización es un proceso que incorpora valores, actitudes y creencias y que permite conocer su entorno e intervenir dinámicamente en este, con base en su experiencia (curva de aprendizaje) y sus habilidades (Fontalvo, Quejada y Puello, 2011). Por último se tiene que el conocimiento se crea con los datos e información al compararse, analizar las consecuencias, buscar conexiones y hablar con otros acerca de la información recibida (Sequeira y Marques, 2011).

Por otra parte, la innovación es la conversión de ideas y conocimientos en productos, procesos o servicios mejorados para el mercado, satisfaciendo así las necesidades de los ciudadanos, empresas y administraciones públicas (Afuah, 1999; Corma, 2011). Mathison, Gándara, Primera y García (2007) señalan que la innovación constituye "la capacidad para transformar los procesos empresariales y crear organizaciones más competitivas, ágiles y eficaces" (p. 69).

Hjalager (2010) enfatiza que la IP en el turismo se refiere a las iniciativas que apuntan a la escalada de la eficiencia, la productividad y el flujo. La inversión en tecnología se convierte en la principal fuente, y generaría mayor eficiencia si se combina con otra estrategia y medidas de gestión, como el desarrollo de competencias y la gestión de recursos humanos. Algunos ejemplos serían la rapidez en la preparación de alimentos o la mejora en el servicio de huéspedes.

La Io, de acuerdo con Jacob y Aguiló (2008), estimula mejorar la productividad y la calidad de los servicios turísticos en virtud de que los cambios organizativos coadyuvan en la motivación de innovaciones para enfrentarse a nuevos desafíos y dificultades. En tanto Hjalager (2010) dice que las innovaciones gerenciales llevan a formas de organización distintas en donde la colaboración interna, la dirección y la capacitación de personal se conjuntan, además de la creación de carreras y la compensación del salario. Se hace énfasis en el reto que tiene la empresa turística para desarrollar métodos que le permitan retener al personal y su satisfacción laboral, mantener flexibilidad y control de costos, cuidar los conocimientos y el activo de competencia. 
En relación con el concepto de EF se menciona que es una organización controlada y operada por los miembros de una familia (Belausteguigoitia, 2012; Leach, 1999; Rodríguez et al., 2013). Lorenzo y Núñez-Cacho (2012) plantean que existen tres puntos en común en las definiciones de EF: la propiedad, que se refiere al porcentaje de acciones o control efectivo de la empresa; la gestión, que atiende el desempeño de tareas ejecutivas y el nombramiento de ejecutivos, normalmente personas de la familia; $y$, por último, la continuidad, que alude a las generaciones familiares implicadas en la gestión de la empresa.

La EF hotelera se relaciona con el turismo por sus implicaciones y servicios de alojamiento que brinda a esa actividad, convirtiéndose en una unidad básica con un papel esencial en los destinos turísticos (Barron y Baum, 2007). Al respecto, el estudio de Peters y Buhalis (2004) sobre la planificación estratégica y la necesidad de educación y entrenamiento en las EF hoteleras da cuenta de resultados que tienen impacto en la innovación, ya que el empresario se ve a sí mismo y a su familia como la principal fuerza motriz de la actividad de innovación, dejando de lado a los empleados; por otra parte, otros hallazgos que se obtuvieron reflejan que los clientes y las ferias de turismo son impulsores externos de la innovación.

Por lo anterior, el conocimiento para la innovación en la EF hotelera se entiende como un recurso intengible que se procesa a través de valores, actitudes y creencias, el cual permite la interpretación del entorno y se interviene dinámicamente, además de ser la base de los aprendizajes e innovaciones, por lo que resulta una estrategia de gestión.

\section{La integración de conocimiento y la innovación}

En este artículo, la integración de conocimiento y la innovación en las EF hoteleras se relaciona con los enfoques teóricos de la agencia en la organización, el de recursos y capacidades, el capital intelectual, los relativos a gestión del conocimiento y, con ello, el de uso de la información en las organizaciones y los vínculos de conocimiento. En este sentido, los antecedentes de investigaciones que se mencionan a continuación llevan a demostrar cada perspectiva teórica.

En la teoría de la agencia se encuentra el aspecto positivo de la agencia, sobre lo cual Charreaux (2000) comenta que el conocimiento es relevante en el desempeño organizacional y de suyo en la eficiencia al contribuir en la toma de decisiones, por lo que existe un costo al transferir conocimiento entre actores; el ideal es encontrar el menor costo y ponerlo a disposición de los tomadores de decisiones. Al respecto, Hülsbeck et al. (2011) citado por Steeger y Hoffmann (2015) señalan que las EF tienen dificultades para utilizar su ventaja potencial, subrayan que los problemas de agencia en ellas son mayores que en los negocios no familiares, resultado de la concentración en la propiedad, teniendo como consecuencia el impacto innovador a la inversa. En el estudio de estos autores una de sus conclusiones es la aversión para enfrentar el riesgo a innovar en la EF.

De acuerdo con Ochoa, Prieto y Santidrián (2012), la teoría de los recursos y capacidades contempla la heterogeneidad empresarial y la construcción de la estrategia sobre 


\section{Conocimiento para la innovación en la empresa familiar hotelera}

Caso: destino turístico Mazatlán

los recursos de los que dispongan, así como la obtención de mayor renta y eficiencia. Los recursos provienen desde el producto de su historia "suerte y decisiones pasadas, sobre los que puede sustentar una ventaja competitiva y en la medida en que esta ventaja competitiva sea sostenible, le proporcionará una renta a largo plazo" (Ochoa, Prieto y Santidrián, 2012, p. 36). En este enfoque teórico, Lorenzo y Núñez-Cacho (2012) y Sirmon y Hitt (2003) identifican los recursos y las capacidades de la EF como un potencial, además de hacer énfasis en su desarrollo en la búsqueda de ventajas competitivas. Sirmon y Hitt (2003) concluyen en su investigación que el capital humano, y con ello el conocimiento, es de los recursos más importantes para una EF; es intangible, socialmente complejo y difícil de imitar, lo cual la conduce a crear una ventaja competitiva, sin embargo, este capital humano en ocasiones es inaccesible fuera de la familia, por lo que se requiere de una gestión efectiva de los recursos.

La perspectiva teórica del capital intelectual se refiere a la acumulación de conocimiento en una organización y que le aporta valor cognitivo. Este valor se compone de activos intangiles, que en combinación con los otros capitales físicos y financieros proporcionan ventajas competitivas en el mercado (Bueno, Salmador y Merino, 2008). Estudios y propuestas en la hotelería se han realizado desde este enfoque. Al respecto, Gazzera (2014), en la conjunción de la perspectiva de la gestión del conocimiento y del capital intelectual, propone el concepto de gerencia del conocimiento en la organización, cuya función radica en gerenciar los activos intangibles que permitan mantener y fortalecer la competitivdad de la empresa y argumenta que la distinción organizacional actualmente reside en la capacidad de combinar fuentes internas y externas del conocimiento para aprovechar las oportunidades comerciales.

Otra propuesta es la teoría dinámica del capital intelectual de Millán, Gómez y Vargas (2017) que contribuya a incrementar la competitividad en la hotelería. Los autores destacan que la limitada capacidad para aprender, innovar y reorganizarse se debe "a falta de sistematización de la información generada a partir de sus relaciones, a la demanda de implementación de tecnologías de la información que hagan eficientes sus procedimientos y a la alta rotación de personal” (p. 102), lo cual provoca que se pierdan conocimientos y experiencia. La concreción de la propuesta es transitar del capital intelectual estático que contiene los activos de los capitales humano, relacional y estructural hacia el capital intelectual dinámico mediante la aplicación sistemática de los activos del capital intelectual en los niveles administrativo, tecnológico y de información. Esto conduce a la competitividad e innovación.

En el enfoque teórico de la gestión del conocimiento, según Medina, Medina y Nogueira (2017), esta se entiende como un proceso que "promueve la generación, colaboración y utilización del conocimiento para el aprendizaje organizacional e innovación, con el que se genera nuevo valor y se eleva el nivel de competitividad en aras de alcanzar los objetivos organizacionales con eficiencia y eficacia" (p. 17).

La gestión del conocimiento incorpora ventajas a la organización, ya que incrementa la capacitación y la profesionalización de las personas y sus roles laborales, integra diferentes 
puntos de vistas de las distintas áreas de la empresa y de enfoques complementarios, genera nuevas formas de gestión y de operatividad, reduce costos y tiempos de entrega o fabricación, aumenta la innovación, entre otras (Contreras y Tito, 2013).

El soporte teórico en la gestión del conocimiento desde los modelos son citados por Farfán y Garzón (2006) como sigue: modelo de Bueno (2002); modelo Andersen (1999); proceso de creación del conocimiento de Nonaka y Takeuch (1995), que se da en un ciclo de socialización, exteriorización, combinación e interiorización; Knowledge Management Assessment Tool (KMAT), cuyos componentes son liderazgo, cultura, tecnología y medición; modelo de gestión del conocimiento de KPMG Consulting de Tejedor y Aguirre (1998); modelo Gopal \& Gagnon (1995); administración del conocimiento, administración de la información, administración del aprendizaje y modelo dinámico de creación de conocimiento, en donde se relacionan mercado y estrategia, estructura y procesos, conocimiento y sistemas con las personas y la motivación.

Hernández (2016) señala que la formulación de una estrategia adecuada para la gestión del conocimiento contribuye con lo siguiente: proponer una buena práctica; mejorar la comprensión de la actividad de gestionar el conocimiento en la organización; articular la actividad empresarial e identificar beneficios potenciales; obtener el compromiso de la alta dirección; lograr recursos para la implementación del sistema; ofrecer un plan claro y comunicable acerca de dónde se está, a dónde se quiere llegar y cómo se planifica llegar hasta ahí, y dar una base para medir el progreso.

Nagles (2007) plantea el esquema de gestión del conocimiento a partir de tres dimensiones: las barreras para su integración, la transferencia de conocimiento y las acciones para una efectiva gestión. En lo que se refiere a la transferencia de conocimientos, la divide en dos, primero en los elementos del proceso: adquisición y apropiación de conocimiento, solución de problemas, implementación e integración de soluciones, y experimentación y generación de prototipos; y, segundo, en proceso de transferencia, integración de nuevos conocimientos, localización y adaptación de conocimientos, adecuación de sistemas en la organización y diseño de nuevos productos, servicios y procesos. Medina et al. (2017) proponen la cadena de valor del conocimiento que tiene su alcance en la adquisición, la organización, la divulgación, el uso y la medición, esto último ya con el producto o servicio, y la detección de nuevas necesidades de información.

Hjalager (2010) menciona cuatro procesos de búsqueda y adquisición de conocimiento para la innovación en el turismo: el conocimiento incorporado; las competencias y el conocimiento basado en recursos; el conocimiento localizado y, por último, la investigación basada en el conocimiento.

Hallin y Marnburg (2007) argumentan que en el caso de la hotelería resulta relevante la incorporación de estrategias para la gestión del conocimiento, algunas razones se deben a implicaciones que se tienen: por un lado, el servicio de alojamiento con el de alimentos y bebidas, además de la gama de colaboradores que intervienen: centro de convenciones, agencias de viaje en línea, turoperadores, entretenimientos y tiendas con diversos productos, amén de la relación directa entre empleados y visitantes. 
Dos Anjos, Flores, Gadotti y Domareski (2011) indican que las contribuciones de la gestión del conocimiento a las empresas turísticas se tienen en Formica y Xiang (2007), Yang y Wan (2004), Yang (2004) y Yang (2008). Estas investigaciones hacen un análisis en compañías aéreas, agencias de viajes y hoteles. Las aportaciones aparecen en los ámbitos de la gestión estratégica, el conocimiento del consumidor, las prácticas de la gestión del conocimiento, el aprendizaje organizacional y el estímulo para compartir el aprendizaje individual y organizacional.

En el enfoque del uso de la información dentro de la teoría de gestión del conocimiento se distinguen tres formas, de acuerdo con Choo (1998): la de la percepción, que permite la interpretación; la de la creación de conocimiento, que convierte la información; y la de la toma de decisiones, en donde se analiza la información. En la forma de creación de conocimiento se concentra la idea de la organización que aprende, la creación se logra a través de la relación sinérgica entre conocimiento tácito y explícito y el diseño de procesos sociales que llevan al nuevo conocimiento; el autor enfatiza que al especializarse en la conversión de conocimientos se impulsa la innovación y el desarrollo de nuevos productos y servicios.

Respecto al enfoque teórico mencionado anteriormente, Borman (2015) señala que en las organizaciones hoteleras la inversión en gestión del conocimiento es relevante ya que lleva a un mejor rendimiento, por lo que no debería existir brecha para la captación de información en virtud de que esta permite una mejor planificación, toma de decisiones y la formulación de políticas.

En relación con la vinculación de conocimiento, Choo (1998) se refiere a la creación de conocimiento en la organización no de una manera aislada sino como colaboración de los miembros en lo interno y en sociedades con otras organizaciones, así es como Badaracco citado por Choo (1998) acuña el concepto de vínculos de conocimiento, para lo cual establece cuatro rangos: el primero es que el objetivo central de los vínculos es aprender y crear conocimiento, que se interesa por desarrollar capacidades en un plazo más largo; el segundo alude a la intimidad de los vínculos de conocimiento, lo que implica que los asociados aprendan, creen o fortalezcan las capacidades especializadas, y se requiere que el personal trabaje íntimamente; el tercero corresponde a la diversidad de vínculos con los asociados, entre compradores y proveedores, investigadores universitarios y compañías, sindicatos y sus empresas; y el cuarto es el potencial estratégico de los vínculos de conocimiento que aumentan las capacidades básicas de la organización. Ante ello, el conocimiento estratégico de la organización se encuentra en sus capacidades para generar conocimiento a través del tiempo y a largo plazo.

En conclusión, la distinción de adquisición de conocimientos en el turismo de Hjalager (2010), al relacionarse con los vínculos de conocimiento para la organización que mencionan la OCDE (2006) y Choo (1998), se aprecia en el cuadro 1. 
Cuadro 1. Adquisición de conocimiento para la innovación en el turismo y forma de vinculación de la organización

\begin{tabular}{|c|c|c|}
\hline $\begin{array}{l}\text { Adquisición de } \\
\text { conocimiento para } \\
\text { la innovación }\end{array}$ & Situación & $\begin{array}{c}\text { Vínculo de } \\
\text { conocimiento }\end{array}$ \\
\hline $\begin{array}{l}\text { Conocimiento } \\
\text { incoporado }\end{array}$ & $\begin{array}{l}\text { En su incorporación son fundamentales las cadenas de } \\
\text { negocios o redes que son relevantes para la transferencia de } \\
\text { conocimiento en el turismo. La crítica que se menciona es que } \\
\text { la estadarización se convierte en un obstáculo para el espíritu } \\
\text { innovador de las empresas. }\end{array}$ & Exterior \\
\hline $\begin{array}{l}\text { Las competencias y } \\
\text { conocimientos basados } \\
\text { en recursos }\end{array}$ & $\begin{array}{l}\text { El conocimiento significativo está disponible en la empresa y } \\
\text { en los integrantes, como tácito; ante ello, es necesario que } \\
\text { sea explicitado, entendido adecuadamente, interpretado, } \\
\text { restaurado y adaptado a las innovaciones específicas, pero } \\
\text { también recodificado. En este escenario se enfatiza que los } \\
\text { recursos humanos, y con ello el conocimiento y la capacidad } \\
\text { de innovación, se caracterizan por la migración, por lo que } \\
\text { son parámetros que deben estarse indagando en el mercado } \\
\text { laboral. }\end{array}$ & Interior \\
\hline $\begin{array}{l}\text { El conocimiento } \\
\text { localizado }\end{array}$ & $\begin{array}{l}\text { En este escenario de fuente de conocimiento, Hjalager observa } \\
\text { al destino turístico como un depósito de competencias y } \\
\text { conocimientos, únicos e inimitables, de las empresas y que } \\
\text { permiten el desarrollo de productos y servicios. Además hace } \\
\text { hincapié en conocimientos intersectoriales con que cuentan } \\
\text { los destinos. }\end{array}$ & $\begin{array}{l}\text { Exterior para la } \\
\text { empresa } \\
\text { Interior para el destino }\end{array}$ \\
\hline $\begin{array}{l}\text { Conocimiento basado } \\
\text { en la investigación }\end{array}$ & $\begin{array}{l}\text { Participación de la academia. Hjalager menciona que los } \\
\text { recursos que se desginan para este tipo de fuente son } \\
\text { escasos; además de la necesidad de empleo de personal bien } \\
\text { educado de cara a la alta rotación de personal y un bajo nivel } \\
\text { educativo general en la actividad. }\end{array}$ & Exterior \\
\hline
\end{tabular}

Fuente: Elaboración propia con base en Hjalager (2010), Choo (1998) y ocDE (2006).

\section{Metodología}

Esta comunicación tiene como base el proyecto de investigación DIPTDMS, que focalizó la IP e 10 en los establecimientos de servicio turístico, cuyos resultados arrojaron, entre otras, la línea de investigación Innovación en la empresa familiar hotelera. En este sentido, la integración de conocimiento es una variable que se abordó como propulsora de la actividad de innovación en las organizaciones y, en este caso, en las EF hoteleras.

El objetivo de identificar la integración de conocimientos para la IP e Io en la EF hotelera de Mazatlán, Sinaloa, llevó a decidir el enfoque cuantitativo a partir del fundamento teórico de cuatro dimensiones: las actividades de innovación, las fuentes de información de libre 


\section{Conocimiento para la innovación en la empresa familiar hotelera \\ Caso: destino turístico Mazatlán}

acceso o gratuitas, la adquisición de conocimiento y tecnología por compra y, por último, la cooperación, y con ello la vinculación interna o externa del conocimiento (OCDE, 2006; Choo, 1998). De esta manera, se analizan descriptivamente los promedios alcanzados en las dimensiones y categorías que son fuente y vínculo del conocimiento para la IP e IO.

Las dimensiones señaladas se definen a continuación, de acuerdo con la OCDE (2006):

1. Las actividades de innovación son el conjunto de actuaciones científicas, tecnológicas, organizativas, financieras y comerciales que conducen a la introducción de innovaciones (p. 25).

2. Las fuentes de información de libre acceso o gratuitas se entienden como la información de difusión libre, que no requiere la compra de tecnología o derechos de propiedad intelectual; además incluye la investigación y desarrollo que se realiza dentro de la empresa, así como el conocimiento que se transmite por organizaciones del mismo grupo (p. 91).

3. La adquisición de conocimientos y tecnología se establece por la compra de conocimiento externo y de tecnología que se encuentra en bienes de equipo o servicios (p. 92).

4. La fuente de cooperación se entiende como la cooperación activa que se tiene con otras empresas o instituciones públicas de investigación (p. 92).

Además, al indagar estudios similares a este objeto y formas metodológicas de abordarlos se encontró que el conocimiento y la innovación en la EF han sido poco investigados (Lorenzo y Núñez-Cacho, 2012); así, estos autores analizan la innovación y aplican el modelo de inercias de Rumelt a la EF; por su parte, Steeger y Hoffmann (2015), a través del modelo Tobit, realizan una investigación de tipo transversal, y Borman (2015) estudia la empresa hotelera en Ghana a partir del sistema de gestión del conocimiento y las ventajas competitivas mediante el enfoque cuantitativo.

Por otro lado, esta investigación es transversal, ya que la recolección de datos se hizo en un mes (julio de 2017) ${ }^{3}$ a partir de la aplicación de un cuestionario elaborado y adaptado con base en el Manual de Oslo (OCDE, 2006); cabe destacar que este documento contempla la importancia de la innovación en los sectores de servicio y con baja densidad en investigación y desarrollo y contiene preguntas dicotómicas. En la primera parte del instrumento se inquirió sobre información general de los establecimientos: la asociación a la que pertenece el establecimiento de hospedaje, característica del hotel en estrellas, número de empleados que laboran, porcentaje de usuarios tanto nacionales como extranjeros que se hospedan, y si se realizan actividades innovadoras y sus tipos.

En la segunda parte se preguntó primero por la dimensión actividades de innovación que contiene nueve ítems (investigación y desarrollo interno; adquisición de investigación y desarrollo externa; introducción, desarrollo, ensayos y métodos de procesos; planificación

\footnotetext{
${ }^{3}$ Este proyecto fue financiado por el Programa para el Desarrollo Profesional Docente, para el Tipo Superior (Prodep), por lo que se ajusta a un periodo de un año para su diseño, ejecución y finalización. Además, las fechas de aplicación del cuestionario fueron concertadas con los gerentes de los establecimientos con base en su disposición de tiempo.
} 
e introducción de nuevos métodos de organización; adquisición de equipos y máquinas; adquisición de terrenos; formación de capital humano; gastos corrientes e innovación; e inversión en capital fijo en innovación). Después se abordó la dimensión integración de conocimiento y tecnología a la IP e 10 con tres variables: fuentes de información de libre acceso o gratuitas; adquisición de conocimiento y tecnología por compra y, la última, por cooperación activa en innovación.

En cuanto al caso estudiado, el destino turístico Mazatlán se ubica en el estado de Sinaloa, al noroeste de la república mexicana, en donde la actividad económica preponderante es el turismo que se caracteriza por ser de sol y playa. Los establecimientos hoteleros en el destino suman 183 (INEGI, 2017), y los integrados a las dos asociaciones que existen son 40 que se compone de cadenas hoteleras, corporativos y EF, 13 corresponden a establecimientos registrados en la Asociación de Hoteles y Moteles Tres Islas de Mazatlán (АНMтIM) y 27 a la Asociación de Hoteles y Empresas Turísticas de Mazatlán (АHETM). De esta población, la muestra fue de 15 hoteles que cubrían los criterios que se consideraron desde el diseño original del proyecto DIPTDMs. Ahora bien, al ampliar la línea de investigación Innovación en la empresa familiar, se seleccionaron cuatro EF hoteleras que se distribuyeron de manera proporcional en función de la asociación a la que pertenecen y se tuvieron en cuenta los criterios siguientes:

a) Los informantes seleccionados para el cuestionario fueron los gerentes generales de los establecimientos.

b) Ubicación geográfica: hoteles que se encuentran sobre la playa o que se separan de esta mediante una calle.

c) Establecimientos integrados en alguna de las dos asociaciones.

d) Establecimientos con funcionamiento en el mercado superior a los tres años y con una sucesión como mínimo.

e) Las actividades de innovación se refieren solo a IP e 10.

Asimismo, se utilizan variables nominales que contienen categorías no jerárquicas ni ordenadas para efectos de la evaluación y de comparación como la media aritmética, la cual indica el valor promedio y de frecuencia relativa. En el análisis entre variables e indicadores que lo integran, se busca identificar y explicar, en función de los avances mostrados, que la integración de conocimiento ha tenido impacto en las actividades de innovación.

\section{Resultados}

Los resultados se presentan en tres segmentos: el primero se refiere a la información general de los establecimientos informantes, después se señalan las actividades de innovación y, por último, se describen los hallazgos que tienen que ver con la integración de conocimiento a las IP e IO. 


\section{Conocimiento para la innovación en la empresa familiar hotelera \\ Caso: destino turístico Mazatlán}

\subsection{Información general de los establecimientos}

Los datos de los hoteles informantes arrojaron los hallazgos siguientes: los cuatro hoteles son de cuatro estrellas, y por el número de empleados que los integran son: $25 \%$ de 50 a $99,50 \%$ de 100 a 249 y $25 \%$ de 250 a 999. El origen de sus usuarios es: $25 \%$ (70\% nacionales y $30 \%$ internacionales), $25 \%$ (80 \% nacionales y $20 \%$ internacionales), $25 \%$ (85 $\%$ nacionales y $15 \%$ internacionales) y $25 \%$ (91\% nacionales y $9 \%$ internacionales). Los cuatro establecimientos informaron que han realizado innovaciones en las tipologías de producto o servicio, proceso, organizativas y de mercadotecnia.

\subsection{Actividades de innovación}

Los establecimientos señalaron (figura 1) que $100 \%$ planifica e introduce nuevos métodos de organización y realiza actividades de investigación y desarrollo interno, 25 \% adquirió terrenos y cuenta con gastos corrientes en innovación. En este sentido, las actividades de innovación que se efectúan se concentran en investigación y desarrollo interno con una formación de capital humano de $75 \%$.

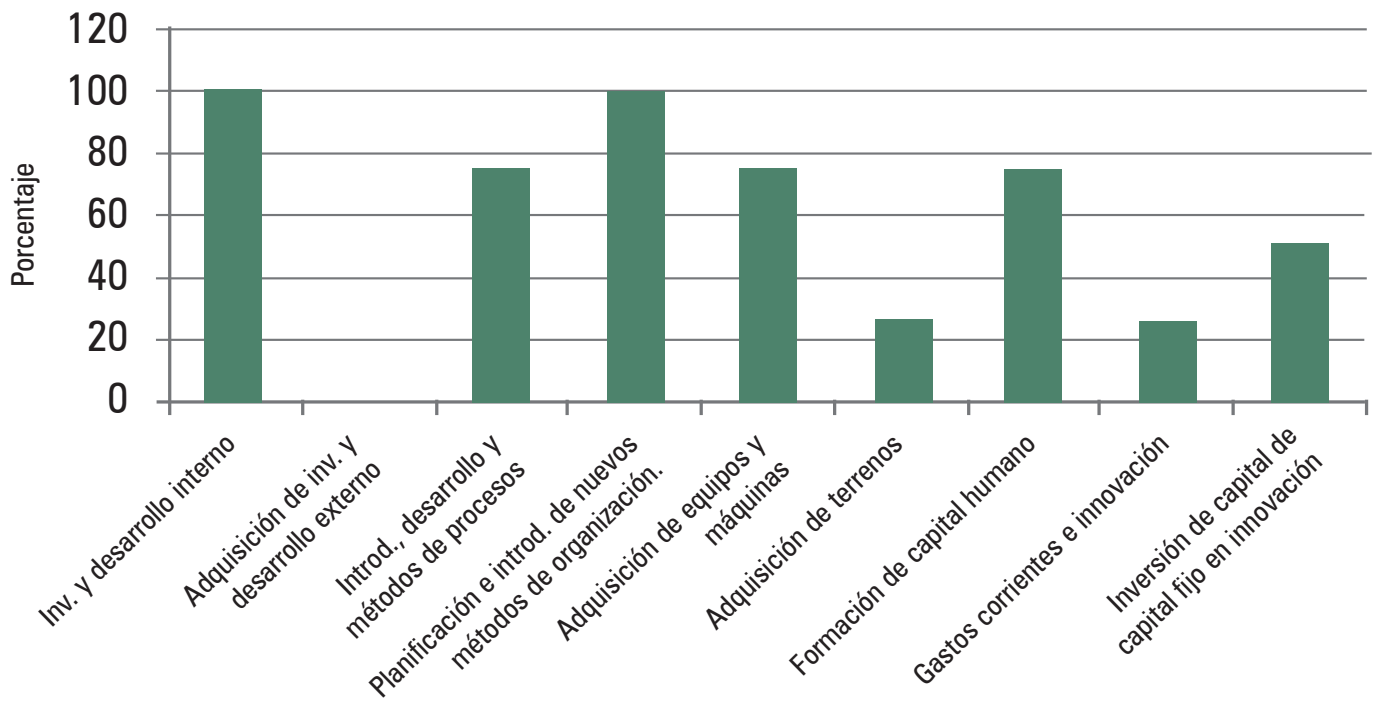

Fuente: Elaboración propia.

Figura 1. Actividades de innovación

\subsection{Integración de conocimiento a la innovación de procesos y organizativa gratuitas}

En esta dimensión se integran las fuentes gratuitas, por compra y por cooperación. De esta manera, la integración de conocimiento a través de estas fuentes (figura 2) demuestra que en las IP por compra arroja un promedio de $61.2 \%$, mientras que por cooperación 


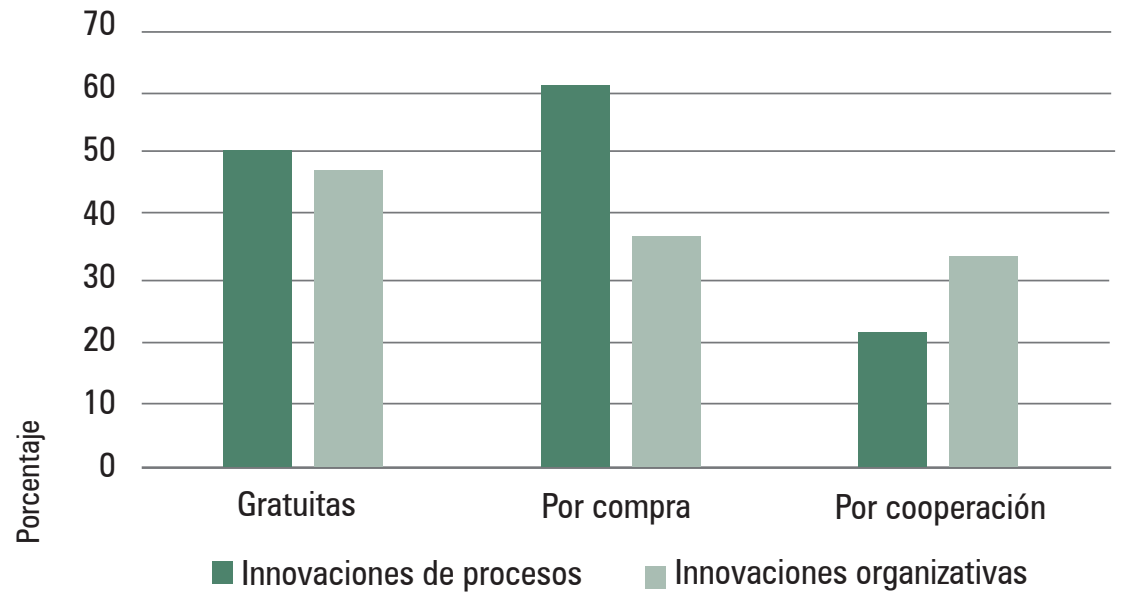

Fuente: Elaboración propia.

FiguRA 2. Integración de conocimiento por fuentes: gratuitas, por compra y por cooperación

es de $22 \%$. En las 10, las gratuitas reflejan $47.4 \%$, y las de cooperación $33.7 \%$. Esta información visibiliza que la cooperación es escasa y no se aprovechan suficientemente las relaciones, por ejemplo, con las instituciones educativas y de investigación para incorporar conocimiento.

Por otra parte, en relación con la integración de conocimiento y tecnología al establecimiento mediante fuentes gratuitas (figura 3), se observa en las IP a las internas con un promedio de $66.7 \%$, como el más alto; en tanto, el menor se tiene en las fuentes de información general con $39.3 \%$. En las Io se observa que las fuentes comerciales y de mercados exteriores son las más altas con 60 \% y las menores recaen en fuentes que dependen del sector público con $33 \%$.

Los informantes señalaron que estas fuentes las obtienen primordialmente de expertos, investigación y desarrollo interno, clientes y redes informales, y que la experiencia del personal es un factor relevante en la integración de conocimiento.

Respecto a la integración de conocimiento y tecnología por compra (figura 4), en las IP los resultados arrojan que $45 \%$ integran conocimiento a través de fuentes comerciales y mercados exteriores, mientras que $50 \%$ de fuentes de información y general. En las ı, $31.2 \%$ obtiene conocimiento mediante fuentes de información generales.

Los informantes comentaron que la fuente principal para la integración de conocimiento por compra son los proveedores y las ferias y exposiciones; es decir, se manifiesta la confianza en el conocimiento probado, pero también en el que se demuestra con una experiencia con resultados positivos, como el caso del exhibido en exposiciones.

Por último, sobre la integración de conocimiento y tecnología por cooperación (figura 5) se observa que, para las IP, 35 \% proviene de fuentes comerciales y mercados exteriores, 
Conocimiento para la innovación en la empresa familiar hotelera

Caso: destino turístico Mazatlán

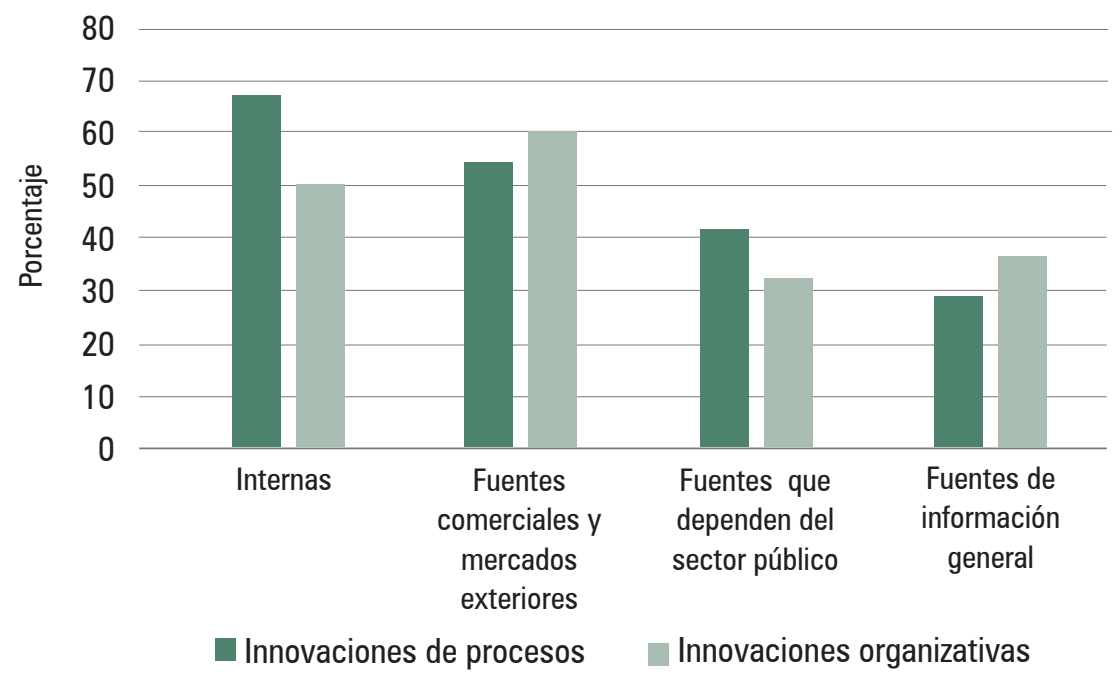

Fuente: Elaboración propia.

FiguRa 3. Integración de conocimiento y tecnología con fuentes de información gratuitas

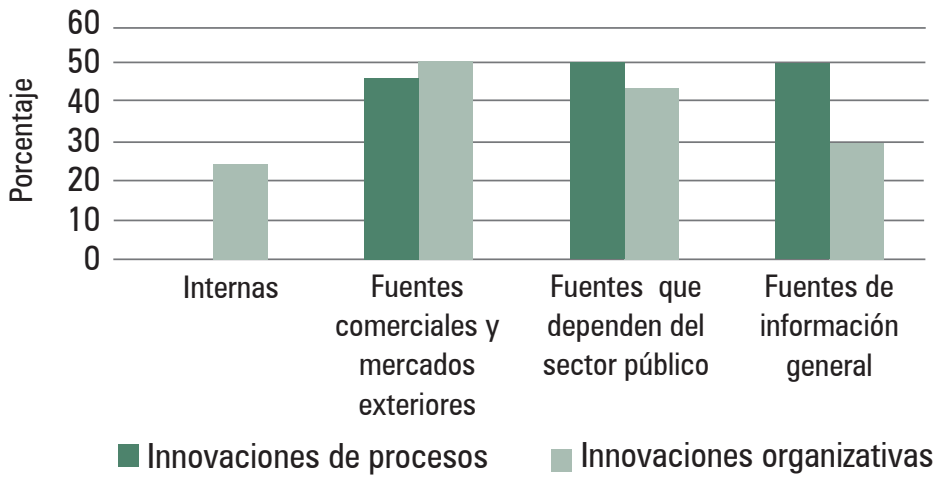

Fuente: Elaboración propia.

FIGURA 4. Integración de conocimiento y tecnología por compra

mientras que $6.2 \%$ de fuentes que dependen del sector público. Las Io lo obtienen en $50 \%$ de fuentes internas, y en $7 \%$ de fuentes que dependen del sector público.

En estas fuentes destacan las que se adquieren de los competidores y de los clientes/ usuarios. Este hallazgo denota que las recomendaciones y la confianza en los clientes-visitantes son un factor relevante en la integración de conocimiento de frente a la satisfacción del servicio y con la posibilidad de que retorne al establecimiento. 


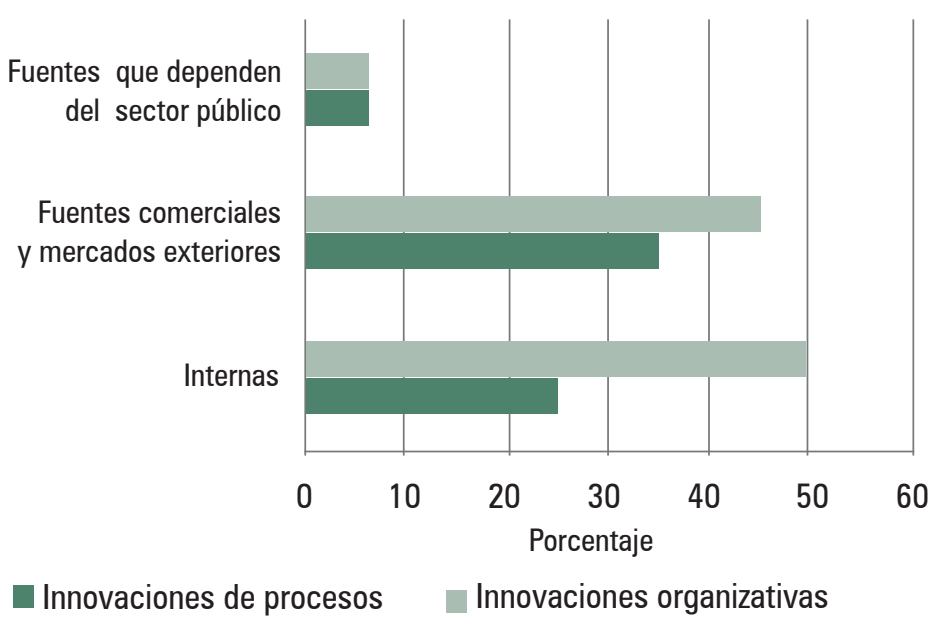

Fuente: Elaboración propia.

Figura 5. Integración de conocimiento y tecnología por cooperación

\section{Análisis y discusión}

Las ef hoteleras estudiadas en el destino turístico Mazatlán, por el número de empleados, son medianas y grandes (INEGI, 2009), y ofrecen servicios de alojamiento a usuarios nacionales y extranjeros.

Las cuatro EF hoteleras que forman parte del estudio señalaron haber realizado actividades de innovación en los últimos tres años en las tipologías de producto o servicio, proceso, organizativas o de mercadotecnia, de acuerdo con la OCDE (2006); sin embargo, en la gama de actividades expuesta es significativo el resultado nulo de la adquisición de investigación y desarrollo externo; al respecto, Hjalager (2010) indica que en el turismo las barreras para innovar tienen que ver con el acercamiento al conocimiento, como por ejemplo patentes, y a la difusión de la información; además, este hallazgo se relaciona con la teoría de la agencia y las aportaciones de Steeger y Hoffmann (2015) al apuntar que la concentración en la propiedad en ocasiones no permite correr el riesgo para innovar en la EF debido al costo que representa.

En cuanto a las actividades de innovación, también se observa que la formación de capital humano no se presenta en el total de los establecimientos; este hallazgo se vincula con la teoría de los recursos y capacidades y con lo planteado por Sirmon y Hitt (2003), ya que el conocimiento se convierte en una ventaja competitiva de la organización que requiere de una gestión efectiva de los recursos. Asimismo se manifiesta una gerencia de los activos intangibles insuficientes para aprovechar las oportunidades comerciales (Gazzera, 2014).

Respecto a los vínculos de conocimiento, los hallazgos dan cuenta de que las EF hoteleras agencian información para crear conocimiento, teniendo el siguiente comportamiento: 
es medianamente significativo el resultado obtenido de fuentes gratuitas, por compra y por cooperación; por ejemplo, para la integración de información por compra para IP, cuyo resultado es el más alto, se adquiere sobre todo de empresas del mismo grupo y proveedores de equipos y materiales, es decir, internas y externas. En ıo, las fuentes gratuitas no alcanzan $50 \%$ en la más alta, y aquí se tiene que son las área de hospedaje, alimentos y bebidas, esparcimiento y diversión, y administración de la organización, principalmente, las que aportan la información con la que se crea conocimiento. Este comportamiento se liga con lo que menciona Badaracco (1991) citado por Choo (1998) a correr el riesgo de no observarse el potencial estratégico que proporcionan los vínculos de conocimiento y que aumentan las capacidades básicas de la organización.

De la relación entre las actividades de innovación y los resultados de la integración de conocimiento por fuentes: gratuitas, por compra y por cooperación, son medianamente aprovechadas las gratuitas y por cooperación para incorporar IP, lo que impacta en las actividades de introducción y desarrollo de nuevos métodos; esto es, las capacidades de la organización se manifiestan limitadas por la falta de sistematización de información generada a partir de sus relaciones (Millán, Gómez y Vargas, 2017), por ejemplo, con las universidades.

Por otro lado, en las EF hoteleras la priorización a vínculos externos (expertos, clientes y redes informales) aunados a internos, la experiencia del personal, da cuenta de que se tiene una perspectiva del proceso de transferencia, ya que se integran nuevos conocimientos, se localizan y adaptan esos conocimientos (Nagles, 2007), pero también un acercamiento al modelo dinámico de creación de conocimiento en donde se relacionan el mercado y la estrategia, estructura y procesos, conocimiento y sistemas con las personas y la motivación (Farfán y Garzón, 2006).

Además, es significativo el bajo promedio alcanzado en fuentes gratuitas, por compra y por cooperación tanto para IP como para Io en las que dependen del sector público, es decir, hay una escasa relación con este sector. Esto se vincula con el conocimiento estratégico y la capacidad como resultado de la calidad de la red externa de la organización, según Choo (1998).

\section{Conclusiones}

En la economía del conocimiento y en la globalización de los mercados el valor de este recurso intengible es relevante, ya que a través de su gestión estratégica y sistematización mediante su adquisición, organización, divulgación, uso y medición constante, se lograrán mantener o crear ventajas competivas e innovaciones en las organizaciones.

Al identificar la integración de conocimientos para la IP e Io en la ef hotelera de Mazatlán, Sinaloa, se confirma que el conocimiento es un recurso clave, y que sus fuentes y vínculos externos e internos deben gestionarse permanentemente. En este sentido, los resultados contribuyen en las perspectivas teóricas de gestión del conocimiento y del capital intelectual, además, en los estudios del turismo a través de las fuentes de conocimientos 
localizados y las competencias y conocimientos basados en recursos que han permitido actividades de investigación y desarrollo interno en cuatro ef hoteleras (Hjalager, 2010).

Las EF hoteleras que prestan servicios a usuarios nacionales y extranjeros del destino turístico Mazatlán no introducen investigación y desarrollo externo, es decir, evitan riesgos para innovar, por un lado, por el costo que representa y, por otro, por una limitada gerencia del conocimiento, lo que disminuye sus ventajas competitivas. Así pues, resulta recomendable que las ef formulen estrategias adecuadas de gestión del conocimiento (Hernández, 2016) como una buena práctica y para articular la actividad empresarial e identificar los beneficios potenciales.

Por otra parte, el rol del capital humano y el de los visitantes que se hospedan en las EF hoteleras son cardinales. Los primeros, con su contribución para el desarrollo de actividades de investigación interna, aunque la formación de este recurso no se da en la totalidad de las organizaciones; mientras que los visitantes se convirten en los principales proveedores de conocimiento, a los que se perfilan en la categoría de cooperación.

El conocimiento localizado (Hjalager, 2010) en estas EF hoteleras es un valor y una oportunidad en un destino tradicional, ya que sus competencias únicas contribuyen al desarrollo de los servicios de alojamiento que proporcionan en la actividad turística.

El alcance del estudio recae en cuatro EF hoteleras que se seleccionaron con base en criterios, por una parte teóricos para contar con resultados válidos y espaciales para asegurar los establecimientos que brindan el servicio turístico. Esto se convierte en una limitación, por lo cual es recomendable ampliar la muestra del estudio.

Por último, la continuación de la investigación se puede orientar a analizar la gestión del conocimiento a partir del modelo dinámico de creación de conocimiento o también el impacto del capital intelectual dinámico en las EF hoteleras.

\section{Fuentes consultadas}

Afuah, A. (1999). La dinámica de la innovación organizacional, el nuevo concepto para lograr ventajas competitivas y rentabilidad. México: Oxford.

Bañegil, T., Barroso, A. y Sanguino, R. (2013). La gestión del conocimiento en las empresas familiares. En W. Fernández, Nuevas investigaciones sobre la gestión de la empresa familiar en España (pp. 69-84). Barcelona: OmniaScience. Disponible en http:// dx.doi.org/10.3926/oms.03

Barron, P. y Baum, T. (2007). El alojamiento. En Ch. Cooper, J. Fletcher, A. Fyall, D. Gilbert y S. Wanhill, El turismo, teoría y práctica (pp. 459-498). Madrid: Síntesis.

Belausteguigoitia, I. (2012). Empresas familiares, dinámicas, equilibrio y consolidación. México: McGraw-Hill.

Borman, F. (2015). Assessing implementation of Knowledge Management Systems in hoteIs: The case of Ho, Ghana. African Journal of Hospitality, Tourism and Leisure, 4(2), 1-11. Recuperado de http://www.ajhtl.com/uploads/7/1/6/3/7163688/article11vol4(2)june_2015.pdf 
Bueno, E., Salmador, M. P. y Merino, C. (2008). Génesis, concepto y desarrollo del capital intelectual en la economía del conocimiento: Una reflexión sobre el Modelo InteIlectus y sus aplicaciones. Estudios de Economía Aplicada, 26(2), 43-63. Recuperado de http:/ /www.redalyc.org/articulo.oa?id=30113187003

Charreaux, G. (2000). La theorie positive de l'agence: positionnement et apports. En Revue d'économie industrielle, 92(2e), 193-214. Recuperado de https://doi. org/10.3406/rei.2000.1046

Choo, Ch. (1998). La organización inteligente. El empleo de la información para dar significado, crear conocimiento y tomar decisiones. México: Oxford University Press.

Contreras, F. y Tito, P. L. (2013). La gestión del conocimiento y las políticas públicas. Lima: Universidad María Auxiliadora. Recuperado de repositorio.uma.edu.pe/handle/ UMA/ 111

Corma, F. (2011). Innovación, innovadores y empresa innovadora. Madrid: Díaz de Santos.

Davenport, T. y Prusak, L. (1998). Working Knowledge: How Organizations Manage What They Know. Boston: Harvard Business School Press.

Dos Anjos, F. A., Flores, P., Gadotti, S. A. y Domareski, T. C. (2011). Contribuciones de la gestión del conocimiento a los servicios turísticos. Estudio en una agencia de viajes. Estudios y Perspectivas en Turismo, 20(3), 722-737. Recuperado de http:// www.redalyc.org/articulo.oa?id=180717583011

Farfán, D. Y. y Garzón, M. A. (2006). La gestión del conocimiento (Documento de investigación 29). Bogotá: Universidad del Rosario.

Fontalvo, T., Quejada, R. y Puello, J. (2011). La gestión del conocimiento y los procesos de mejoramiento. Dimensión Empresarial, 9(1), 80-87. Disponible en https://dialnet. unirioja.es/revista/16449/V/9

Gazzera, M. A. (2014). Los recursos humanos en la gerencia del conocimiento. Sector Hotelero, Patagonia, Argentina. Revista Electrónica CECIET, VI, 78-98.

Hallin, C. A. y Marnburg, E. (2007). Knowledge management in the hospitality industry: A review of empirical research. Tourism Management, 1-15. doi:10.1016/j.tourman.2007.02.019

Herbert, J. (25 de enero de 2019). El camino hacia Mazatlán. ¿Cómo se ha transformado uno de los grandes puertos mexicanos? Gatopardo, 197. Recuperado de https:// gatopardo.com/no-197-diciembre-2018-enero-2019/julian-herbert/

Hernández, V. (2016). La gestión del conocimiento en las organizaciones. Buenos Aires: Alfaomega Grupo Editor.

Hjalager, A. M. (2010). A review of innovation research in tourism. Tourism Management, 31, 1-12. Recuperado de https://www.academia.edu/5254430/Progress_in_Tourism_Management_A_review_of_innovation_research_in_tourism.

INEGI. (2009). Micro, pequeña, mediana y gran empresa. Estratificación de los establecimientos. Censos Económicos 2009. Instituto Nacional de Estadística y Geografía. Disponible en http://www.inegi.org.mx/est/contenidos/espanol/proyectos/censos/ ce2009/pdf/mono_micro_peque_mediana.pdf

INEGI. (2016). Anuario Estadístico y Geográfico de Sinaloa 2016. Instituto Nacional de Estadística y Geografía.

INEGI. (2017). Anuario Estadístico y Geográfico de Sinaloa 2017. Instituto Nacional de Estadística y Geografía. 
Jacob, M. y Aguiló, E. (2008). La innovación en el sector turístico: el caso de Baleares. Rotour/Revista de Ocio y Turismo, 1, 51-64.

KPMG México. (2013). Empresas familiares en México: El desafío de crecer, madurar y permanecer. Recuperado de https://assets.kpmg/content/dam/kpmg/mx/ pdf / 2016/12/Empresas\%20Familiares\%20en\%20M\%C3\%A9xico\%20el\%20desaf\%C3\%ADo\%20de\%20crecer\%20madurar\%20y\%20permanecer.pdf

Leach, P. (1999). La empresa familiar. Buenos Aires: Ediciones Garnica.

Lorenzo, J. D. y Núñez-Cacho, P. (2012). Inercia e innovación en la empresa familiar: una primera aproximación. Revista de Empresa Familiar, 2(2), 23-40. Recuperado de http://dx.doi.org/10.24310/ejfbejfb.v2i2.4027

Martínez, J. (2010). Empresas familiares, reto al destino. Buenos Aires: Ediciones Garnica.

Mathison, L., Gándara, J., Primera, C. y García, L. (2007). Innovación: Factor clave para lograr ventajas competitivas. Revista NEGOTIUM/Ciencias Gerenciales, 3(7), 46-83. Recuperado de http://www.redalyc.org/articulo.oa?id=78230705

Medina, D., Medina, A. y Nogueira, D. (2017). Procesos y factores claves en la gestión del conocimiento. Universidad y Sociedad, 9(2), 16-23. Recuperado de http://rus.ucf. edu.cu/index.php/rus

Millán, C., Gómez, M. del R. y Vargas, E. (2017). Gestión del capital intelectual (cI) dinámico en la hotelería, una reflexión teórica. Teoría y Praxis, 22, 85-112. Recuperado de http://www.redalyc.org/articulo.oa?id=456152576005

Nagles, G. (2007). La gestión del conocimiento como fuente de innovación. Revista Escuela de Administración de Negocios, 61, 77-87. Recuperado de http://www.redalyc. org/articulo.oa?id=20611495008

OCDE. (2006). Manual de Oslo. Madrid: Grupo Tragsa.

Ochoa, M. L., Prieto, M. G. y Santidrián, A. (2012). Una revisión de las principales teorías aplicables al capital intelectual. Revista Nacional de Administración, 3(2), 3548. Recuperado de http://investiga.uned.ac.cr/revistas/index.php/rna/article/ view/486/389

Ozigbo, N. y Taiwo, E. (2014). The dynamics of knowledge management practices for sustainable adoption in the nigerian hospitality industry. International Journal of Advanced Research in Statistics, Management and Finance, 2(1), 77-89. Recuperado de http://www.internationalpolicybrief.org/images/journals/Stat2.1/Stat7.pdf

Peters, M. y Buhalis, D. (2004). Family hotel Businesses: Strategic planning and the need for education and training. Education+Training, 46(8/9), 406-415. doi: $10.1108 / 00400910410569524$

Rodríguez, D. (2006). Modelos para la creación y gestión del conocimiento: una aproximación teórica. Educar, 37, 25-39. Recuperado de https://ddd.uab.cat/pub/educar/0211819Xn37/0211819Xn37p25.pdf

Rodríguez, P., Pico, B. y Méndez, F. J. (2013). Capacidad innovadora en la empresa familiar como área de oportunidad hacia el desarrollo de México. Economía, Sociedad y Territorio, XIII(43), 779-794. Recuperado de http://www.redalyc.org/articulo. oa?id=11127581007

San Martín, J. M. y Durán, J. (2017). Radiografía de la empresa familiar en México. Puebla: Fundación de la Universidad de las Américas. Recuperado de https:/ /www.udlap. $\mathrm{mx} /$ empresasfamiliares/assets/files/radiografiaEmpresaFamMex.pdf 


\section{Conocimiento para la innovación en la empresa familiar hotelera}

Caso: destino turístico Mazatlán

Sequeira, B. y Marques, J. F. (2011). Knowledge management in tourism organisations: Proposal for an analytical model. Discussion Papers-Spatial and Organizational Dynamics, 7. Recuperado de http://sapientia.ualg.pt/handle/10400.1/4580

Sirmon, D. y Hitt, M. (2003). Managing resources: Linking unique resources, management, and wealth creation in family firms. Entrepreneurship, Theory and Practice, 27(4), 339-358. doi: 10.1111/1540-8520.t01-1-00013

Steeger, J. y Hoffmann, M. (2015). Innovation and Family Firms: Departing From R\&D Mediations (WiSo-HH Working Paper Series, Working Paper 13). Universidad de Hamburgo. Recuperado de https://www.wiso.uni-hamburg.de/forschung/archiv/workingpaper/wpneuesdesign/wp27 


\title{
Percepción del turismo como fUente de bienestar en COMUnidades RURALes de Colima
}

\author{
Carlos Amaya Molinar \\ Irma Magaña Carrillo \\ ILEANA OCHOA LLAMAS \\ Yadira Guerra Montes \\ Facultad de Turismo, Universidad de Colima
}

\begin{abstract}
El turismo basado en la comunidad (TBC) busca el empoderamiento de la población para superar la pobreza y mejorar su calidad de vida, así como lograr beneficios socioculturales y medioambientales. El objetivo del estudio fue explorar la influencia de unidades de negocios turísticos rurales en la superación de la pobreza y en el bienestar de la población, para lo cual se realizó una investigación descriptiva en comunidades rurales de Colima, con técnicas de investigación cualitativas y cuantitativas. Los hallazgos presentados son preliminares y no respaldan los planteamientos del TBC, aunque sí una percepción de la población en torno al turismo como fuente de bienestar.
\end{abstract}

Palabras clave: Turismo, comunidad, pobreza, sostenibilidad, bienestar.

\section{Perception of tourism as a source of Well-being in RURAL COMMUNities OF Colima}

Community-based tourism seeks the population's empowerment so they can overcome poverty, improve their quality of life, and obtain socio-cultural and environmental benefits. The aim of this study was to explore the influence of rural tourist business units in overcoming poverty and improving the well-being of the population. To accomplish this, a descriptive research was conducted in rural communities of Colima using qualitative and quantitative research techniques. The results presented here are preliminary and do not support the approaches of community-based tourism, although there is a perception of tourism as a source of well-being for the population.

Key words: Tourism, community, poverty, sustainability, welfare.

Fecha de recepción: 18 de enero de 2019. Fecha de aceptación: 29 de marzo de 2019

CÓMO CITAR: Amaya, C., Magaña, l., Ochoa, I. y Guerra, Y. (2019). Percepción del turismo como fuente de bienestar en comunidades rurales de Colima. Dimensiones Turísticas, 3(4), 63-86. https://doi.org/10.47557/TKQS1346 
I soporte del trabajo teórico se apoya básicamente en dos campos temáticos que se han desarrollado en el pasado reciente en relación con el estudio de la actividad turística: el turismo basado en la comunidad y el turismo y la superación de la pobreza. La literatura académica atribuye una gran cantidad de virtudes económicas, sociales y medioambientales a la modalidad de operación turística denominada turismo basado en la comunidad ( $\mathrm{TBC}$ ). En el pasado reciente se ha producido una gran cantidad de trabajos académicos en este campo, entre los que destacan los de Asker, Boronyak, Carrard y Paddon (2010), Fernández (2011), Goodwin y Santilli (2009), Hiwasaki (2006), Silva y Wimalaratana (2013), y Tasci, Semrad y Yilmaz (2013), entre otros.

En el ámbito institucional, han surgido iniciativas por parte de organismos internacionales como el Banco Mundial y la Organización Mundial del Turismo para impulsar el turismo como una herramienta con la cual superar la pobreza, respaldados por un conjunto de trabajos académicos de autores como Croes y Rivera (2015), Donaldson (2007), y Jamieson, Goodwin y Edmunds (2004); el Gobierno de la República (2013) reconoce este potencial del turismo para sacar a la población de la pobreza en su Plan Nacional de Desarrollo, mientras que el estudio bibliométrico de Gutiérrez-Pérez, Medina-Muñoz y Medina-Muñoz (2014) documenta su relevancia académica actual.

En el trabajo de campo sobre твс se examinan cuestiones como la sostenibilidad, en sus vertientes económica, social y ambiental, así como algunos de los factores de éxito y beneficios que se le atribuyen. En el tema del turismo y superación de la pobreza, básicamente se explora la percepción del turismo como fuente de bienestar en las comunidades rurales con unidades de negocios turísticos investigadas.

Además de la revisión de la literatura académica sobre esos temas, se realizó trabajo de campo en seis comunidades rurales, obteniendo 908 cuestionarios de la población para conocer su percepción del turismo como fuente de bienestar; por otra parte, se efectuaron entrevistas a líderes de las unidades de negocios y a más de 40 trabajadores para explorar asuntos relacionados con la gestión de los negocios turísticos. De la misma manera, se hicieron observaciones de la operación turística, concentrándose en temas vinculados con el aspecto de la unidad de negocios, la sustentabilidad de la operación y la afluencia de visitantes.

Al inicio, la investigación se apoyó principalmente en el campo teórico del TBC para aproximarse al estudio de las unidades de negocios incluidas en la muestra; sin embargo, los primeros resultados llevaron a buscar otro tipo de soportes académicos que permitieran comprender los fenómenos observados en los diversos objetos de estudio abordados. A pesar de la proximidad geográfica, entre los principales resultados arrojados por el trabajo de campo se encuentran el carácter único y original de cada una de las unidades de negocios estudiadas, con sus formas de organización, sus problemas específicos y sus resultados. Algunas unidades de negocios presentan situaciones de estancamiento permanente, una más prácticamente desapareció por problemas organizacionales, otra manifiesta problemas de sustentabilidad ambiental y solo un par destaca por sus logros económicos positivos y los empleos que genera.

Es oportuno señalar que en este documento se ofrecen resultados preliminares, con una visión panorámica. La información recabada se encuentra aún en proceso de análisis y 
posteriormente se publicarán resultados en profundidad por cada unidad de negocios; de igual modo, los avances alcanzados en los reportes exigen regresar a recopilar información complementaria.

\section{Antecedentes}

En este apartado se presenta información sobre los campos de estudio básicos que fundamentan la investigación. En primer lugar se expone información acerca del modelo teórico denominado turismo basado en la comunidad ( $\mathrm{TBC}$ ), en un momento previo a la exposición de los planteamientos sobre el turismo como herramienta para la superación de la pobreza y la generación de bienestar entre grupos de población excluidos de los beneficios económicos. Los temas se presentan en ese orden asumiendo, en el plano de la teoría, que el TBC funciona como un instrumento para superar la pobreza en la muestra estudiada.

\subsection{El turismo basado en la comunidad en la literatura académica}

En las últimas décadas se han realizado en diversos países del mundo numerosos trabajos sobre el TBC, los cuales han analizado estudios de casos, al igual que desarrollos de modelos teóricos y conceptuales. En los trabajos han participado tanto académicos como organismos internacionales y organizaciones no gubernamentales. Una definición típica del TBC incluye ambientes culturales no occidentales, donde aspectos como el estilo de vida, el folclore, la cultura, la vestimenta, la comida, la bebida y los ambientes naturales forman parte de los atractivos turísticos de las unidades de negocios. Con frecuencia, las comunidades se ubican en zonas rurales alejadas de los núcleos urbanos y, comúnmente, marginadas (Tasci, Semrad y Yilmaz, 2013).

Entre los atributos del TBC se menciona la sostenibilidad, sugiriendo que las operaciones de atención a los visitantes deben realizarse atendiendo a criterios de protección del medio ambiente, a resultados financieros positivos con rentabilidad económica y a una apropiada distribución social de beneficios; esto es, se propone una sostenibilidad en sus vertientes ambiental, económica y social. Otra característica de esta modalidad turística se refiere a la participación directa de la comunidad en la gestión de las operaciones turísticas, involucrando a la mayor proporción posible de integrantes de la comunidad, si no es posible en la operación, sí en la distribución de beneficios.

Desde el punto de vista económico, se menciona que uno de los principales propósitos de la gestión turística comunitaria es contribuir con beneficios económicos y disminuir la pobreza de la población. En la vertiente sociocultural, un rasgo atribuido a este modelo de operación turística es la participación de los visitantes en las manifestaciones culturales, lúdicas y productivas de la comunidad; otras definiciones señalan como característica de esta modalidad la pernocta en hospedajes locales.

En un contexto más amplio, el TBC se inscribe en el campo de las empresas de base comunitaria, que busca movilizar a los miembros de una comunidad para identificar sus 
propios problemas y necesidades, tomar decisiones conjuntas y asumir responsabilidades (The World Bank, 2013). Más puntualmente, Fernández (2011) define a la empresa de base comunitaria como un emprendimiento social colectivo de un grupo de personas que comparte valores, identidad y capital social, procediendo a crear y gestionar una empresa con miras a producir un valor social que le permita obtener beneficios sociales, culturales y financieros.

Una cuestión referida con frecuencia en la literatura académica sobre las empresas de base comunitaria en general y sobre el TBC en particular es el empoderamiento de la colectividad, que lleva a sus integrantes a movilizarse para adquirir un papel más activo en la toma de decisiones, controlar las actividades que influyen en su vida y gestionar sus recursos. El propósito del empoderamiento es que la población de la comunidad supere su estado de subordinación y marginación socioeconómica (Goodwin y Santilli, 2009).

Como en cualquier destino turístico, el atractivo constituye el motivo fundamental que lleva a los visitantes a desplazarse para consumirlo. En el TBC pueden identificarse numerosas categorías de atractivos turísticos, entre los que se mencionan los naturales, culturales, paisajes, recorridos y actividades productivas. En general, los atractivos de las empresas de TBC suelen ser muy similares a los atractivos turísticos comunes; la diferencia radica en la forma de operar los servicios turísticos, misma situación que se presenta cuando se abordan temas de gestión de la organización, como la participación en la toma de decisiones, la mercadotecnia, la rendición de cuentas, etcétera.

En la literatura académica se han postulado algunos principios para la gestión de proyectos y unidades de negocios de TBC; algunos de ellos se señalan en la misma definición del término, como la participación y el control de las actividades turísticas por la comunidad, la planeación participativa y la equidad en la distribución de los beneficios. Otros lineamientos propuestos son la adaptación del sistema económico de la unidad de negocios turística a las características locales, la respuesta a los intereses y necesidades de la comunidad, la complementariedad de la operación turística con sus actividades tradicionales y, un tema trascendental, la implementación de un sistema de formación para el desarrollo de las competencias operativas necesarias para la apropiada gestión del negocio turístico (Asker, Boronyak, Carrard y Paddon, 2010).

La literatura académica atribuye al TBC un conjunto de beneficios económicos, socioculturales y ambientales que se presentan en mayor o menor grado en las localidades donde opera; en el cuadro 1 se enlistan algunos de estos beneficios coincidentes con los planteamientos sobre sustentabilidad. Entre ellos, algunos de los más tangibles son los económicos, ya que los habitantes de las comunidades pueden percibirlos directamente. Los beneficios socioculturales resultan menos tangibles, su maduración es paulatina y de largo plazo; entre estos se encuentran la mejora del capital social, el fortalecimiento de la identidad local, el desarrollo del capital humano, la mejora en la calidad de vida y el desarrollo comunitario. Los beneficios ambientales conferidos a esta modalidad turística resultan cruciales, frecuentemente el éxito de la empresa depende de la conservación de 
Cuadro 1. Algunos beneficios del turismo basado en la comunidad

\begin{tabular}{|c|c|c|}
\hline Económicos & SOCIOCULTURALES & AmBientales \\
\hline $\begin{array}{l}\text { Incremento de empleos e } \\
\text { ingresos }\end{array}$ & $\begin{array}{l}\text { Desarrollo de capital humano } \\
\text { mediante educación y } \\
\text { capacitación }\end{array}$ & $\begin{array}{l}\text { Uso sustentable y conservación } \\
\text { del capital natural de la } \\
\text { comunidad }\end{array}$ \\
\hline Superación de la pobreza & $\begin{array}{l}\text { Mejora del capital social y de } \\
\text { las relaciones con organismos } \\
\text { externos }\end{array}$ & $\begin{array}{l}\text { Diversificación del uso de } \\
\text { recursos }\end{array}$ \\
\hline Recuperación económica & $\begin{array}{l}\text { Preservación del patrimonio } \\
\text { cultural e histórico de la } \\
\text { comunidad }\end{array}$ & $\begin{array}{l}\text { Uso no consuntivo de los } \\
\text { recursos naturales }\end{array}$ \\
\hline Desarrollo de infraestructura & $\begin{array}{l}\text { Mejora de la calidad de vida } \\
\text { y de la infraestructura de la } \\
\text { comunidad }\end{array}$ & $\begin{array}{l}\text { Incremento de la conciencia } \\
\text { ambiental }\end{array}$ \\
\hline Diversificación económica & $\begin{array}{l}\text { Desarrollo comunitario, mejora } \\
\text { de la identidad comunitaria, } \\
\text { sensación de orgullo, cohesión } \\
\text { social y empoderamiento }\end{array}$ & $\begin{array}{l}\text { Mayor comprensión de la } \\
\text { relación entre el medio ambiente } \\
\text { y el desarrollo económico } \\
\text { sustentable }\end{array}$ \\
\hline
\end{tabular}

Fuente: Twining-Ward (2007).

los recursos naturales: un atractivo natural exitoso puede resultar víctima de su propio éxito, pues corre el riesgo de degradarse por sobreexplotación (Twining-Ward, 2007).

De la misma manera, la literatura académica postula un conjunto de principios para la organización y operación de las unidades de negocios de TBC, que pueden contribuir a su éxito comercial y socioeconómico (cuadro 2). Algunos de estos principios enunciados son muy similares a los beneficios y a las definiciones de la modalidad turística mencionados anteriormente; en este sentido, se enuncian la organización de la comunidad y su empoderamiento; la participación e involucramiento de los agentes interesados en la gestión, operación y toma de decisiones en la unidad de negocios; la participación y distribución equitativa de costos, inversiones, actividades y beneficios entre los integrantes de la comunidad (Asker et al., 2010). Un conjunto de autores menciona la sustentabilidad ambiental, social y cultural como principio organizacional del TBC (Goodwin y Santilli, 2009; Salazar, 2012; Kyrgyz Community Based Tourism Association, 2013).

Asker et al. (2010), Silva y Wimalaratana (2013), Salazar (2012) y el Banco Mundial (The World Bank, 2013) proponen integrar a las unidades de negocios de turismo comunitario en mecanismos de participación público privada (PPP) con instituciones gubernamentales de diversos niveles, organizaciones no gubernamentales y empresas. Estos mismos autores señalan uno de los principios esenciales de cualquier actividad de gestión: la transparencia y la rendición de cuentas en la administración de los recursos de la unidad de negocios frente a la comunidad.

En el ámbito específico de la gestión de negocios se subrayan como importantes principios de operación la rentabilidad y la viabilidad económica de los proyectos, aludiendo 
Cuadro 2. Algunos principios para el éxito del turismo basado en la comunidad mencionados en la literatura académica

\begin{tabular}{|c|c|c|}
\hline Proximidad al mercado turístico & Inclusión de stakeholders & $\begin{array}{l}\text { Gestión por habitantes de la } \\
\text { comunidad }\end{array}$ \\
\hline Ventaja competitiva & $\begin{array}{l}\text { Conservación del medio } \\
\text { ambiente }\end{array}$ & Conservación del capital social \\
\hline Motivación de la comunidad & Educación, capacitación & $\begin{array}{l}\text { Transparencia y rendición de } \\
\text { cuentas }\end{array}$ \\
\hline Calidad del producto & Viabilidad comercial & Orientación a la demanda \\
\hline Gestión financiera & $\begin{array}{l}\text { Distribución equitativa de } \\
\text { costos y beneficios }\end{array}$ & Existencia de infraestructura básica \\
\hline
\end{tabular}

Fuente: Elaboración propia.

a numerosos casos de proyectos de turismo comunitario que van a la quiebra y son abandonados una vez que se suspenden los apoyos externos o institucionales (Salazar, 2012; Kyrgyz Community Based Tourism Association, 2013; Silva y Wimalaratana, 2013; Goodwin y Santilli, 2009). En este contexto, Dixey (2005) es un autor que enfoca sus planteamientos en la gestión comercial de la empresa, mencionando como principios la calidad del producto, el aprovechamiento de ventajas competitivas, la administración financiera, la asociación con empresas turísticas y la proximidad a los mercados. El Banco Mundial (The World Bank, 2013) designa la orientación a la demanda como principio organizacional. Por su parte, el Thailand Community Based Tourism Institute (2013) y Goodwin y Santilli (2009) destacan como principio la formación de los miembros de la comunidad mediante acciones de educación y capacitación; en tanto, Asker et al. (2010), la disposición de una adecuada infraestructura de acceso y sólidos mecanismos de mercadotecnia.

La literatura académica también registra limitaciones del TBC. Goodwin y Santilli (2009) mencionan información sobre 200 unidades de negocios de TBC que muestran una tasa de ocupación de $5 \%$ para proveedores de hospedaje, señalando que el resultado más común para los proyectos de turismo en esta modalidad es que colapsen una vez que se agota el financiamiento, especialmente por dificultades de acceso al mercado y dirección.

Goodwin y Santilli (2009) y Tasci et al. (2013) enumeran un conjunto de estudios de casos de unidades de negocios de TBC en diversos países, la mayoría de ellos considerados economías emergentes o en vías de desarrollo. Su análisis permitió identificar factores de éxito, de fracaso o de ralentización; cada una de las unidades de negocios estudiadas presenta características únicas. El objetivo central perseguido en todos los casos es llevar a las unidades de negocios comunitarias desde su origen, apoyado por organizaciones externas, hasta la autosuficiencia, la autogestión y la sustentabilidad de la operación turística en sus vertientes económica, sociocultural y ambiental. El trabajo de estos autores 
ha hecho posible determinar las circunstancias que permiten a un proyecto de TBC salir adelante o malograrse.

En esta investigación, en el campo de estudios del TBC, se examinan aspectos relacionados con la forma de organización, empleos generados, sostenibilidad ambiental, problemática específica identificada y afluencia estimada de visitantes.

\subsection{Turismo y superación de la pobreza}

La información recabada mediante la revisión de la literatura académica sobre TBC sugiere que esta modalidad de operación turística resulta apropiada para contribuir a mejorar la calidad de vida e incrementar el ingreso y los niveles de bienestar entre la población de las comunidades que componen la muestra investigada.

El estudio bibliométrico realizado por Gutiérrez-Pérez et al. (2014) ilustra que los trabajos académicos sobre el turismo como herramienta para el alivio de la pobreza publicados en revistas indexadas de diferentes disciplinas han crecido en forma sostenida, pasando de un trabajo en 1999 a 20 en 2011; en ese periodo se identificó un total de 80 artículos publicados, derivados de estudios efectuados en 36 países de los distintos continentes del planeta, comprobando la relevancia que el tema ha adquirido en la comunidad científica. Los trabajos se han publicado en revistas académicas de muy variadas disciplinas, aunque temáticamente se concentran en las áreas de gestión y ciencias sociales. En cuanto a las tipologías de turismo analizadas, los autores señalan que los trabajos tienden a concentrarse en los temas de turismo en general, turismo de naturaleza y turismo comunitario. Las investigaciones revisadas comprenden aproximaciones teóricas y empíricas, y emplean tanto métodos cuantitativos como cualitativos de diversa índole.

La pobreza se ha definido en términos simplistas y complejos. El Banco Mundial (The World Bank, 2018) establece una línea fijada entre 1.90 dólares estadounidenses para definir la pobreza en términos de paridad de poder de compra del año 2011. Datos proporcionados por esta institución manifiestan que la pobreza extrema ha pasado de 35.9 a $11 \%$ entre 1990 y 2015, mostrando una tendencia decreciente, con un comportamiento desigual entre diversas regiones del planeta, pues zonas del África subsahariana y el sur de Asia están excluidas de tal tendencia; de la misma manera, persisten diferencias entre variables como los medios rural y urbano y el género. México aparece en estas estadísticas entre los 40 países con mayor proporción de población en condición de pobreza y mayor desigualdad en la distribución del ingreso.

El Consejo Nacional de Evaluación de la Política de Desarrollo Social (Coneval, 2018) propone un enfoque multidimensional para medir la pobreza, y determina que la población en situación de pobreza es aquella que carece de por lo menos uno de los derechos sociales y de los ingresos requeridos para adquirir los bienes y servicios con los cuales satisfacer sus necesidades, estableciendo la línea de pobreza por ingresos en el valor total de las canastas alimentaria y no alimentaria por persona al mes (Coneval, 2019). 
También el Coneval (2019) informa que desde el inicio de sus mediciones en 2008, hasta 2016, la población mexicana en situación de pobreza pasó de 44.4 a 43.6 \%, registrando una disminución de 0.08 \% en el periodo, prácticamente $0.01 \%$ anual, por lo que resulta difícil mencionar un incremento significativo de la proporción de la población sobre la línea de bienestar económico, con la disminución de las carencias sociales presentando resultados mixtos en las diversas regiones del país. En el caso de Colima, la población en situación de pobreza pasó de 27.4 a 33.6 \% mostrando una tendencia negativa superior a la media nacional.

Entre los grupos sociales, alrededor de $75 \%$ de la población indígena y 60 \% de la población rural presentan niveles de pobreza superiores a la media nacional, al igual que 50 \% de menores de 18 años y personas con algún tipo de discapacidad. Tres de cada cuatro mexicanos sufren por lo menos una carencia social, destacando la falta de acceso a la seguridad social. Chiapas, Guerrero, Chiapas y Veracruz exhiben la mayor proporción de población en situación de pobreza (Coneval, 2019). En este contexto de pobreza mayoritaria entre la población rural nacional, resulta comprensible que los habitantes de las comunidades busquen aprovechar cualquier oportunidad que se les presente de generar ingresos para sus familias, como es la actividad turística.

Durante la reunión Cumbre del Milenio 2000, la Organización de la Naciones Unidas identificó a la pobreza como uno de los mayores desafíos mundiales, y fijó a la erradicación de la pobreza extrema como uno de sus Objetivos de Desarrollo del Milenio. En 2002, la Organización Mundial del Turismo respondió anunciando la Iniciativa ST-EP (Sustainable Tourism-Eliminating Poverty) en la Cumbre Mundial sobre Desarrollo Sostenible de Johannesburgo. Esta iniciativa promueve el alivio de la pobreza a través del apoyo a proyectos de desarrollo turístico sostenible.

Desde fines del siglo xx, la Organización Mundial del Turismo ha propuesto utilizar el turismo como herramienta para superar la pobreza, destacando el programa ST-EP y un conjunto de manuales e investigaciones orientado a ese fin. Señala que en muchos países emergentes el turismo es la opción de desarrollo económico más viable y sostenible y una importante fuente de divisas -el ritmo de crecimiento anual de llegadas en destinos emergentes duplica el de las economías avanzadas-. Asimismo, propone que la disminución de la pobreza debe ser el objetivo central del desarrollo turístico, e identifica varias formas en que el turismo beneficia a la población: empleo directo e indirecto, venta de bienes y servicios, incentivos fiscales, donaciones, construcción de infraestructura y operación de empresas turísticas (World Tourism Organization, 2004 y 2010).

Investigadores de diversos países han abordado el tema desde la academia. Jamieson et al. (2004) destacan que el turismo puede generar impactos positivos o negativos en la población receptora, por lo que deben medirse sus efectos económicos, ambientales y sociales en comunidades rurales y urbanas. Goodwin (2006) indica que se conoce poco sobre el impacto del turismo en la superación de la pobreza: los resultados del turismo se expresan en términos macroeconómicos abstractos y la política turística tiende a orientarse a la captación de divisas. Este autor encontró impactos positivos significativos en casos 
de estudio de trabajadores en situación de pobreza en operaciones turísticas en Egipto, Tanzania y Gambia.

La generalidad de los trabajos consultados sobre el impacto del turismo en la superación de la pobreza le atribuye resultados positivos, aunque puntualiza que tales efectos pueden optimizarse mediante políticas específicas y que no siempre es sencillo cuantificarlos.

Blake, Saba, Sinclair y Kuhl (2008) estudian el impacto del turismo en la economía brasileña, encontrando que todos los grupos sociales de ese país se benefician, pero los pobres en menor medida. Donaldson (2007) y Croes (2014) analizan los efectos mixtos del turismo y los resultados diferenciados en la población en situación de pobreza en China y en América Latina. Hawkins y Mann (2007) cuestionan la decisión del Banco Mundial de abandonar el financiamiento a proyectos turísticos a mediados de la década de 1970, a la luz de los resultados obtenidos, señalando también la necesidad de presentar mayores evidencias de los impactos del turismo en la reducción de la pobreza. Los trabajos de Manyara y Jones (2007), Mitchell y Ashley (2009), Scheyvens y Russell (2012), Torres y Momsen (2004), y Zapata, Hall, Lindo y Vanderschaeghe (2011) coinciden en que el turismo contribuye a disminuir la pobreza, aunque tal contribución podría ser mayor operando con políticas y condiciones específicas.

El Plan Nacional de Desarrollo 2013-2018 de México (Gobierno de la República, 2013) considera al turismo como un sector estratégico con alta capacidad para generar empleo e incrementar los mercados para las pequeñas y medianas empresas y con capacidad para preservar la riqueza natural y cultural de la nación, agregando que 87 \% de la población en municipios turísticos en nuestro país tiene un nivel de marginación "muy bajo”, mientras que ese dato en los municipios no turísticos es de $9 \%$. En línea con los planteamientos de la Organización Mundial del Turismo, establece que todas las políticas de desarrollo del sector deben enfocarse a incrementar la contribución del turismo a la reducción de la pobreza y a la inclusión social.

En sus trabajos sobre el impacto socioeconómico del turismo en el bienestar de la población, Croes (2014) y Croes y Rivera (2015) apuntan que el turismo es un poderoso instrumento para superar la pobreza mediante mecanismos directos e indirectos. A la definición oficial de esta condición basada en una línea de ingreso que imposibilita el acceso a límites mínimos de consumo y al desarrollo de las capacidades, los autores agregan situaciones de disparidad, rechazo, fragilidad, aislamiento, carencias y penurias. Las investigaciones establecen la conveniencia de apoyar a los pobres de manera altruista, pues invertir en su alimentación, formación, servicios médicos e infraestructura impulsaría la productividad de la economía en general.

En el campo de estudios del turismo y superación de la pobreza se emplean los planteamientos de Croes (2014) y Croes y Rivera (2015) en las variables utilizadas para la medición de la percepción del turismo como fuente de bienestar y de satisfacción con la vida entre la población de las comunidades rurales. 


\section{Metodología}

El estado de Colima se ubica en el occidente de México, sobre la costa del Pacífico mexicano. Se caracteriza por su terreno accidentado y por presentar una acentuada pendiente desde la cumbre del Volcán de Fuego hasta la línea costera, con una altitud media sobre el nivel del mar de 570 metros. La temperatura promedio en los municipios de Colima y Comala es de alrededor de $25^{\circ} \mathrm{C}$, con lluvias concentradas entre junio y octubre. Su vegetación es muy diversa, compuesta por selvas bajas, bosques de pino, encino y vegetación de montaña, con alguna presencia de matorrales y pastizales (Instituto Nacional de Estadística y Geografía, 2018). La riqueza de la biodiversidad de su ecosistema, los diversos cuerpos de agua existentes y los rasgos fisiográficos de la región favorecen la práctica de actividades de recreación en contacto con la naturaleza.

Durante el desarrollo de la investigación se aplicaron diversas técnicas, cuantitativas y cualitativas. Se estudiaron seis unidades de negocios ubicadas en comunidades rurales de dos municipios de la zona norte del estado de Colima: Colima y Comala; su operación gira mayormente alrededor de cuerpos de agua y manantiales, aunque algunas son establecimientos de alimentos y bebidas. La investigación de campo consistió en la aplicación de encuestas, entrevistas y guías de observación; estuvo a cargo de profesores y estudiantes de licenciatura y posgrado de la Facultad de Turismo de la Universidad de Colima. El trabajo de campo se realizó entre agosto de 2016 y junio de 2017.

En el campo de las técnicas cuantitativas se aplicó una encuesta que logró reunir 908 cuestionarios, empleando un procedimiento de muestreo de conveniencia; en términos de proporciones, el número de cuestionarios cubre $11 \%$ del total de la población de las comunidades estudiadas, aunque esta proporción no se distribuye equitativamente entre todas ellas, pues en Suchitlán solo se cubrió 8 \% de la población, mientras que en Acatitán, 23 \%. El cuestionario se adaptó del trabajo de Croes y Rivera (2015), buscando detectar la percepción del impacto de la actividad turística en el bienestar de la población y la satisfacción con la vida.

Se aplicaron entrevistas al personal que presta sus servicios en las unidades de negocios examinadas, orientadas a extraer información sobre las características y la percepción de la calidad de los empleos generados por la actividad turística, con lo cual se obtuvo un total de 42 instrumentos; en la comunidad de Zacualpan no se efectuaron entrevistas porque su unidad de negocios no está operando. También se aplicaron entrevistas a los dirigentes de las unidades de negocios, con el propósito de conocer las prácticas de gestión de las unidades. Asimismo se realizó observación estructurada en comunidades y unidades de negocios.

Como ya se comentó, la presente investigación se encuentra actualmente en proceso y la gran cantidad de información recabada está siendo procesada por diversos métodos de análisis estadístico y cualitativo. El cuadro 3 muestra la cantidad de técnicas e instrumentos de investigación aplicados en las comunidades estudiadas. 
Cuadro 3. Métodos y técnicas utilizados en el estudio

\begin{tabular}{|c|c|c|c|c|c|c|}
\hline \multicolumn{7}{|c|}{ Avances en el proceso de investigación } \\
\hline $\begin{array}{l}\text { Unidad de } \\
\text { negocios }\end{array}$ & $\begin{array}{c}\text { Centro } \\
\text { Recreativo } \\
\text { La María }\end{array}$ & $\begin{array}{c}\text { Centro } \\
\text { Turístico } \\
\text { Carrizalillo }\end{array}$ & $\begin{array}{c}\text { Parador } \\
\text { "Gastronómico" }\end{array}$ & $\begin{array}{c}\text { Parador } \\
\text { "Gastronómico" }\end{array}$ & $\begin{array}{l}\text { Manantiales } \\
\text { de Zacualpan }\end{array}$ & El Cahuite \\
\hline Municipio & & & Comala & & & Colima \\
\hline Comunidad & La Becerrera & Suchitlán & $\begin{array}{l}\text { Cofradía de } \\
\text { Suchitlán }\end{array}$ & La Nogalera & Zacualpan & Acatitán \\
\hline $\begin{array}{l}\text { Población de la } \\
\text { comunidad }\end{array}$ & 274 & 4083 & 1601 & 354 & 1724 & 191 \\
\hline $\begin{array}{l}\text { Encuesta a } \\
\text { trabajadores }\end{array}$ & 7 & 4 & ND & 17 & ND & 14 \\
\hline Encuesta (908) & 24 & 326 & 163 & 64 & 288 & 43 \\
\hline \% Población & $9 \%$ & $8 \%$ & $10 \%$ & $18 \%$ & $17 \%$ & $23 \%$ \\
\hline $\begin{array}{l}\text { Entrevistas a } \\
\text { dirigentes }\end{array}$ & Sí & Sí & Sí & En proceso & Sí & Sí \\
\hline Observación & Sí & Sí & Sí & Sí & Sí & Sí \\
\hline
\end{tabular}

Fuente: Elaboración propia.

\section{Resultados}

Cinco de las comunidades investigadas se localizan en el municipio de Comala y una más en Colima, y se advierten importantes diferencias en su población; también puede percibirse que los empleos directos creados en las unidades de negocios son relativamente pocos, y Acatitán y La Nogalera generan una cantidad proporcionalmente mayor. El cuadro 4 exhibe los atractivos y servicios de las unidades de negocios estudiadas. Así, dos unidades de negocios se basan en lagunas, dos en servicios de alimentos y bebidas y dos más son balnearios alimentados por manantiales. Las unidades de negocios basadas en lagunas presentan una mayor cantidad de servicios y una mayor complejidad, seguidas por los balnearios y por los corredores gastronómicos, con una oferta simple de alimentos y bebidas.

La totalidad de las comunidades donde se ubican las unidades de negocios examinadas cuenta con infraestructura de servicios básicos, como carretera pavimentada, electricidad, agua potable, drenaje, cobertura de telefonía fija y celular y televisión abierta; aunque no existen instalaciones en todas las comunidades incluidas, la población tiene acceso a servicios educativos y de salud básicos. 
CuAdro 4. Atractivos y servicios de las unidades de negocios estudiadas

\begin{tabular}{|c|c|c|c|}
\hline $\begin{array}{l}\text { Unidad de } \\
\text { negocios }\end{array}$ & Atractivo & Servicios & Complementos \\
\hline $\begin{array}{l}\text { Centro Recreativo } \\
\text { La María }\end{array}$ & Laguna & $\begin{array}{l}\text { Hospedaje, alimentos y } \\
\text { bebidas, cobertizos, tienda }\end{array}$ & $\begin{array}{l}\text { Alquiler de lanchas, } \\
\text { pesca, albercas, canchas, } \\
\text { campamento }\end{array}$ \\
\hline $\begin{array}{l}\text { Centro Turístico } \\
\text { Carrizalillo }\end{array}$ & Laguna & $\begin{array}{l}\text { Hospedaje, alimentos y } \\
\text { bebidas, cobertizos }\end{array}$ & $\begin{array}{l}\text { Alquiler de lanchas, } \\
\text { bicicletas y caballos, } \\
\text { canchas, juegos infantiles, } \\
\text { gotcha }\end{array}$ \\
\hline $\begin{array}{l}\text { Parador } \\
\text { "Gastronómico" } \\
\text { Cofradía de } \\
\text { Suchitlán }\end{array}$ & Gastronomía & $\begin{array}{l}\text { Alimentos y bebidas: } 4 \\
\text { cocinas económicas, } 2 \\
\text { cafeterías, } 1 \text { merendero }\end{array}$ & \\
\hline $\begin{array}{l}\text { Parador } \\
\text { "Gastronómico" } \\
\text { La Nogalera }\end{array}$ & Gastronomía & Alimentos y bebidas & \\
\hline $\begin{array}{l}\text { Manantiales de } \\
\text { Zacualpan }\end{array}$ & Manantial & $\begin{array}{l}\text { Balneario natural, alimentos y } \\
\text { bebidas, cobertizos }\end{array}$ & \\
\hline El Cahuite & Manantial & $\begin{array}{l}\text { Albercas, toboganes, } \\
\text { cobertizos, tienda }\end{array}$ & Canchas, campamento \\
\hline
\end{tabular}

Fuente: Elaboración propia.

\subsection{Resultados por unidad de negocios}

El cuadro 5 es un resumen de los resultados generales preliminares del presente estudio, donde se concentra información sobre la importancia y el impacto percibido del turismo por las comunidades investigadas, la valoración de los resultados, los apoyos gubernamentales recibidos y la iniciativa para la creación de las unidades de negocios.

\subsection{Resultados por comunidad}

\subsubsection{Manantiales de Zacualpan}

El cese de operaciones del balneario Manantiales de Zacualpan representa el caso más extremo de las amenazas que enfrenta una unidad de negocios de твс. El balneario fue una víctima colateral de un intenso conflicto por recursos que ocurrió en la comunidad indígena de Zacualpan, Comala, originado en el extranjero y en las altas esferas del gobierno 
CuAdRo 5. Impactos y apoyos de las unidades de negocios estudiadas

\begin{tabular}{|c|c|c|c|c|c|c|}
\hline Municipio & & & COMALA & & & COLIMA \\
\hline $\begin{array}{l}\text { Unidad de } \\
\text { negocios }\end{array}$ & $\begin{array}{l}\text { Centro } \\
\text { Recreativo } \\
\text { La María }\end{array}$ & $\begin{array}{c}\text { Centro } \\
\text { Turístico } \\
\text { Carrizalillo }\end{array}$ & $\begin{array}{c}\text { Parador } \\
\text { “Gastronómico" }\end{array}$ & $\begin{array}{c}\text { Parador } \\
\text { “Gastronómico" }\end{array}$ & $\begin{array}{l}\text { Manantiales } \\
\text { de Zacualpan }\end{array}$ & El Cahuite \\
\hline Comunidad & La Becerrera & Suchitlán & $\begin{array}{l}\text { Cofradía de } \\
\text { Suchitlán }\end{array}$ & La Nogalera & Zacualpan & Acatitán \\
\hline Población & 274 & 4083 & 1601 & 354 & 1724 & 191 \\
\hline Trabajadores & 7 & 4 & ND & 17 & ND & 14 \\
\hline $\begin{array}{l}\text { Importancia } \\
\text { de la } \\
\text { actividad }\end{array}$ & 1 & 3 & 3 & 1 & ND & 2 \\
\hline Resultados & Moderados & Limitados & Limitados & Muy positivos & Eliminados & $\begin{array}{l}\text { Muy } \\
\text { positivos }\end{array}$ \\
\hline Iniciativa & Gubernamental & Gubernamental & Imitación & Mujeres & Comunitaria & Comunitaria \\
\hline $\begin{array}{l}\text { Apoyos } \\
\text { oficiales }\end{array}$ & $\begin{array}{l}\text { Construcción } \\
\text { de } \\
\text { instalaciones }\end{array}$ & $\begin{array}{l}\text { Construcción } \\
\text { de } \\
\text { instalaciones }\end{array}$ & Nulos & Reducidos & $\begin{array}{l}\text { Construcción } \\
\text { de } \\
\text { instalaciones }\end{array}$ & $\begin{array}{l}\text { Construcción } \\
\text { de } \\
\text { instalaciones }\end{array}$ \\
\hline
\end{tabular}

Fuente: Elaboración propia.

federal, y en el cual intervino una gran cantidad de actores internos y externos a la comunidad. El desenlace fue la suspensión de operaciones y la destrucción de las instalaciones del balneario. Básicamente, Manantiales de Zacualpan ilustra el caso de una unidad de negocios de TBC gestionada sin transparencia y sin rendición de cuentas, con los dirigentes actuando a espaldas de la población y buscando su beneficio particular.

Zacualpan es la única localidad del estado de Colima con población indígena y propiedad comunal de la tierra y los recursos. El balneario comunitario venía operando con cierta regularidad hasta noviembre de 2013, cuando una empresa minera recibió una concesión del gobierno federal para explotar una superficie de 200 hectáreas, casi la totalidad de la superficie de la comunidad; el objetivo de la empresa minera era extraer oro, plata y cobre del territorio comunitario. Dentro de la comunidad surgió una profunda división, y la mayoría rechazó la presencia de la mina, lo cual llevó a la destitución del presidente del Comisariado de Bienes Comunales de Zacualpan, quien era apoyado por un grupo minoritario.

En noviembre de 2013 se creó la organización denominada Consejo Indígena por la Defensa del Territorio de Zacualpan, con el propósito expreso de impedir la instalación de la empresa minera en la comunidad. El gobierno del estado de Colima, con la intervención de la Procuraduría Agraria, ha intentado convertir el régimen de propiedad comunal de la localidad en régimen ejidal, para que posteriormente pueda devenir propiedad privada y desparezca el régimen comunal (Red Mexicana de Afectados por la Minería, 2017). 
Además, la operación de la mina contaminaría el manantial de Zacualpan, del cual se abastecen las ciudades de la zona conurbada de la capital estatal, integrada por los municipios de Colima y Villa de Álvarez, con una población cercana a los 290000 habitantes.

En el conflicto han intervenido el gobierno federal, el gobierno de Colima, el ayuntamiento de Comala, el congreso del estado y el Tribunal Unitario Agrario local. Apoyando a los comuneros que rechazan la instalación de la mina, participaron la organización ecologista Biosiguana A. C., el Frente de Pueblos Indígenas de Puebla, Tlaxcala, Morelos y la Red Mexicana de Afectados por la Minería. El caso de Zacualpan se registra entre los 265 conflictos entre comunidades y empresas mineras documentados por el Observatorio de Conflictos Mineros de América Latina (2018). La división de la comunidad ha ocasionado episodios de violencia, y hasta este momento el enfrentamiento entre sus integrantes impide la reapertura del balneario, cuyas instalaciones fueron destruidas en actos de vandalismo promovidos por miembros del grupo minoritario de la comunidad aliado con la empresa minera.

\subsubsection{Centro Turístico Carrizalillos}

Fundado en 1973 por iniciativa gubernamental en el ejido Suchitlán, le fueron donadas todas las instalaciones de que dispone, a saber, habitaciones hoteleras, restaurante (en la actualidad concesionado), canchas, cobertizos, casetas y caminos. Hoy en día ofrece servicios complementarios como alquiler de lanchas, bicicletas y caballos. Su administración depende del ejido, y su operación se ha visto interrumpida ocasionalmente. Entre sus principales fortalezas se encuentran sus vistas a los volcanes y su ambiente apacible. Si bien cuenta con habitaciones hoteleras, su principal fuente de ingresos son grupos de paseantes que emplean los cobertizos para asar carne o hacer pícnics. Está posicionado como un lugar de paseo entre la población regional y los visitantes, aunque el volumen de su operación turística es exigua.

Genera cuatro empleos y difícilmente puede considerarse un éxito comercial o financiero. El impacto socioeconómico de sus actividades es percibido por la comunidad como muy limitado; sus instalaciones lucen abandonadas. El problema primordial que enfrenta la unidad de negocios es la amenaza de la desaparición de la laguna, su principal atractivo, la cual disminuyó de manera alarmante su nivel durante el estío del año 2017. Existen diversas explicaciones tentativas al riesgo de desaparición del cuerpo de agua; entre otras, que existen grietas en su fondo que filtran el agua; se han mencionado la deforestación, el efecto barrera de la carretera que la circunda, la escasez de lluvias y el desvío de sus fuentes para fines agrícolas. Finalmente, el deterioro de las condiciones de la laguna se atribuye a problemas de gestión y a sus limitados ingresos, que impiden brindarle el mantenimiento apropiado.

Desde el punto de vista del TBC, no se cumplen los planteamientos de la sustentabilidad ambiental, pues los encargados de la gestión de la unidad de negocios no muestran el interés ni la capacidad requerida para aprovechar, mantener y conservar sus atractivos y recursos turísticos. 


\subsection{3 "Paradores gastronómicos" de La Nogalera y Cofradía de Suchitlán}

Los paradores gastronómicos de La Nogalera y Cofradía de Suchitlán agrupan un conjunto de restaurantes, cafeterías y fondas que se han establecido a la orilla de la carretera Comala-San Antonio, sobre la zona federal, aprovechando el tránsito de viajeros, turistas y paseantes que se genera sobre la carretera federal 16 de Colima; en su mayoría, son establecimientos irregulares y espontáneos que toman la oportunidad económica ofrecida por el tránsito de pasajeros. Es un caso típico del efecto imitación, pues la actividad fue iniciada en la comunidad de La Nogalera por una señora procedente del Estado de México con experiencia en la operación de establecimientos de alimentos y bebidas, originando la atracción de comensales; las mujeres de la comunidad, al percatarse de la afluencia de clientela, decidieron abrir sus propios negocios. Con el paso del tiempo, la cantidad de estos creció, hasta integrar un "clúster" de fondas de comida típica que se ha popularizado entre visitantes y la población de los municipios aledaños. Las operadoras de los negocios han recibido algunos apoyos gubernamentales menores y concesiones provisionales restringidas para ejecutar sus actividades en la zona federal.

En rigor, estos conglomerados de establecimientos no pueden considerarse una unidad de negocios, como tampoco presentan una figura organizacional de TBC. De hecho, son un conjunto de establecimientos independientes y rústicos, desarrollados por las mujeres de la comunidad. El apelativo "parador gastronómico" que le ha sido asignado por las autoridades locales resulta claramente un eufemismo, pues los alimentos ofrecidos quedan en la categoría de comida casera o antojitos típicos, lo cual no afecta su éxito comercial. Sin embargo, las encuestas y entrevistas realizadas en la comunidad muestran que los establecimientos han tenido un importante impacto socioeconómico entre la población, en especial por ser una iniciativa de mujeres, que canalizan la totalidad de sus ingresos al hogar y a la familia.

El parador gastronómico de Cofradía de Suchitlán es un caso de efecto imitación de una imitación. Algunos emprendedores de la comunidad, al percibir el éxito comercial registrado por los negocios de La Nogalera, ubicándose sobre la misma vía y en la misma zona, decidieron organizarse y crear su propio corredor. Existen siete establecimientos de alimentos y bebidas, de los cuales cuatro son cocinas económicas, dos son cafeterías y uno es merendero. Al principio hubo una organización que se encargó de gestionar los permisos para situarse a la orilla de la carretera frente a la Secretaría de Comunicaciones y Transportes; por necesidades económicas, el líder de la incipiente organización emigró al vecino país del norte y esta se desintegró. No obstante, los establecimientos continúan operando, aunque los titulares de los permisos los transfirieron o subarrendaron. Sus características y su oferta de alimentos y bebidas son más heterogéneas que en La Nogalera y sus resultados económicos son mixtos: algunos logran mayores rendimientos que otros.

Por su falta de organización formal y su modalidad de gestión, los paradores gastronómicos de La Nogalera y Cofradía de Suchitlán no pueden considerarse unidades de negocios de TBC, a pesar de que en La Nogalera los empleos generados, el impacto socioeconómico en la comunidad y la percepción del turismo como fuente de bienestar resultan muy positivos. 


\subsubsection{Centro Ecoturístico La María}

Presenta muchas similitudes con Carrizalillo, aunque con mejores resultados. También se trata de un conjunto de cabañas construidas alrededor de una laguna; cuenta con albercas, restaurantes, cobertizos, alquiler de lanchas, canchas, espacio para acampar y pesca. El centro fue financiado y construido por el gobierno federal en la misma época en que se creo Carrizalillo; su gestión es ejidal y su operación se ha visto ocasionalmente interrumpida. El impacto de la actividad económica percibido en la comunidad es más palpable; su cuerpo de agua y sus instalaciones se encuentran en buen estado y la comunidad brinda gran importancia a la actividad turística; genera siete empleos. Sus efectos socioeconómicos pueden considerarse moderados.

\subsubsection{Centro Ecoturístico "El Cahuite"}

Ubicado en el municipio de Colima, este centro turístico es propiedad de ejidatarios, pero para su gestión se integraron en una Sociedad de Producción Rural. Inició operaciones en 2002; sus instalaciones han sido financiadas por diversos organismos gubernamentales, con una diferencia relevante: la iniciativa surgió de los propios ejidatarios. El atractivo principal del centro es un conjunto de albercas alimentadas con agua de manantial, que ha sido complementado con toboganes, canchas, cobertizos, tienda y restaurante; su mercado se integra por segmentos de clase media y popular, y registra una gran demanda. Genera 14 empleos e importantes ingresos, en comparación con el resto de las unidades de negocios estudiadas. Presenta un elevado nivel de organización y liderazgo competente; en mercadotecnia, cuenta con su propia página web y Facebook. Sus resultados socioeconómicos pueden considerarse muy positivos, sin embargo, existe cierto resentimiento de algunos integrantes de la comunidad que no participan en el negocio, básicamente porque decidieron no invertir al momento de comenzar el proyecto.

Puede decirse que, originalmente, el Centro Ecoturístico “El Cahuite” se concibió como un proyecto de TBC que, más tarde, a fin de incrementar su eficiencia y sus rendimientos, evolucionó hacia una forma de organización empresarial, aunque los beneficios de la empresa alcanzan a la mayoría de los ejidatarios y a la comunidad de Acatitán en general.

\subsection{Resultados generales de la encuesta a la población}

El cuestionario utilizado se adaptó del formato de Croes y Rivera (2015) e incluye dos variables: la primera mide la satisfacción con la vida y la segunda contempla la percepción del turismo como fuente de bienestar por la población de las comunidades estudiadas; los resultados de la primera variable fueron inconsistentes, por lo que no se incluyen en la presentación de resultados. La segunda variable se compone de 21 ítems formulados en la modalidad de escala de Likert de 5 puntos. Los resultados de los datos recabados mediante los 908 cuestionarios válidos obtenidos se procesaron con el software sPSs 22 , presentando una distribución normal y un alfa de Cronbach de 0.9 (figura 1). 


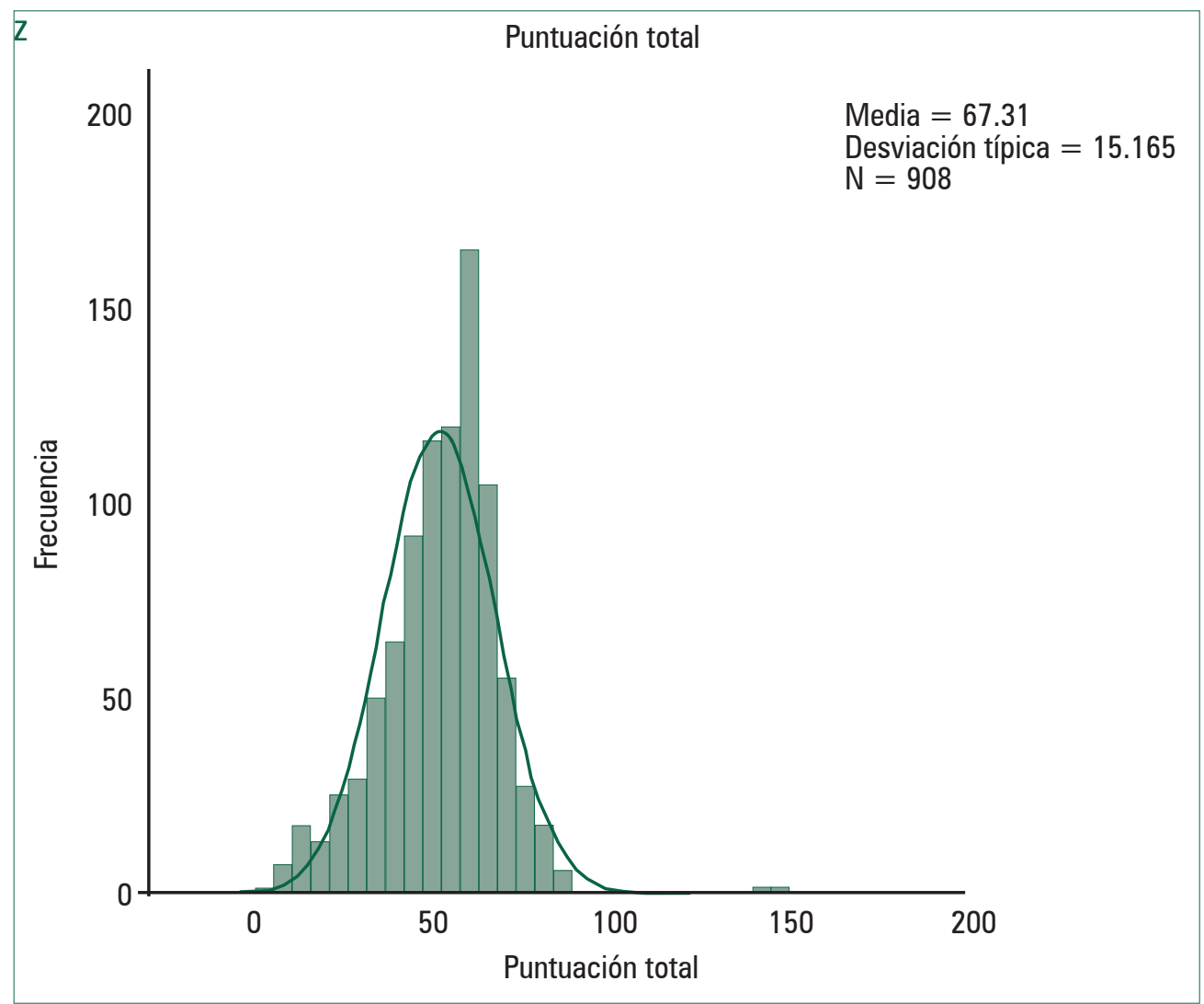

Fuente: Elaboración propia.

FIgURA 1. Distribución normal de los datos de la encuesta recabada en las comunidades estudiadas

La figura 2 muestra los resultados de la percepción general del turismo como fuente de bienestar en las comunidades examinadas, registrando un resultado promedio de 68.59 $\%$. Los resultados más bajos se obtienen en la comunidad de Zacualpan, donde los diversos conflictos llevaron a la desaparición de la unidad de negocios. Los resultados más positivos son para La Nogalera, donde las mujeres de la comunidad operan el "corredor gastronómico". Llama la atención que Acatitán aparece en tercer lugar, con la unidad de negocios más eficiente y productiva del conjunto, lo cual parece explicarse por la percepción de aquellos habitantes de la comunidad que no participan en el exitoso negocio turístico. Los resultados de Suchitlán y La Becerrera parecen derivar de los resultados económicos limitados registrados por las unidades de negocios de Carrizalillos y La María. 


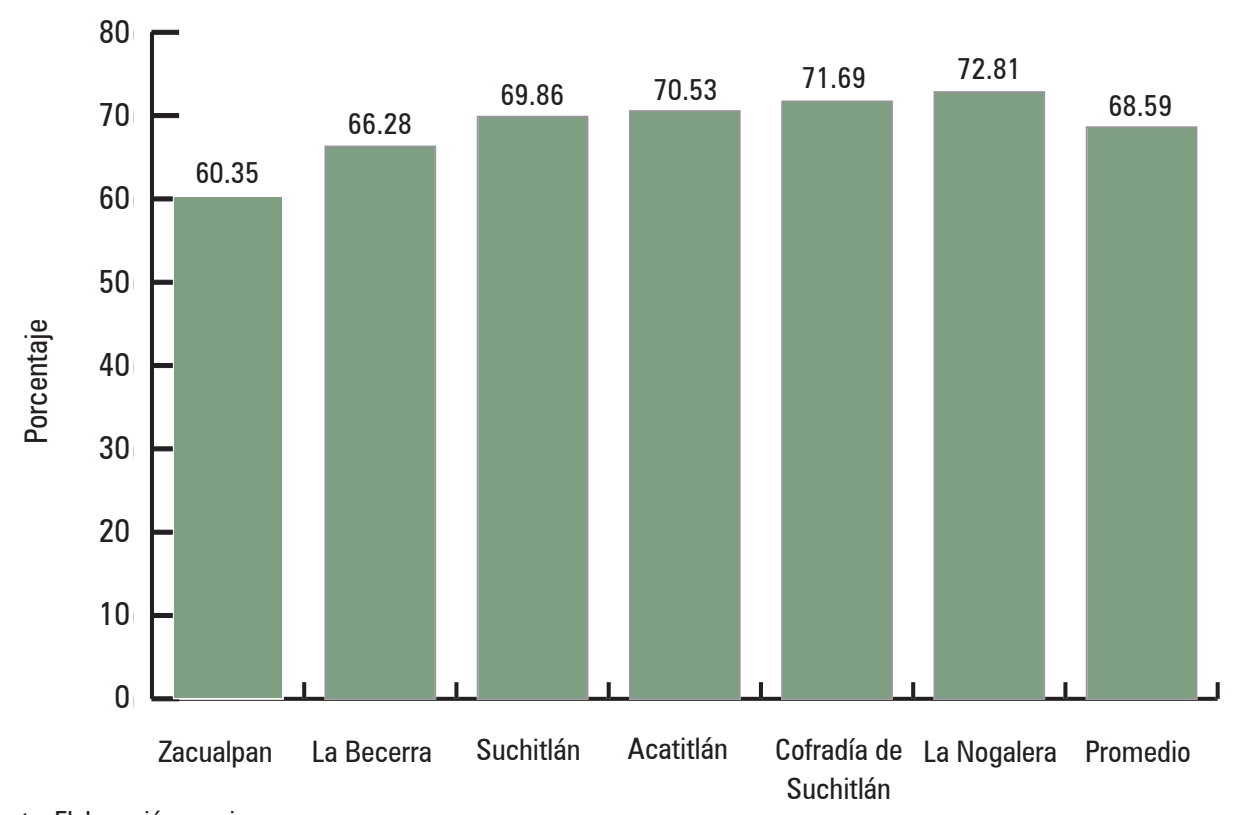

Fuente: Elaboración propia.

Figura 2. Percepción del turismo como fuente de bienestar en las comunidades rurales

\section{Discusión}

Con la información recabada y analizada hasta este momento en la investigación en curso, pueden extraerse algunas conclusiones preliminares. De entrada, más que operadores de TBC, parece tratarse de grupos de pobladores rurales dedicados a trabajos tradicionales en agricultura o ganadería en busca de ingresos complementarios, que de manera imprevista se ven convertidos en operadores turísticos, motivados por la oportunidad de generar recursos adicionales para sus familias. Uno de los factores que contribuyen a comprender la percepción del turismo como fuente de bienestar entre la población de las comunidades encuestadas es la denominación de Comala como pueblo mágico, que ha influido en la proliferación de empresas turísticas e impulsado la cultura turística; de hecho, las empresas más importantes del municipio son turísticas, dejando en segundo término a las actividades agropecuarias tradicionales.

Los resultados del trabajo sugieren que, más que referirse a TBC, es apropiado mencionar unidades de negocios turísticas ubicadas en el medio rural; en la muestra estudiada, dos de ellas fueron iniciativas gubernamentales completamente financiadas y equipadas por el gobierno federal: los centros turísticos de Carrizalillos y La Becerrera; el resto fueron iniciativas campesinas. Solo en dos de las unidades de negocios examinadas se puede hablar de un empoderamiento de la comunidad en los términos propuestos por Goodwin y Santilli (2009): Acatitán y La Nogalera; del resto, el parador gastronómico de Cofradía de 
Suchitlán y los centros turísticos de Carrizalillos y La María puede decirse que subsisten. El balneario de Zacualpan se autodestruyó por conflictos internos derivados de la falta de transparencia y rendición de cuentas en la administración de sus recursos frente a la comunidad, resultando una lamentable ilustración del incumplimiento de esos principios, de la manera en que proponen Dixey (2005), Asker et al. (2010), Silva y Wimalaratana (2013), Salazar (2012) y el Banco Mundial (The World Bank, 2013).

Como beneficiarios principales de las unidades de negocios estudiadas se encuentran los dirigentes, los trabajadores y sus familias, con la población de las comunidades beneficiándose de forma secundaria e indirecta. Goodwin y Santilli (2009) señalan atinadamente que, en algunos casos, la población de las comunidades es demasiado grande para que los ingresos generados por sus unidades de negocios turísticas logren alcanzar a todos los habitantes, como sucede con Zacualpan y Suchitlán.

Los resultados preliminares de la investigación sugieren que mientras mayor es el número de empleos creados por la unidad de negocios, en relación con el tamaño de la población de la comunidad, mayor es la percepción del turismo como fuente de bienestar por los habitantes, como puede observarse en el cuadro 5, en función de la cantidad obtenida de entrevistas a trabajadores. Croes (2014) y Croes y Rivera (2015) mencionan la capacidad del turismo para superar la pobreza, que a su vez parece derivarse en gran medida de la capacidad de la unidad de negocios para generar empleos.

Entre los beneficios del TBC indicados por Twining-Ward (2007), presentados en el cuadro 1, prevalece el económico sobre el sociocultural y el ambiental; entre las comunidades y unidades de negocios estudiadas no se logró identificar la determinación o algún interés especial por la protección del medio ambiente y el fortalecimiento de la identidad sociocultural.

La demanda por los servicios también aparece como un factor de éxito relevante, del modo en que propone el Banco Mundial (The World Bank, 2013); en el caso del presente estudio, la demanda por las albercas de El Cahuite y por los antojitos tradicionales de La Nogalera presenta un importante contraste frente a los servicios de hospedaje existentes en La María y Carrizalillos. Esto parece indicar que ofrecer servicios más sencillos resulta más conveniente que presentar un abanico más amplio de opciones; Goodwin y Santilli (2009) ya han señalado que la oferta de servicios de hospedaje no ha tenido éxito en los proyectos de turismo de base comunitaria, a pesar de que Responsible Travel (2013) incluye en su definición de твс a la provisión de hospedaje.

Autores como Salazar (2012), Kyrgyz Community Based Tourism Association (2013), Silva y Wimalaratana (2013) y Goodwin y Santilli (2009) han apuntado como principios fundamentales de la operación del turismo comunitario la rentabilidad y la viabilidad económica de las unidades de negocios, señalando numerosos casos de proyectos de esta modalidad que cierran operaciones al suspenderse los apoyos institucionales.

En relación con los proyectos estudiados, se observa que la participación de organismos gubernamentales de diversos niveles en el fomento al TBC ha sido inconstante; han distribuido importantes cantidades de recursos entre algunas de las unidades de negocios investigadas para construcción, habilitación y capacitación, entre otros rubros, solo que 
los recursos y apoyos se han entregado de manera intermitente, no se observa un seguimiento permanente, un acompañamiento continuo a las unidades de negocios.

Desde el punto de vista de los beneficiarios, el aprovechamiento y la gestión de los apoyos gubernamentales obtenidos parecen derivar de la iniciativa de los operadores, aunque los resultados no son concluyentes. Al analizar las dos unidades de negocios más exitosas se advierte que una de ellas prácticamente carece de estructura organizacional y del uso de herramientas de gestión (La Nogalera), mientras que El Cahuite cuenta con una sólida estructura organizacional que aplica herramientas de gestión y algunas tecnologías contemporáneas.

Los casos de los desastres sociales y ambientales de Zacualpan y Carrizalillos demuestran la fragilidad de las organizaciones comunitarias; en el primer caso, las poderosas fuerzas económicas y políticas de los intereses mineros internacionales pusieron en crisis a la comunidad, generando divisiones internas y enconos que hasta el momento no se han resuelto, sin que las autoridades hayan intervenido para lograr la reconciliación de los habitantes. En el segundo caso, se percibe desinterés, negligencia o incapacidad de los operadores turísticos para proteger las instalaciones y su recurso clave, la laguna. Estas dos unidades ilustran negativamente la falta de organización y de rendición de cuentas, la escasa participación de la población de las comunidades en la toma de decisiones y la ausencia de sustentabilidad en la operación turística.

En cuanto a los beneficios del TBC propuestos por Twining-Ward (2007), el desarrollo de infraestructura en algunas de las unidades de negocios estudiadas, como Carrizalillos y La María, no se ha visto reflejado en el incremento de empleos, ingresos y superación de la pobreza, aunque, en lo general, sí se ha generado cierta diversificación económica. En lo que se refiere al desarrollo sociocultural de la comunidad como producto de las actividades turísticas, parece presentarse solo en función de los resultados económicos, a la inversa de los planteamientos de ese autor. La sustentabilidad no se encuentra entre los asuntos prioritarios de las unidades de negocios examinadas, por lo menos no en los términos propuestos por Goodwin y Santilli (2009), Salazar (2012) y Kyrgyz Community Based Tourism Association (2013).

Si bien es cierto que la totalidad de las unidades de negocios estudiadas en la muestra ha recibido educación y capacitación por parte de organismos gubernamentales e instituciones de educación superior, en los términos planteados por Asker et al. (2010) y Goodwin y Santilli (2009), su impacto resulta limitado, al ser cursos o eventos de capacitación aislados, realizados en forma dispersa. En lo relativo a la gestión comercial y empresarial de la empresa como propone Dixey (2005), su presencia en las unidades de negocios analizadas resulta muy incipiente, con excepción de El Cahuite. De hecho, la gestión de las unidades de negocios más antiguas, como Carrizalillos y La María, ha exhibido una operación intermitente, con interrupciones recurrentes y cambios frecuentes de administración. 


\section{Conclusiones}

Los resultados preliminares del trabajo sugieren que los resultados económicos de la operación turística en las unidades de negocios estudiadas prevalecen sobre aspectos como la protección del medio ambiente, la identidad sociocultural y la organización de base comunitaria. Los volúmenes de ventas, las dimensiones de la demanda, la cantidad de empleos generados y el monto de los ingresos obtenidos parecen inducir una percepción del turismo como fuente de bienestar y una herramienta para superar la pobreza por la población de las comunidades. Aparentemente, estos indicadores tienen un peso mayor que la capacidad de organización y de gestión de los operadores turísticos, pues son factores comunes en los dos extremos de las unidades de negocios: La Nogalera, con las señoras cocineras operando sin organización formal ni herramientas de gestión, frente a los empresarios rurales de El Cahuite, que exhiben una sólida organización, técnicas de gestión profesionales y el empleo incipiente de tecnologías de información y comunicación.

En términos generales, los resultados económicos y la distribución de sus beneficios se manifiestan como el factor prevaleciente sobre un conjunto de elementos propuestos en la literatura académica para la gestión del TBC y su sustentabilidad. Los planteamientos en torno a la participación de la comunidad en la toma de decisiones, la gestión participativa, la sustentabilidad, el empleo de herramientas contemporáneas de gestión, el desarrollo de la comunidad, la sustentabilidad de la operación turística y la conservación de la identidad y la cultura local se presentan como asignaturas pendientes en la muestra investigada.

Los resultados del trabajo también apuntan a la iniciativa de los interesados como un factor potencial de éxito de las unidades de negocios analizadas; esto es, existen indicios de que aquellas unidades de negocios surgidas por iniciativa de los habitantes de la comunidad producen resultados más positivos que cuando la iniciativa del proyecto ha sido del gobierno. Esto puede ilustrarse comparando los casos de centros turísticos estancados, como Carrizalillo y La María, con el dinamismo de La Nogalera y El Cahuite, que pueden considerarse las unidades de negocios estudiadas en la muestra con mejores resultados económicos en términos de clientela y volúmenes de ventas. La iniciativa de los interesados como factor de éxito de las unidades de negocios turísticas en el medio rural no se menciona en la literatura académica consultada.

En relación con el tema de la demanda de servicios turísticos, un factor que pudiera inhibir el desarrollo de las unidades de negocios examinadas es la reducida captación de turistas nacionales y extranjeros en el estado de Colima; a pesar de la considerable cantidad de recursos naturales y culturales que posee, se ubica en el lugar 29 de 32 entidades federativas en términos de captación de turistas, de los cuales más de 95 \% son nacionales (Secretaría de Turismo, 2018); de hecho, la mayoría de la clientela de las unidades de negocios estudiadas es regional.

Otro componente que se ha mencionado como limitante del desarrollo de las unidades de negocios revisadas es la falta de diversificación de su oferta turística y su carácter 
pasivo; básicamente se trata de lagunas, manantiales y paisaje, con restringida oferta de actividades lúdicas, deportivas o de entretenimiento. Si bien existen los recursos, llama la atención la escasez de oferta de recorridos de aventura o de naturaleza, al igual que la ausencia de oferta turística basada en folclore, arte y tradiciones, propuestos por Tasci et al. (2013) como atractivos en el turismo de base comunitaria.

Así, puede destacarse que la operación turística habitual en las comunidades rurales dista mucho de corresponder con los planteamientos y elaboraciones teóricas de los académicos sobre el TBC, aunque la población de las comunidades examinadas sí percibe a la actividad turística como fuente de bienestar. Una vez que se concluya con el levantamiento y el análisis de la información, se presentará el reporte completo del estudio, realizando análisis en profundidad por cada una de las comunidades.

\section{Fuentes consultadas}

Asker, S., Boronyak, L., Carrard, R. y Paddon, M. (2010). Effective Community Based Tourism: A Best Practice Manual. Sustainable Tourism Cooperative Research Centre. Recuperado de http://publications.apec.org/-/media/APEC/Publications/2010/6/ Effective-Community-Based-Tourism-A-Best-Practice-Manual-June-2010/210_ twg_CommunityBasedTourismWEB.pdf

Blake, A., Saba, J., Sinclair, M. y Kuhl, V. (2008). Tourism and poverty relief. Annals of Tourism Research, 30(1), 107-126. Recuperado de https://www.sciencedirect.com/ science/article/abs/pii/S0160738307000916.

Coneval. (2018). Anexo único de los "Lineamientos y criterios generales para la definición, identificación y medición de la pobreza”. Actualización 2018. Metodología para la medición multidimensional de la pobreza en México. Recuperado de https://www. coneval.org.mx/Medicion/MP/Paginas/Lineamientos_DOF.aspx

Coneval. (2019). Medición de la pobreza. Evolución de las líneas de pobreza por ingresos. Recuperado de https://www.coneval.org.mx/Medicion/MP/Paginas/Lineas-de-bienestar-y-canasta-basica.aspx

Croes, R. (2014). Tourism and poverty reduction in Latin America: Where does the region stand? Worldwide Hospitality and Tourism Themes, 6(3), 293-300.

Croes, R. y Rivera, M. (2015). Poverty Alleviation through Tourism Development: A Comprehensive and Integrated Approach. Boca Ratón: CRC Press.

Dixey, L. (2005). Inventory and Analysis of Community Based Tourism in Zambia. Recuperado de http://fsg.afre.msu.edu/zambia/resources/PROFIT\%20Community\%20 Tourism\%20Survey\%20-\%20Final\%20CBT\%20Report.pdf

Donaldson, J. (2007). Tourism, development and poverty reduction in Guizhou and Yunnan. China Quarterly, 190, 333-351.

Fernández, M. (2011). Turismo comunitario y empresas de base comunitaria turísticas: ¿estamos hablando de lo mismo? El Periplo Sustentable, 20, 31-74.

Gascón, J. (enero, 2011). La metodología "Pro-Poor Tourism": un análisis crítico. Opiniones en Desarrollo. Programa Turismo Responsable. Artículo 9. Recuperado de://www. alainet.org/images/turismo.pdf 
Gobierno de la República. (2013). Plan Nacional de Desarrollo. Recuperado de http://pnd. gob.mx/

Goodwin, H. (2006). Measuring and Reporting the Impact of Tourism in Poverty. Recuperado de http://www.icrtourism.org

Goodwin, H. y Santilli, R. (2009). Community-Based Tourism: A Success? Recuperado de http://www.haroldgoodwin.info/uploads/cbtasuccesspubpdf.pdf

Gutiérrez-Pérez, F. J., Medina-Muñoz, D. R. y Medina-Muñoz, R. D. (2014). Turismo y alivio de la pobreza: una revisión de la literatura académica. Tourism \& Management Studies, 10(2), 104-115.

Hiwasaki, L. (2006). Community-based tourism: A pathway to sustainability for Japan's protected areas. Society and Natural Resources, 19(8): 675-692. doi: $10.1080 / 08941920600801090$

Hawkins, D. y Mann, S. (2007). The World Bank's role in tourism development. Annals of Tourism Research, 34(2), 348-363.

Instituto Nacional de Estadística y Geografía. (2018). Información por entidad. Recuperado de http://www.inegi.org.mx/

Jamieson, W., Goodwin, H. y Edmunds, C. (2004). Contribution of Tourism to Poverty Alleviation. Pro-Poor Tourism and the Challenge of Measuring Impacts. Recuperado de www.haroldgoodwin.info

Kyrgyz Community Based Tourism Association. (2013). Kyrgyz Community Based Tourism Association. Recuperado de http://www.cbtkyrgyzstan.kg/index.php/en/o-nas/ chto-takoe-tos

Manyara, G. y Jones, E. (2007). Community-based tourism enterprises development in Kenya: An exploration of their potential as Avenues of Poverty Reduction. Journal of Sustainable Tourism, XV(6), 628-644.

Mitchell, J. y Ashley, C. (2009). Tourism and Poverty Reduction. Pathways to Prosperity. Londres: Routledge.

Observatorio de Conflictos Mineros de América Latina. (2018). Conflicto minero: Proyecto minero en Zacualpán: saqueo y contaminación de agua. Recuperado de https:// mapa.conflictosmineros.net/ocmal_db-v2/conflicto/view/906

Red Mexicana de Afectados por la Minería. (2017). Zacualpan y su lucha contra la minería. Recuperado de http://www.remamx.org/category/colima/

Responsible Travel. (2013). Responsible Travel. Recuperado de http://www.responsibletravel.com/copy/what-is-community-based-tourism

Salazar, N. (2012) Community-based cultural tourism: Issues, threats and opportunities. Journal of Sustainable Tourist, 20(1), 9-22.

Scheyvens, R. y Russell, M. (2012). Tourism, land tenure and poverty alleviation in Fiji. Tourism Geographies: An International Journal of Tourism Space, Place and Environment, 14(1), 1-25.

Secretaría de Turismo. (2018). DATATUR. Compendio Estadístico del Turismo en México 2017. Recuperado de https://www.datatur.sectur.gob.mx/SitePages/CompendioEstadistico.aspx

Silva, D. A. C. y Wimalaratana, W. (2013). Community Based Sustainable Tourism Development in Sri Lanka: Special Reference to Moneragala District. Recuperado de http:/ / www.haroldgoodwin.info/PPT/PPTMonaragala.pdf 
Tasci, A., Semrad, K. y Yilmaz, S. (2013). Community Based Tourism Finding the Equilibrium in the COMCEC Context Setting the Pathway for the Future. Ankara: COMCEC.

Thailand Community Based Tourism Institute. (2013). Thailand Community Based Tourism Institute. Recuperado de www.cbt-i.org

Torres, R. y Momsen, J. (2004). Challenges and potential for linking tourism and agriculture to achieve pro-poor tourism objectives. Progress in Development Studies, 4(4), 294-318.

Twining-Ward, L. (2007). A Toolkit for Monitoring and Managing Community-based Tourism. University of Hawaii, School of Travel Industry Management.

The World Bank. (2013). Regional Study on Community Based Tourism in the Caucasus. Recuperado de http://Inweb90.worldbank.org/eca/eca.nsf/d1e666886eb626e2852567d 100165168/780a475beed61c07852568fc005df707 / \$FILE/Regional\%20Studies\%20on\%20Community-Based\%20Tourism\%20in\%20the\%20Caucasus.pdf.

The World Bank. (2014). Policy Research Report 2014: A Measured Approach to Ending Poverty and Boosting Shared Prosperity: Concepts, Data, and the Twin Goals.

The World Bank. (2018). Poverty and Shared Prosperity 2018: Piecing Together the Poverty Puzzle. Washington, D. C.: Autor. Recuperado de http://www.worldbank.org/en/ research/publication/a-measured-approach-to-ending-poverty-and-boosting-shared-prosperity.

World Tourism Organization. (2004). Manual on Tourism and Poverty Alleviation - Practical Steps for Destinations. Madrid: Autor.

World Tourism Organization. (2010). Tourism and Poverty Alleviation. Recommendations for Action. Madrid: Autor.

Zapata, M., Hall, C., Lindo, P. y Vanderschaeghe, M. (2011). Can community-based tourism contribute to development and poverty alleviation? Lessons from Nicaragua. $\mathrm{Cu}$ rrent Issues in Tourism, 14(8), 725-749. 


\title{
GOBERNANZA Y GESTIÓN DEL TURISMO MÉDICO EN LA REGIÓN fronteriza de Ciudad Juárez-El Paso
}

\author{
María Teresa Martínez-Almanza \\ tmartine@uacj.mx \\ Santos Alonso Morales-Muñoz \\ samorale@uacj.mx \\ Carlos Jesús González-Macías \\ cgonzalez@uacj.mx \\ Universidad Autónoma de Ciudad Juárez
}

\begin{abstract}
El objetivo de este trabajo fue profundizar en el conocimiento de la gestión del turismo médico y su relación con elementos de buena gobernanza en la región fronteriza Ciudad Juárez-El Paso, destino de gran potencial en este segmento del turismo. Mediante 30 entrevistas en profundidad a informantes clave, analizadas temáticamente, los hallazgos enfatizaron la falta de planeación, organización e integración de stakeholders para el turismo médico, y de coordinación entre los tres niveles de gobierno. Las conclusiones destacan la participación de stakeholders clave y la identificación de vacíos de poder, estancamiento del sector turístico e incipientes componentes de gobernanza.
\end{abstract}

Palabras clave: Gobernanza, turismo médico, gestión, frontera, Ciudad Juárez-El Paso.

\section{Medical Tourism Governance and Management in the Border Region of Ciudad Juarez-El Paso}

The objetive of this paper is to approach the existing relationship between medical tourism management and elements of good governance in the border region of Ciudad Juárez-El Paso, a destination of great potential in this segment of tourism. The research is based on the thematic analysis of 30 in-depth interviews with key informants. The results emphasize the lack of planning, organization and integration of medical tourism stakeholders, as well as the lack of coordination between the three levels of government. The conclusions highlight the participation of key stakeholders and the identification of power gaps, tourism sector stagnation and emerging governance components.

Key words: Governance, medical tourism, management, border, Juarez-El Paso. 
I presente trabajo tiene como propósito profundizar en el conocimiento de la gestión del turismo médico y su relación con elementos de buena gobernanza, tomando como base para el análisis los criterios propuestos por el Programa de las Naciones Unidas para el Desarrollo (PNUD) publicados en 2009 en torno a este tema y el turismo. Estos principios están asociados con la sostenibilidad de un destino turístico y son: participación, imperio de la ley, transparencia, capacidad de respuesta, orientación al consenso, equidad, eficacia y eficiencia, rendición de cuentas y visión estratégica.

La gestión de destinos se centra en administrar y apoyar la integración de diferentes recursos, actividades y agentes involucrados a través de políticas y medidas apropiadas. Conlleva, por tanto, competencias tanto gubernamentales en materia de toma de decisiones como funcionales (planificación, organización y control de actividades empresariales), que normalmente deberían incumbir al sector público (Manente, 2008).

En lo relativo al concepto de gobernanza, no obstante que ha sido empleado de diversas maneras y adopte distintos significados, existe un acuerdo general de que se trata de una nueva forma de gobernar, más cooperativa, en la cual parece que se pierden los límites entre los sectores gubernamental, privado y social. Es esa nueva gobernanza, con mayor interacción, cooperación y coordinación entre gobierno, sociedad civil y sector privado, que además supone un cambio de rumbo, debido a que el Estado ha perdido el monopolio de los recursos económicos e institucionales (Natera, 2005).

Interesa conocer el concepto de turismo médico, para el cual aún no existe consenso de los estudiosos del tema, pero para este trabajo será el siguiente: viajes médicos, turismo de salud o asistencia sanitaria global. Términos inicialmente utilizados por agencias de viaje y los medios de comunicación para describir la creciente práctica de viajar a través de las fronteras internacionales con el propósito de obtener atención médica. En términos sencillos se refiere a las personas que van a diferentes países para conseguir atención de salud (Manhas y Ramjit, 2015).

Para la realización de este trabajo, se recurrió a la consulta de una amplia fuente de recursos bibliográficos; también se contó con el apoyo de 30 stakeholders del turismo médico que incluyen autoridades de gobierno federal, estatal y municipal, directivos de hospitales, médicos cirujanos, asociaciones profesionales, sector turismo y educación, de quienes se recogieron importantes contribuciones mediante entrevistas en profundidad.

El análisis del proceso de buena gobernanza (PNUD, 2009) que se utiliza para la gestión de un destino de turismo médico en una región fronteriza significa un aporte inicial y necesario para el estudio de este tipo de fenómenos complejos y de las relaciones que de ellos se derivan. De la revisión de la literatura es posible observar que existe una incipiente producción académica sobre el tema, la cual procede principalmente de países europeos (Barbini et al., 2011). Así pues, con esta investigación se pretende establecer un punto de partida para conocer los principales lineamientos en el nivel nacional e internacional, a fin de profundizar en el conocimiento de la gobernanza en el campo turístico médico.

El trabajo se divide en seis apartados. El primero resalta la importancia de los principios de una buena gobernanza para avanzar hacia un destino turístico médico sostenible; 
el segundo se refiere a la gestión del turismo médico y la participación de los stakeholders seleccionados; el tercero presenta los métodos utilizados en la investigación; el cuarto expone los resultados; el quinto aborda la discusión; y el último ofrece las conclusiones y recomendaciones.

\section{Principios de una buena gobernanza}

La palabra gobernanza "en su uso actual no es sinónimo de gobierno; contrariamente, implica un cambio en su significado al estar referido al nuevo proceso de gobierno $o$ al nuevo método con el que se gobierna a la sociedad" (Rhodes, 2005, p. 100). Por otra parte, Peters (2003) define a la gobernanza como la capacidad presente en el gobierno para conducir la economía y la sociedad y puede señalarse como el proceso de proporcionar dirección a la sociedad.

La gobernanza es un término más extenso y vasto que el de un mero gobierno, ya que incluye y reconoce una participación activa de stakeholders privados, existiendo y permitiendo una interdependencia entre organizaciones, así como interacciones continuas entre los miembros de redes autoorganizadas en aras de intercambiar recursos y negociar objetivos compartidos y en las que si bien el Estado ya no ocupa una posición privilegiada y soberana sí puede dirigir las redes indirecta y limitadamente (Rhodes, 2005).

Para el desarrollo de una propuesta preliminar de base para su conceptualización, la Organización Mundial del Turismo (2010) establece lo siguiente:

Entendemos por gobernanza turística el proceso de conducción de los destinos turísticos a través de los esfuerzos sinérgicos y coordinados de los gobiernos en sus diferentes niveles y atribuciones, de la sociedad civil que habita en las comunidades receptoras y del tejido empresarial relacionado con la operación del sistema turístico [pp. 31-32].

Un caso de éxito digno de ser mencionado es la experiencia de Tijuana, Baja California. Las principales acciones en el periodo inicial de la transición hacia la gobernanza en Tijuana se resumen en la promoción para atraer inversiones; mejorar la coordinación público-privada; el apoyo a las micro, pequeñas y medianas empresas (mipymes), y el desarrollo urbano (infraestructura). Como resultado de un adecuado ejercicio tanto de coordinación intergubernamental como público-privada, se logró el fortalecimiento de clústeres industriales, con la finalidad de incrementar la competitividad y la economía local (Rodríguez, 2016).

Por su parte, Flores y Gómez-Sánchez (2010), en relación con la importancia que debe atribuírsele a la gobernanza en materia de salud, enuncian lo siguiente:

el análisis de la gobernanza del sistema de salud, además de tomar en cuenta el rol de los actores tradicionales en la prestación de servicios médicos y en la conducción de las políticas de salud; se debe estudiar la influencia de los gobiernos locales, los grupos organizados de la sociedad civil -de base comunitaria, sindicatos, etc.-, las instancias académicas y los agentes económicos -la industria farmacéutica, de tecnología médica, etc. [p. 145]. 
En particular algunos países en desarrollo, entre los que se encuentra México, han identificado en el turismo médico un nicho de oportunidad para la generación de beneficios económicos, donde conllevará una gran importancia en la gobernanza como proceso de toma de decisiones que afectará de forma directa e indirecta a su sistema de salud en aras de proveer la mejor atención posible, mediante acciones regidas por los principios de equidad, igualdad, solidaridad y participación (Flores y Gómez-Sánchez, 2010).

Se considera importante indagar sobre las formas de interacción de los stakeholders turísticos participantes en relación con el desarrollo del turismo médico en una ciudad fronteriza, ya que "ningún stakeholder tiene un potencial de acción suficiente para dominar de forma unilateral” (Kooiman, 2005, p. 61). El término stakeholder incluye a todas aquellas personas o grupos de personas que tienen, o reclaman, propiedad, derechos o intereses en una organización y sus actividades, pasadas, presentes o futuras, quienes desarrollan similares intereses, reclamos o derechos (Clarkson, 1995). Kooiman (2005), al igual que

Cuadro 1. Principios de buena gobernanza según el PNUD (2009)

\begin{tabular}{|c|c|}
\hline $\begin{array}{l}\text { Principios de buena } \\
\text { gobernanza }\end{array}$ & Significado \\
\hline Participación & $\begin{array}{l}\text { Todos los hombres y las mujeres deben intervenir en la toma de decisiones, ya sea } \\
\text { directamente o por medio de legítimas instituciones intermedias que representan } \\
\text { sus intereses. Esta amplia participación se basa en la libertad de asociación y ex- } \\
\text { presión, así como las capacidades para participar de manera constructiva. }\end{array}$ \\
\hline Imperio de la ley & $\begin{array}{l}\text { Los marcos legales deben ser justos y aplicados de manera imparcial, en particular } \\
\text { las leyes sobre los derechos humanos. }\end{array}$ \\
\hline Transparencia & $\begin{array}{l}\text { La transparencia se basa en el libre flujo de información. Los procesos de las ins- } \\
\text { tituciones y la información son directamente accesibles a los interesados y se les } \\
\text { proporciona lo suficiente para comprender y vigilar. }\end{array}$ \\
\hline Capacidad de respuesta & Instituciones y procesos que tratan de servir a todos los interesados. \\
\hline Orientación al consenso & $\begin{array}{l}\text { El buen gobierno interviene para lograr llegar a un consenso amplio sobre lo que es } \\
\text { el mejor interés para el grupo y, cuando sea posible, sobre las políticas y procedi- } \\
\text { mientos. }\end{array}$ \\
\hline Equidad & $\begin{array}{l}\text { Todos los hombres y las mujeres tienen oportunidades de mejorar o mantener su } \\
\text { bienestar. }\end{array}$ \\
\hline Eficacia y eficiencia & $\begin{array}{l}\text { Los procesos y las instituciones han de producir resultados que satisfagan las ne- } \\
\text { cesidades, y al mismo tiempo, hagan el mejor uso de los recursos. }\end{array}$ \\
\hline Rendición de cuentas & $\begin{array}{l}\text { Quienes toman las decisiones en el gobierno, el sector privado y las } \\
\text { organizaciones de la sociedad civil, son responsables ante el público, así como } \\
\text { ante las instituciones interesadas. Esta responsabilidad varía en función de la or- } \\
\text { ganización y si la decisión es interna o externa a la organización. }\end{array}$ \\
\hline Visión estratégica & $\begin{array}{l}\text { Los líderes y el público tienen una perspectiva amplia y a largo plazo en } \\
\text { la buena gobernanza y en el desarrollo humano, junto con un sentido de lo que se } \\
\text { necesita para dicho desarrollo. Hay también una comprensión de las complejidades } \\
\text { históricas, culturales y sociales en que se basa esa perspectiva. }\end{array}$ \\
\hline
\end{tabular}


Mayntz (2001), otorga relevancia a las relaciones entre los diferentes tipos de stakeholders como portadores de propuestas y poder para generar cambios.

La gobernanza es entendida como una forma innovadora de gobierno, distinta al antiguo modelo jerárquico, cuya estructura está compuesta por diversos stakeholders y organizaciones involucrados y las interacciones que entre ellos se generan. Además, el concepto de gobernanza permite reflexionar sobre la participación local en las políticas públicas que conciernen al turismo, tornándose necesaria su incorporación a los estudios turísticos. Para este trabajo se utilizaron los principios de buena gobernanza propuestos por el PNUD en 2009, cuyo significado se presenta en el cuadro 1.

\section{Gestión del turismo médico y participación de los stakeholders}

Una buena gestión del destino de turismo médico es concebida como un conjunto de acciones que, administrando recursos de diversa naturaleza, persigue el desarrollo turístico de un espacio o lugar de consumo determinado. En los últimos años además se considera necesario que el proceso incorpore dos principios: la implicación de todos los stakeholders interesados y la sostenibilidad (Asociación Española de Expertos Científicos en Turismo, 2001). Cualquiera que sea la propuesta conceptual sobre la gestión de destinos resulta indiscutible que los actores públicos deberían estar jugando un papel importante en ella, aunque sobre esta cuestión la investigación es aún escasa (Velasco, 2007). Los organismos de planificación y gestión turísticas se han convertido en los responsables del liderazgo, la coordinación, la promoción, la creación de productos, el marketing y el desarrollo de tales destinos, así como de la información turística que se proporciona en ellos (Ejarque y Bernet, 2005).

El problema de carecer de una buena gestión del turismo médico en la región fronteriza de Ciudad Juárez-El Paso merece ser estudiado a profundidad debido al actual desconocimiento del verdadero impacto que la ausencia de los principios de buena gobernanza puede significar, ya que esto podría obstaculizar el desarrollo de un destino de turismo médico sostenible, el cual procura dirigirse a las necesidades conjuntas de todos los actores del destino turístico (la comunidad local, el entorno físico y cultural, los negocios turísticos y los propios turistas) (Rodríguez y Fraiz, 2010) en una aproximación en la que su objetivo es el disminuir todos aquellos posibles conflictos y fricciones que se pudiesen presentar debido a la continua, pero sobre todo compleja, interacción entre los actores involucrados (Bramwell y Lane, 1993).

Cabrero (2002) destaca cuatro tipos de estrategias innovadoras para la gestación de nuevos esquemas de gobernabilidad. Se trata de una dinámica que rompe claramente con las tradiciones políticas del país, debilitando los cacicazgos locales, fragmentando los núcleos de concentración del poder y abriendo nuevos espacios para la hechura de programas y políticas en conjunto con la ciudadanía, los cuales son: un nuevo tipo de liderazgo, más abierto y horizontal; implantar nuevos mecanismos de interacción permanente entre gobierno y ciudadanos; la aparición de nuevos esquemas de relaciones intergubernamentales y 
nuevos sistemas de gestión administrativa, con experiencias de modernización altamente exitosas, como el caso de Tijuana, Baja California.

El estudio de la gestión del turismo médico a partir de los principios de buena gobernanza: participación, imperio de la ley, transparencia, capacidad de respuesta, orientación al consenso, equidad, eficacia y eficiencia, rendición de cuentas y visión estratégica, toma relevancia debido a que los habitantes de la ciudad han experimentado una etapa de crisis económica, de inseguridad, violencia e insuficiencia de servicios desde 2007, de la cual aún no ha sido posible recuperarse. Ante la creciente demanda de atención en materia de salud por parte de algunos pacientes del vecino país, el turismo médico podría convertirse en una opción de desarrollo socioeconómico. No obstante, es necesario planificar el desarrollo proveniente de la prestación de servicios de salud para que realmente se convierta en una oportunidad de generar inversión, empleos y comercio, sin perjudicar la atención médica que se oferta a la población local (Martínez-Almanza, Guía y Serra, 2017).

Ciudad Juárez aparece en la lista de destinos de turismo médico en México que promueve el gobierno federal, amén de ser conocido como un centro que oferta servicios médicos de calidad a precios razonables (ProMéxico, 2013). A pesar de las limitadas acciones realizadas para fomentar el turismo médico y de la mala reputación de la ciudad debido a la etapa de inseguridad y violencia vivida en la última década, existe una creciente demanda de servicios de salud para procedimientos específicos, que van desde la cirugía bariátrica hasta los servicios dentales especializados, además de la consulta médica general y especializada en varios hospitales y clínicas de la ciudad (Martínez, Morales y Zizaldra, 2016). Desafortunadamente, Ciudad Juárez carece de una estructura o una planificación para el desarrollo del segmento del turismo médico, dejando de explotar al máximo una de sus principales ventajas: su ubicación geográfica, que implica costos más bajos de los tratamientos, servicios de atención sanitaria más expedita, sin listas de espera para los pacientes internacionales, generación de empleos y un mayor desarrollo socioeconómico para la ciudad fronteriza (Martínez-Almaza, Guía y Serra, 2014).

Ejarque (2005) afirma que en un sistema de destino difuso los productos y los atractivos turísticos no están integrados entre sí porque no hay coordinación ni colaboración entre los productores de los servicios. La consecuencia de ello es que el destino no puede tener una personalidad clara en el mercado. Existen muchos destinos de este tipo, que desarrollan una oferta que no está organizada de ningún modo en el nivel territorial.

Debido a que el fenómeno del turismo médico, en cuanto tal, ha sido estudiado mayormente en los países y destinos de salud más exitosos, como Tailandia y Malasia, a partir de la década de los setenta, en este trabajo se ejemplifica con los países que cuentan con mayor información sobre el tema de gestión y políticas públicas para el desarrollo del turismo médico. Por ejemplo, la participación integral del Estado en la industria del turismo médico en Singapur y Malasia debe entenderse en relación con sus estrategias de desarrollo económico y el carácter del Estado. Ambas naciones heredan las instituciones estatales burocráticas bien desarrolladas al pasar a ser políticamente independientes de Gran Bretaña. Los estados poscoloniales, para su desarrollo, adoptan modelos capitalistas 
Cuadro 2. Comparación de sistemas de salud en países seleccionados

\begin{tabular}{|c|c|c|c|c|}
\hline $\begin{array}{l}\text { Elemento para el } \\
\text { análisis/ países }\end{array}$ & Tailandia & Malasia & Singapur & México \\
\hline $\begin{array}{l}\text { Estrategia } \\
\text { nacional } \\
\text { (Planeación) }\end{array}$ & $\begin{array}{l}\text { Centro Regional de } \\
\text { Salud }\end{array}$ & $\begin{array}{l}\text { Estrategia industrial } \\
\text { para desarrollar el } \\
\text { turismo }\end{array}$ & $\begin{array}{l}\text { Estrategia de creci- } \\
\text { miento económico } \\
\text { para desarrollar } \\
\text { industrias biomédi- } \\
\text { cas. Apoyo a R\&D } \\
\text { biomédico }\end{array}$ & $\begin{array}{l}\text { Promoción inter- } \\
\text { nacional a través } \\
\text { de ProMéxico y } \\
\text { certificación de } \\
\text { hospitales }\end{array}$ \\
\hline $\begin{array}{l}\text { Estructura } \\
\text { organizacional } \\
\text { (Organización) }\end{array}$ & $\begin{array}{l}\text { Centros de exce- } \\
\text { lencia en algunos } \\
\text { hospitales privados } \\
\text { Bangkok }\end{array}$ & $\begin{array}{l}\text { Creciente sector } \\
\text { privado de salud } \\
\text { por el movimiento } \\
\text { de mano de obra } \\
\text { calificada nacional }\end{array}$ & $\begin{array}{l}\text { Equilibrada mezcla } \\
\text { público-privado, el } \\
\text { sector público cor- } \\
\text { porizado }\end{array}$ & $\begin{array}{l}\text { Sistema de salud } \\
\text { mixto }\end{array}$ \\
\hline $\begin{array}{l}\text { Interacción de } \\
\text { Stakeholders } \\
\text { (Dirección) }\end{array}$ & $\begin{array}{l}\text { Agencia de la Junta } \\
\text { de Inversiones. } \\
\text { Ministerios de } \\
\text { Comercio } \\
\text { Departamento de } \\
\text { Promoción de } \\
\text { Exportaciones }\end{array}$ & $\begin{array}{l}\text { Sociedad de Ca- } \\
\text { lidad de la Salud } \\
\text { de Malasia (MSOH) } \\
\text { Asociación de Hos- } \\
\text { pitales Privados de } \\
\text { Malasia } \\
\text { Asociación Médica } \\
\text { de Malasia }\end{array}$ & $\begin{array}{l}\text { Junta de Turismo } \\
\text { Ministro de Comer- } \\
\text { cio e Industria }\end{array}$ & $\begin{array}{l}\text { Impulso a la crea- } \\
\text { ción de clústeres } \\
\text { en los destinos } \\
\text { turísticos que cuen- } \\
\text { tan con recursos e } \\
\text { infraestructura para } \\
\text { el turismo médico }\end{array}$ \\
\hline $\begin{array}{l}\text { Impacto de las } \\
\text { Políticas } \\
\text { (Control) }\end{array}$ & $\begin{array}{l}\text { Problemas de cre- } \\
\text { ciente desigualdad } \\
\text { y división urba- } \\
\text { no-rural }\end{array}$ & $\begin{array}{l}\text { División público-pri- } \\
\text { vada; desigualdad } \\
\text { racial entre secto- } \\
\text { res público-privado }\end{array}$ & $\begin{array}{l}\text { Reducidos espacios } \\
\text { de diferencia en } \\
\text { ingresos entre los } \\
\text { sectores público y } \\
\text { privado }\end{array}$ & $\begin{array}{l}\text { Considerable au- } \\
\text { mento de la deman- } \\
\text { da de servicios de } \\
\text { salud privados }\end{array}$ \\
\hline
\end{tabular}

Fuente: Pocock y Phua (2011) adaptado para incluir México y elementos de gestión.

de libre mercado y priorizan el desarrollo económico en sus agendas. El cuadro 2 permite comparar los sistemas de salud, a través de las cuatro funciones de la gestión, en países seleccionados.

De acuerdo con Soto, Lutzow y González (2010), México cuenta con un sistema de salud mixto, ya que combina, en distinta proporción, cada una de las características de estos modelos. La descentralización ha sido una política clave para conciliar las exigencias de la liberalización de mercados con aquellas de la modernización del Estado en regímenes híbridos. Sin embargo, aún es notable la falta de coordinación de políticas entre los distintos niveles de gobierno ante un turismo de salud o un turismo médico que adquieren cada día una mayor relevancia (Haldenwang, 2005).

Los elementos de gestión en los tres países seleccionados en el cuadro 2 difieren en sus propósitos, prioridades y características distintivas de la política de cada uno. Pocock y Phua (2011) señalan que en Malasia, Singapur y Tailandia existe un conflicto entre los tres niveles que se basa en la definición de lo que es más importante desarrollar: la salud o la riqueza. Ya que en algunos países no se han desarrollado por completo los servicios públicos de 
salud, mientras que los privados sí lo han hecho. "Si bien el plan nacional de salud de Malasia no menciona el turismo médico como un objetivo estratégico, el Ministerio de Salud formó un Comité interministerial para la promoción del turismo médico y de salud (MNCPHT) en 2003" (Pocock y Phua, 2011, p. 5). La política del centro médico de Tailandia fue iniciada en 2003 por el gobierno y la Agencia de la Junta de Inversiones de Tailandia, en tanto que los ministerios de Comercio, el Departamento de Promoción de Exportaciones y el Ministerio de Salud, en colaboración con hospitales privados, ahora son los principales implementadores de la política (Pocock y Phua, 2011).

En cambio, en México todavía no hay una política definida con claridad para el desarrollo del turismo médico, solo acciones aisladas carentes de una planificación integral en todos los niveles. Esta situación parece existir particularmente en Ciudad Juárez, donde aún no se cubre la demanda de servicios de salud de la población local (A. Riosvelasco, comunicación personal, diciembre, 2017).

\section{Metodología}

El presente trabajo forma parte del proyecto de investigación "El turismo médico como estrategia de desarrollo para Ciudad Juárez, Chihuahua, México”, y busca obtener resultados de primera mano de los actores participantes en el desarrollo del turismo médico en esta ciudad fronteriza respecto a los elementos de gobernanza para un destino sostenible. La investigación tuvo como guía orientadora la siguiente pregunta: ¿Cómo se caracteriza la gestión del turismo médico en un destino de frontera y su relación con los principios de buena gobernanza?

El eje principal del trabajo ha sido el seguimiento de la evolución del proceso de gobernanza del destino médico fronterizo de Ciudad Juárez, Chihuahua, México; más concretamente, de las acciones realizadas por los actores gubernamentales, empresariales y los prestadores de servicios de salud, comercio y turismo que reciben visitantes de las ciudades vecinas en Estados Unidos.

El abordaje metodológico seleccionado fue exploratorio debido a que no hay muchos estudios que relacionen la gobernanza de un destino turístico médico con la frontera. Al ser un fenómeno novedoso dentro del ámbito de aplicación se requiere un marco que aporte flexibilidad para poder indagar acerca del tema. Siguiendo las ideas de Selltiz, Jahoda, Deutsch y Cook (1965) y Denzin y Lincoln (2005), este tipo de esquema proporciona tal herramienta que permite lograr un conocimiento más preciso del fenómeno a efectos de generar una base empírica.

La metodología utilizada se ubica dentro del enfoque cualitativo en tanto que busca comprender las acciones humanas y la realidad del fenómeno. El método básico elegido fue la teoría fundamentada (Charmaz, 2000; Glaser y Strauss, 1967). La selección del enfoque y de las técnicas empleadas derivó de la contextualización de la zona de estudio y de la definición de objetivos de investigación. Como podrá 
apreciarse, existen consideraciones relevantes derivadas del contexto y de las incipientes aproximaciones al estudio de la gobernanza del destino turístico fronterizo, que favorecieron la inclinación hacia un enfoque cualitativo, ya que coinciden con las ideas de Brewer y Hunter (1989), quienes mencionan la importancia que adquieren los estudios cualitativos ante la dificultad de identificar una población como objeto de estudio.

Se buscó que las personas que participaran en las entrevistas en profundidad tuvieran conocimientos y experiencia en relación con el tema de interés. Se utilizó una forma de muestreo por conveniencia, en el cual las decisiones relativas a la selección de estas personas incluyeron criterios como conocimientos especializados en el tema de investigación, la capacidad y la voluntad de los participantes que serían más propensos a aportar datos adecuados, tanto en términos de relevancia como de profundidad. Con base en el modelo de Caballero y Mugomba (2006) y Heung, Kucukusta, y Song (2010), quienes han estudiado a los stakeholders y la gestión del turismo médico, se eligieron las categorías de stakeholders mostradas en el cuadro 3.

Se ha tenido presente la aceptación de este tipo de métodos como los más convencionales y utilizados en la investigación empírica. Las entrevistas se efectuaron seleccionando a los participantes por un muestreo por conveniencia y con la técnica "bola de nieve" hasta lograr la saturación teórica, es decir, cuando los datos eran repetitivos y no había información nueva. Esto ocurrió en la entrevista número 30. Estas tuvieron una duración

Cuadro 3. Actores principales por grupo de categorías de Stakeholders

\begin{tabular}{|c|c|}
\hline Categorías de Stakeholders & Entrevistas realizadas \\
\hline Autoridades de gobierno federal & 2 \\
\hline Autoridades de gobierno estatal & 3 \\
\hline Autoridades de gobierno municipal & 5 \\
\hline Directivos de hospitales & 6 \\
\hline Médicos cirujanos especialistas & 2 \\
\hline Asociaciones profesionales & 4 \\
\hline Sector turismo & 6 \\
\hline Sector educación & 2 \\
\hline Total de entrevistas realizadas & 30 \\
\hline
\end{tabular}

Fuente: Construcción propia con base en trabajo empírico.

aproximada de 90 minutos y fueron procesadas con el software N-VIVO como apoyo para su codificación, creación de nodos y categorías de análisis para la construcción de teoría sustentando pasos y operaciones en el nivel del texto. Además, en el nivel conceptual, al definir relaciones entre códigos, categorías superiores, subcategorías y redes de categorías. 
Se tomó como base un estudio cualitativo de Casey, Crooks, Snyder y Turner (2013) sobre turismo médico. Se eligió la secuencia de pasos a seguir para el desarrollo del análisis temático de esta investigación. Esto debido a que se trata de un estudio sobre el turismo médico que también usa este tipo de análisis para la construcción de categorías; además, porque los autores mencionados han realizado valiosas aportaciones al estudio del turismo médico, utilizando el método cualitativo.

La secuencia de pasos para la realización de este trabajo fue la siguiente: todas las entrevistas fueron grabadas y transcritas, y se llevó a cabo su revisión en profundidad y notas; la identificación de unidades de análisis y extracción de significados; codificación; puesta en común con el grupo de investigadores participantes; identificación de tendencias y patrones relevantes; y, por último, la comparación con los conocimientos existentes en la literatura.

En el cuadro 4 se observan algunos de los tópicos cubiertos en las entrevistas mencionadas. Las preguntas fueron de elaboración propia con base en los principios de buena gobernanza del PNUD (2009).

Cuadro 4. Preguntas de entrevista seleccionadas

$$
\text { Pregunta Tema }
$$

1. ¿Cree usted que todos los participantes intervienen en la toma de decisiones, Participación ya sea directamente o por medio de legítimas instituciones intermedias que representan sus intereses?

2. ¿Considera usted que existen suficientes Instituciones, organismos y procesos Capacidad de respuesta que tratan de servir a todos los interesados en el desarrollo del Turismo Médico en la localidad? ¿Las que existen, tratan de servir a todos los interesados?

3. ¿Cuál es su opinión sobre la intervención del gobierno para lograr llegar a un consenso amplio sobre lo que es el mejor interés para el grupo y, cuando sea posible, sobre las políticas y procedimientos? ¿Qué ha hecho falta a este respecto?
4. ¿Considera usted que existen oportunidades de mejorar o mantener su bienestar, de manera equitativa para todas las personas que desean participar en el desarrollo del turismo médico en Ciudad Juárez?

5. ¿Cuál es su opinión sobre la obtención de resultados de los procesos y las instituciones que coordinan el turismo médico, en cuanto a la satisfacción de las necesidades de los participantes en el desarrollo del turismo médico? ¿Y en cuanto al uso de los recursos?

6. ildentifica usted la existencia de liderazgos y de actores clave que tienen un Visión estratégica sentido claro de lo que se necesita hacer para el desarrollo del turismo médico, en un marco del desarrollo humano?

7. ¿Cuál es su opinión respecto a las barreras que impiden el desarrollo del turismo Barreras para el desarrollo médico en La frontera Juárez-El Paso?

Fuente: Construcción propia con base en principios de buena gobernanza del PNUD (2009). 


\section{Resultados}

Se identificó una falta de efectividad en la gestión del turismo médico, la cual podría atribuirse a la ausencia de planificación del desarrollo de este segmento turístico en los tres niveles de gobierno. Uno de los pilares que sustentan el desarrollo de la industria del turismo médico es la normatividad y, hasta este momento, aún sigue en proceso la aprobación de la Ley de Turismo Médico propuesta por el Partido Acción Nacional (PAN) ante el Congreso. Al preguntar sobre las barreras que los actores reconocen para el desarrollo del turismo médico, las personas participantes referían una falta de planeación, integración de actores y coordinación.

El fenómeno del turismo médico es en esencia complejo. Desde la perspectiva de la oferta, intervienen varias dependencias de gobierno que pertenecen a distintas secretarías de Estado, lo que hace complicada la colaboración y la coordinación. Mientras que, del lado de la demanda, los pacientes enfrentan una realidad en la que habrán de tomar decisiones sobre la atención de su salud ante un contexto sociocultural diferente, el cual puede significar un reto para ellos. Los entrevistados aún no perciben el apoyo del gobierno federal para el desarrollo del turismo médico. A continuación, se presentan sus opiniones sobre la integración y coordinación entre los diferentes niveles de gobierno para el desarrollo del turismo médico en la frontera Juárez-El Paso:

Existe el problema del centralismo, no hay disposición del gobierno federal de entender a la zona fronteriza, no le importa. [...] No, esto no es de ahorita, ni por la violencia, ni por la inseguridad [C. Riquelme, comunicación personal, 8 de agosto, 2017].

Otros advierten una ausencia de visión estratégica y de planeación:

Se ha priorizado a la industria maquiladora para realizar estrategias que favorezcan su desarroIlo, mientras que otras opciones que requieren mayor inversión, tiempo y recursos de los que se carece, han quedado como proyectos interesantes, pero que no pasan de allí [F. Salcido, comunicación personal, 14 de noviembre, 2017].

Lo anterior refleja una falta de dirección, de liderazgo de actores, además de apoyo y financiamiento público al desarrollo de las actividades del turismo y del turismo médico, lo cual sería indispensable para el progreso de un destino turístico. Las personas entrevistadas de las distintas dependencias de gobierno de los tres niveles, quienes tenían cargos jerárquicos de primer y segundo nivel, nunca mencionaron conocer las acciones específicas para promocionar al destino médico de Ciudad Juárez, motivo por el cual se puede afirmar que existe un desconocimiento de ello. El único ejercicio plenamente identificado y señalado por varios de los entrevistados fue la creación del sistema de calidad para la certificación de hospitales, por la Secretaría de Salud.

El gobierno federal está impulsando la creación de clústeres en los estados con las características de infraestructura y recursos para ofrecer servicios de salud a pacientes internacionales. El grupo de autoridades de gobierno estatal entrevistado manifestó que se 
han realizado acciones para sensibilizar a los directivos y administradores de los hospitales privados participantes de Ciudad Juárez, en las cuales no han sido convocadas las autoridades de gobierno municipal. Por tanto, se observó una falta de coordinación entre los tres niveles de gobierno para avanzar hacia el logro de los objetivos de la política pública de turismo médico en México:

Cuando empezamos a tratar el tema del turismo médico, se percibió que todavía no llama la atención al nivel que pudiera hacerlo y esto se explica debido a que cuando los estados no tienen un desarrollo como lo tiene Chihuahua en el tema industrial, es más fácil que encaje un nuevo modelo económico que les permite desarrollar ese tema porque requieren con inmediatez de un producto para poder atraer más inversiones [F. Salcido, comunicación personal, 14 de noviembre, 2017].

Esta opinión es relevante, ya que permite advertir que el turismo médico no representa una prioridad para el gobierno del estado ni para el municipal. Es más, en varias de las entrevistas se mencionó que el municipio de Juárez no le ha otorgado al turismo médico la importancia que requiere para su desarrollo. De esta forma se explica que los apoyos existentes son orientados al reposicionamiento de la industria maquiladora. Por su parte, el gobierno municipal argumenta la ausencia de apoyo por parte del gobierno federal a la región Juárez-El Paso como causante de la falta de unión en el nivel de municipios fronterizos para la gestión de recursos y políticas públicas para el desarrollo de la frontera en el ámbito federal. Se sabe que el gobierno federal distribuye los recursos a través de los estados y, en ocasiones, estos no priorizan las necesidades de sus municipios de una manera acorde a la realidad, sino fundamentados en intereses de carácter político:

Si analizamos por qué no ha despegado el turismo médico en Juárez, yo siento que es 80 \% por cuestiones políticas y 20 \% por razones económicas [C. Flores, comunicación personal, 15 de noviembre, 2017].

Los resultados del trabajo demuestran que los aspectos de planeación e integración son determinantes en el desarrollo del destino, a través de lo cual se puede lograr un avance significativo en la consolidación del destino médico, además de favorecer el desarrollo del capital social.

En lo relativo a la participación en el clúster de turismo médico, uno de los entrevistados comentó:

Al inicio del clúster se convocaron 250 personas, de las cuales asistían 70, y posteriormente, a las reuniones de desarrollo asistían 13 en promedio. Tal vez debido a que tenían una idea errónea de que se buscaría como propósito el beneficio individual, cuando en realidad se trata de desarrollar el sector. Se busca integrar a los participantes a un proceso de calidad que no todos cumplen; en ese sentido, quizá algunos se sintieron excluidos [F. Moreno, comunicación personal, 7 de mayo, 2018].

Asimismo, el Colegio de Enfermeras de Ciudad Juárez no ha sido convocado para participar en el clúster. Estas aportaciones demuestran que los prestadores de servicios que 
atienden al turismo médico emergente no están incluidos, y que el propósito del clúster no es servir a todos los interesados, sino únicamente al grupo de prestadores de servicios que funcionan en el modelo planificado, dejando fuera a la gran mayoría de actores que trabajan en el turismo médico emergente, que reciben al grueso de pacientes de las ciudades vecinas. No se cumple el principio de participación de todos los actores involucrados propuesto por el PNUD.

En lo relativo a la capacidad de respuesta, los resultados de esta investigación demuestran que aún no existen suficientes instituciones, organismos y procesos que traten de servir a todos los interesados en el desarrollo del turismo médico en la localidad. Principalmente se destaca la débil presencia del municipio en el sector turístico y la ausencia de una institución u organismo de promoción del turismo del municipio.

En los inicios de la industria maquiladora, Tijuana era nuestro competidor, como frontera, pero luego nos unimos Juárez y Tijuana. El problema es que nos unimos en lo social pero no en lo político. Tijuana trataba de vincularse con el Distrito Federal, que no tardó en darse cuenta de la importancia de una zona de desarrollo, o una plataforma de la frontera norte como eje de desarrollo con el TLC. Por eso Tijuana tiene mayor avance y apoyo del gobierno federal [C. Riquelme, comunicación personal, 8 de agosto, 2017].

Uno de los hallazgos relevantes se refiere a que la gestión municipal del turismo no la realiza el municipio, sino el Buró de Convenciones y Visitantes de Ciudad Juárez, dependiente de un fideicomiso estatal. Las acciones municipales orientadas al desarrollo del turismo son incipientes, ya que en 2014 se creó una Dirección de Turismo, que depende de la Dirección de Promoción Económica y que promovió la creación de un Reglamento de Turismo Municipal. Esto evidencia una gran debilidad del municipio en el área de turismo, y fortalece la idea de que, en realidad, todo lo que está sucediendo en turismo médico en la ciudad obedece principalmente a la propia iniciativa privada, al gobierno del estado, al Buró de Convenciones y Visitantes, y a la comunidad emergente (quienes funcionan en el modelo teórico de turismo médico desde un marco reactivo-emergente). Lo anterior se atribuye a que el gobierno local ha priorizado el desarrollo de la industria maquiladora, por el beneficio de generación de empleos y recursos que aporta a la ciudad. Esto se explica dado que los proyectos de nueva creación como el turismo médico requieren grandes inversiones, mientras que proyectos consolidados como la industria maquiladora precisan actualmente menos recursos que cuando arrancaron. Así, se favorece a la industria maquiladora para la asignación de recursos y desarrollo de proyectos que la fortalezcan.

El desarrollo del turismo médico en la ciudad requiere el respaldo de una institución con poder, rol que el municipio aún no ha decidido asumir. Es un problema que el municipio no reconozca el valor del turismo médico para el destino turístico. Esto significa que, aunque aparentemente se está en tránsito de un proceso de desarrollo del turismo médico de emergente hacia uno planificado, en realidad han sido los mismos hospitales, clínicas y médicos que funcionan en el marco del modelo teórico del turismo médico planificado quienes realizan las acciones de planificación. 
Es inobjetable que se necesita la colaboración y apoyo tanto del gobierno del estado como del gobierno federal, pero en la medida en que el destino de turismo médico es Ciudad Juárez, consecuentemente el ente público más interesado en su desarrollo debería ser el gobierno municipal, ya que a su vez se constituye en el beneficiario directo de este proyecto.

Sería el municipio el que debería liderar estos procesos, o apoyar lo que ya existe. Pero no puede permanecer al margen. Una de las personas entrevistadas del grupo de facilitadores mencionó:

El turismo médico genera nueve empleos por operador a diferencia de la industria maquiladora que únicamente genera 2.7 empleos por cada uno. Este dato parece que no se ha dimensionado en cuanto a las posibilidades de desarrollo que podría traer a la región [S. Máynez, comunicación personal, 5 de noviembre, 2017].

En una ciudad que tradicionalmente ha fundamentado gran parte de su desarrollo económico en la industria maquiladora, se hace más difícil que se visualice un proyecto por el turismo. Es una competencia entre sectores, y la atención que estos reciben de los tres niveles de gobierno. Por tanto, falta visión estratégica, planeación y coordinación en el nivel de sectores y áreas económicas.

CuAdro 5. Elementos de gobernanza del PNUD identificados en el destino médico fronterizo de Ciudad Juárez - El Paso

\begin{tabular}{|c|c|c|c|}
\hline \multicolumn{4}{|c|}{$\begin{array}{l}\text { Elementos de un buena gobernanza en Ciudad Juárez } \\
\text { para el Turismo Médico }\end{array}$} \\
\hline Criterios del PNUD (2009) & $\mathrm{Si}$ & No & Incipiente \\
\hline Participación & & & $x$ \\
\hline Imperio de la ley & $x$ & & \\
\hline Transparencia & & $x$ & \\
\hline Capacidad de respuesta & & & $x$ \\
\hline Orientación a consenso & & $X$ & \\
\hline Equidad & & $X$ & \\
\hline Eficacia y eficiencia & & & $x$ \\
\hline Rendición de cuentas & & $X$ & \\
\hline Visión estratégica & & $X$ & \\
\hline
\end{tabular}

Fuente: Construcción propia con base en trabajo empírico. 


\section{Discusión}

La discusión sobre los hallazgos de las entrevistas realizadas a los actores participantes en el turismo médico de Ciudad Juárez se basa en teorías que sugieren que un destino turístico médico que lleva a cabo una buena gestión que incluya elementos de gobernanza tiene mayor probabilidad de cumplir sus objetivos de desarrollo.

El estudio de caso de Ciudad Juárez destaca un gran interés de los participantes en el desarrollo de la industria del turismo médico, no obstante, la forma de conducir las actividades económicas y los grupos sociales difieren con los conceptos de Rhodes (2005), quien enfatiza que en la gobernanza existe una nueva forma de gobierno mucho más participativa; aspecto que todavía no se identifica en el caso de estudio. También se observó que, en sentido opuesto a la definición de Peters (2003), existe una limitada capacidad del gobierno para proporcionar dirección a la sociedad ante una industria turística médica en pleno auge, cuya demanda de servicios por parte de pacientes del vecino país crece más cada día.

La información obtenida de los stakeholders participantes, expertos en políticas de salud, administración de la atención médica, y los sectores de turismo y educación, enfatiza la falta de planeación e integración de actores para el turismo médico. Este aspecto difiere del concepto de gobernanza propuesto por la Organización Mundial del Turismo (2010), que hace referencia al proceso de conducción de los destinos turísticos a través de los esfuerzos sinérgicos y coordinados de los gobiernos en sus diferentes niveles y atribuciones, de la sociedad civil que habita en las comunidades receptoras y del tejido empresarial relacionado con la operación del sistema turístico. En el caso del Hospital de la Familia -ubicado en el centro de la ciudad, justamente al atravesar una calle del cruce internacional Santa $\mathrm{Fe}-$, los entrevistados mencionaron el interés por continuar ofreciendo servicios de salud a pacientes del país vecino, e incluso señalaron contar con un plan estratégico de largo alcance, que incluye formación de recursos humanos para el turismo médico, para lo cual se construyó una escuela de enfermería con formación que incluye dominio del idioma inglés. Se observó una clara orientación al tratamiento de pacientes extranjeros para maximizar sus ganancias, sin embargo, este hospital no participa en el clúster de turismo médico, debido a que atiende pacientes de escasos recursos de ambos lados de la frontera y no ha sido convocado a tomar parte en las iniciativas de desarrollo del turismo médico, pese a que recibe en promedio 30000 pacientes al año provenientes de las ciudades cercanas en Estados Unidos.

A Ciudad Juárez se le presenta el reto de aprender de la experiencia de éxito de otras ciudades fronterizas en lo relativo a la gobernanza, por ejemplo Tijuana, Baja California. Rodríguez (2016) afirma que esta ciudad ha tenido periodos de administración municipal con muy buenos resultados sobre una base de planeación y de la promoción para atraer inversiones; mejorar la coordinación público-privada; el apoyo a las mipymes, y el desarrollo urbano (infraestructura). Como producto de un adecuado ejercicio tanto de coordinación intergubernamental como público-privada, se logró el fortalecimiento de clústeres industriales, con la finalidad de incrementar la competitividad y la economía local. 
La mayoría de los participantes en las entrevistas habló negativamente sobre las formas de gestión del turismo médico en Ciudad Juárez: se identifica una falta de planeación, organización, dirección y control en todos los niveles de gobierno, además de una ausencia de coordinación e integración de actores; esto se considera trascendente debido a que en 2014 aún no se contaba en el municipio con un reglamento de turismo y tampoco existe en la actualidad una dependencia municipal que promueva, organice y planifique las actividades turísticas, pese a la relevancia que estas tienen. Las funciones de promoción las realiza el Buró de Convenciones y Visitantes, dependiente del gobierno del estado, lo que nos lleva a advertir que no se cumplen los roles de los actores tradicionales, ni mucho menos se tiene la apertura para dirigir y motivar a los actores hacia una participación y compromiso con el desarrollo de la industria de este segmento del turismo. La influencia del gobierno local no se percibe y faltan liderazgos políticos que impulsen la gobernanza en materia de salud mencionada por Flores y Gómez-Sánchez (2010).

De tal suerte, se puede apuntar que el ente encargado de la gestión del turismo y del turismo médico en Ciudad Juárez es el Buró de Convenciones y Visitantes, que no tiene en cuenta el principio de participación, ya que parte de la gestión del turismo médico se lleva a cabo por empresarios que invierten en recursos turísticos médicos del destino, como la construcción de los hospitales Ángeles y Star Médica, con una limitada participación de los actores locales. El control y el poder están en manos de empresas e instituciones de fuera de la zona, creando malestar social entre los stakeholders locales.

En este sentido, no se cumple con lo establecido en el proceso que recomiendan Kooiman (2005) y Mayntz (2001) al hablar de una orientación institucional técnicamente estructurada, basada en principios, normas, procedimientos y prácticas para decidir de manera colectiva sobre objetivos comunes de convivencia y cómo coordinar y cooperar para el logro de los objetivos planteados. Asimismo, se señala que la rendición de cuentas del organismo de gestión es deficitaria, por lo que esta entidad no cumple con los principios de buena gobernanza en su gestión.

Las barreras para el desarrollo del turismo médico identificadas son similares a las que indican algunos autores, por ejemplo Keyser (2002), quien planteó que el restringido acceso a los mercados financieros, la escasa confianza por parte de los inversores internacionales y nacionales, los requisitos y los procedimientos tributarios complicados, la asignación presupuestaria limitada, la falta de integración y de promoción turística son elementos que inhiben el desarrollo del turismo en una región en particular.

En el caso de Tijuana, se considera relevante el resultado de un adecuado ejercicio tanto de coordinación intergubernamental como público-privada. Los elementos de éxito en la gestión de esta ciudad fronteriza se advierten precisamente como algunas de las barreras que han impedido el desarrollo del turismo médico en Ciudad Juárez, como la falta de planeación y de promoción para atraer inversiones, de la mejora en la coordinación público-privada, de apoyo a las mipymes, y el desarrollo urbano (infraestructura).

Las limitaciones de gestión del sector identificadas en las entrevistas refieren un plan de implementación inadecuado, ya que la creación del clúster de turismo médico incluye 
solo a los grandes hospitales y médicos ubicados en infraestructura de alto standing, los stakeholders participantes en el turismo médico emergente han desplegado sus propias estrategias individuales y carecen de una planeación del desarrollo del sector. Además, se advirtió una capacidad institucional deficiente, lo cual habla de problemas de organización, falta de rendición de cuentas y limitada capacidad de respuesta (véase figura 1).

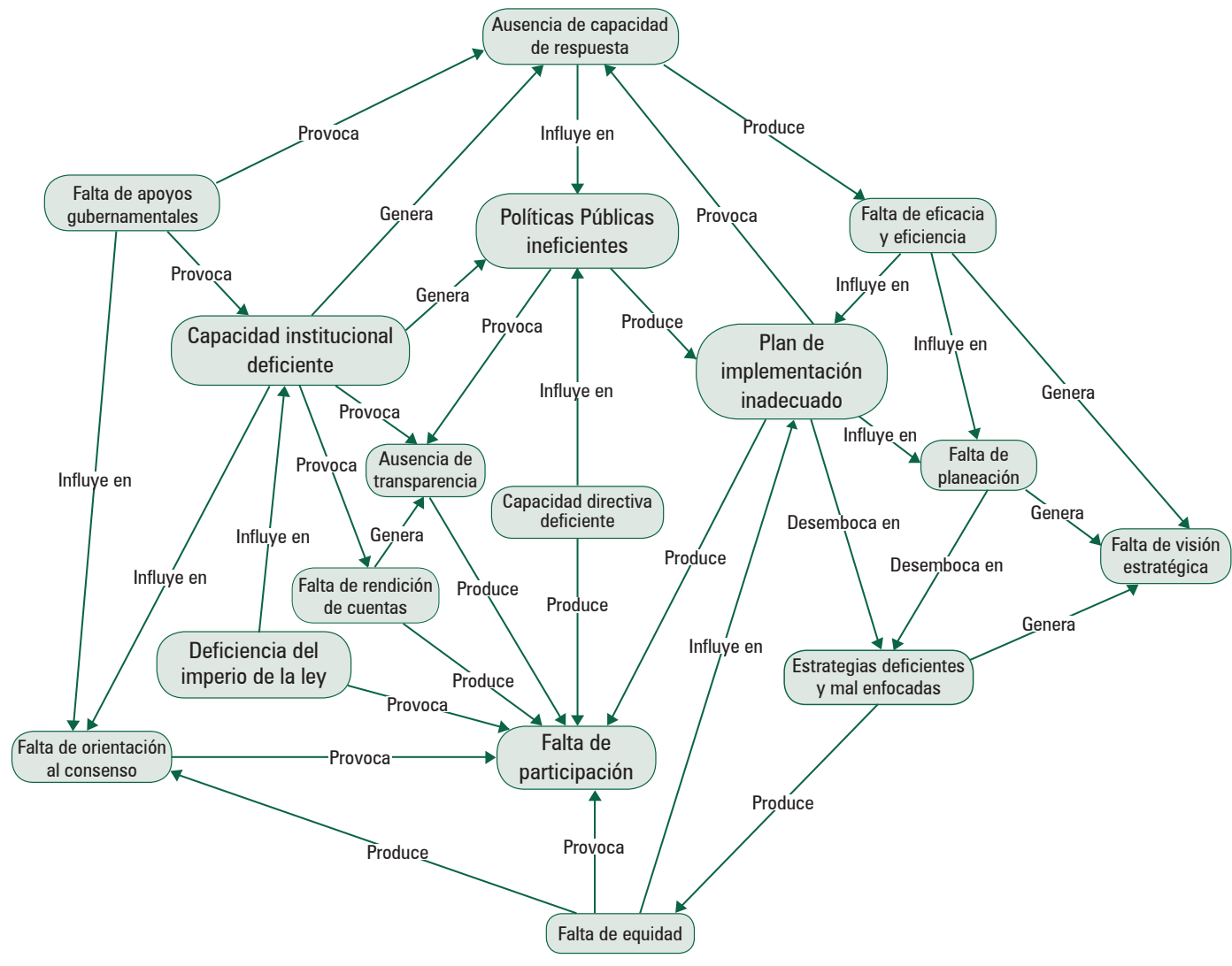

Figura 1. Red Semántica de Elementos de Gestión y Gobernanza en Ciudad Juárez

En esta investigación se ha encontrado información sobre el apoyo del gobierno de México, con acciones de promoción a través de ProMéxico y con la creación del sistema de calidad para la certificación de hospitales por medio de la Secretaría de Salud. Sin embargo, todo parece indicar que aún no ha decidido apostar por el turismo médico como estrategia de desarrollo con acciones más determinantes, a diferencia de Singapur y Tailandia, países que destacan por sus políticas y buena gestión del turismo médico.

Pocock y Phua (2011) afirman que el turismo médico ofrece una oportunidad para la coordinación de políticas entre ministerios de Salud, de Comercio y de Turismo. Se refiere a la experiencia de coordinación en Tailandia, Singapur y Malasia, en donde se está llevando a cabo una aparente convergencia en las prioridades comerciales, de turismo y del 
Ministerio de Salud, lo cual refleja la creciente aceptación de la salud como un bien privado en el ámbito mundial. En este caso de estudio, los descubrimientos indican la existencia de una escasa coordinación entre los distintos niveles de gobierno. Incluso los actores del sector privado parecían tener mayor conocimiento de las acciones realizadas por el gobierno federal que los actores del sector público.

Heung et al. (2010) destacan la importancia de la coordinación entre las instituciones médicas y los hoteles para el periodo de recuperación de los pacientes luego de una cirugía. Empero, en Ciudad Juárez aún no se observa este tipo de coordinación, quizá debido a que los pacientes que requieren permanecer algunos días después del tratamiento médico prefieren hospedarse en la vecina ciudad de El Paso, Texas, en Estados Unidos. Por otra parte, la existencia de hospitales especialmente construidos para la atención del turismo médico reduce la necesidad del servicio de hostelería, dado que la gente se hospeda en el mismo hospital, que tiene características de un hotel de lujo. Además, en la revisión de literatura no se encontraron referencias en las que se mencione un destino turístico médico que brinde un servicio integrado en una ciudad región, donde la atención sanitaria se ofrezca en un sitio y los servicios complementarios como el transporte aéreo y el hospedaje se oferten del otro lado de la frontera. Por lo anterior, se considera que la aportación del caso empírico de la región fronteriza Ciudad Juárez-El Paso a la literatura es de gran relevancia.

También Heung et al. (2010) sostienen que los productos de turismo médico combinan los componentes de la salud y el turismo. No obstante, los hallazgos del caso de estudio revelan elementos distintos en el sentido de que el producto va a la prestación de servicios de salud, donde la coordinación entre los sectores de la salud y el turismo es escasa. Probablemente debido a que son pocos los atractivos turísticos, y los que existen están poco desarrollados. Hay ausencia de un organismo potente con respaldo institucional para gestionar el turismo en la localidad.

En cuanto al liderazgo, Cabrero (2002) pone como ejemplo el caso exitoso de Tijuana, Baja California, como una de las estrategias innovadoras de gobernanza local que basa su acción en un nuevo tipo de liderazgo, más abierto y horizontal, que promueve acciones de trabajo en equipo en programas y políticas conjuntamente con la ciudadanía. En cuanto a Ciudad Juárez, existen iniciativas como el Plan Estratégico de Juárez, que tiene por objetivo la construcción de una fuerza ciudadana que participe en los asuntos públicos. Sin embargo, todavía no se aprecian resultados tangibles de sus acciones.

\section{Conclusiones y recomendaciones}

La presente investigación contribuye a la literatura del turismo médico mediante un examen crítico a las iniciativas de la política gubernamental para el desarrollo sostenible de la industria del turismo médico en México, identificando una brecha significativa en la región fronteriza de Ciudad Juárez-El Paso en materia de gestión y elaboración de políticas sobre turismo médico, concluyendo así que existe una incipiente aplicación de los criterios de 
buena gobernanza propuestos por el PNUD en la gestión del turismo médico en la frontera Juárez-El Paso.

En cuanto a la participación en la toma de decisiones, se concluye que se está aplicando este principio de manera incipiente, dado que algunas de las personas entrevistadas argumentan no haber sido convocadas aún para participar en el clúster de turismo médico.

Se cuenta con pleno conocimiento de las necesidades que presentan los pacientes del extranjero que pueden solicitar servicios de salud en México. Esto se puede afirmar con base en las acciones del gobierno federal de México para favorecer el desarrollo del turismo médico, que, hasta el momento de esta investigación, han sido meramente de promoción de los destinos y la creación del sistema de calidad para la certificación de hospitales, planteando la conjetura de que esto puede deberse a la previsión del impacto del desarrollo del turismo médico a gran escala en el sistema de salud del país, el cual enfrenta en la actualidad una realidad social compleja.

Es de esperarse que la demanda de servicios de salud por parte de pacientes del extranjero continúe al alza, ya que los gobiernos de los países desarrollados y empleadores están viendo cada vez más el turismo médico como una opción para reducir los costos derivados de atención en salud pública, no solo los pacientes con seguro médico público o privado sino también el paciente consumidor que carece de seguro y paga los servicios de su propio bolsillo (Wendt, 2012).

En cuanto a aspectos de integración de stakeholders, el papel mediador de la coordinación y colaboración establecido en la literatura, al igual que el impacto de la integración en los productos y atractivos turísticos, es muy relevante, aunque desafortunadamente aún hay un largo camino por recorrer en la región fronteriza, debido a la existencia de un sistema de destino difuso donde los productos y los atractivos turísticos no están integrados entre sí gracias a la ausencia de coordinación y colaboración entre los productores de los servicios, por lo que el destino no puede tener una personalidad clara en el mercado, ni desarrollar una oferta organizada de ningún modo en el nivel territorial (Ejarque, 2005).

Estas características se identificaron en el modelo de turismo médico emergentereactivo, donde la evolución de la oferta de servicios se relaciona con el creciente comportamiento de la demanda, pero sin coordinación ni colaboración de los stakeholders. Por tanto, se recomienda que las instituciones que cuentan con un liderazgo grupal orienten sus acciones al fortalecimiento de la colaboración entre los actores participantes.

De la misma manera, fue posible comprobar para el modelo de turismo médico planificado la importancia del papel mediador de los operadores externos al destino o facilitadores. Para este tipo de turismo médico se advirtió la existencia de un sistema de destino donde la integración, desarrollo de los productos y su propuesta de valor están en manos de operadores externos, o bien, de los turoperadores. El organismo de gestión turística no puede entonces desarrollar su papel de coordinación y promoción de la oferta debido a la falta de autonomía y autoridad sobre el producto, y, en consecuencia, no puede ofrecer un valor añadido propio. Se podría especular que, en el caso de los prestadores de servicios de turismo médico que contratan los servicios de facilitadores externos, puede llegar a generarse este tipo de dependencia. 
Por otra parte, en la forma de operación del turismo médico en Ciudad Juárez se identifica la ausencia de una organización que gestione el destino (Destination Marketing Organization, DMo) en el nivel municipal, afectando los resultados de su evolución. El turismo médico que existe en la ciudad ha sido promovido principalmente por los propios hospitales y médicos especialistas, develando una escasa coordinación tanto entre organizaciones privadas como públicas.

Se reconoció que la asociatividad existente entre los proveedores de servicios de salud con los de turismo y hostelería es esencial para brindar una experiencia satisfactoria al paciente que espera un servicio integral. En este sentido, el destino médico aún presenta retos importantes a superar, dado que no se localizó evidencia de acciones de cooperación o asociación entre organizaciones a favor del turismo médico; en cambio, emergió un aspecto positivo referente a la segmentación del mercado. Los prestadores de servicios de salud han podido desarrollar un enfoque centrado en las necesidades del paciente consumidor para la comercialización, el producto y la prestación del servicio, acorde con el perfil del paciente que reciben. Por ejemplo, el Hospital de la Familia atiende más de 30 000 pacientes transfronterizos al año, los cuales buscan un servicio de calidad estándar y cuya satisfacción se demuestra con las cifras de pacientes atendidos, que aumentan en miles cada año. El Centro Médico de Especialidades atiende pacientes en consulta de especialistas reconocidos, que, por su calidad, se han ganado su lealtad desde hace más de 60 años; además de los dos nuevos hospitales que cuentan con la infraestructura y estrategias de marketing que les permiten ofrecer servicios que en ocasiones superan las expectativas de los pacientes extranjeros que los visitan, principalmente por cirugía bariátrica y estética. No obstante, los hospitales carecen de una coordinación entre ellos. Cada uno desarrolla sus propias estrategias, lo cual habla de una falta de planeación, dirección y visión estratégica del destino.

En relación con el liderazgo se concluye que en el destino médico fronterizo hay diferentes liderazgos individuales, los cuales no trabajan de manera conjunta con un fin común. En virtud de que un elemento muy importante de la integración-coordinación es la presencia de liderazgo y de un sistema de gestión sistémico, se torna deseable fomentar la participación y generación de compromisos que ayuden a identificar y consolidar liderazgos de grupo que faciliten el avance en los procesos de desarrollo del turismo médico. Asimismo, se develó la existencia de un problema de falta de arraigo que ha impedido la presencia de liderazgos tanto singulares como sistémicos.

Por lo anterior se concluye que en Ciudad Juárez aún falta un largo camino por recorrer para acercarse a los criterios y recomendaciones para una buena gobernanza propuestos por el PNUD en lo referente a la gestión del turismo médico. 


\section{Fuentes consultadas}

Asociación Española de Expertos Científicos en Turismo. (septiembre, 2001). Nuevas tendencias de ocio y turismo: su especial problemática en destinos singulares. VI Congreso AECIT, Ceuta.

Barbini, B., Biasone, A., Cacciutto, M., Castellucci, D., Corbo, Y. y Roldán, N. (octubre, 2011). Gobernanza y turismo: Análisis del estado del arte. Simposio Internacional Gobernanza y Cambios Territoriales: Experiencias Comparadas de Migración de Amenidad en Las Américas (pp. 111-125). Pucón, Chile.

Bramwell, B. y Lane, B. (1993). Sustainable tourism: An evolving global approach. Journal of Sustainable Tourism, 1(1), 1-5.

Brewer, J. y Hunter, A. (1989). Multimethod Research: A Synthesis of Styles. Newbury Park: Sage.

Caballero-Danell, S., y Mugomba, C. (2007). Medical Tourism and its Entrepreneurial Opportunities-A conceptual framework for entry into the industry. Tesis de Maestría núm. 2006: 91. School of Business, Economics and Law. Gotermburgo, Suecia: Göteborg University.

Cabrero, E. (2002). El premio gobierno y gestión local en México : un mecanismo de institucionalización de la innovación en gobiernos locales. VII Congreso Internacional del CLAD sobre la Reforma del Estado y de la Administración Pública (pp. 1-11).

Casey, V., Crooks, V. A., Snyder, J., y Turner, L. (2013). Knowledge brokers, companions, and navigators: a qualitative examination of informal caregivers' roles in medical tourism. International Journal for Equity in Eealth, 12(1), 94.

Charmaz, K. (2000). Grounded theory: Objectivist and constructivist methods. Handbook of Qualitative Research, 2, 509-535.

Clarkson, M. (1995). A stakeholder framework for analyzing and evaluating corporate social performance. Academy of Management Review, 20, 92-117.

Denzin, N. y Lincoln, Y. (2005). Handbook of Qualitative Research. Thousand Oaks: Sage.

Ejarque, J. (2005). Destinos turísticos de éxito. Diseño, creación, gestión y marketing. Madrid, España: Pirámide.

Ejarque, J. y Bernet, J. E. (2005). Destinos turísticos de éxito. Madrid: Grupo Anaya Comercial, España.

Flores, W. y Gómez-Sánchez, I. (2010). La gobernanza en los Consejos Municipales de Desarrollo de Guatemala: Análisis de actores y relaciones de poder. Revista de Salud Pública, 12, 138-150.

Glaser, B. y Strauss, A. (1967). The discovery of grounded theory: Strategies for qualitative research. Chicago: Aldine.

Haldenwang, C. (abril, 2005). Gobernanza sistémica y desarrollo en América Latina. Revista de la CEPAL, 85, 35-52.

Heung, V., Kucukusta, D. y Song, H. (2010). A conceptual model of medical tourism: Implications for future research. Journal of Travel \& Tourism Marketing, 27(3), 236-251. Recuperado de http://doi.org/10.1080/10548401003744677

Keyser, H. (2002). Tourism Development. Cape Town: Oxford University Press. 
Kooiman, J. (2005). Gobernar en gobernanza. En A. Cerrillo i Martínez (coord.), La gobernanza hoy: 10 textos de referencia (pp. 57-82). Madrid: Instituto Nacional de Administración Pública.

Manente, M. (2008). Gestión de destinos y antecedentes económicos : definición y supervisión de destinos turísticos locales. Documento principal, Sesión 4: Gestión de destinos turísticos. Recuperado de http://cf.cdn.unwto.org/sites/all/files/pdf/ manente_sp.pdf

Manhas, P. y Ramjit., M. (2015). Marketing analysis of medical tourism in India. Enlightening Tourism, 5(1), 1-39.

Martínez, M., Morales, A. y Zizaldra, I. (diciembre, 2016). El turismo médico: tendencia de transformación para Ciudad Juárez, México. TURyDES, Turismo y Desarrollo Local, 21, 1-14.

Martínez-Almanza, M., Guía, J. y Serra, C. (noviembre de 2014). Desarrollo de un destino de turismo médico transfronterizo en Ciudad Juárez, México desde una perspectiva relacional. En Innovación y Competitividad en Áreas Turísticas: Actas del Seminario Internacional "Innovación y competitividad en Áreas Turísticas (ICAT2014)". 5, 6 y 7 de noviembre de 2014. Alicante, España: Instituto de Investigaciones Turísticas de Alicante.

Martínez-Almanza, M., Guía, J. y Serra, C. (2017). Génesis y evolución del turismo médico en Ciudad Juárez, Chihuahua, México. En Tendencias del turismo en Latinoamérica (pp. 176-196). Barranquilla, Colombia: Editorial Uniautónoma, Universidad Autónoma del Caribe,.

Mayntz, R. (2001). El Estado y la sociedad civil en la gobernanza moderna. Reforma y Democracia, 21(21), 7-22.

Natera, A. (2005). La gobernanza como modo emergente de gobierno y gestión pública. Gestión y Análisis de Políticas Públicas, (33-34).

Organización Mundial del Turismo (2010). Proyecto de gobernanza para el sector turismo. Informe Ejecutivo. Estadísticas y Cuentas Satélite de Turismo. Madrid: Autor.

Peters, B. (octubre, 2003). La capacidad para gobernar: ¿retrocediendo hacia el centro? Reforma y Democracia, 27. Recuperado de http://www.clad.org/portal/ publicaciones-del-clad/revista-clad-reforma-democracia/articulos/027-octubre-2003/0047218

PNUD. (2009). Good Governance and Sustainable Human Development. Recuperado de http://mirror.undp.org/magnet/policy/chapter1.htm

Pocock, N. y Phua, K. (2011). Medical tourism and policy implications for health systems: A conceptual framework from a comparative study of Thailand, Singapore and Malaysia. Globalization and Health, 7(12), 1-12.

ProMéxico. (2013). PROMEXICO Turismo Médico. Recuperado de http://mim.promexico. gob.mx/work/sites/mim/resources/LocalContent/374/2/130925_DS_Turismo_de_salud_ESP.pdf

Pulido-Fernández, M. D. L. C. y Pulido-Fernández, J. I. (2014). ¿Existe gobernanza en la actual gestión de los destinos turísticos? Estudio de casos. PASOS. Revista de Turismo y Patrimonio Cultural, 12(4), 685-705.

Rhodes, R. (2005). La nueva gobernanza: gobernar sin gobierno. La Gobernanza Hoy, 10, 99-122. 
Rodríguez, D. y Fraiz, J. (2010). Gestión de crisis en el turismo: La cara emergente de la sostenibilidad. Tourism \& Management Studies, 6, 49-58. Recuperado de http:// www.scielo.gpeari.mctes.pt/pdf/ec/n6/n6a06.pdf

Rodríguez, G. (2016). Gobernanza para el desarrollo local: el caso del Municipio de Tijuana 2007-2013. Tlatemoani, Revista Académica de Investigación, 21, 100-124.

Selltiz, C., Jahoda, M., Deutsch, M. y Cook, S. (1965). Métodos de investigación en las relaciones sociales. Madrid: Ediciones RIALP.

Soto, G., Lutzow, M. A. y González, R. (2010). Rasgos generales del sistema de salud en México. En La salud pública y el trabajo en comunidad (pp. 150-167). México: McGraw-Hill.

Velasco, M. (2007). Gestión de destinos: igobernabilidad del turismo o gobernanza del destino ? Ministerio de Educación y Ciencia.

Wendt, K. (2012). Medical Tourism: Trends and Opportunities (Tesis de maestría). University of Nevada, Las Vegas. 


\title{
El turismo como instrumento de colonización neoliberal: una perspectiva foucaultiana
}

\author{
Tourism as an instrument of neoliberal colonization: \\ a Foucaultian perspective
}

\author{
TZINTLI Chávez Luna \\ Universidad Autonóma \\ del Estado de México
}

\begin{abstract}
as realidades sociales son más complejas que los modelos que las representan, y el Lcaso del modelo de desarrollo no es la excepción. Así pues, las ideas sobre crecimiento, intervencionismo y modelos económicos, se reúnen en teorías parciales incapaces de describir la complejidad de la realidad; con lo que el concepto de desarrollo queda en la indefinición. Como consecuencia, tampoco es claro en qué se basa la diferenciación de países y regiones como desarrollados, subdesarrollados, o en desarrollo, tipología usada ampliamente en discursos académicos y políticos.
\end{abstract}

Es por ello que se observan situaciones que encierran contradicciones en el concepto (o modelo) de desarrollo y en su aplicación; y también se observa una falta de enfoques integrales que contemplen múltiples dimensiones y que sean congruentes con la historia, cultura, saberes y organización político-social de las comunidades. Esto ilustra que los discursos del desarrollo sean narrativas universalistas insostenibles, cuyos principios difícilmente resisten los cuestionamientos de la posmodernidad, que contradicen su explicatividad (Schuurman, 1993).

Con todo, a nivel internacional se atribuye al turismo un potencial de desarrollo; por lo que el "desarrollo turístico" se une frecuentemente a los países menos desarrollados, los cuales son extremadamente importantes como destinos y actores de la actividad global (Timothy \& Nyaupane, 2009, p. 6), pues además el turismo se considera como la única industria en el sector de servicios en la que los países en desarrollo (PED) e incluso los países más pobres, obtienen un saldo positivo en su balanza comercial con respecto a los países desarrollados (PD) (Epler Wood, 2007, p. 159).

En contraposición, se han subrayado los efectos negativos, como costos sociales y ambientales mayores que los beneficios (Nash, 1981). Además, en un contexto global el turismo tiene el riesgo de potencializar malentendidos, y probablemente su resultado no sea la paz y el entendimiento, sino el conflicto (Reisinger et al., 2013, p. 47). Y si bien pudiera suponerse que funde significados al mezclar individuos, culturas o naciones, bien puede resultar en interacciones complejas, difíciles de comprender.

A lo largo de esta crítica se explorarán algunos aspectos turísticos en torno a los discursos de desarrollo y a las otredades que de ellos surgen. Para lograrlo, se ha recurrido a ciertas nociones foucaultianas como discurso, juegos de verdad, significado histórico, agentes 
de normalización, panoptismo, dominación, micropoder, cuidado de sí y gubernamentalidad, con las cuales se explorarán algunas dinámicas de poder presentes entre los Otros involucrados en los discursos de turismo y desarrollo. El objetivo es ofrecer perspectivas que puedan resultar enriquecedoras para otros estudios y que promuevan un ejercicio de reflexión respecto de los discursos involucrados.

Cabe destacar que la presente crítica se realiza desde una posición que puede considerarse de Otredad desde distintos puntos de vista: la que escribe es una mujer situada en un contexto económico calificado como "en desarrollo" y con pertenencia socio-cultural a Latinoamérica (una de las periferias poscoloniales con respecto a Occidente), entre otras; por lo que representa una contraposición a las nociones unívocas de construcción de discursos históricos y sociales (Smith [1987, 1993] cit. por Humberstone, 2004, p. 130-131).

\section{Desarrollo y turismo}

El pensamiento occidental contiene un cúmulo de antagonismos entre los Otros; binomios lingüísticos que afirman a Uno en relación al Otro, negándole a la diferencia su entidad, autonomía, preexistencia y originalidad, y subyugando a la Otredad en una relación centro/ satélite (Ankor \& Wearing, 2013, p. 184-185). Entonces, los discursos están formados por parejas cuyos elementos estando en un mismo plano funcionan, sin embargo, como dos polos aparentemente irreconciliables. Este asunto es fundamental, porque la organización de los significantes en binomios privilegia siempre a un término, separa sus características y relega todo aquello que no es, lo que convierte al segundo término en el Otro, lo excluido, alguien cuyas características (físicas, sociales, culturales, cognitivas) niegan y desmienten las propias, conjunto de diferencias cuya naturaleza infinita implica la imposibilidad de reducción o exclusión absoluta (Derrida, 1994; 1996; 1998). El resultado es que la construcción de opuestos binarios los hace dependientes uno del otro (Hall \& Tucker [2004, p. 8] cit. por Cater, 2007, p. 57), y se crea una relación agónica entre los opuestos. De ahí lo irreconciliable entre Unos y Otros, construido y reafirmado históricamente, y la crítica a esa historia que afirma que el Otro se encuentra al margen del discurso, en un lugar más allá de los límites del lenguaje, que sin embargo es real.

Como parte de los discursos nacidos en Occidente, el del desarrollo se basa en construcciones binomiales, que de manera general se refieren a los opuestos Nosotros, normal, correcto/los Otros, anormal, desviado. Esta construcción no deja espacio a la voz de los Otros, que según el discurso, deben ser excluidos o disciplinados; y que al identificarse con IOS PED, concentran la Otredad en relación con los PD. Es decir, que se puede considerar al concepto de desarrollo como un juego de verdad a través del cual se moldea la imagen Propia y la de los Otros. De esta manera, los condicionamientos del ejercicio del poder moldean las percepciones de la gente, las regulan, organizan y autorizan institucionalmente, y por lo tanto, reflejan los discursos particulares sobre la Otredad, el turismo (Morrison, 2013, pp. 34 y 44) y el desarrollo. 
En la medida en que el Estado y las élites nacionales intervienen en la definición y orientación de las políticas de desarrollo, puede hablarse de gubernamentalidad, y por lo tanto, del desarrollo como tecnología de gobierno. Además del Estado, hay instituciones especializadas en las técnicas de gubernamentalidad en todos los niveles; su intervención se exacerbó con el neoliberalismo, con el que también las empresas han obtenido poder en el puro sentido foucaultiano de conducción de conductas.

Sin embargo, parece claro que los objetivos de las instituciones globales no pueden homologarse ni en diseño ni en aplicación para PD y PED, obligándonos a cuestionar su significado en la reconfiguración espacial, económica, sociocultural y política que acompaña a la globalización. Esto abre la interrogante de por qué se insiste en modelos de desarrollo cuya incompatibilidad con múltiples regiones en loS PED está tan extensamente documentada. Shuurman (1993), por ejemplo, relaciona el desarrollo con una gubernamentalidad institucional que actúa local y globalmente, y genera interacciones internacionales que no han podido ser explicadas ni resueltas, por lo que pese a su horizontalidad en el discurso, existen desigualdades que no se llegan a corregir. De aquí las crecientes diferencias socioeconómicas entre países ricos y pobres, pues los PED aplican políticas de corto plazo vinculadas a su deuda externa y no a largo y mediano plazos, mientras el crecimiento económico ha tenido impactos críticos en materia ambiental.

Debido a lo anterior, es válido preguntarse si los PED se ven obligados a aceptar los modelos respaldados o reconocidos por esas organizaciones o instituciones, a fin de obtener fondos para implementar sus políticas; agotando su resistencia y las oportunidades de supervivencia que pudieran tener a través de otras formas de economía. Entre los grupos sociales o las sociedades nacionales, la aceptación puede ser un síntoma de algo más sutil: que el discurso en cuestión se ha difundido tan eficientemente, que ellos mismos funcionan como agentes normalizadores. Así, lOS PED y sus individuos difícilmente se cuestionan si dichos discursos son compatibles con las conceptualizaciones locales de desarrollo, pobreza y riqueza; de forma que los actores involucrados y hasta los países mismos terminan asumiendo la necesidad de políticas para las cuales no tienen recursos financieros, por lo que recurren a instituciones que aseguran su adscripción al discurso.

Estas incongruencias son las mismas que permean gran parte de las relaciones basadas en la retórica del desarrollo occidental y que convierten a conceptos como el turismo y la sostenibilidad en discursos intervencionistas (Schuurman, 1993). Considerar esta perspectiva permite comprender por qué se plantea el empleo del turismo como herramienta de desarrollo, como la imposición de un dispositivo discursivo. Gracias a instrumentos de este tipo, el turismo se vuelve actividad económica importante para las naciones, mientras apoya la conservación ambiental y ofrecen a los pueblos tradicionales una oportunidad de "subir la escalera de la economía globalizada" (Epler Wood, 2007, p. 172). Pero esa "oportunidad" -asumida incluso académicamente- nació del discurso capitalista; y aunque inicialmente no sea compartida por Otras sociedades, podrá convertirse en su aspiración si los discursos se convierten en juegos de verdad y tecnologías de poder. Así, el turismo forma parte de las tecnologías que aseguran la continuidad del poder de las élites. 
Esto se nota cuando los objetivos de muchos proyectos de desarrollo se encuentran velados entre el discurso de un supuesto desarrollo que mejoraría la calidad de vida de los individuos de los PED. De esta forma se establecen relaciones ambiguas y confusas entre conceptos como desarrollo y pobreza; pero sobre todo porque no reconocen que la pobreza es una necesidad del modelo económico neoliberal, y que ha sido institucionalizada por los discursos y las tecnologías del desarrollo para conservar el estatus de dominación de los PD sobre los recursos económicos del planeta. Pareciera que en realidad se propone que los PED ofrezcan esos recursos a lOS PD a través de actividades terciarias, con la suposición de que las empresas serán sostenibles, o de que los pueblos desean ese tipo de desarrollo. Así, la relación entre los PED y los PD sería típicamente colonialista, pues existe el riesgo de que sus empresas controlen el uso de los recursos.

Así pues, ya que muchos programas y proyectos turísticos para combatir la pobreza son solo paliativos no adaptados a las realidades de las comunidades de los PED, no es sorprendente que las sociedades locales se desilusionen del turismo por la incapacidad que ha demostrado para cumplir con los beneficios locales que se prometen (cfr. Cater, 2007). De esta forma, las comunidades que reciben a los turistas sufren la dominación de discursos político-económicos que han resultado de la sustitución de conocimientos tradicionales por aquellos provenientes de una economía neoliberal globalizada. A través de estos discursos se ha creado en las comunidades una pobreza que favorece el flujo de recursos físicos y humanos al mercado global. Así, la clase dominante mantiene enclaves de mano de obra relativamente barata y motivos suficientes para la generación de campañas que promuevan una imagen socialmente aceptada de promoción del desarrollo.

De esta manera, el turismo puede verse como una forma de neocolonialismo, como parte de una gubernamentalidad global, y un vehículo de distribución de la política y doctrina neoliberal cuyos impactos, límites y gestión son distintos en PD y en PED (Timothy \& Nyaupane, 2009, p. 3). La actividad turística como tecnología de gobierno introduce conocimientos, procedimientos, valores y criterios para deslindar entre normal/anómalo; implica modificaciones en los usos del espacio, actividades productivas y costumbres, de modo que la gente presencia la sustitución de la economía tradicional, la extinción de los oficios, la emigración de residentes, la conversión de sus senderos en carreteras, la transformación de sus zonas de pesca en playas privadas, o la implantación de centros comerciales en sus viejos mercados.

Por eso es preciso considerar las profundas asimetrías que se infiltran en los encuentros turísticos, a través de mecanismos de control y dominación que han prevalecido por siglos, y que impulsan a los receptores a aceptar determinadas condiciones en su trato con el exterior, muchas veces quedando reducidos a la imposibilidad de oponerse, opinar, cuestionar o tomar decisiones, pues la construcción del Tercer Mundo, el subdesarrollo, los países "pobres" o los PED, es resultado de una compleja relación entre poder y conocimiento, que opera a escala local, regional, nacional y mundial.

Es importante señalar que en muchos casos la adopción del turismo como una nueva actividad productiva en una comunidad de un PED, depende en parte de la precariedad de 
su situación, porque muchos pueblos pueden admitirlo por una pobreza realmente grave, o por haber sufrido un muy alto grado de exclusión o saqueo de sus recursos. Esto podría significar que el grupo social en cuestión se ve obligado a someterse al ofrecimiento de grandes corporaciones, su propio Estado o cualquier otra organización relacionada, sin poder negociar mejores salarios o condiciones laborales, y mucho menos que se cumplan leyes ambientales o fiscales, por ejemplo, tal vez del mismo modo que en el pasado.

Si el grupo social quedara convencido del discurso - lo cual requiere cierto grado de normalización que guía a los individuos a creer que su bienestar depende del desarrolloimplicaría que los individuos aceptan las categorías desarrollado/no-desarrollado, y que se asumen a sí mismos como parte de dicho binomio. Lo anterior implica que a los PED no se les ha permitido construir sus propias conceptualizaciones y modelos, por lo que no se ha podido imaginar una realidad más allá del discurso occidental de desarrollo. En el fondo, también podría significar que sus esfuerzos de "vivir mejor" sean moldeados por discursos extranjeros, perdiéndose y convirtiéndose en Otros para sí mismos.

\section{Conclusión}

Con respecto a las ideas sobre el desarrollo, es posible argumentar que las teorías de desarrollo basadas en metadiscursos enfrentan retos fundamentales, como la imposibilidad de que los modelos sean universalizados (Telfer, 2009, pp. 157-160). Tal universalidad engarzada en el dispositivo panóptico adecuado, puede no tener otro resultado que el totalitarismo y derivar en un abuso del poder; una situación en la que ese poder carece de legitimidad y se imponen a los Otros las propias “fantasías, apetitos y deseos", creando una relación perennemente disimétrica (Foucault, 1999, pp. 400-405). Así pues, tendrían que construirse opciones vinculadas a la historia, cultura, saberes, aspiraciones y organización político-social de cada sociedad.

En todo caso, parece evidente que las relaciones PD y PED se replican cuando sus individuos se encuentran en un contexto turístico; y que resultan disimétricas porque se ha promovido un reparto inequitativo de recursos en el que las regiones "desarrolladas" los obtienen en exceso, contrariamente a los Otros. Sin embargo, también es disimétrico porque el mismo discurso otorga facilidades ideológicas, legales e institucionales a quienes lo han creado, lo cual impide que otras regiones que pretenden aplicarlo obtengan resultados favorables. De la misma manera, la difusión del discurso en regiones "en desarrollo" y la ausencia de propuestas alternativas resultan en un escaso cuestionamiento de los instrumentos que de él surgen. Ante esto, es pertinente cuestionar si algún paradigma de desarrollo existente o por venir pudiera emanciparse de este complejo sistema coercitivo

Esto significa entonces que la situación de dominación discursiva no se modificará hasta que la parte coartada asuma la completa responsabilidad de su propia libertad; en la cual no solo se encuentran los PED, sino todos y cada uno de los individuos que se han visto alcanzados por los discursos de desarrollo, muchos de los cuales los han interiorizado profundamente. 
Por estas razones, el cuestionar dichos mecanismos requiere un verdadero esfuerzo reflexivo que implicaría enfrentarse con la posibilidad de dejar atrás ciertas autoconcepciones, y aceptar que se es sujeto de un continuo control y observación. Este cuestionamiento se dificulta en la medida en que los individuos se encuentran normalizados; más aún cuando no se trata solamente de un proceso de liberación discursiva, sino de una práctica de libertad (Foucault, 1999, p. 395), un cuestionamiento profundo de las propias convicciones que permita a los individuos asumirse como entes libres para ver al Otro claramente como ser humano. Si esto ocurre, entonces también parece posible darse cuenta de que los Otros están de la misma forma sujetos a mecanismos de gubernamentalidad iguales o similares, los cuales no han permitido imaginar una convivencia inclusiva, no contestada y sin prejuicios.

\section{Literatura citada}

Ankor, J., \& Wearing, S. (2013). Gaze, Encounter and Philosophies of Otherness. En O. Moufakkir, \& Y. Reisinger (Eds.), The Host Gaze in Global Tourism (pp. 179-190). Oxfordshire, Reino Unido: CAB Intenatinoal.

Cater, E. (2007). Ecotourism as a western construct. En J. Higham (Ed.), Critical Issues in Ecoturism: Understanding a complex tourism phenomenon (pp. 46-69). Oxford, Reino Unido: Elsevier Ltd.

Derrida, J. (1994). The Deconstruction of Actuality. Radical Pholosophy(68), 28-41.

Derrida, J. (1996). Remarks on Deconstruction and Pragmatism. En C. Mouffe (Ed.), Deconstruction and Pragmatism (S. Critchley, Trad., pp. 77-90). Londres, Reino Unido: Routledge.

Derrida, J. (1998). Of Grammatology. (G. Chakravorty, Trad.). Baltimore: Johns Hopkins University Press.

Epler Wood, M. (2007). The role of sustainable tourism in international development: prospects for economic growth, alleviation of poverty and environmental conservation. En J. Higham (Ed.), Critical Issues in Ecoturism: Understanding a complex tourism phenomenon (pp. 158-184). Oxford, Reino Unido: Butterworth-Heinemann.

Foucault, M. (1999). La ética del cuidado de sí como práctica de la libertad. En M. Foucault, Estética, ética y hermenéutica (Á. Gabilondo, Trad., pp. 393-416). Barcelona, España: Paidós.

Humberstone, B. (2004). Standpoint research: multiple versions of reality in tourism theorising and research. En J. Phillimore, \& L. Goodson (Eds.), Qualitative Research in Tourism: Ontologies, epistemologies and methodologies (págs. 119-136). Londres, Reino Unido: Routledge.

Morrison, I. A. (2013). The Thai Host Gaze: Alterity and the Governance of Visitors in Thailand. En O. Moufakkir, \& Y. Reisinger (Edits.), The Host Gaze in Global Tourism (pp. 33-46). Oxfordshire, Reino Unido: CAB International. 
Nash, D. (1981). Tourism as an Anthropological Subject (Comments and Reply). Current Anthropology, 22(5), 461-481.

Reisinger, Y., Kozak, M., \& Visser, E. (2013). Turkish Host Gaze at Russian Tourists: a Cultural Perspective. En O. Moufakkir, \& Y. Reisinger (Eds.), The Host Gaze in Global Tourism (pp. 47-66). Oxfordshire, Reino Unido: CAB Intenational.

Schuurman, F. J. (1993). Introduction: Development Theory in the 1990. En F. J. Schuurman, \& F. J. Schuurman (Ed.), Beyond the Impasse: New Directions in Development Theory (pp. 1-47). Londres, Reino Unido: Zed Books.

Telfer, D. J. (2009). Development Studies and Tourism. En T. Jamal, \& M. Robinson (Eds.), The SAGE Handbook of Tourism Studies (pps. 146-165). Londres, Reino Unido: SAGE Publications Ltd.

Timothy, D. J., \& Nyaupane, G. (2009). Introduction: Heritage tourism and the less-developed world. En D. J. Timothy, \& G. P. Nyaupane (Eds.), Cultural Heritage and Tourism in the Developing World. A regional perspective (pp. 3-19). Abingon, Reino Unido: Routledge. 


\section{RESEÑA \\ XII Congreso Internacional de Investigación Turística Academia Mexicana de Investigación Turística (Амıт)}

José F. Domínguez Estrada Universidad del Caribe fdominguez@ucaribe.edu.mx

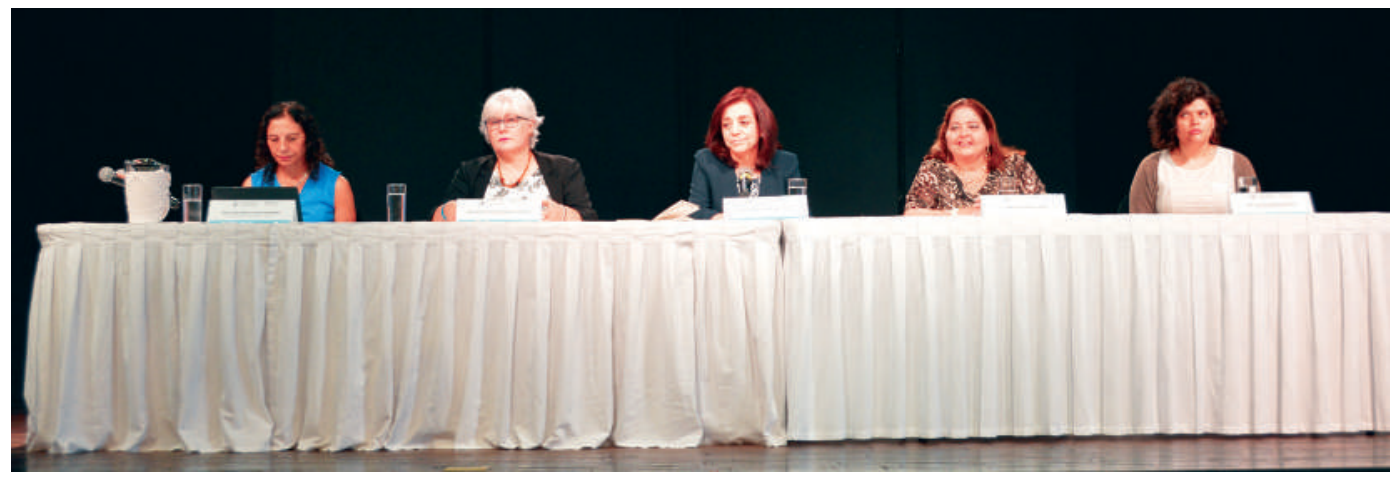

$\int$ on el tema central: "El turismo frente a los objetivos de desarrollo sustentable", la Academia Mexicana de Investigación Turística (AMIT), la Universidad del Caribe (Unicaribe) y la Red de Confluencia Latinoamericana de Investigación Turística (CLAIT) convocaron al XII Congreso Internacional de la AMIT, al XVI Seminario de Turismo y Sustentabilidad de la Unicaribe y al VIII Congreso CLAIT, del 28 al 31 de octubre de 2018 en la ciudad de Cancún, Quintana Roo, México. En la ceremonia de inauguración participaron la Mtra. Teresa Solís Trejo, subsecretaria de Planeación y Política Turística de la Secretaría de Turismo federal, la Mtra. Marisol Vanegas Pérez, secretaria de Turismo del Gobierno del Estado de Quintana Roo, la Dra. Andrea Muñoz Barriga, presidenta del CLAIT, la Dra. Nora L. Bringas Rábago, presidenta de la AmIt, y la anfitriona, la Dra. Ana Pricila Sosa Ferreira, rectora de la Universidad del Caribe. Este congreso fue el marco ideal para intercambiar ideas y reflexionar sobre la contribución real y potencial del turismo al desarrollo sostenible desde una perspectiva crítica.

Durante el congreso, las presentaciones orales se organizaron bajo los siguientes ejes temáticos: 1) Bases epistemológicas y teóricas del turismo; 2) Educación, formación y capacitación en turismo, 3) Comunicación y tecnologías de la información en turismo; 4) Estudios empresariales y administrativos del turismo; 5) Planeación y gestión del turismo; 6) Impactos socio territoriales y ambientales del turismo; 7) Turismo sustentable, de naturaleza o en áreas naturales; 8) Turismo rural, agroturismo o turismo comunitario; 


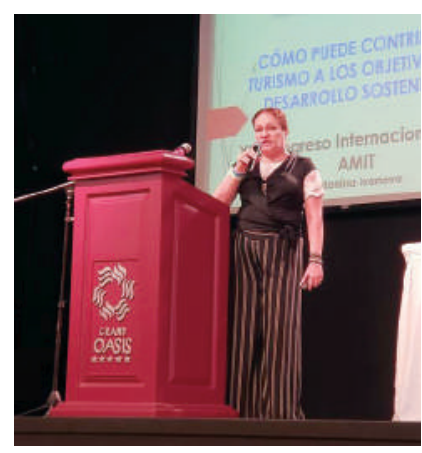

Dra. Antonina Ivanova Boncheva, investigadora de la Universidad Autónoma de Baja California Sur

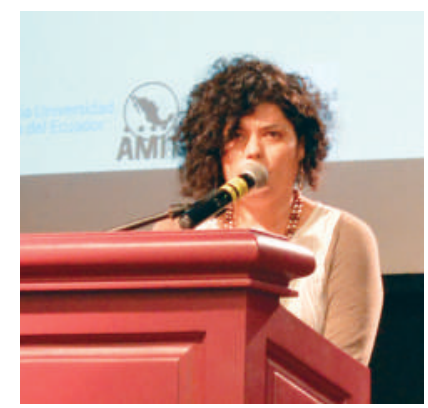

Dra. Andrea Muñoz Barriga. Conferencia magistral: Contradicciones del turismo para la conservación y desarrollo en el paraíso. Galápagos, Ecuador
9) Turismo, cultura y patrimonio; 10) Políticas públicas en turismo, 11) Turismo médico o de salud y turismo deportivo; 12) Metodologías cualitativas y cuantitativas en turismo; 13) Multi, inter y transdisciplinariedad del turismo; y 14) Género y turismo. Adicionalmente se propusieron y presentaron las siguientes mesas especiales: a) Turismo residencial, b) Turismo gastronómico, c) Turismo y parques nacionales; d) Formación superior en turismo y hospitalidad; y e) Turismo alternativo.

Después de la inauguración, la Dra. Antonina Ivanova Boncheva, investigadora de la Universidad Autónoma de Baja California Sur, dio inicio al programa académico con la conferencia magistral: ¿Cómo puede contribuir el turismo a los objetivos del desarrollo sustentable?, e hizo una breve reflexión en torno al tema central del congreso pero con énfasis en la necesidad de visualizar un modelo de desarrollo turístico sustentable más incluyente y al alcance de los sectores más desamparados.

Acto seguido se llevó a cabo el panel: Turismo y Sustentabilidad, coordinado por la Mtra. Marisol Vanegas Pérez, y como participantes el Lic. Francisco Córdova Lira, empresario en Cancún, Quintana Roo; el Mtro. Gonzalo Merediz Alonso, presidente de Amigos de Sian Ka'an; y la C. Zendy Euán, líder comunitaria de la Red de Turismo Comunitario de la Zona Maya. El objetivo del panel fue discutir sobre los logros, obstáculos y pendientes para un turismo sustentable, desde las diversas perspectivas de los actores, de sus programas y proyectos turísticos.

La segunda conferencia magistral estuvo a cargo de la Dra. Andrea Muñoz Barriga, con el tema Contradicciones del turismo para la conservación y desarrollo en el paraíso. Galápagos, Ecuador. La ponente expuso ejemplos claros sobre la preservación y las problemáticas vinculadas con el turismo en esa incomparable área natural protegida de su país.

El segundo panel, fue coordinado por la Dra. Maribel Osorio García, investigadora de la Universidad Autónoma del Estado de México, con el tema Una mirada al turismo desde diferentes disciplinas. El objetivo de este panel fue discutir acera del estudio disciplinario del conocimiento turístico, para reconocer sus alcances y limitaciones e identificar alternativas de fortalecimiento interdisciplinario. Participaron 


\section{J. F. Domínguez Estrada}

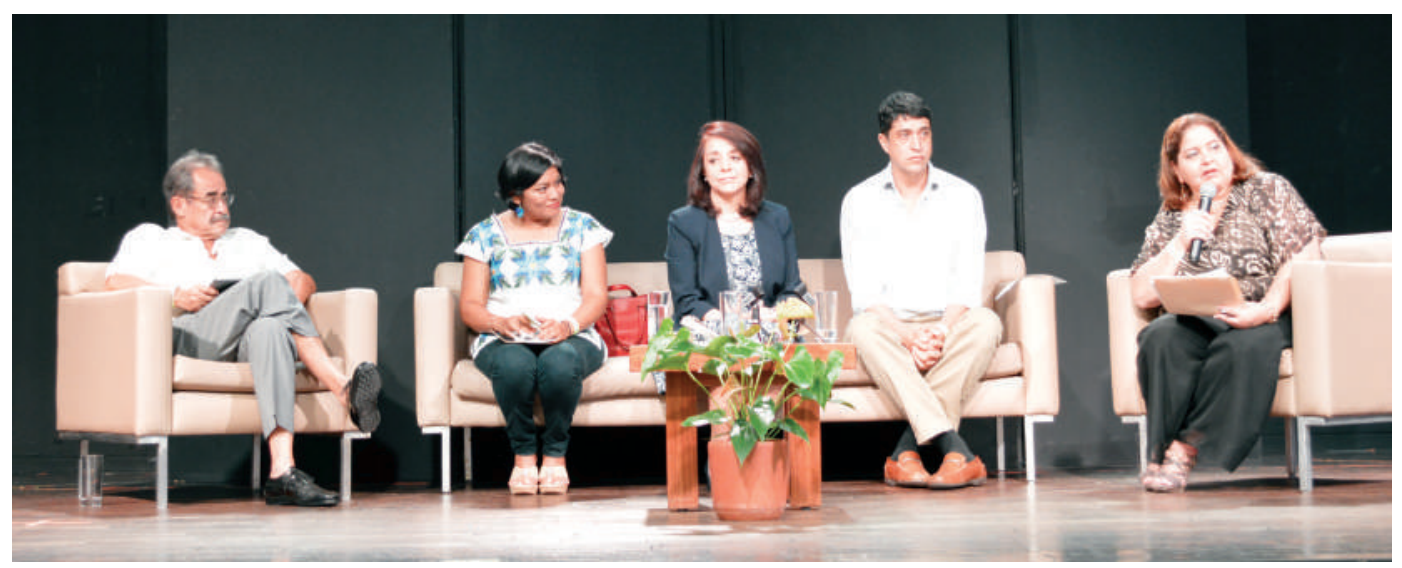

Panel Turismo y sustentabilidad, coordinado por la Mtra. Marisol Vanegas Pérez

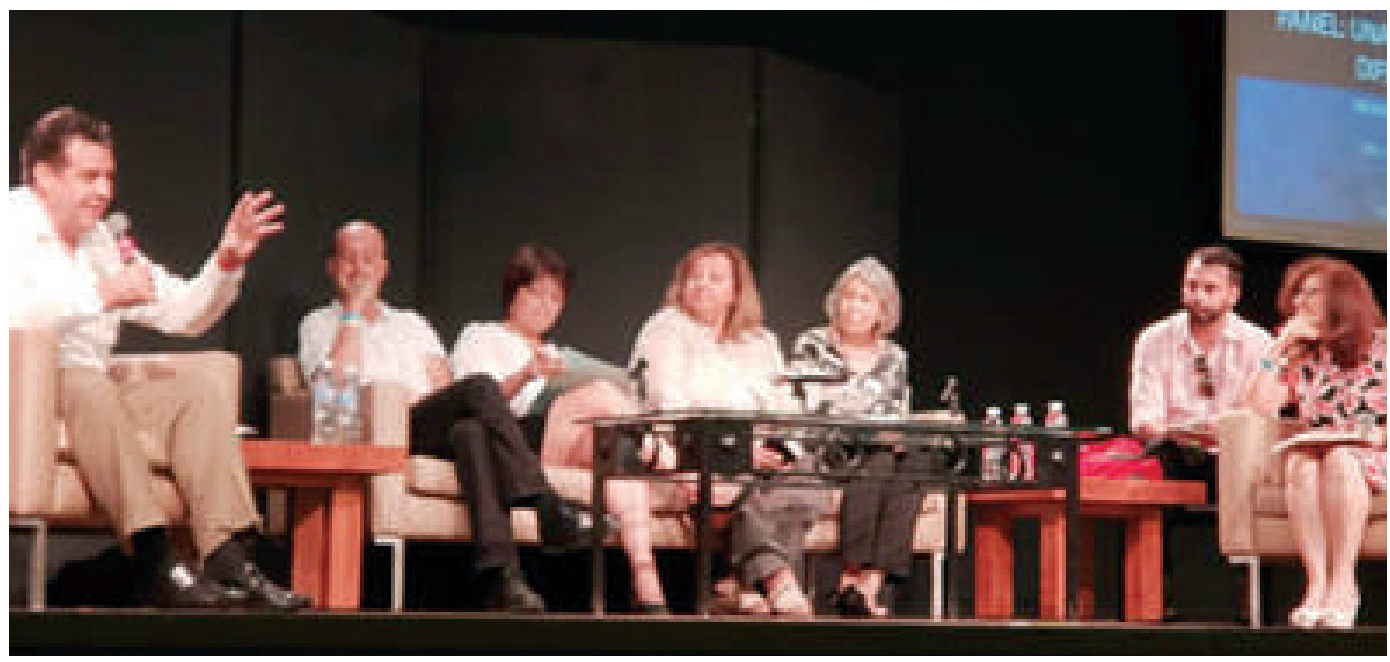

Panel Una mirada al turismo desde diferentes disciplinas, coordinado por la Dra. MariBel Osorio García

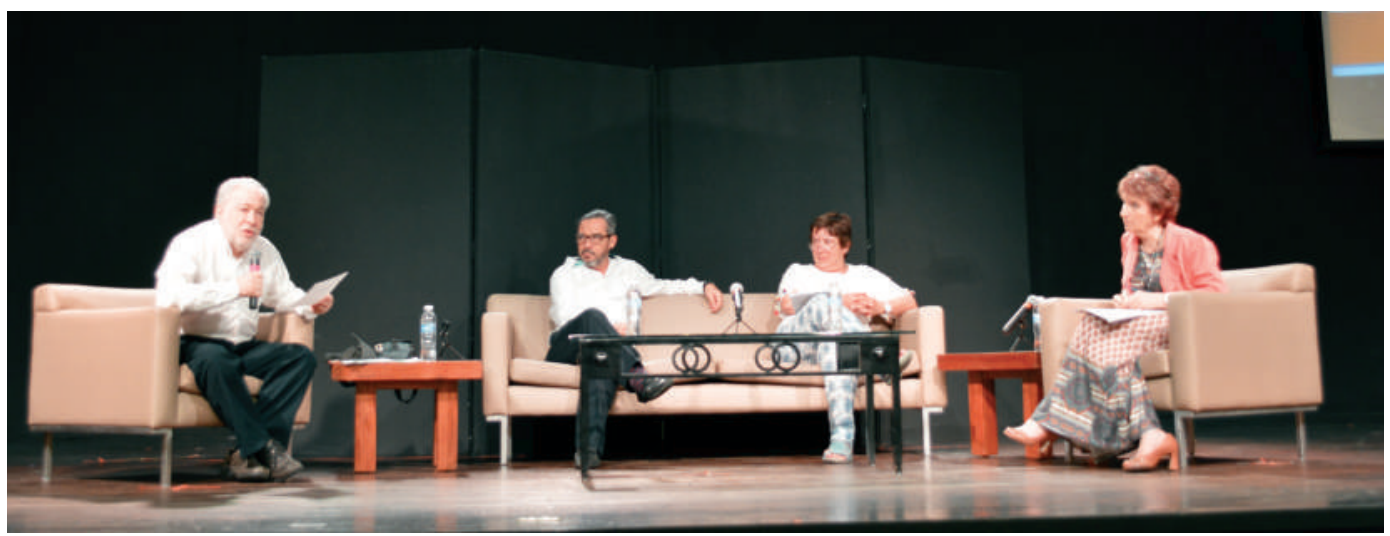

Panel Formación de posgrados en turismo en América Latina: investigación, innovación, internacionalización e interdisciplinariedad, coordinado por el Dr. Pablo Szmulewicz 
Panel Revistas científicas de turismo, coordinado por el Dr. Agustín Santana Talavera, director de la revista PASOS

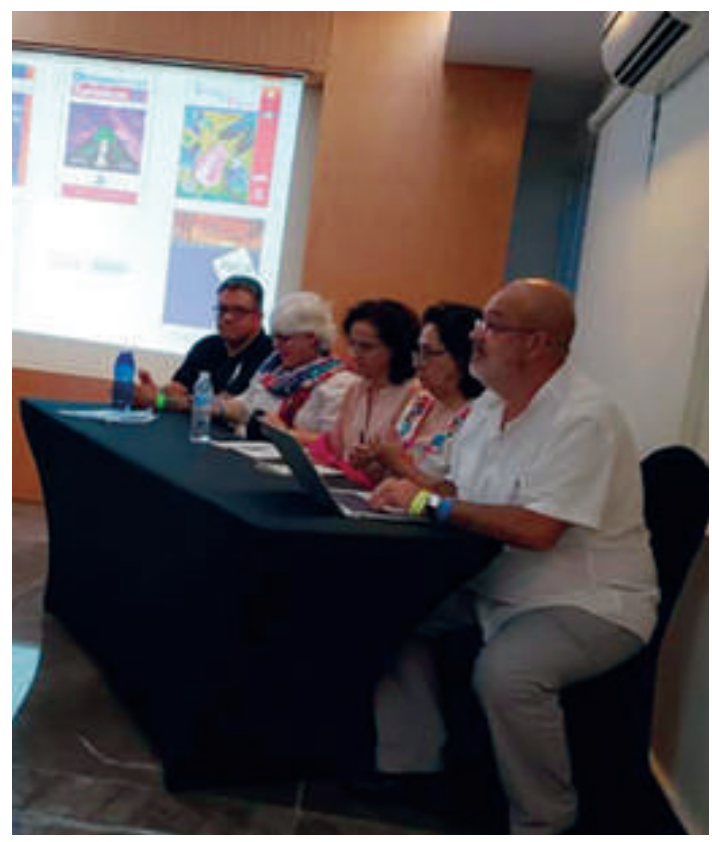

en el evento el Dr. Pedro Moncada Jiménez, secretario Académico de la Universidad del Caribe, por México; el Dr. Alejandro Mantecón Terán, investigador de la Universidad de Alicante, por España; la Mtra. María Alejandra Gazzera, investigadora de la Universidad Nacional del Comahue, por Argentina; la Dra. Mirian Rejowski, investigadora de la Universidad de Sao Paulo, por Brasil; y la Dra. Marisela Janette Pilquiman Vera, investigadora de la Universidad de los Lagos, por Chile.

Para finalizar el primer día de trabajo se celebraron dos paneles simultáneos. El primero con el tema Revistas científicas de turismo, coordinado por el Dr. Agustín Santana Talavera, director de la revista PASOS, y con la participación de la Dra. Rocío del Carmen Serrano Barquín, directora de la revista El Periplo Sustentable; la Dra. Nora L. Bringas Rábago, directora de la revista Dimensiones Turísticas; el Dr. Alejandro Palafox Muñoz, director de la revista Teoría y Praxis; y la Dra. María del Pilar Espeso Molinero, miembro del Comité Editorial de la revista Investigaciones Turísticas. El objetivo de este panel fue analizar la visibilidad de las revistas, las causas del limitado reconocimiento por las agencias evaluadoras, la propuesta de métricas e indicadores para la evaluación de las revistas, la búsqueda de mejoras en los procesos editoriales (disminución en plazos de revisión y publicación, estandarización de un código ético, afrontar el plagio, formas de evitar el sesgo de revisión, etc.) y las formas de financiación del acceso abierto.

El segundo panel, intitulado Formación de posgrados en turismo en América Latina: investigación, innovación, internacionalización e interdisciplinariedad, coordinado por el Dr. Pablo Szmulewicz, director del magíster en Gestión e Innovación del Turismo de la Universidad Austral de Chile, contó con la participación de la Dra. Marcia Capellano do Santos, 


\section{J. F. Domínguez Estrada}

directora del magíster y doctorado en Turismo de la Universidad Caxías do Sul, Brasil; el Dr. Carlos Gauna de León, coordinador de la maestría y doctorado en Ciencias para el Desarrollo, la Sustentabilidad y el Turismo del Centro Universitario de la Costa, Universidad de Guadalajara; y la Mtra. Rossana Campodónico, investigadora de la Universidad de la República en Uruguay y representante del magíster en Turismo de la Universidad de Quilmes, Argentina.

En este panel se analizaron distintas estrategias de fortalecimiento para los programas de posgrado en turismo, especialmente en materia de formación teórico-práctica, de investigación, de capacidades de innovación, de prácticas docentes y de modalidades de titulación innovadoras; así también, se discutieron las vías para la mayor internacionalización de estudiantes y docentes y la formación de redes.

El segundo día tuvo lugar la conferencia magistral El turismo en la teoría social: controversias y desafíos actuales, dictada por el Dr. Alejandro Mantecón Terán, de la Universidad de Alicante, España, a través de la cual reflexionó sobre las perspectivas teóricas aplicadas en el estudio del turismo en los niveles macro o micro y presentó el debate actual sobre estos planteamientos.

Posteriormente se efectuó el foro Los retos de la investigación turística en México, dirigido por la Dra. Nora L. Bringas Rábago y el Dr. Basilio Verduzco Chávez, quienes expusieron los resultados de un reciente estudio realizado por ellos entre los sectores académico, público y privado vinculados al turismo, para identificar las fortalezas y debilidades de la investigación turística en México.

El tercer y último día del Congreso, se llevó a cabo el panel Redes de investigación, dirigido por la Dra. Marta Gemma Nel-Lo Andreu, líder de la Red Internacional de Investigadores en Turismo, Cooperación y Desarrollo (Coodtur); se contó con la participación de la Dra. Alba Font Barnet, secretaria científica de la Red Coodtur, la Dra. Bonnie Lucía Campos Cámara, líder de la Red de Estudios Multidisciplinarios del Turismo de la Península de Yucatán, México (Remtur), y la Dra. Ligia Aurora Sierra Sosa, líder de la Red Universitaria de Antropología Aplicada (RUAA). El objetivo de este panel fue generar un espacio de encuentro y reflexión para analizar la importancia y necesidad de investigar

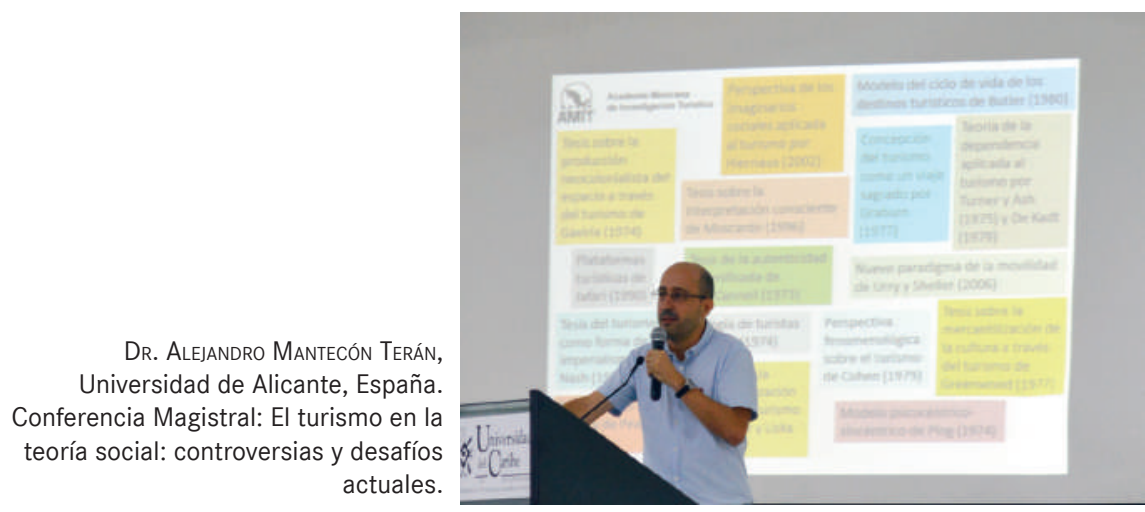




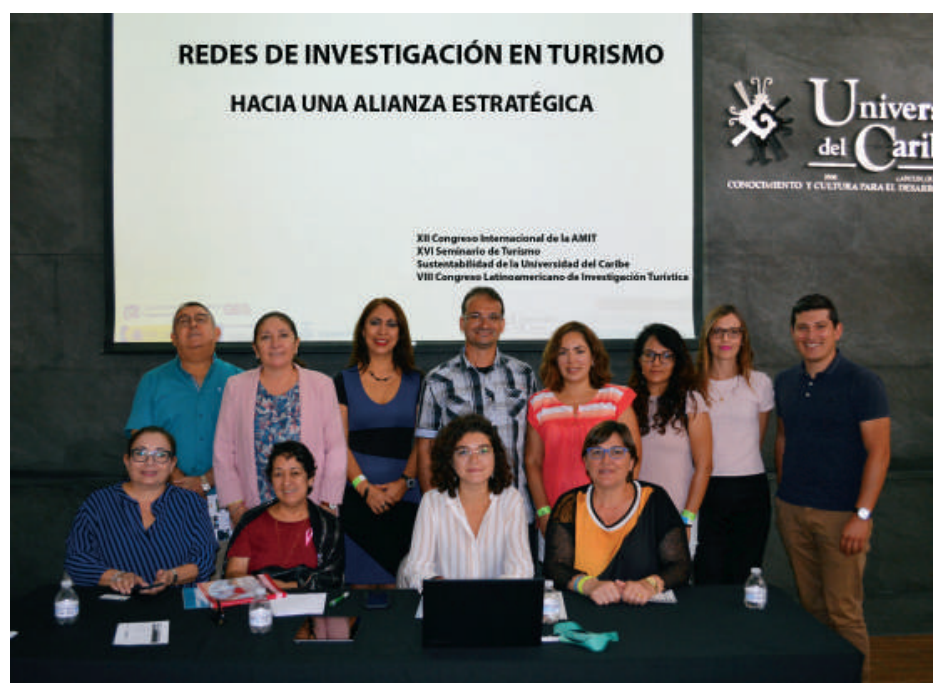

Panel Redes de investigación, dirigido por la Dra. Marta Gemma Nel-Lo Andreu, líder de la Red Internacional de Investigadores en Turismo, Cooperación y Desarrollo

en red, así como aportar criterios para mejorar la calidad, alcance y transferencia de los resultados de la investigación científica en el campo del turismo a nivel internacional.

Para cerrar las conferencia magistrales, la Dra. Raquel Huete Nieves, directora general de Turismo de la Generalitat Valenciana, España, dictó la titulada De la ciudad inteligente al destino turístico inteligente, en la que presentó las acciones llevadas a cabo por la oficina a su cargo para convertir y posicionar a los destinos turísticos localizados en la Comunidad Valenciana -entre ellos el importante centro de Benidorm- en destinos inteligentes destacados en España y en la costa del Mediterráneo; la Dra. Huete Nieves compartió su experiencia, alcances y retos en esta iniciativa.

Durante el Congreso se presentaron también siete libros de destacados investigadores del turismo, la mayoría miembros de la AMIT: Turismo oscuro en México, coordinado por Álvaro López López y Anne Marie Van Broeck; Desarrollo local y turismo en la región de Bahía de Banderas, escrito por María de los Ángeles Huizar Sánchez; Tendencias del turismo en Latinoamérica, de Beatriz Díaz Solano y Tomás J. Cuevas Contreras; Impactos socioculturales del turismo. Dimensiones conceptuales, teóricas y empíricas, de Carlos Monterrubio; Modelo-método holístico Iruma Desu. La innovación a través de las competencias cuantitativas y las competencias cualitativas en la dimensión de lo intangible-cualitativo, de Irma Magaña Carrillo, Karla Y. Covarrubias Cuéllar y Ana B. Uribe Alvarado; Turismo y género. Una mirada desde Iberoamérica, coordinado por Rocío del C. Serrano-Barquín, Gregoria Rodríguez y Daniela Palmas-Castrejón; y Tendencias de investigación en turismo en América Latina. Estudios de caso, coordinado por Andrea Muñoz Barriga, Maribel Osorio y Gabriela Guijarro. 


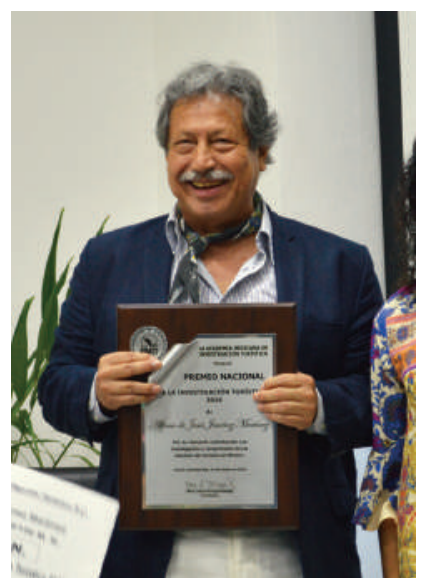

Dr. Alfonso de Jesús Jiménez Martínez, Premio Nacional a la Investigación Turística 2018.

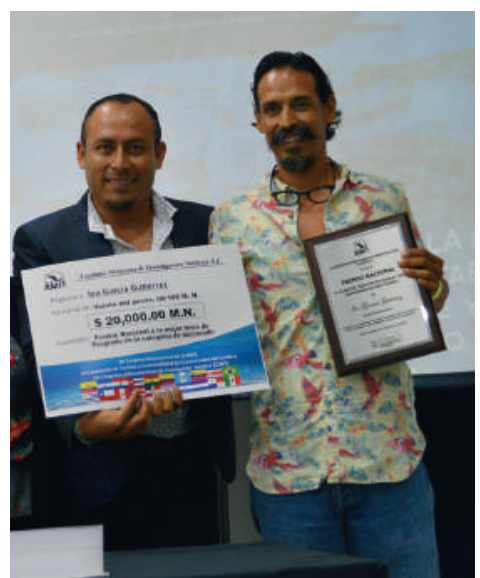

Ivo García Gutiérrez, Premio Nacional a la Mejor Tesis de Doctorado 2017, y su director de tesis Dr. Álvaro López López.

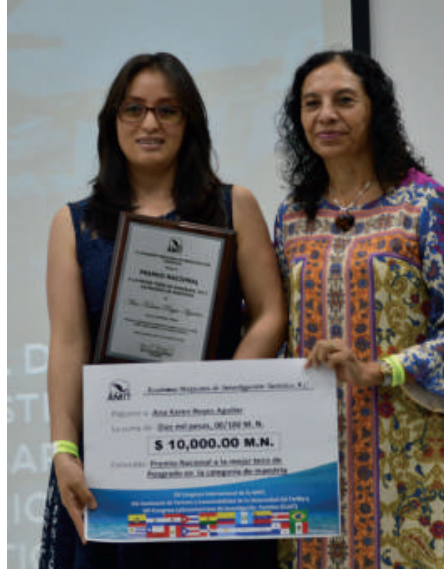

Ana Karen Reyes Aguilar, Premio Nacional a la Mejor Tesis de Maestría 2017, y su directora de tesis Dra. Rocío del Carmen Serrano Barquín.

En el marco de la clausura del Congreso, la AmIT hizo entrega de los siguientes premios. El Premio Nacional a la Investigación Turística 2018 le fue otorgado al Dr. Alfonso de Jesús Jiménez Martínez, quien recibió un diploma de reconocimiento por su trayectoria y la aportación de sus conocimientos a lo largo de cuarenta años para la consolidación de los estudios turísticos y el desarrollo de su investigación, principalmente en el ámbito mexicano, lo que contribuyó a líneas de trabajo importantes académicamente, pero también con una incidencia notable en la transferencia de conocimiento, la mejora de la planificación y políticas turísticas y el esfuerzo en la divulgación. El Dr. Jiménez es profesor-investigador en la Facultad de Turismo de la Universidad Autónoma de Guerrero; adicionalmente recibió un cheque por cuarenta mil pesos.

Igualmente se otorgó el Premio Nacional a la Mejor Tesis de Posgrado 2017, en las categorías de maestría y doctorado. En esta convocatoria se invitó a participar a posgraduados con tesis elaboradas de forma individual por nacionales o extranjeros residentes en el país que concluyeron y defendieron su tesis de grado ante un jurado durante el año 2017, y cuyo tema central se relacionara con el turismo en México. Se recibieron trece participaciones de maestría y cuatro de doctorado de distintas instituciones del país.

En la categoría de doctorado, la tesis premiada fue Impactos socioculturales del turismo asociado al área de protección de flora y fauna Cuatro Ciénagas: Una perspectiva geográfica, de Ivo García Gutiérrez, en el Doctorado en Geografía de la Universidad Nacional Autónoma de México (UNAM); el director de tesis fue el doctor Álvaro López López.

En la categoría de maestría la tesis ganadora fue Mujeres, conservación ambiental y turismo rural en el ejido Adolfo López Mateos, Los Tuxtlas, Veracruz, presentada por Ana Karen Reyes Aguilar, en la Maestría en Ciencias Ambientales de la Universidad Autónoma del Estado de México (UAEM); su directora de tesis fue la Dra. Rocío del Carmen Serrano 
Barquín. Ambos ganadores recibieron un diploma de reconocimiento y un cheque; por diez mil pesos en la categoría de tesis de maestría, y veinte mil pesos en la categoría de la tesis de doctorado.

Como parte del programa recreativo del Congreso se llevó a cabo un brindis de bienvenida, una visita guiada por la ciudad, dos visitas de campo: una a comunidades de Felipe Carrillo Puerto y la otra al Pueblo mágico de Isla Mujeres, y una noche de coctel de despedida en el hotel sede. Estas actividades constituyeron momentos propicios para incentivar la convivencia de los asistentes y los miembros de la AMıT, quienes año tras año se dan cita para intercambiar ideas y resultados de investigación, pero también para encontrar afinidad profesional y personal.

En suma, durante los tres días del evento se presentaron cuatro conferencias magistrales, cuatro paneles, un foro de análisis, 189 ponencias, cuarenta mesas temáticas, diecinueve carteles y siete libros; se congresaron más de 200 especialistas de distintas disciplinas, procedentes de Argentina, Brasil, Colombia, Costa Rica, Chile, España, Ecuador, Uruguay y México, que compartieron sus experiencias y los resultados de sus investigaciones sobre turismo.

Luego de tres días intensos de trabajo, el Congreso llegó a su fin; como parte de este ejercicio intelectual se presentaron las siguientes conclusiones generales. Con respecto al desarrollo teórico de la investigación en turismo y la sustentabilidad, se resaltó que la sustentabilidad fue un hilo conductor del evento y se discutieron aportaciones teóricas y metodológicas en torno al pensamiento de la sustentabilidad como perspectiva de trabajo y como objeto de estudio. Se discutió el concepto de sustentabilidad a la luz del análisis de los retos reales de los actores que toman decisiones en el ámbito público y privado, y se concibió como posible el vincular las conceptualizaciones con las trayectorias profesionales de personas que representan los intereses reales: comunidades, organizaciones cívicas, y empresas, entre otros. Se identificaron retos y avances en la construcción teórica de la relación turismo-desarrollo sustentable, señalando sus cuestionamientos conceptuales, pero a la vez reconociendo las experiencias de la realidad Latino-iberoamericana.

Con relación a los avances metodológicos, se observó que las investigaciones han avanzado en el uso de metodologías mixtas, y que se refleja en mayor medida un trabajo interdisciplinario. Se denotó un mayor nivel de sofisticación metodológica en el estudio de los procesos de la realidad turística, a través de explicaciones causales mejor ordenadas y análisis multivariados cuanti-cuali, reflejando una mayor rigurosidad y consistencia. Sobre la relación investigación-docencia, el evento permitió a estudiantes exponer los avances de sus tesis y recibir retroalimentación de especialistas en el tema, lo que permitió fortalecer su formación de largo plazo. Como parte de este ejercicio de reflexión se discutieron también los alcances y retos de los posgrados en turismo y la necesidad de consolidar su calidad educativa.

Durante el congreso se hizo patente que la comunidad académica congregada está debatiendo sobre diversos temas, entre ellos: la condición de género y la sexualidad, los 


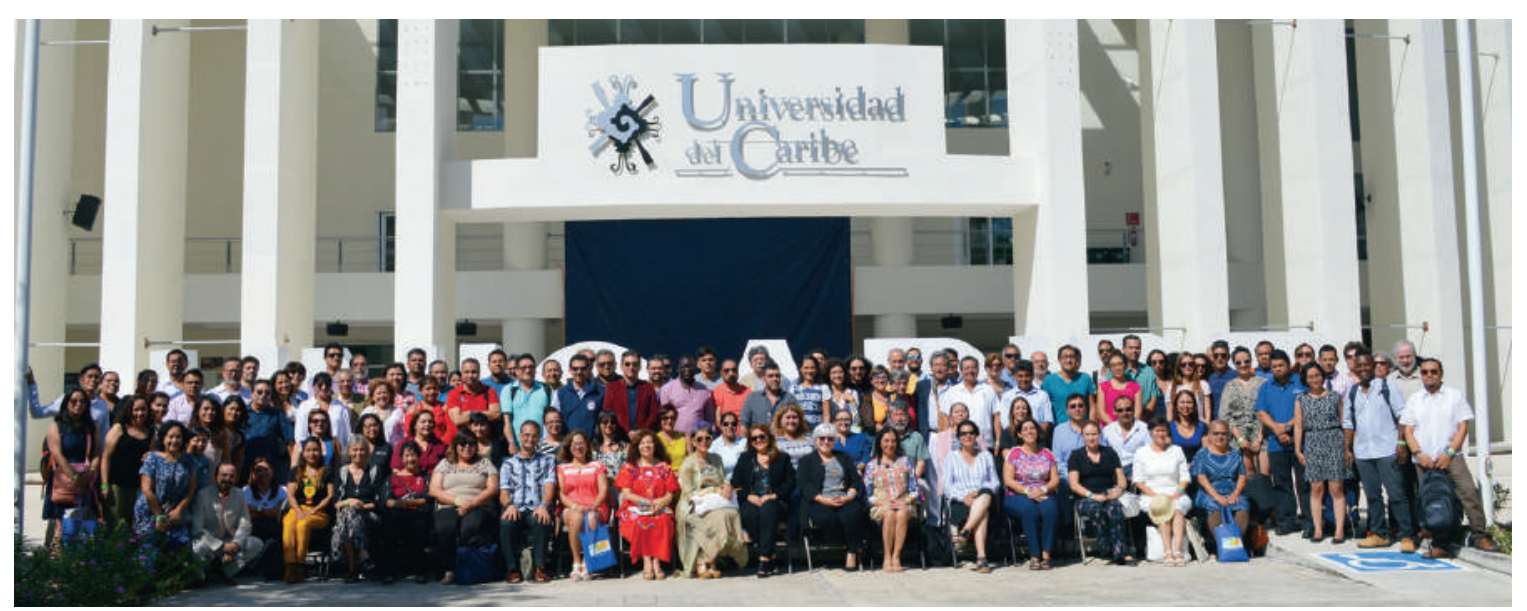

Más de 200 investigadores participaron en el XII Congreso Internacional de Investigación Turística Academia Mexicana de Investigación Turística (Аміт), en el que compartieron sus experiencias y los resultados de sus investigaciones sobre turismo.

procesos de desarrollo local y regional, la organización del territorio y del espacio urbano, los flujos de turistas, el manejo de los sistemas de información y los impactos del uso de las TIC, particularmente reflejado en el interés por los destinos inteligentes y el fenómeno del Airbnb. Sobre la formación de redes y cooperación internacional, se puso de manifiesto el interés de conjuntar esfuerzos y ampliar el diálogo internacional que ayude a compartir discursos y hallazgos de la región Latino-iberoamericana, así como poner en evidencia lo que une a dicha comunidad académica en aspectos como los posgrados, las revistas científicas y las redes de investigación, entre otros.

Finalmente, se dejaron plasmadas distintas recomendaciones sobre la actuación de la comunidad científica del turismo; entre otras, hacer extensiva y permanente la incorporación de tesis en las mesas de trabajo para enriquecer las investigaciones y la formación de recursos humanos; incrementar los diálogos y debates con otras disciplinas y campos, pero también con otros actores y tomadores de decisiones; ampliar nuestras miradas a distintas y diversas expresiones del turismo, contribuyendo a borrar la fragmentación categorial entre lo turístico y lo no turístico, lo cual significa y redimensiona que a través del turismo se puede analizar la realidad social, política y económica de una sociedad en un momento determinado. 


\section{Impactos socioculturales del turismo. Dimensiones conceptuales, teóricas y empíricas \\ México: Trillas}

Alfonso González Damián

Universidad de Quintana Roo

Unidad Académica Cozumel gonzalezd@uqroo.edu.mx

U na de las preocupaciones que con el tiempo ha ido ganando atención respecto al desarrollo acelerado del turismo en el mundo es la de sus impactos socioculturales en el ámbito de las sociedades receptoras del turismo, pero también de aquellos que suceden en las sociedades emisoras de turistas, tras la realización de sus viajes. La preocupación surgió desde hace más de cuatro décadas, con la realización y publicación de profusos estudios sobre los impactos socioculturales, al grado de considerarse uno de los temas más trabajados en los estudios turísticos (Deery et al., 2012), lo que no es de sorprenderse puesto que estos impactos son, entre los distintos que acontecen al turismo, los que más atentan contra la sostenibilidad del desarrollo turístico, y que no obstante, son los menos comprendidos. Monterrubio en su obra, Impactos socioculturales del turismo publicada por Trillas (2018), argumenta, con mucha razón, que si bien los estudios en la temática resultan prolíficos, en una revisión profunda, no abundan entre ellos los que se sustenten en una argumentación teórica sólida que permita no solo saber qué impactos propicia el turismo sino por qué y cómo suceden tales impactos, los factores que los propician, lo que permitiría eventualmente servir como antecedente para que se puedan mitigar, contrarrestar, limitar o evitar.

La obra se posiciona en este punto como una plataforma de partida, auténtica base conceptual para que los estudios de los impactos socioculturales del turismo sean comprendidos de manera articulada y tendiente hacia una mayor y mejor comprensión teórica y empírica de su devenir. En opinión del que suscribe, la obra está destinada a posicionarse como libro básico, texto guía o básico para quienes desde el ámbito académico o profesional se interesen en los estudios de los impactos socioculturales del turismo: estudiantes de licenciatura y posgrado, nuevos y consolidados investigadores, grupos de investigación, profesionales y gestores del turismo.

Una de las primeras y más notorias virtudes de la obra consiste en que el autor nos acerca a los textos publicados en lengua inglesa, en la que de manera prolífica se ha 
abordado el tema de los impactos socioculturales del turismo, no necesariamente en el mundo anglosajón, y que a lo largo de los años se ha constituido en la corriente principal en el campo de la temática y que no siempre se encuentran accesibles para el hispanoparlante, tanto por las limitaciones lingüísticas como por tratarse en muchos casos de documentos accesibles mediante pago o suscripción. Además de identificar y analizar los principales textos y sus modelos y conceptos, el autor los presenta de manera ordenada, no sólo desde un punto de vista puramente cronológico, sino desde una lógica que bien puede calificarse de antecedente hacia una clasificación teórica o metaconceptual de los productos analizados.

El libro se integra de seis partes: cuatro partes conceptuales, una teórica y una parte final empírica. Las cuatro primeras conceptualizan la evaluación de impactos sociales, de impactos del turismo, los de tipo sociocultural en ese ámbito, así como las características que presentan. La parte teórica se divide en dos apartados, uno sobre las teorías elaboradas desde la información empírica y que son ampliamente reconocidas y referidas en la literatura turística, y otro sobre las teorías tomadas de diversas disciplinas y que se han utilizado con mayor o menor éxito para entender los impactos socioculturales del turismo. Finalmente la parte empírica presenta cuatro casos específicos estudiados por el propio autor.

La noción de impacto como tal surge de la idea de desarrollo. Se sabe que todo proyecto de desarrollo generará cambios en las sociedades, algunos de los cuales podrían considerarse benéficos, pero otros serán perjudiciales para distintos grupos, segmentos o capas de la población. En tal sentido, estos cambios, entendidos como impactos de los proyectos de desarrollo, requieren ser identificados, entendidos, evaluados y monitoreados, antes, durante y a lo largo de la implementación de cualquier proyecto, de los que sin duda no escapan los proyectos turísticos. Desde los primeros estudios sobre el tema en cuestión, se ha enfatizado en los impactos que la actividad produce en los sitios de destino, y se ha clasificado a los impactos en tres grandes bloques: económicos, socioculturales y naturales, en los que afecta la vida individual y colectiva de los miembros de poblaciones locales. El enfoque que ha prevalecido en la concepción de tales impactos, se ha centrado en la valoración de sus beneficios y costos, así como en su posible evaluación.

Los impactos del bloque sociocultural, o más propiamente para el autor, los impactos socioculturales del turismo, no solo se presentan en los habitantes locales en los sitios de destino turístico, sino también en los turistas que les visitan, aunque la literatura académica se ha volcado mayoritariamente en el análisis de los impactos en las poblaciones receptoras de turismo. Al respecto, el autor nos llama a la reflexión respecto a que los temas no solo deberían definirse desde lo que dice la literatura, sino a partir de las condiciones socioeconómicas y culturales específicas de cada destino turístico, a partir del estudio de las percepciones y actitudes de los residentes hacia el turismo y también de las de los turistas hacia sus viajes.

En la obra, el autor clasifica a los impactos socioculturales del turismo con base en distintos atributos que han sido señalados en la literatura académica, que los hacen ser 
tangibles e intangibles; macro, meso y micro; individuales y colectivos; directos e indirectos; positivos y negativos; planeados, no planeados y multiplicadores; a corto, mediano y largo plazo. Algunos factores de alta relevancia para determinar el tipo y magnitud de los impactos del turismo mencionados por el autor son: modalidad turística, número de turistas, comportamiento de los turistas, etapa del ciclo de vida del destino, diferencia económica entre locales y turistas, diferencia cultural entre locales y turistas, papel de los intermediarios, nivel de participación local, estacionalidad turística, otros agentes de cambio. En conjunto estos factores aceleran, maximizan, disminuyen o agudizan los cambios inducidos por el turismo.

Si bien, el autor señala que los estudios sobre los impactos socioculturales del turismo se han caracterizado por su falta de fundamentación teórica y conceptual, esto no significa que no existan esfuerzos encomiables y que se han tornado en modelos ejemplares en la literatura especializada; es el caso de las propuestas que el autor denomina "modelos teóricos del turismo": la matriz de actitudes y comportamiento hacia el turismo de Butler (1980); el índice de irritación turística de Doxey (1975); el ciclo de vida de un área turística de Butler (1980); las estrategias culturales de enfrentamiento local de Dogan (1989); el continuo de estrategias de adopción -retirada de Ap y Crompton-. Asimismo, el autor menciona otras teorías desarrolladas en diversas disciplinas o campos del conocimiento que se han aplicado para la explicación de los impactos del turismo: teoría del intercambio social, teoría de las representaciones sociales, teoría de la amenaza integrada, teoría de la identidad social y teoría de la identidad con el lugar.

En la parte final, el autor presenta el análisis de cuatro casos de estudio con su abordaje metodológico y conceptual, así como perspectivas teóricas adecuadas a la necesidad o particularidad de cada uno de los casos: 1) Estereotipos, turistas y actitudes de prestadores de servicios turísticos en Huatulco, México; 2) Spring break y actitudes locales en Acapulco, México; 3) Turismo nudista y estigmatización, en Zipolite, México; y 4) Turismo y la máscara Boruca, en el sur de Costa Rica.

A manera de reflexión final, se puede afirmar que el estudio de los impactos socioculturales del turismo se encuentra aún en desarrollo y si bien muchos de los trabajos producidos en la literatura especializada se caracterizan por ser exploratorios y descriptivos, el analizar en profundidad sus causas y procesos es un reto que bien puede encontrar bases en trabajos comprensivos e integradores como el que nos entrega Monterrubio. Durante años. la industria del turismo internacional no se preocupó por los aspectos socioculturales, pero hoy, con el auge de los nuevos turismos, como el ecoturismo o el turismo cultural que poco a poco pero inexorablemente van ganando presencia frente al turismo convencional masificado, comienza a darse cuenta de que corre el riesgo de acabar con el cuerno de la abundancia, si no es que ya lo hizo antes, al afectar las costumbres, las tradiciones, la cultura y en general a las sociedades tanto receptoras como emisoras.

Muy particularmente, para quienes formamos parte de las sociedades receptoras de turismo, nos encontramos día a día con el hecho de que por la presencia y desarrollo del turismo, nuestro mismo entorno, la sociedad, la economía y la vida en general son 
impactados en mayor o menor medida. Si deseamos que la actividad turística nos beneficie pero a la vez que no nos sobrepase, que no nos excluya ni nos despoje, que nos permita avanzar hacia un desarrollo sostenible, necesitamos entender cómo se producen los impactos socioculturales, cómo se construyen, cómo se relacionan entre ellos y por qué; es decir, necesitamos estudiarlos con bases más sólidas, bases a las que contribuyen obras como la de Monterrubio Cordero.

\section{Referencias}

Ap, J., y Crompton, J. L. (1993). Residents' Strategies for Responding to Tourism Impacts. Journal of Trave/ Research, 32(1), 47-50. https://doi.org/https://doi.org/10.117 7\%2F004728759303200108

Butler, R. W. (1980). The concept of a tourist area cycle of evolution: implications for management of resources. The Canadian Geographer/Le Géographe Canadien, 24(1), 5-12.

Deery, M., Jago, L., y Fredline, L. (2012). Rethinking social impacts of tourism research: A new research agenda. Tourism Management, 33(1), 64-73. https://doi.org/10.1016/j.tourman.2011.01.026

Doğan; H. Z. (1989). Forms of adjustment. Sociocultural impacts of tourism. Annals of Tourism Research; 16(2); 216-236. https://doi.org/10.1016/0160-7383(89)90069-8

Doxey, G. (1975). A causation theory of visitor-resident irritants: Methodology and research inferences. En The impact of tourism, Sixth Annual Conference Procedures of the Travel Research Association.

Monterrubio Cordero, J. C. (2018). Impactos socioculturales del turismo. Dimensiones conceptuales, teóricas y empíricas. México: Trillas. 


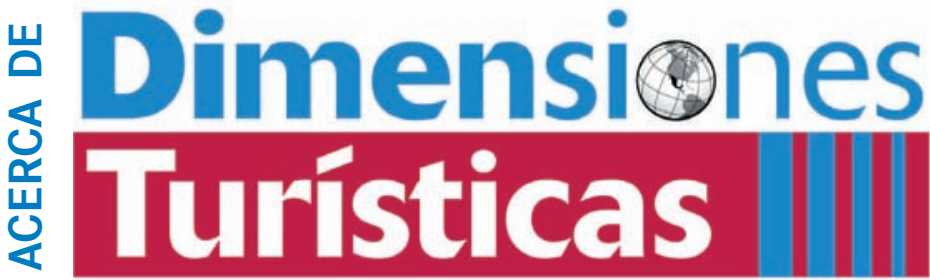

\section{POLÍTICAS}

\section{Enfoque y alcance}

Dimensiones Turísticas es una publicación científica, digital y de distribución gratuita que publica y difunde trabajos originales de investigación que abordan temáticas turísticas en México y en otros contextos internacionales. Dimensiones Turísticas se especializa en el estudio de los distintos procesos sociales, culturales, económicos, políticos, ambientales y territoriales vinculados con la actividad turística a través de investigaciones analíticas, críticas y reflexivas desde una perspectiva inter y multidisciplinaria con el propósito de difundir los principales hallazgos de investigación tanto entre la comunidad académica, como con el sector gubernamental, empresarial y la sociedad en su conjunto.

Su objetivo es constituirse en un espacio que permita exponer nuevos enfoques, teorías, metodologías, estudios, experiencias y hallazgos de investigación que posibiliten avanzar en la construcción y difusión del conocimiento acerca del turismo, así como contribuir al enriquecimiento de debates actuales sobre la investigación turística.

\section{Políticas de sección}

Dimensiones Turísticas publica textos inéditos de carácter científico que analicen teorías, metodologías o procesos sociales, culturales, económicos, administrativos, políticos, ambientales y territoriales vinculados con la actividad turística desde una perspectiva inter y multidisciplinaria. Se publicarán tres tipos de trabajos: artículos, notas críticas y reseñas bibliográficas.

Artículo: Se refiere a trabajos originales que expongan los principales hallazgos teóricos, empíricos o metodológicos de investigaciones concluidas o en curso que analicen desde distintas disciplinas procesos vinculados a la actividad turística.

Notas críticas: Es una reflexión académica sobre temas actuales o avances de investigación.

Reseña: Es un texto breve que refiere o analiza publicaciones en formato físico o electrónico recientes que aborden temáticas de turismo o de investigación. El Comité editorial será el responsable de sugerir los libros a reseñar. 


\section{Proceso de evaluación por pares}

Los trabajos académicos serán sometidos a un proceso de evaluación anónima por pares. Las notas críticas serán sometidas al mismo proceso de evaluación que los artículos. Las publicaciones reseñadas no deberán tener una fecha de publicación mayor a dos años anteriores al año de envío de la propuesta.

Debido al proceso editorial anónimo, los datos de autores/as como adscripción, currículo sucinto, dirección electrónica y postal figurarán en una hoja aparte. Los trabajos serán sometidos a la revisión de un comité de expertos para avalar la calidad científica y deberán enviarse en su versión final y completa, ya que no se permitirán modificaciones posteriores una vez iniciado el proceso de evaluación.

El proceso para la revisión blindada de artículos es el siguiente:

Recepción del manuscrito y aviso de recepción al autor en un plazo no mayor a 72 horas. Posteriormente, inicia el proceso que consta de las siguientes fases:

1. Primera fase: Envío de la propuesta al Comité editorial para realizar una pre-evaluación de la calidad del manuscrito, la pertinencia temática y la conformidad de las normas editoriales. El manuscrito podrá ser aceptado o rechazado por el Comité, que basa su decisión en criterios de calidad académica, aportación al campo científico y a la temática y normatividad. Si el manuscrito es aceptado, pasa a la segunda fase; en caso contrario, se envía un aviso de rechazo al/la autor/a.

2. Segunda fase: en caso de que el pre-dictamen sea favorable, el manuscrito anónimo se enviará a dos evaluadores/as externos/as, con especialidad en la línea de investigación, temática o materia de la propuesta. En caso de contar con dictámenes contradictorios, el manuscrito se envía a un tercer evaluador/a, también especialista, cuya decisión será determinante para el dictamen final.

Los dictámenes podrán tener los siguientes resultados:

1. Dictamen positivo: indica un resultado favorable; el manuscrito puede ser evaluado como:
a) Publicar sin cambios;
b) Publicar cuando se hayan cumplido con modificaciones menores;
c) Publicar una vez que se haya efectuado una revisión a fondo.

2. No publicable: El manuscrito se rechaza de forma definitiva.

En caso de que el dictamen final solicite cambios o modificaciones, los/as autores/as disponen de cuatro semanas para incorporarlos y volver someter el manuscrito para su revisión. La revisión la realiza el Comité editorial. Si los cambios se incorporan adecuadamente, el manuscrito se acepta finalmente; si se considera que no se han hecho las modificaciones requeridas se pedirá a los/las autores/as que revisen su propuesta y se contará con un 
plazo no mayor a dos semanas para incorporar los cambios solicitados. Si los cambios se incorporan, será aceptado para su publicación; si los cambios no se incorporan en este segundo periodo, el manuscrito se rechaza.

Para que las propuestas sean enviadas al Comité editorial deberán cumplir con las normas editoriales de AмIт (APA 6). En caso contrario, serán devueltas a los/las autores/as para que ajusten sus propuestas a las Directrices.

Una vez aceptado el trabajo para su publicación, los/as autores/as conceden a la Dimensiones Turísticas los derechos de los artículos publicados, conservando sus derechos morales conforme lo establece la Ley de derechos de autor

\section{Frecuencia de publicación}

Dimensiones Turísticas es una publicación semestral. Se publica en junio y diciembre La convocatoria para recepción de trabajos se mantiene abierta durante todo el año.

\section{Política de acceso abierto}

Dimensiones Turísticas brinda un acceso abierto y gratuito al contenido de sus investigaciones con la finalidad de difundir y garantizar un intercambio amplio y directo del conocimiento generado.

Dimensiones Turísticas no cobra cuotas por el envío, gestión o publicación de los trabajos enviados a evaluar.

\section{Derechos de los/las autores/as}

Los/las autores/as serán responsables únicos de las ideas, afirmaciones y opiniones expresadas en su texto, por lo que la revista no asume responsabilidad alguna en este sentido. Los/las autores/as conserva/n sus derechos morales conforme lo establece la Ley de derechos de autor. Dimensiones Turísticas autoriza la reproducción de su material a través de medios magnéticos, electrónicos y de reprografía siempre y cuando no se alteren los contenidos, sea sin fines de lucro y se cite la fuente completa.

\section{DIRECTRICES PARA AUTORES/AS}

Los trabajos serán sometidos a evaluación por un comité de expertos. Todas las propuestas pasarán por un proceso editorial que se desarrollará en varias fases, por lo que es necesario que la presentación de los manuscritos siga una serie de normas que faciliten la edición y eviten el retraso de la publicación.

1. Los trabajos que se envíen a Dimensiones Turísticas para su publicación deberán ser originales y académicos, no haber sido publicados en otros medios impresos, ni electrónicos. Tampoco deberán haber sido sometidos de manera simultánea a otras 
revistas u órganos editoriales. Deberán atender de manera estricta la presente guía para autores.

2. Los trabajos deberán enviarse en su versión final y completa, ya que no se admitirán modificaciones posteriores una vez iniciado el proceso de evaluación.

3. Dimensiones Turísticas publicará tres tipos de trabajos: artículos, notas críticas y reseñas bibliográficas.

4. Todos los trabajos serán revisados para verificar que se ajusten estrictamente a la presente guía para autores. En caso contrario se remitirán a los/las autores/ as para que realicen los ajustes correspondientes. Una vez establecido que el trabajo cumple con los requisitos solicitados por la revista, será enviado a dos árbitros, quienes determinarán en forma anónima:

a) Dictamen positivo: indica un resultado favorable; el manuscrito puede ser evaluado:

- Publicar sin cambios;

- Publicar cuando se hayan cumplido con modificaciones menores;

- Publicar una vez que se haya efectuado una revisión a fondo.

b) No publicable: El manuscrito se rechaza de forma definitiva.

5. En caso de discrepancia entre ambos resultados, el texto será enviado a un tercer árbitro, cuyo dictamen será determinante para decidir si se acepta o no. Los resultados del proceso de evaluación serán inapelables en todos los casos.

6. Los trabajos enviados por académicos/as adscritos/as a alguna institución serán sometidos a consideración de árbitros externos a la misma.

7. Los dictámenes serán enviados a los/las autores/as oportunamente.

8. Los trabajos enviados deberán estar escritos de manera clara, sencilla y bien estructurada, omitiendo la redacción en primera persona, ya sea en singular o plural (yo o nosotros).

9. Los párrafos adoptarán el estilo de párrafo moderno (sin sangría).

10. Los trabajos podrán estar escritos en español o en inglés.

\section{Requisitos para los artículos}

1. Todos los trabajos deberán estar escritos en el programa Word 2011 o anterior, en hojas tamaño carta, en una sola faz, a espacio y medio y con márgenes de tres centímetros. Tipo de letra Times New Roman de 12 puntos.

2. La extensión mínima del artículo será de 20 cuartillas y la máxima de 30 cuartillas tamaño carta, a espacio y medio, incluyendo resumen, cuadros, gráficos y figuras (mapas, ilustraciones, diagramas, fotografías) y bibliografía.

3. En la primera página deberá aparecer el título del trabajo (redactado en alta y bajas, en negritas y en español e inglés), que deberá ser breve y referir claramente 
el contenido. Enseguida se incluirá un resumen en español e inglés (abstract) con una extensión máxima de 600 caracteres, en el que se destaque el objetivo, la relevancia del análisis, el método utilizado, los principales resultados o hallazgos más relevantes. Es responsabilidad del autor proveer una traducción correcta del resumen. Asimismo, se requieren cinco palabras clave en español e inglés (key words). Se sugiere que estas palabras sean: una geográfica, dos disciplinares y dos temáticas, con su respectiva traducción al inglés o español que permitan identificar el contenido del artículo. Enseguida se presenta el texto principal y las referencias.

4. El texto deberá organizarse como sigue (los títulos de secciones son indicativos, las propuestas pueden llevar otro título, pero respetar los contenidos):

a) Título

b) Resumen (español e inglés) y palabras clave en ambos idiomas

c) Introducción

d) Cuerpo del trabajo: antecedentes, metodología, resultados, discusión y/o hallazgos.

e) Conclusiones

f) Bibliografía

5. Los títulos o subtítulos deberán diferenciarse entre sí, para ello se recomienda el uso del sistema decimal progresivo, cuidando que la numeración de los subtemas o secciones no sea excesiva o mayor a dos órdenes (2., 2.1, 2.1.1, 2.1.2).

6. Las siglas y acrónimos deberán ser claramente definidos en su primer uso en el texto.

7. No se aceptan abreviaturas.

8. Todas las referencias a material previamente publicado y a fuentes estadísticas deberán estar identificadas en el texto utilizando el sistema de citas autor y fecha de APA 6, anotando entre paréntesis el primer apellido del autor/a o autores, seguido del año de publicación y página(s) de referencia precedida(s) por las letras p. o pp. Por ejemplo: (Hiernaux, 2010, p. 63) o (Hiernaux y Osorio, 2015, pp. 231-235).

9. Las notas de pie de página deberán ser las estrictamente necesarias, estar numeradas sucesivamente en números arábigos y estar situadas a pié de página. Se utilizarán sólo para hacer comentarios puntuales o aclaraciones del autor y no para referencias bibliográficas. Deberán presentarse con letra Times New Roman de 9 puntos evitando anexos o apéndices.

10. Los cuadros, tablas y gráficos deberán incluir información estadística concisa, en formato de hoja de cálculo, preferiblemente en Microsoft Excel. Igualmente deberán colocarse en formato editable en el lugar propuesto en el documento, con el título colocado en la parte superior del objeto, con tipología Times New Roman 10 puntos y con su respectiva fuente de referencia colocada en la parte inferior. 
11. Las figuras deberán respaldarse en un archivo aparte, en formato de imagen jpeg (.jpg) o tiff (.tif) con una resolución de 300 dpi y preferentemente en color y un archivo por cada objeto. También deberán colocarse en formato editable en el lugar propuesto en el documento, con el título colocado en la parte superior de la figura, con tipología Times New Roman 10 puntos y con su respectiva fuente de referencia colocada en la parte inferior.

12. Tanto los cuadros, tablas, gráficos y demás figuras serán numerados con el sistema arábigo (cuadro 1, 2, 3, etc.). Las fotografías son consideradas como figuras (figura 1, 2, 3, etcétera). Estas últimas deberán manejarse en formato JPG a 300 dpi como mínimo y deberán especificar como pie de foto, el autor y el año en que fueron tomadas, con tipología Times New Roman 10 puntos y con su respectiva fuente de referencia, colocada en la parte inferior.

13. Cada archivo debe ir titulado en primer lugar por el tipo de objeto, su número consecutivo y la página en que queda ubicado (graf1p8.jpg; mapa1p15.tif; fig1p12. jpg; fig2p16.xls; etcétera). En el cuerpo del texto deberá incluirse cada objeto en el lugar correspondiente en formato editable.

14. La bibliografía se incluirá al final del artículo ordenada alfabéticamente por autor, incluyendo exclusivamente las obras citadas en el cuerpo del texto como libros, capítulos de libros, artículos en revistas digital o impreso, notas periodísticas, archivos de Internet, películas, entre otros.

\section{Requisitos para las notas críticas}

1. Las notas críticas son reflexiones sobre temas de actualidad o avances de investigación. Deberán tener una extensión mínima de ocho cuartillas tamaño carta y un máximo de diez, a espacio y medio, en Times New Roman de 12 puntos, con márgenes de tres centímetros.

2. Las notas críticas serán seleccionadas por el Comité Editorial de la revista considerando su calidad, originalidad en el análisis, actualidad y pertinencia temática.

3. Las notas críticas deberán atender las mismas indicaciones con respecto al título (bilingüe), así como para citar referencias y bibliografía.

\section{Requisitos para las reseñas bibliográficas}

1. Las reseñas deben referirse a libros relevantes publicados dentro de los dos años anteriores a la fecha de publicación de la revista y su extensión máxima deberá ser de cuatro páginas tamaño carta, a espacio y medio, en Times New Roman de 12 puntos, con márgenes de tres centímetros en todos los lados. 
2. La reseña deberá contener la referencia completa de la obra (formato APA 6), seguida de los comentarios de quien hace la reseña y los datos de identificación (nombre y apellidos, adscripción institucional y correo electrónico).

3. Las reseñas deberán atender las mismas indicaciones con respecto al título (bilingüe), así como para citar referencias y bibliografía.

Normas para citar las referencias bibliográficas

Las referencias a fuentes consultadas deberán incluirse al final en orden alfabético, sin distinguir el tipo de fuente y en formato APA 6.

\section{Artículos y publicaciones periódicas impresas}

Apellido, A. A., Apellido, B. B. y Apellido, C. C. (Año). Título del artículo (en redondas). Nombre de la revista (en cursivas), volumen(en cursivas)(número), pp.-pp.

Ejemplo:

Bertoncello, R. (2002). Turismo y territorio otras prácticas, otras miradas. Aportes y Transferencias, 6(2), 29-50.

\section{Artículo y publicaciones digitales o electrónicas}

Apellido, A. A., Apellido, B. B. y Apellido, C. C. (Año). Título del artículo (en redondas). Nombre de la revista (en cursivas), volumen(en cursivas)(número), pp.-pp. Recuperado de www.direcciónelectrónica.com

Ejemplo:

Valcuende del Río, J. M. (2012). Turismo y poblaciones indígenas: Espacios, tiempos y recursos. Scripta Nova. Revista Electrónica de Geografía y Ciencias Sociales, XVI(410), 2855. Recuperado de http://www.raco.cat/index.php/ScriptaNova/issue/view/18634

\section{Artículo con DoI}

Apellido, A. A., Apellido, B. B. y Apellido, C. C. (Año). Título del artículo (en redondas). Nombre de la revista (en cursivas), volumen(en cursivas)(número), pp.-pp. Dol: XXX-YYYY Ejemplo:

Valcuende del Río, J. M. (2012). Turismo y poblaciones indígenas: Espacios, tiempos y recursos. Scripta Nova. Revista Electrónica de Geografía y Ciencias Sociales, XVI(410), 28-55. DOI: $1138-9788$

\section{Libros}

Apellido, A. A. (Año). Título (en cursivas). Ciudad, País: Editorial.

Ejemplos:

Santana, A. (1997). Antropología y Turismo. ¿Nuevas hordas, viejas culturas? Barcelona, España: Ariel. 
Casez, G. (1992a). Fondements pour une géographie du tourisme et des loisirs. París, Francia: Bréal Editions.

Casez, G. (1992b). Tourisme et tiers-monde, un bilan controversé. París, Francia: L'Harmattan (Tome II).

\section{Libros con editor, compilador o coordinador:}

Apellido, A. A. (Ed.). (Año). Título (en cursivas). Ciudad, País: Editorial.

Ejemplo:

Vera Rebollo, J. F. (coord.). (2011). Análisis territorial del turismo y planificación de destinos turísticos. Valencia, España: Tirant Lo Blanch.

\section{Versión electrónica o digital de libro impreso:}

Apellido, A. A. (Año). Título (en cursivas). Editorial. Recuperado de www.direcciónelectrónica.com

Ejemplo:

Ascanio, A. (2013). Economía del turismo [e-book]. Ediciones de la U.

\section{Capítulo de libro:}

Apellido, A. A. y Apellido, B. B. (Año). Título del capítulo (en redondas). En A. A. Apellido (Ed.), Título del libro (en cursivas) (pp. nn-nn). Ciudad, País: Editorial.

Ejemplos:

Luka, N. (2011). Del espacio al lugar y al paisaje cultural: segundas residencias a orillas de ríos y lagos en Canadá central. En T. Mazón, R. Huete y A. Mantecón (eds.), Construir una nueva vida. Los espacios del turismo y la migración residencial (pp. 2146). Santander, España: Milrazones.

Salvat, J., Meritxell, S. y Olmos, P. (1998). Evaluación del potencial turístico: las montañas de Prades. En J. Oliveras y S. Antón (eds.), Turismo y planificación del territorio en la España de fin de siglo (pp. 107-115). Tarragona, España: Universitat Rovira I Virgili.

\section{Videos, grabaciones y otros soportes digitales:}

Apellido, A. A. (Productor) y Apellido, B. B. (Director). (Año). Título (en cursivas) [Película cinematográfica]. País de origen: Estudio.

Ejemplo:

Secretaría de Turismo de México (2015). Compendio estadístico del turismo en México 2016 [disco compacto]. México: Sectur.

\section{Videos, podcast y otras fuentes en línea:}

Apellido, A. A. (día, mes, año). Nombre del programa o evento (en cursivas) [Tipo de archivo]. Recuperado de www.direcciónelectrónica.com 
Ejemplo:

Boehm, P. (26 de noviembre de 2014). La entrevista de Herta Müller en Hay Festival Cartagena 2013 [Audio en podcast]. Recuperado de http://programas.cooperativa.cl/ unanuevamanana/

\section{Páginas web}

Apellido, A. A. (Año). Título de la página web (en cursivas). Recuperado de www.direcciónelectrónica.com

Ejemplo:

Instituto Nacional de Estadística y Geografía (INEGI) (2014). Cuenta Satélite del Turismo (CST) de México. Recuperado de http://www.beta.inegi.org.mx/app/biblioteca/ficha. html?upc=702825060640

\section{Simposios y conferencias}

Apellido, A. y Apellido, B. (mes, año). Título de la presentación (en redondas). En A. Apellido del Presidente/organizador del Congreso (Presidencia), Título de/ simposio (en cursivas). Simposio dirigido por Nombre de la Institución Organizadora, Lugar.

Ejemplo:

Ibáñez, R. (noviembre, 2013). Retos en materia de turismo y sustentabilidad en pequeñas localidades costeras de Baja California Sur (BCs). En 7mo. Congreso Internacional de la Academia Mexicana de Investigación Turística. Academia Mexicana de Investigación Turística y Universidad Autónoma de Chiapas, San Cristóbal de Las Casas, Chiapas, México.

\section{Tesis}

Apellido, A. (Año). Título de la tesis (en cursivas) (Tesis de [grado]). Nombre de la Institución, lugar de presentación.

Ejemplo:

Gaxiola Aldama, R. (2010). Turismo sexual masculino y las prácticas sociales de uso del espacio urbano en la ciudad de Tijuana (Tesis de doctorado en Ciencias Sociales con especialidad en Estudios Regionales). El Colegio de la Frontera Norte, Tijuana, Baja California, México.

\section{Comunicaciones personales y entrevistas}

Si bien las comunicaciones personales (correos, cartas privadas, memorandos, entrevistas telefónicas) deberán aparecer referidas en el cuerpo del texto según lo sugerido por las normas APA 6, no se incluyen en las referencias bibliográficas, por no considerarse fuentes consultables. 


\section{ENVÍos}

Los trabajos podrán enviarse atendiendo cualquiera de las dos opciones:

1. Enviar el archivo digital del trabajo a la dirección: amit.dimentur@gmail.com, asegurándose de eliminar las referencias de autoría y filiación.

2. Subir el archivo digital del trabajo directamente en el siguiente enlace: www.amiturismo.org/envio-de-articulo

\section{Información adicional}

1. Para asegurar el anonimato, además del texto completo del artículo o reseña, es necesario enviar en hoja independiente o capturar directamente en el siguiente enlace www.amiturismo.org/envio-de-articulo

- Tipo de colaboración

- Título de la colaboración.

- Nombre completo del/la autor/a.

- Correo electrónico del/la autor/a.

- Institución y dependencia de adscripción.

- Dirección postal

- País

2. Currículo abreviado de el/la autor/a o autores/as (máximo 600 caracteres), que incluya el último grado académico y la institución donde obtuvo el grado, ocupación actual, líneas de investigación y título de los últimos tres trabajos publicados.

Lista de comprobación de preparación de envíos

Como parte del proceso de envío se requiere que los autores indiquen que el mismo cumple puntualmente con las siguientes características:

1. Que la propuesta no ha sido publicada previamente, ni se ha enviado simultáneamente a otra revista.

2. Que el fichero enviado está en formato Microsoft Word.

3. Que se han añadido direcciones web para las referencias donde sea posible.

4. Tipografía Times New Roman a 12 puntos para el texto y de 10 para títulos de cuadros, gráficas y figuras y para notas de pie de página el tamaño es 9.

5. Texto interlineado a espacio y medio.

6. Que el texto cumple con los requisitos bibliográficos y de estilo indicados en la presente Guía para autores. 
Los trabajos que no cumplan con estas indicaciones pueden ser devueltos al/la autor/a, quien podrá enviar de nuevo su manuscrito siempre y cuando cumpla con los puntos solicitados.

Aviso de derechos de autor

- Los/as autores/as conceden a Dimensiones Turísticas el permiso para que su material se difunda en la revista y medios magnéticos, electrónicos y fotográficos. Los derechos de autor de los artículos publicados en Dimensiones Turísticas son cedidos a la Academia Mexicana de Investigación Turística, A.C. (AMIT) tras la aceptación del original para que éste se publique y distribuya en versión electrónica; asimismo, los/las autores/as conserva(n) sus derechos morales conforme lo establece la Ley de derechos de autor.

- El/la autor/a principal recibirá una forma de Declaración de originalidad y cesión de derechos de autor que deberá firmar y remitir a Dimensiones Turísticas (amit.dimentur@gmail.com) conjuntamente con la versión final del trabajo. Será su responsabilidad obtener la firma y consentimiento de los/las demás autores/as si los hubiere.

- Por otra parte, los/as autores/as podrán usar el material de su artículo en otros trabajos o libros publicados por ellos mismos, con la condición de citar a Dimensiones Turísticas como la fuente original de los textos.

- Es responsabilidad de los/las autores/as obtener por escrito la autorización correspondiente para todo aquel material que forme parte de su artículo (Vg. fotografías o mapas satelitales) y que se encuentre protegido por la Ley de derechos de autor.

\section{Declaración de privacidad}

Los nombres y direcciones de correos administrados por Dimensiones Turísticas se usarán exclusivamente para los fines declarados por la revista y no estarán disponibles para ningún otro propósito u otra persona.

\section{OTROS}

\section{Declaración de ética}

Dimensiones Turísticas suscribe el código de conducta del cope (Committee on Publication Ethics), que adopta las siguientes recomendaciones de la Guía de buenas prácticas revisada y aprobada por el COPE en 2011: 
- La dirección de la revista y demás miembros del equipo editorial son responsables de garantizar un proceso de evaluación anónimo entre autores y evaluadores. La información sobre el manuscrito se mantendrá en estricta confidencialidad y sólo se informará a autores/as responsables de la propuesta y al equipo editorial.

- La dirección de la revista mantendrá anónima la identidad de los/as evaluadores/as.

- Dimensiones Turísticas se compromete a elegir evaluadores/as calificados/as según la temática y con capacidad probada para evaluar de forma ética y profesional, evitando conflictos de intereses.

- Dimensiones Turísticas cuidará la calidad académica y ética de la comunicación con los/las evaluadores/as, cualquier falta, descortesía o mala conducta de un/a dictaminador/a será revisada y la revista se compromete a no recurrir a evaluadores / as que realicen tales prácticas.

- Las propuestas serán sometidas a dictamen considerando su contenido intelectual, sin sesgos ni discriminación de edad, género, creencias políticas o religiosas y respetando la libertad de expresión.

- Las decisiones editoriales de aceptación o rechazo estarán basadas en la importancia, originalidad y claridad del manuscrito, en la validez del estudio científico y en su vínculo con la línea editorial de la revista. El/la directora/a sólo podrán revocar propuestas o contribuciones en caso de que se identifiquen problemas serios con las mismas, como plagio, faltas éticas, entre otras, aunque estuvieran previamente aprobadas para su publicación.

- En caso de ser necesario y estar comprobado, Dimensiones Turísticas puede hacer públicas cuestiones de mala conducta vinculadas a la investigación y a las propuestas incluyendo prácticas de plagio y duplicidad por parte de los/as autores/as.

- La dirección de la revista y el Consejo editorial recomiendan a sus revisores/as el uso de software para detectar plagios (Turnitin, Paper Rater, Viper, entre otros).

En cuanto a los/las evaluadores/as, éstos deberán comprometerse a lo siguiente:

Revisar las propuestas de forma confidencial y no utilizar la información de la revisión para otros fines distintos a la evaluación del trabajo.

- Informar a la dirección de la revista en caso de existir algún conflicto de cualquier tipo (de interés o vinculado con la metodología, contenidos o procedimientos de la investigación, los/las evaluadores/as deberán informar a la dirección).

- Informar a la dirección de la revista cuestiones de mala ética vinculadas a la investigación y a las propuestas incluyendo prácticas de plagio y duplicidad por parte de los/as autores/as.

En cuanto a los/las autores/as, éstos deberán comprometerse a lo siguiente:

- Las propuestas son responsabilidad de quien sustenta la autoría; los/las autores/ as se comprometen a someter obras académicas inéditas y originales elaboradas 
por ellos mismos. Las propuestas no deberán ser sometidas a otros procedimientos editoriales ni haber sido objeto de plagio, falsificación o manipulación.

- Todo material no producido por quien sustenta la autoría, deberá estar claramente citado de acuerdo a las normas de Dimensiones Turísticas.

- Los/las autores/as tienen la obligación de no incurrir en falsificación de participación de autoría, por lo que deberán equilibrar su participación a fin de que no aparezcan autorías o colaboraciones fantasmas.

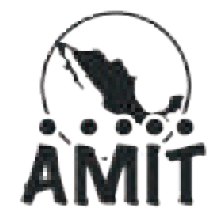

